This item was submitted to Loughborough's Research Repository by the author.

Items in Figshare are protected by copyright, with all rights reserved, unless otherwise indicated.

\title{
Influence of flame retardant additives on the processing characteristics and physical properties of $A B S$
}

PLEASE CITE THE PUBLISHED VERSION

PUBLISHER

(c) R. Seddon

LICENCE

CC BY-NC-ND 4.0

\section{REPOSITORY RECORD}

Seddon, Richard. 2014. "Influence of Flame Retardant Additives on the Processing Characteristics and Physical Properties of ABS". figshare. https://hdl.handle.net/2134/14228. 


\section{Loughborough University}

This item was submitted to Loughborough University as a PhD thesis by the author and is made available in the Institutional Repository

(https://dspace.lboro.ac.uk/) under the following Creative Commons Licence conditions.

\section{cc) creative}

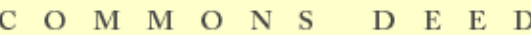

Attribution-NonCommercial-NoDerivs 2.5

You are free:

- to copy, distribute, display, and perform the work

Under the following conditions:

Attribution. You must attribute the work in the manner specified by the author or licensor.

Noncommercial. You may not use this work for commercial purposes.

No Derivative Works. You may not alter, transform, or build upon this work.

- For any reuse or distribution, you must make clear to others the license terms of this work.

- Any of these conditions can be waived if you get permission from the copyright holder.

Your fair use and other rights are in no way affected by the above.

This is a human-readable summary of the Leqal Code (the full license).

Disclaimer 민

For the full text of this licence, please go to: http://creativecommons.org/licenses/by-nc-nd/2.5/ 


\section{Pilkington Library}

E Loughborough University
Author/Filing Title
SEDDON

Vol. No.

Class Mark

$T$

Please note that fines are charged on ALL overdue items.

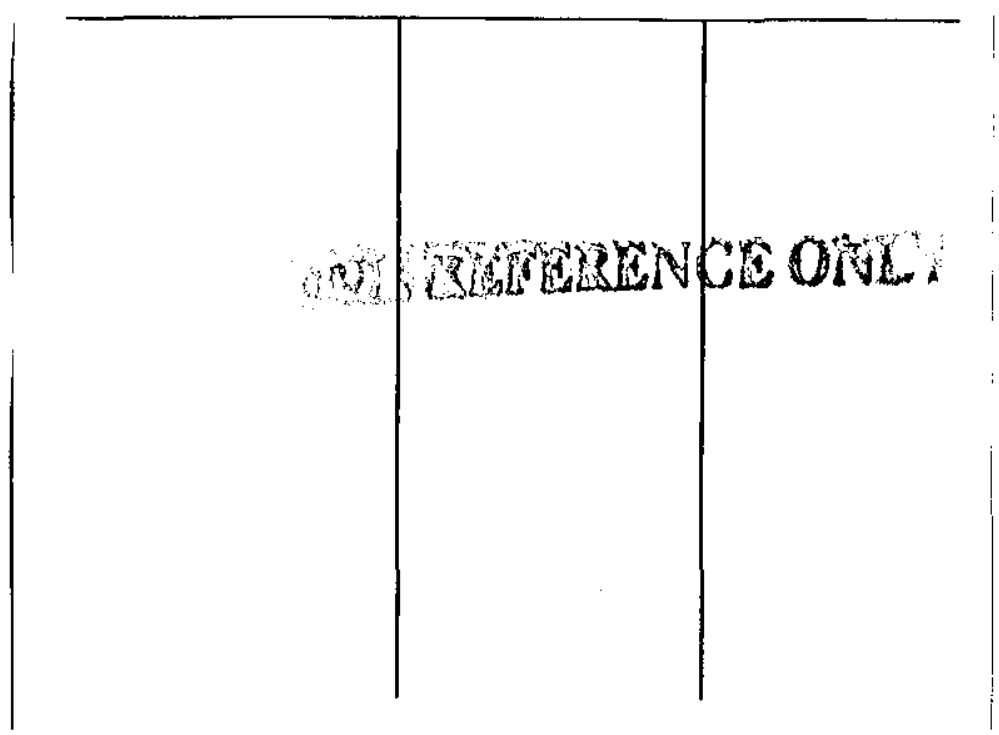




\section{Influence of Flame Retardant Additives on the Processing Characteristics and Physical Properties of ABS}

by

Richard Seddon

A Doctoral Thesis Submitted in Partial Fulfilment of the Requirement for the award of Doctor of Philosophy of Loughborough University

November 2000

Supervised by Mr J.F. Harper

Sponsored by Anzon Ltd (Great Lakes Chemicals) and EPSRC

Institute of Polymer Technology and Materials Engineering

(C) R. Seddon 2000 


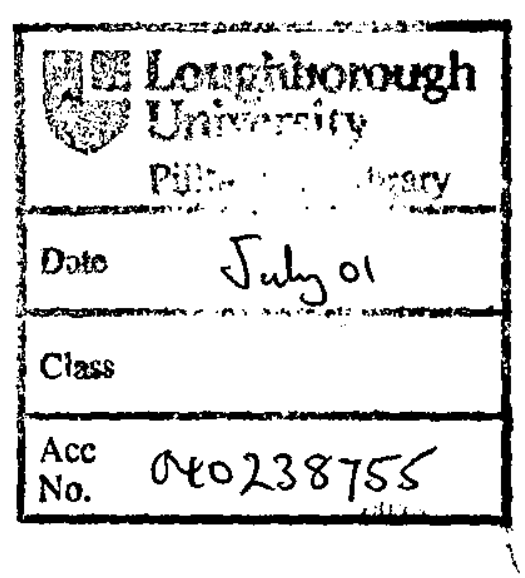




\section{Acknowledgements}

Throughout my time at IPTME I have been helped and supported by many people and I would like to take this opportunity to thank them all. Firstly my thanks go to my academic supervisor, Mr John Harper, for his guidance through both my final year degree project and this research thesis. His patience and support have been invaluable during my time here - thank you very much John.

I have received a lot of help and support from the sponsoring company, Anzon Ltd, and I would like to thank John Morley, Alan Docherty, Jelle Kaspersma for their guidance and encouragement. I would especially like to thank Steve Devine for his continued help in supplying both materials and information when required. Many apologies for all those phone calls that had you dashing up and down the stairs! Also thanks to Gale Smith for all the titration analysis.

The staff in IPTME have been a great help and my many thanks go to Trevor Atkinson, John Bates, Mick Hallam, Fred Miller, Ray Owens, Frank Page and Andy Trotter. Special thanks to Andy for his friendship and help in the processing lab and also to Mick for his help with keyless locks and other assorted problems!

Thanks to all my friends and fellow research students in who have made my time in the department an enjoyable one: thanks to Shaun, Gary, Steve, Mark, Dave, Carol, Simon, Mike, Luke, Darren, Roslan and Shahid.

Big thanks go to Mum, Dad and Sez, as well as the rest of the family (especially Nana), for all your support, encouragement and patience during the past few years, especially all those times when a calming influence was needed - I will always appreciate everything you've done for me. Also big thanks to Gordon Stainton without your help with the computer upgrade this thesis would still be being printed out!

The greatest thanks have to go to my girlfriend Ana, whose endless support, love and extreme patience got me through this project. I know it was tough at times but I really appreciate everything you've done for me. Te quiero siempre cariño. $x x x x$ 


\begin{abstract}
Antimony trioxide $\left(\mathrm{Sb}_{2} \mathrm{O}_{3}\right)$ and halogenated additives are used together in flameretarded formulations due to their synergistic retardant properties. A study has been made to determine the effects of adding different grades of $\mathrm{Sb}_{2} \mathrm{O}_{3}\left(\mathrm{~d}_{50}\right.$ particle sizes $0.11 \mu \mathrm{m}, 0.52 \mu \mathrm{m}$ and $1.31 \mu \mathrm{m}$ ) into ABS polymer either alone or with commercial brominated materials (BTBPE, TBBA, DBDPO) and an experimental bromine grade (sDBDPO). The $\mathrm{Sb}_{2} \mathrm{O}_{3}$ was added at $4 \mathrm{wt} \%$ loadings and the bromines at $20 \mathrm{wt} \%$ loadings. The results consider the influence of the additives on processing, mechanical, morphological and flame retardant properties.
\end{abstract}

All compounds were produced using a twin-screw co-rotating extruder and then an injection moulder was used to mould notched impact (falling weight testing), flexural, LOI and UL-94 flame test bars. Samples of all the compounded formulations were titrated to determine $\mathrm{Sb}_{2} \mathrm{O}_{3}$ and $\mathrm{Br}$ contents. Fracture surface, morphology, size and dispersion analysis was carried out using both SEM and TEM equipment. Osmium tetroxide $\left(\mathrm{OsO}_{4}\right)$ staining was used to determine relative locations of filler particles and polybutadiene phase.

Additions of the different antimony trioxide grades showed that the $0.52 \mu \mathrm{m}$ and $1.31 \mu \mathrm{m}$ grades lowered impact energy absorption $(-25$ to $-30 \%)$ when added at $4 \mathrm{wt} \%$ loading. The use of a sub-micron size grade $(0.1 \mu \mathrm{m})$ did not significantly lower impact properties $(-3 \%)$ and had similarly small effects on the flexural modulus and flexural strength. Additions of the brominated materials had much greater effects causing large reductions in impact properties $(-20$ to $-70 \%)$. The presence of the bromines generally increased flexural modulus and lowered flexural strength with the exception of TBBA, which increased both modulus and strength. Compounds containing both $1.31 \mu \mathrm{m} \mathrm{Sb} \mathrm{O}_{3}$ and bromines suffered a further reduction in impact energies, with the bromine properties dominating. Using the $0.1 \mu \mathrm{m} \mathrm{Sb}_{2} \mathrm{O}_{3}$ grade again improved impact and flexural properties compared to the $1.31 \mu \mathrm{m}$ grade. The $0.1 \mu \mathrm{m}$ grade resulted in improvements in fire resistance as measured by the UL-94 properties when used with all bromine grades.

Keywords: Flame retardant, ABS polymer, antimony trioxide, halogen, bromine, particle size, sub-micron, impact strength, impact modifier. 


\section{List of Abbreviations}

$\begin{array}{ll}\text { A05: } & \text { Timonox A05 (antimony trioxide) } \\ \text { AZUB: } & \text { Anzon Sub-micron (antimony trioxide) } \\ \text { LOI: } & \text { Limiting Oxygen Index } \\ \text { RS: } & \text { Red Star (antimony trioxide) } \\ \text { TEM: } & \text { Transmission Electron Microscopy } \\ \text { TGA: } & \text { Thermogravimetric Analysis } \\ \text { SEM: } & \text { Scanning Electron Microscopy } \\ \text { UL-94: } & \text { Underwriters Vertical Burn Test }\end{array}$




\section{List of Symbols}

\begin{tabular}{ll} 
A & Shape factor of filler \\
$a_{m}$ & Area of gas molecule used for surface area determination \\
$b$ & Sample width of flexural test specimen \\
$c$ & Defect size \\
C & BET constant \\
$\mathrm{C}_{\mathrm{f}}$ & Final concentration in end LOI column \\
$\mathrm{d}$ & Interplanar spacing lattice parameter \\
& Sample thickness of flexural test specimen \\
& LOI test step size \\
$\mathrm{d}_{50}$ & Average particle diameter \\
$\mathrm{D}$ & Diameter of compounder screw \\
$\mathrm{E}$ & Young's modulus \\
$\mathrm{E}_{\mathrm{b}}$ & Young's modulus calculated from flexural bend test \\
$\mathrm{E}_{\mathrm{R}}$ & Relative elastic modulus \\
$\mathrm{E}^{\prime}$ & Storage modulus \\
$\mathrm{E}^{\prime \prime}$ & Loss modulus \\
$\mathrm{F}$ & Maximum applied load \\
$\phi$ & Filler volume fraction \\
$\phi_{\mathrm{m}}$ & Maximum filler packing fraction \\
$\mathrm{G}$ & Shear modulus \\
$\mathrm{G}_{\mathrm{f}}$ & Shear modulus of filler \\
$\mathrm{G}_{\mathrm{p}}$ & Shear modulus of polymer \\
$\Delta \mathrm{G}$ & Free energy of mixing \\
$\gamma$ & Shear rate \\
$\gamma_{\mathrm{f}}$ & Energy to form a unit surface area \\
$\Delta \mathrm{H}$ & Enthalpy change of mixing \\
$\eta_{\mathrm{f}}$ & Viscosity of a filled system \\
$\eta_{\mathrm{o}}$ & Viscosity of an unfilled polymer \\
$\mathrm{k}$ & Statistical value used for determining LOI \\
& Material consistency used in the power law \\
\hline
\end{tabular}




\begin{tabular}{|c|c|}
\hline $\mathrm{L}$ & Span of support \\
\hline & Capillary die length \\
\hline & Length of compounder screw \\
\hline $\mathrm{m}$ & Mass of sample \\
\hline & Slope of force/deflection trace in linear region \\
\hline $\mathrm{M}_{\mathrm{w}}$ & Weight average molecular weight \\
\hline$M_{n}$ & Number average molecular weight \\
\hline $\mathrm{n}$ & Measure of non-Newtonian behaviour in the power law \\
\hline & Integer in Bragg's equation \\
\hline $\mathrm{n}^{\mathrm{s}}$ & Adsorbed amount of gas \\
\hline $\mathrm{n}_{\mathrm{m}}^{\mathrm{s}}$ & $\begin{array}{l}\text { Adsorbed amount of gas corresponding to monolayer surface } \\
\text { coverage }\end{array}$ \\
\hline $\mathrm{N}_{\mathrm{A}}$ & Avogadro's number \\
\hline $\mathrm{O}$ & Pass in LOI test \\
\hline$P$ & Total pressure drop in a capillary die \\
\hline $\mathrm{P}_{\mathrm{L}}$ & Pressure drop in a capillary die \\
\hline $\mathrm{P}_{\mathrm{O}}$ & Pressure drop in a capillary die due to convergence \\
\hline$\rho$ & Specific gravity of filler \\
\hline Q & Material flow rate \\
\hline $\mathrm{r}$ & Radius of die \\
\hline$\Delta \mathrm{S}$ & Entropy change during mixing \\
\hline $\mathrm{S}_{\mathrm{m}}$ & Specific surface area per unit mass \\
\hline$\sigma_{\mathrm{b}}$ & Flexural strength \\
\hline$\sigma_{\mathrm{f}}$ & Fracture stress (after Griffith) \\
\hline $\mathrm{T}$ & Temperature \\
\hline $\mathrm{T}_{\mathrm{g}}$ & Glass transition temperature \\
\hline $\mathrm{T}_{5}$ & Temperature at which $5 \%$ mass loss occurs \\
\hline$\tau_{\mathrm{w}}$ & Shear stress at wall \\
\hline v & Poisson's ratio \\
\hline $\mathrm{v}$ & Velocity of polymer melt \\
\hline $\mathrm{x}$ & Relative pressure \\
\hline $\mathrm{X}$ & Fail in LOI test \\
\hline
\end{tabular}




\section{Contents}

CHAPTER 1：INTRODUCTION 1

1.1 The Hazard of Fire 1

1.2 The Burning Process . 2

1.2.1 Flame Retardants 4

1.2.2 Methods of Flame Retardancy 5

1.3 Antimony Trioxide and Halogen Materials 7

$\begin{array}{llr}1.4 & \text { ABS Polymer } & 8\end{array}$

1.5 Objectives of Work ? 9

CHAPTER 2: LITERATURE SURVEY 11

2.1 Acrylonitrile-Butadiene-Styrene (ABS) 11

2.1.1 ABS Polymerisation Process 11

2.1.2 Physical and Mechanical Properties 13

2.1.3 ABS Processing 16

2.1.3.1 Compounding 16

2.1.3.2 Moulding 17

$\begin{array}{lll}2.2 & \text { Fillers } & 17\end{array}$

$\begin{array}{lll}2.2 .1 & \text { Properties of Fillers } & 18\end{array}$

2.2.2 Methods of Filler Characterisation 19

2.2.3 Agglomeration 21

2.2.3.1 Deagglomeration and dispersion of fillers 23

2.2.3.2 Properties of filled styrene plastics 24

2.3 Antimony Trioxide and Halogen Materials 25

2.3.1 Production and Properties of Antimony Trioxide 25

2.3.2 Halogen Materials * a 28

2.3.3 Halogen Materials for ABS Polymers 29

2.3.3.1 Decabromodiphenyl oxide 29

2.3.3.2 Bis(Tribromophenoxy)ethane 29

2.3.3.3 Tetrabromobisphenol A . 29

2.3.4 Halogen Flame Retardancy Mechanisms 30

2.3.5 Antimony Trioxide and Halogen Systems 31

2.3.5.1 Synergistic effects 31 
2.3.5.3 Flame retarded ABS 35

2.4 Filled Polymer Systems 36

2.4.1 Influence of Processing on Properties of Filled Polymer Systems 36

2.4.1.1 Compounding . 36

2.4.1.2 Injection moulding $\quad 37$

2.4.2 Mechanical Properties of Filled Polymer Systems 38

2.4.2.1 Impact 38

2.4.2.1.1 Effect of Particle Size on Filled ABS 41

2.4.2.2 Flexural modulus 43

2.4.2.3 Tensile properties 45

2.4.2.4 Elongation at break 46

2.4.3 Flammability/Combustion Characteristics $\quad 46$

2.4.3.1 Influence of particle size $\quad 47$

CHAPTER 3: EXPERIMENTAL PROCEDURES 48

3.1 Materials Used 48

$\begin{array}{lll}3.1 .1 & \text { Polymers } & 48\end{array}$

3.1.1.1 ABS polymer 48

3.1.1.2 Masterbatch polymer $\quad 49$

3.1.2 Antimony Trioxide $\quad 49$

3.1.2.1 Timonox $®$ Red Star . $\quad 49$

3.1.2.2 Microfine $® A 05 \quad 49$

3.1.2.3 Anzon sub-micron (AZUB) $\quad 49$

3.1.3 Brominated Materials $\quad 50$

3.2 Raw Material Characterisation 51

3.2.1 ABS 51

3.2.2 Particle Sizing 51

3.2.3 Apparent Bulk Density $\quad$. 52

3.2.4 Oil Absorption $\quad 52$

3.2.5 Thermogravimetric Analysis (TGA) 53

3.3 Processing Method 53

3.3.1 Compounding 53

3.3.1.1 Compounds 54 
3.3.2 Injection Moulding 56

3.3.2.1 Conditioning of compounds 56

3.3.2.2 Injection moulder settings $\quad 57$

3.4 Analysis of Compounds $\quad 58$

3.4.1 Antimony Content Analysis $\quad 58$

3.4.1.1 Ashing $\quad 58$

3.4.1.2 Volumetric titration analysis $\quad 59$

3.4.2 Bromine Content Analysis $\quad 60$

3.4.3 Rheology 61

3.4.3.1 Haake Rheology 61

3.4.4 Electron Microscopy 62

3.4.4.1 Scanning Electron Microscopy (SEM) 62

3.4.4.2 Transmission Electron Microscopy (TEM) 63

3.4.5 Impact Testing 64

3.4.6 Flexural Testing 66

3.4.7 Thermogravimetric Analysis (TGA) 67

3.4.8 Flame Testing 68

3.4.8.1 Limiting Oxygen Index (LOI) Flame Test 68

3.4.8.2 Underwriters Laboratory (UL-94) Vertical Burn Test · 69

CHAPTER 4: RESULTS 71

4.1 Analysis of Materials Used 71

$\begin{array}{lll}\text { 4.1.1 Cycolac T (ABS) Polymer } & 71\end{array}$

4.1.2 Antimony Trioxide 72

4.1.3 Brominated Halogens 77

4.2 Analysis of Unfilled ABS Compounds $\quad 81$

4.2.1 Mechanical Properties $\quad 81$

4.2.2 Thermogravimetric Analysis 84

4.2.3 Limited Oxygen Index (LOI) 85

4.3 Influence of Antimony Trioxide Particle Size (direct addition) 85

4.3.1 Compounding 85

4.3.2 Mechanical Properties 86

4.3.3 Microscopy Analysis $\quad 88$

$\begin{array}{lll}\text { 4.3.4 Flame Testing } & 91\end{array}$ 
4.4 Analysis of $\mathrm{Sb}_{\mathbf{2}} \mathrm{O}_{\mathbf{3}}$ Addition Using Masterbatches 92

4.4.1 Compounding . 92

4.4.2 Mechanical Properties 95

$\begin{array}{lll}4.4 .3 & \text { Microscopy Analysis } & 98\end{array}$

$\begin{array}{lll}4.4 .4 \text { Flame Testing } & 100\end{array}$

4.5 Influence of Bromine Additives 101

$\begin{array}{ll}\text { 4.5.1 Compounding } & 101\end{array}$

$\begin{array}{ll}\text { 4.5.2 Mechanical Properties } & 101\end{array}$

$\begin{array}{lll}4.5 .3 & \text { Microscopy Analysis } & 104\end{array}$

$\begin{array}{lll}\text { 4.5.4 Flame Testing } & 107\end{array}$

4.6 Influence of Bromine and $\mathrm{Sb}_{2} \mathrm{O}_{3}$ Addition 108

4.6.1 Compounding 108

$\begin{array}{ll}\text { 4.6.2 Mechanical Properties } & 110\end{array}$

4.6.3 Microscopy Analysis 115

$\begin{array}{ll}\text { 4.6.4 Flame Testing } & 117\end{array}$

$\begin{array}{lr}\text { CHAPTER 5: DISCUSSION } & 119\end{array}$

5.1 Analysis of Materials Used $\quad 119$

$\begin{array}{ll}5.1 .1 \text { Cycolac T (ABS) Polymer } & 119\end{array}$

$\begin{array}{ll}\text { 5.1.2 Antimony Trioxide } & 119\end{array}$

5.1.2.1 Particle sizing 119

$\begin{array}{ll}\text { 5.1.2.2 Packing characteristics } & 120\end{array}$

5.1.3 Brominated Halogens 121

5.2 Analysis of Unfilled ABS Compounds $\quad 122$

$\begin{array}{lll}5.2 .1 & \text { Processing } & 122\end{array}$

5.2.2 Thermal Properties 122

5.2.3 Impact and Fracture Properties 122

$\begin{array}{lll}\text { 5.2.4 Flexural Properties . } & 124\end{array}$

$\begin{array}{lll}5.2 .5 & \text { Flame Properties } & 124\end{array}$

5.3 Influence of Antimony Trioxide Particle Size (direct addition) 124

$\begin{array}{lll}5.3 .1 \text { Compounding } & 124\end{array}$

5.3.2 Impact Properties 125

$\begin{array}{lll}\text { 5.3.3 Flexural Properties } & 126\end{array}$

$\begin{array}{lll}\text { 5.3.4 Dispersion } \quad 127 & 127\end{array}$ 
$\begin{array}{lll}\text { 5.3.5 Fracture } & 128\end{array}$

5.3.6 Flame Properties $\quad 130$

5.4 Analysis of $\mathrm{Sb}_{2} \mathrm{O}_{3}$ Addition Using Masterbatches 131

5.4.1 Compounding 131

5.4.2 Impact Properties 133

5.4.3 Flexural Properties 134

$\begin{array}{lll}\text { 5.4.4 Dispersion } & 135\end{array}$

$\begin{array}{lll}\text { 5.4.5 Fracture } 135 & 135\end{array}$

5.4.6 Flame Properties · 136

5.5 Influence of Bromine Additives 136

5.5.1 Compounding 136

5.5.2 Impact Properties 137

$\begin{array}{lll}\text { 5.5.3 Flexural Properties } & 138\end{array}$

$\begin{array}{lll}\text { 5.5.4 Dispersion } & 139\end{array}$

$\begin{array}{lll}\text { 5.5.5 Fracture } & 140\end{array}$

5.5.6 Flame Properties 141

5.6 Influence of Bromine and $\mathrm{Sb}_{\mathbf{2}} \mathbf{O}_{\mathbf{3}}$ Addition 142

5.6.1 Compounding 142

5.6.2 Impact Properties $\quad 142$

5.6.2.1 Red Star 142

5.6.2.2. $A Z U B \quad 144$

5.6.3 Flexural Properties 145

$\begin{array}{lll}\text { 5.6.4 Dispersion } & 146\end{array}$

5.6.5 Fracture 146

$\begin{array}{lll}\text { 5.6.6 Flame Properties } & 147\end{array}$ 
CHAPTER 6: SUMMARY

CHAPTER 7: CONCLUSIONS

CHAPTER 8: FUTURE WORK

REFERENCES

APPENDIX A: Material Characterisation

APPENDIX B: Impact Test Results

REFERENCES: Flexural Test Results

REFERENCES: LOI Flame Test Results 


\section{List of Tables}

Table 2.1: Typical properties of antimony trioxide materials. 26

Table 3.1: $\quad$ Screw configuration and barrel temperature profiles. 54

Table 3.2: List of compounds. $\quad 55$

Table 3.3: Injection moulder dimensions. $\quad 57$

Table 3.4: Injection moulding profile for impact and flexural specimen bars. $\quad 57$

Table 3.5: Injection moulding profile for LOI and UL-94 specimen bars. $\quad 58$

Table 3.6: Flexural testing conditions. 67

Table 4.1: Particle sizing and packing properties of antimony trioxide grades. 73

Table 4.2: Characterisation of brominated halogen grades. · 78

Table 4.3: Bromine contents of brominated halogen grades. 78

Table 4.4: TGA mass loss data for brominated halogen grades. $\quad 80$

Table 4.5: Mechanical properties of unfilled ABS controls. 81

Table 4.6: Influence of $\mathrm{Sb}_{2} \mathrm{O}_{3}$ particle size (and castor wax) on compounding. 85

Table 4.7: Impact properties of $\mathrm{Sb}_{2} \mathrm{O}_{3}$ filled compounds. 86

Table 4.8: $\quad$ Flexural properties of $\mathrm{Sb}_{2} \mathrm{O}_{3}$ filled compounds. $\quad 87$

Table 4.9: Flexural properties of $\mathrm{Sb}_{2} \mathrm{O}_{3}$ filled compounds. 91

Table 4.10: Haake Rheocord data for blends of Blendex 310(S)
and Cycolac T.

Table 4.11: Blendex 310(S) masterbatches. $\quad 94$

Table 4.12: Impact properties of masterbatched $\mathrm{Sb}_{2} \mathrm{O}_{3}$ compounds. 95

Table 4.13: Flexural properties of masterbatched $\mathrm{Sb}_{2} \mathrm{O}_{3}$ compounds. 97

Table 4.14: Compounding data for $20 \mathrm{wt} \%$ bromine formulations. 101

Table 4.15: Impact properties of bromine containing compounds. 102

Table 4.16: Flexural properties of bromine containing compounds

Table 4.17: Influence of bromine material on flame properties of ABS. 108

Table 4.18: Compounding data for formulations containing bromine and $\mathrm{Sb}_{2} \mathrm{O}_{3} .109$

Table 4.19: Impact properties of compounds containing bromine and $\mathrm{Sb}_{2} \mathrm{O}_{3} . \quad 110$

Table 4.20: Failure impact energy properties of $\mathrm{Br}$ and $\mathrm{Sb}_{2} \mathrm{O}_{3}$ compounds. 111

Table 4.21: Flexural properties of masterbatched $\mathrm{Sb}_{2} \mathrm{O}_{3}$ compounds $\begin{array}{ll}\text { and references. } & 113\end{array}$

Table 4.22: Influence of bromine material on flame properties of ABS. 118 


\section{List of Figures}

Figure 1.1: Flammability cycle. 2

Figure 1.2: $\quad$ Sequence of events or phases in fire. 3

Figure 1.3: Surface degradation caused by an external heat source and the energy balance on the surface.

Figure 2.1: Chemical structure of ABS constituents. 11

Figure 2.2: $\quad$ Typical stress-strain curve for ABS polymers. 14

Figure 2.3: Rate constant expressions for ideal and real flame-retardants. 32

Figure 3.1: $\quad$ Structure of 1,2-bis(Tribromophenoxy)ethane (BTBPE). 50

Figure 3.2: $\quad$ Structure of Tetrabromobisphenol A (TBBA). 50

Figure 3.3: $\quad$ Structure of decabromodiphenyl oxide (DBDPO). 50

Figure 3.4: Rosand Instrumented Falling Weight Impact testing machine. $\quad 65$

Figure 3.5: Limiting Oxygen Index apparatus. $\quad 68$

Figure 3.6: Underwriters Laboratory UL-94 apparatus. $\quad 70$

Figure 4.1: $\quad$ Antimony trioxide particle size distribution curves. 72

Figure 4.2: $\quad$ TGA curves for brominated materials (and ABS control). $\quad 80$

Figure 4.3: TGA curves for ABS before and after compounding. $\quad 84$

Figure 4.4: Influence of $\mathrm{Sb}_{2} \mathrm{O}_{3}$ particle size on impact properties (\% ABS). $\quad 87$

Figure 4.5: Influence of $\mathrm{Sb}_{2} \mathrm{O}_{3}$ particle size on flexural properties. 88

Figure 4.6: Haake Rheocord - torque versus time $\left(\mathrm{T}=200^{\circ} \mathrm{C}\right.$ at $\left.\mathrm{t}=0\right) . \quad 93$

Figure 4.7: Impact properties of masterbatched $\mathrm{Sb}_{2} \mathrm{O}_{3}$ compounds (\% unfilled ABS). $\quad 96$

Figure 4.8: Relationship between increasing PB content and impact energies. $\quad 96$

Figure 4.9: Flexural properties of masterbatched $\mathrm{Sb}_{2} \mathrm{O}_{3}$ compounds. 98

Figure 4.10: Impact properties of bromine only compounds (\% ABS). 102

Figure 4.11: Flexural properties of bromine containing compounds. 104

Figure 4.12: Impact properties of Red $\mathrm{Star} \mathrm{Sb}_{2} \mathrm{O}_{3}$ and bromine compounds. $\quad 112$

Figure 4.13: Impact properties of $\mathrm{AZUB} \mathrm{Sb}_{2} \mathrm{O}_{3}$ and bromine compounds. 112

Figure 4.14: Flexural properties of Red Star and bromine compounds. 114

Figure 4.15: Flexural properties of AZUB and bromine compounds. 114

Figure 5.1: Graph showing relationship between LOI value and $\mathrm{Sb}_{2} \mathrm{O}_{3}$ loading. 131

Figure 5.2: Hake Rheocord data showing temperature increase with time. 132

Figure 5.3: $\quad$ Predicted and actual energy losses (RS + Br compounds). 143

Figure 5.4: $\quad$ Predicted and actual energy losses (AZ + Br compounds). 144 


\section{List of Plates}

Plate 4.1: $\quad$ TEM image of Cycolac T ABS morphology. 71

Plate 4.2: $\quad$ TEM image of Red Star antimony trioxide particles.

Plate 4.3: $\quad$ TEM image of Microfine A05 antimony trioxide particles. $\quad 74$

Plate 4.4: $\quad$ SEM image of spray dried AZUB material. 75

Plate 4.5: $\quad$ TEM image of a sphere of sAZUB material.

Plate 4.6: $\quad$ TEM image of sAZUB sphere surface. $\quad 75$

Plate 4.7: $\quad$ SEM image of particle of AZUBRS material. 76

Plate 4.8: $\quad$ SEM image of pan dried AZUB material. 76

Plate 4.9: $\quad$ TEM image of pan dried AZUB material.

Plate 4.10: $\quad$ SEM image of spray dried DBDPO material. $\quad 79$

Plate 4.11: TEM image of a sphere with sDBDPO material. 79

Plate 4.12: $\quad$ SEM image of unfilled ABS control. $\quad 82$

Plate 4.13: Optical microscope image of unnotched ABS control. 82

Plate 4.14: TEM image of stress-whitened zone in unfilled ABS. 83

Plate 4.15: TEM image of crazing between larger butadiene particles. $\quad 83$

Plate 4.16: TEM image of crazing between larger butadiene particles. $\quad 84$

Plate 4.17: $\quad$ TEM image of $\mathrm{AZUB}^{(\mathrm{RS})}$ dispersed in ABS. $\quad 89$

Plate 4.18: $\quad$ TEM image of sAZUB material dispersed in ABS. 89

Plate 4.19: $\quad \mathrm{SEM}$ image of $\mathrm{A} 05 \mathrm{Sb}_{2} \mathrm{O}_{3}$ agglomerate in parabolic crater. $\quad 90$

Plate 4.20: SEM image of fracture surface of SAZUB compound. 90

Plate 4.21: $\quad$ TEM image of enlarged polybutadiene particles (4wt\% MB1). $\quad 99$

Plate 4.22: $\quad$ SEM image of compound 9 fracture surface (12wt\% MB1). 99

Plate 4.23: $\quad$ SEM image of compound 13 fracture surface (16wt\% MB4). $\quad 100$

Plate 4.24: TEM image of DBDPO particle in ABS. 105

Plate 4.25: TEM image of sDBDPO particles in ABS (inc. crazing). 105

Plate 4.26: SEM image of BTBPE compound fracture surface. 106

Plate 4.27: $\quad$ SEM image of TBBA compound fracture surface. 106

Plate 4.28: $\quad$ SEM image of DBDPO fracture surface. 106

Plate 4.29: $\quad$ SEM image of sDBDPO compound fracture surface. 107

$\begin{array}{lll}\text { Plate 4.30: } & \begin{array}{l}\text { Back scattered electron image of sAZUB } \\ \text { and DBDPO particle dispersion. }\end{array}\end{array}$ 
Plate 4.31: $\quad$ SEM image of sAZUB agglomerate (and DBDPO particles).

Plate 4.32: Optical microscope image of MB RS + BTBPE fracture surface. 116

Plate 4.33: Optical microscope image of MB RS + TBBA fracture surface. 117

Plate 5.1: $\quad$ SEM image showing RS particles embedded in fracture surface. 129

Plate 5.2: $\quad$ SEM image of fracture surface of RS compound. 130 


\section{INTRODUCTION}

Nowadays our working and home environments are increasingly filled with polymers as designers and manufacturers make greater use of polymers as a construction material. In recent years end users have become more demanding and requirements for certain properties, or combinations of properties, have been constantly increasing. As industrially produced commodity polymers have a number of drawbacks there is demand that the mechanical properties, flammability characteristics, lifetime, resistance to chemicals and other useful properties be improved, to create broader and more effective use [1].

\subsection{The Hazard of Fire}

Fire is an ever-present hazard in the built environment and history is littered with cases where fire has claimed many lives and destroyed property, including the famous fires of Rome and London [2] and the more recent fires at the Bradford City Football Ground and Kings Cross Station [3]. Modern improvements in fire-fighting methods along with improved fire regulations has not prevented the increase in the number of fatalities and the damage to property caused by both the fire and associated hazards (the two biggest hazards being toxic fumes and smoke emissions) [3-5]. In the UK, about 1000 people die in fires each year and a further 6000 are seriously injured. With the increase in the amount of polymeric materials used in modern buildings and the replacement of traditional building materials by more flammable substitutes their presence is an increased threat to safety and therefore of considerable concern [6]. The rate at which combustion occurs will vary greatly from polymer to polymer. Overall, therefore, it can be said that the fire hazard of a system is a function of both the fire performance of a polymer as well as the degree of exposure to fire that the polymer experiences $[1,7,8]$. 


\subsection{The Burning Process}

Fire involves the chemical reaction between the following parameters:

i. a combustible substance or fuel

ii. heat, supplied either externally or from the combustion process

iii. an oxidizing gas, primarily oxygen.

This definition may be depicted by the following diagram (Figure 1.1), which shows the three requisite components for a fire.

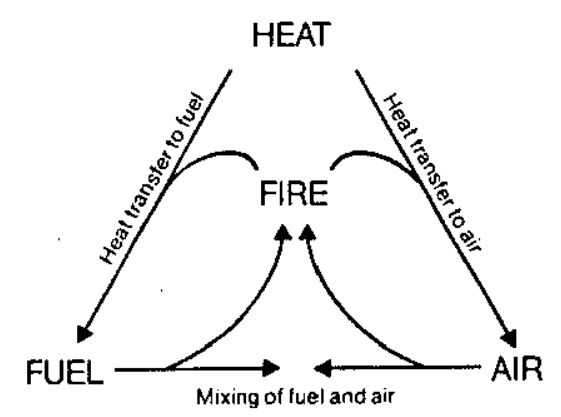

Figure 1.1: Flammability cycle [6].

The reduction or removal of a sufficient amount of any one of these will sufficiently slow (and stop) a fire, thereby eliminating the hazard. This concept forms the rudimentary beginnings of the technology of fire and flame retardancy. Figure 1.2 shows the general sequence of events in a fire, although not all fires necessarily follow all phases [9]. In most cases though, this diagram depicts the occurring phases. 


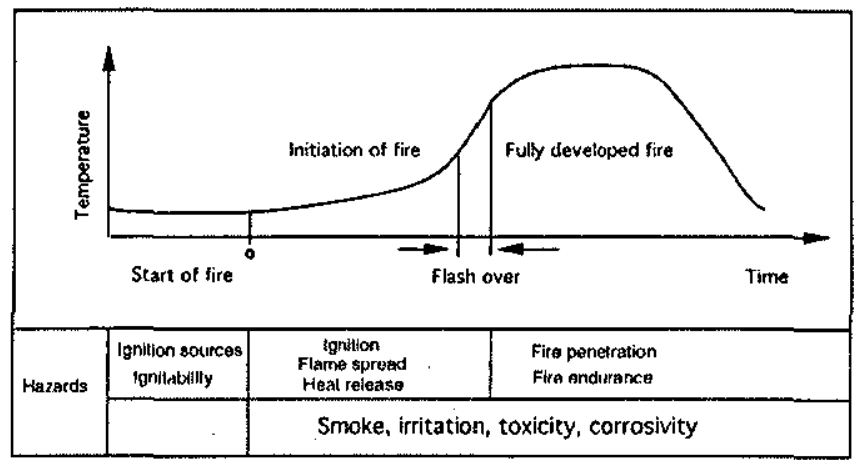

Figure 1.2: Sequence of events or phases in fire [2].

The combustion of a polymeric material exposed to an external source of heat can therefore be considered as occurring in five stages:
i. heating,
ii. degradation and decomposition,
iii. ignition,
iv. combustion,
v. propagation.

The rate of temperature rise in the heating stage depends on the polymer's physical characteristics: specific heat, thermal conductivity, latent heat of fusion and, possibly, latent heat of vaporisation. Decomposition starts once the material reaches a high enough temperature, during which both combustible and non-combustible gases are evolved. Combustion begins when the gaseous products ignite, either as a result of a spark or neighbouring flame, or spontaneously at a somewhat higher temperature. If the length of the heating and degradation (growth/initiation) stage of the process can be extended in order to delay ignition then this would allow greater escape time. During the combustion stage the heat evolved by the burning gaseous products raises the temperature of the surrounding material and may bring them also into the combustion process, hence propagating the fire. The duration of this period will depend on the amount of available fuel and the amount and rate of delivery of oxygen. If either of 
these can be reduced then the flame cycle can be interrupted which will lead to extinction of the flame [8].

In the burning process of a plastic material, these five stages are simultaneously present in various zones of the material, the culminating effect being depicted in the energy balance diagram (Figure 1.3) [10]. The majority of plastics produce two zones as illustrated in this figure: the site of the gas evolution (pyrolysis zone) covered by the carbonaceous layer of the porous solid residue. The primary combustion products are formed in the pyrolysis zone and then pass through the char layer, often undergoing further reactions [11].

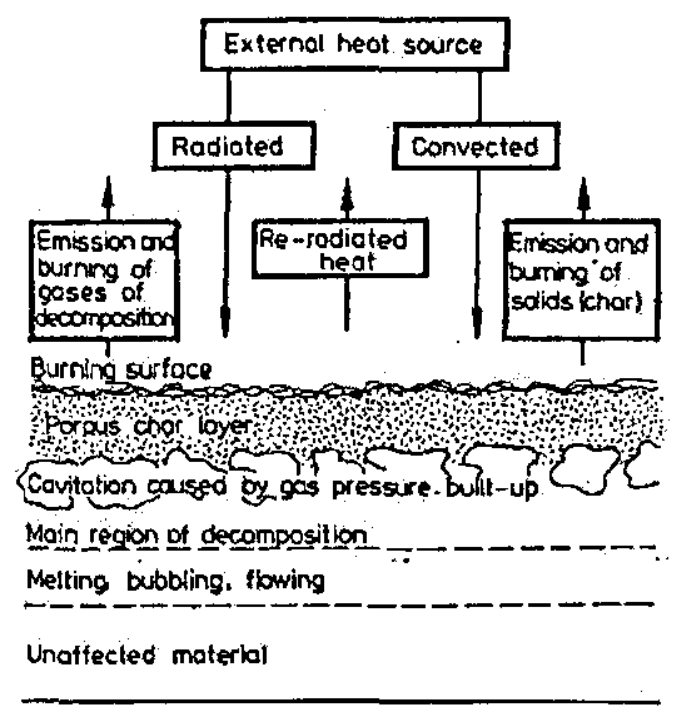

Figure 1.3: Surface degradation caused by an external heat source and the energy balance on the surface.

\subsubsection{Flame Retardants}

Although many polymers have an inherent resistance to ignition and combustion, under suitable conditions of heat flux and oxygen availability, they can sustain combustion [1]. To reduce flammability, flame retardant chemicals are used either as additives or as an inherent part of the polymer structure, typically in low to moderate cost commodity polymers [12]. In general, the term flame retardant (FR) is used to describe chemical compounds used to formulate products meeting specified tests or fire codes. Flame retardation is used to describe the process by which these chemicals are used to alter the 
normal degradation or combustion processes of the polymers [13]. The extent of flame retardancy imparted to any specific polymer can vary substantially depending on the product formulation, processing conditions and environmental conditions when used. The degree of resistance to flammability is defined normally as a numerical value (determined through standard tests), which is higher than the unmodified polymer, and therefore more resistant to flame or fire.

A good flame retardant additive must meet the following requirements:

i. be thermally stable up to the processing temperature of the polymer,

ii. have no interaction with the main chain of the polymer, yet must be compatible with the host polymer at the same time,

iii. retain its flame retardant properties during its application, and

iv. be non-poisonous or lead to the evolution of toxic and corrosive gases.

Since no single additive can meet all these requirements, all present flame-retardants are, to lesser or greater extents, compromises. Flame retarded materials can be formulated to be more resistant to ignition than non-flame-retarded materials, or to have slower rates of flame spread in a major fire that is initiated by another source; however, the flame-retarded article will ultimately burn.

\subsubsection{Methods of Flame Retardancy}

A basic understanding of the different theories by which flame retardants function is essential for identifying and selecting the optimum material for any given situation. As has been stated earlier, combustion occurs in five stages and for a compound to function as a flame retardant it must interrupt the combustion cycle in some way. The three main mechanisms through which this retardancy can be achieved are heat absorption, condensed phase and vàpour phase reactions.

\section{Heat absorption reactions}

Ignition can be prevented if the surface of the polymer is sufficiently cooled by the additives. This can be done either by providing a heat sink through the evaporation of water or by hydration. A flame retardant acting as a thermal heat sink operates either by 
reducing the fuel concentration below the lower flammability limit or by increasing the heat capacity of the system. Alumina trihydrate (ATH) is an example of an additive, which works in this manner, with the heat that is absorbed by the ATH allowing it to undergo an endothermic dehydration resulting in water evolution.

\section{Condensed phase reactions}

These flame-retarded species can act by promoting the formation of carbonaceous char instead of the volatile and combustible gases. The char also serves to insulate the unreacted surface of the sample from the heat source, thereby acting as a physical preventative barrier. Phosphorous containing additives (such as ammonium polyphosphate) predominantly work as a flame retardant in this manner.

\section{Vapour phase reactions}

In vapour phase reactions the decomposition products are less exothermic than the process of combustion itself with two significant effects to be noted. In the first, the flame retardant decomposes at the burning temperature, producing non-combustible vapours. These dilute the flammable gases evolved from the pyrolysed polymer to a concentration below the flammability limit. Effective diluents include $\mathrm{HCl}, \mathrm{H}_{2} \mathrm{O}, \mathrm{CO}_{2}$ and $\mathrm{SO}_{2}$ resulting from the thermal decomposition of additives. In the second, flameretardants can function in the gas phase by producing free radical terminators ('quenchers') when heated to that of the flame temperature. These quenchers interfere with the chain reaction occurring in the flame and inhibit combustion. The use of halogenated materials as flame-retardants makes use of this method of flame quenching. The ability to quench a flame using halogens is improved with the incorporation of antimony trioxide material. 


\subsection{Antimony Trioxide and Halogen Materials}

Antimony trioxide $\left(\mathrm{Sb}_{2} \mathrm{O}_{3}\right)$ and halogens (usually $\mathrm{Br}$ and $\mathrm{Cl}$ ) are used as a synergistic package to flame retard materials. The antimony trioxide is commonly used as a means of reducing the levels of a halogen required to achieve a particular level of flame retardancy. This lowering of the amount of halogen required leads to both an improvement in cost-effectiveness and also to an improvement in flame retardancy properties. However even at low loadings of antimony trioxide (4 to $6 \mathrm{wt} \%$ ) and a halogen (18 to $24 \mathrm{wt} \%$ ) the physical properties of polymer systems are detrimentally affected.

This effect is still somewhat lower than the drop in properties caused by other flame retardant systems. Hydrated fillers such as alumina trihydrate or magnesium hydroxide need to be incorporated at much higher loadings (approximately 50 to $60 \mathrm{wt} \%$ ) to have the same retardancy effects and these high filler loadings significantly reduce the mechanical and physical properties of polymers. These additives are seen as less toxic than halogenated systems and recent environmental concerns over $\mathrm{Sb}_{2} \mathrm{O}_{3}$ are inducing producers to look more seriously at these alternatives [14-17]. Currently these are viewed as less efficient and have lower performance versus brominates [18], which is reflected in the fact that in 1998, brominated materials accounted for $39 \%$ of the global polymer flame-retardant market ( $\$ 2$ billion), with antimony oxides accounting for $17 \%$ [19].

Styrenic polymers are one such group that is particularly susceptible to property reductions when filled with fillers or flame-retardants. Acrylonitrile-butadiene-styrene (ABS) is one grade of these polymers that suffer and a balance is needed between maintaining the existing properties for which the polymer is used, whilst still incorporating enough flame retardant material to be suitably flame resistant. The lower loadings used with halogen and antimony trioxide systems means that these types of retardants are predominantly used in styrene polymers, including ABS. 


\subsection{ABS Polymer}

ABS polymers are composed of a continuous rigid phase of styrene and acrylonitrile copolymer (SAN) in which the elastomer phase is dispersed in the form of spherical particles. Grafted SAN on the surface of the polybutadiene particles forms a compatible link between the particles and the matrix. By varying the amount of the components, the manner by which they are combined and the size and number of elastomer particles, $\mathrm{ABS}$ resins can be manufactured to a wide specification range [20]. This range includes low to high impact, low gloss, glass reinforced, fire retarded, high heat and plating grades to name a few. These grades have different properties and therefore a wide variety of end uses, with each grade bringing benefits to various processing, mechanical and electrical properties [21]. They range in price from $£ 1500 /$ tonne (high heat) to $£ 2600 /$ tonne (30\% glass filled) [22]. This diversity of properties and the fact that the prices are still lower than other more expensive engineering polymers means that the range of $\mathrm{ABS}$ polymers are widely used.

Demand for ABS is primarily spread throughout the US, the Far East, Western and Eastern Europe, Central and South America. The region of largest growth is in the Far East (mainly through market expansion in China) with $3.39 \mathrm{~m}$ tonnes capacity quoted for 1998 [23]. The versatility of ABS makes the polymer less dependent on one industry or region with the polymer being very strong in key markets [24-26]. Consumer goods, including small (kitchen appliances, power tools) and large appliances (refrigerator linings), accounts for nearly $30 \%$ of worldwide ABS consumption; automotive (consoles, glove boxes, mirror housings, wheel trims) for $22 \%$; business machines and telecommunications for nearly $14 \%$ with pipes and fittings contributing $7 \%$ [27]. The rest of its uses include toys, medical applications, recreational products and garden furniture.

The large diversity of end uses makes ABS one of the most successful available engineering thermoplastics. However due to the effects of flame-retardants on the mechanical properties it is clear that further work is required in this area. 


\subsection{Objectives of Work}

The main aims of the research were to investigate the influence of both antimony trioxide and brominated halogen materials on the properties of ABS. The presence of the two additives has a well-documented detrimental effect on the mechanical properties of ABS, when added at optimum loadings for flame retardancy. The main objective of this work therefore was to improve the impact strength of filled ABS compounds. This was done with the initial emphasis placed on the antimony trioxide, due to the interests of the sponsoring company Anzon Ltd.

Initially a characterisation program was established to examine all the polymers, antimony trioxide and halogen materials prior to their being compounded. A processing and testing programme was also established with sample formulations being compounded to become familiar with the equipment and its effect on the compound properties. A standard method for testing was established for all the compounds during this research.

The influence of several commercial and experimental grades of $\mathrm{Sb}_{2} \mathrm{O}_{3}$, all with different particle sizes, was first studied at loadings of $4 \mathrm{wt} \%$ in ABS (direct addition). The results were compared with the findings on the materials from the characterisation programme, with particular emphasis on the experimental grades. The relative dispersion of the antimony trioxide, the fracture mechanisms observed and their relation to impact properties were of significant importance. Several compounds were formulated using $\mathrm{Sb}_{2} \mathrm{O}_{3}$ masterbatches of both commercial and experimental grades, which were 'let down' into the final compound. A high impact modifier for ABS polymers was used for the masterbatch resin.

Several commercial halogenated materials from the parent sponsoring company (Great Lakes Chemicals) were incorporated into ABS at loadings typically seen in industry in order to discover their influence on physical, mechanical and flammability properties. One experimental grade was also supplied for compounding, which used the same technology as that for the experimental antimony trioxide grades. 
The halogenated and antimony trioxide materials were finally compounded together to create fully flame-retarded systems. The effects of both additives on the compound properties were then compared against the earlier sections in order to draw overall conclusions for this work. 


\section{LITERATURE SURVEY}

\subsection{Acrylonitrile-Butadiene-Styrene (ABS)}

Acrylonitrile-butadiene-styrene (ABS) contains three monomeric units, acrylonitrile (AN), butadiene (B) and styrene (S). The elastomeric component, usually polybutadiene [28] (PB) or a butadiene copolymer, exists as a discrete phase dispersed in the thermoplastic component - a copolymer of styrene (S) and acrylonitrile (AN) [29]. Typical ABS polymers consist of these three components in a wide range of levels: acrylonitrile (21 to $27 \%$ ), polybutadiene (12 to $25 \%$ ) and styrene (54 to $63 \%$ ). ABS has the beneficial SAN properties of rigidity, processability and resistance to chemicals and solvents [30], while the elastomeric component increases impact resistance.

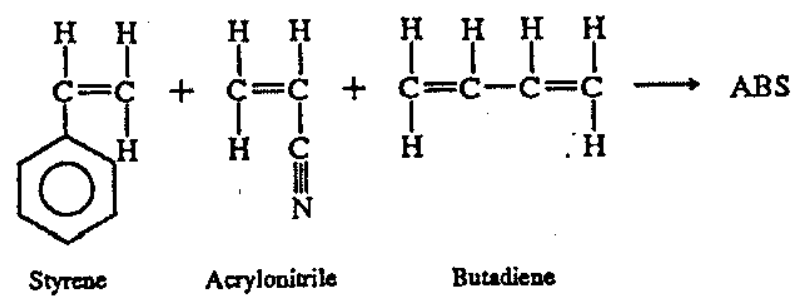

Figure 2.1: Chemical structure of ABS constituents. [31]

\subsubsection{ABS Polymerisation Process}

The manufacture of ABS is carried out commercially by a number of well-documented methods [27, 32-34]. The most common polymerisation methods are emulsion, mass (or bulk) and suspension polymerisation. Emulsion polymerisation is a more complex process than the other methods, but is still widely used and has been for many years. Its complexity arises from the fact that processing takes place in a heterogenous system, which consists of an aqueous medium, which acts as a heat sink; discrete monomer or polymer droplets/particles; a surfactant stabilizer and a free radical initiator. More recent work looks at the use of antioxidants to protect the polymer during the drying stage of its manufacture [35]. Its continued use lies in its ability to produce ABS with a wider range of compositions and higher rubber contents than other methods. 
Production of $\mathrm{ABS}$ starts with a polybutadiene latex (usually containing 30 to $60 \% \mathrm{~PB}$ ) and most commonly prepared using a batch reaction process. The butadiene is only partly polymerised through the use of a short-stopping agent, which prevents too much crosslinking taking place. Sufficient crosslinking must take place though to ensure that monomer/polymer swelling ratios are kept low, as this will reduce the amount of occluded SAN possible in the polybutadiene in later stages. After the correct particle size / size distribution has been achieved through the use of controlled acid additions any residual monomer is removed. The latex is then introduced to the styrene and acrylonitrile monomers in the presence of more water along with an emulsifier and a water-soluble initiator. Polymerisation is controlled so that SAN forms a layer around each polybutadiene particle where grafting occurs between the two phases. This ensures that there is good bonding across the phase boundary. This grafted latex can then be blended with separately prepared free SAN copolymer to the desired ratios. Whilst it is also possible to prepare ABS in a single step process, using several stages allows greater control of many variables such as the rubber particle size and distribution, the amount of grafted SAN, the S/AN ratio, the crosslink density of the rubber and the grafted rubber morphology. Particle morphology can vary from the ideal core/shell structure, i.e. a uniform SAN shell polymerised around the PB particle, to multi-lobed particles, as well as to greater amounts of SAN occlusions within the PB particles. This last factor is important as this can effect the dispersion of these particles in the SAN matrix. This subsequently affects the physical property performance of the ABS blend [27].

The more modern ABS process is one where a separate high rubber graft is made, usually in emulsion batch, with at least $50 \%$ rubber and as little free SAN as possible $(\mathrm{S} / \mathrm{AN}$ ratio $\geq 2.3$ ). A SAN is optimised for flow separately in an aqueous suspension, achieving a $\mathrm{S} / \mathrm{AN}$ ratio $>2.5(<28 \% \mathrm{AN})$. This results in a type of ABS with rubber optimised for impact and SAN optimised separately for flow [36]. 


\subsubsection{Physical and Mechanical Properties}

The physical and mechanical properties of ABS reflect its composition as an isotropic mixture of two phases with widely differing properties: a hard, transparent and relatively brittle thermoplastic (SAN) and a soft, elastomeric phase containing crosslinked PB.

The physical properties of ABS are intermediate between those of the 'glass' and the rubber, while the mechanical properties, with the notable exception of impact toughness, are much closer to those of the glassy material than those of the rubber. The material is naturally opaque with a yellow tint when the dispersed phase is based on emulsion particles. ABS typically absorbs 0.2 to $0.4 \%$ of its own weight of water during 24 hours in saturated vapour due to the presence of polar nitrile groups [27]. This places it in the middle of the range for values of thermoplastics at a slightly higher value than SAN [30]. This slight water affinity can cause problems during processing which can lead to defects in the final product(s).

The mechanical properties of ABS can be divided into two groups according to strain rate:

i. those relating to the static or low strain rate behaviour, such as the elastic, creep and isothermal fatigue behaviour,

ii. those obtained under the high strain rate of impact conditions.

The elastic properties of ABS are those of the SAN matrix modified in proportion to the volume fraction that is occupied by the elastomer-containing phase of the material. Due to the presence of occluded SAN and grafted material this value is not the straightforward polybutadiene volume fraction but actually a slightly higher value. In emulsion systems this can be up to two times the volume fraction of the rubber. The elastic modulus for a two-phase isotropic system follows a simple rule of mixtures involving these volume fractions. Since the rubber has essentially zero modulus relative to the SAN (1 MPa compared to $3000 \mathrm{MPa}$ ), the addition of the second phase reduces the elastic modulus in proportion to the volume fraction occupied by that phase. Quoted 
elastic modulus values for SAN are between 3000 and $3600 \mathrm{MPa}$, whilst for ABS they are approximately $2000 \mathrm{MPa}$, depending upon the polybutadiene loading. The Poisson's ratio of ABS is approximately 0.4 which is intermediate between that of SAN $(0.35)$ and polybutadiene $(0.5)$ [27].

The load-displacement curve for a typical ABS in a tensile test shows a quasi-elastic region extending up to 0.50 to $0.75 \%$ strain, followed by a yielding at stresses in the order of 4 to $6 \mathrm{MPa}$, and a strain softening region in which the load roughly remains constant until failure. The elongation at break is typically $30 \%$ or greater and increasing the rubber content can quickly increase this value. Higher rates of strain lower elongation values but raise the yield strengths and elastic modulii.

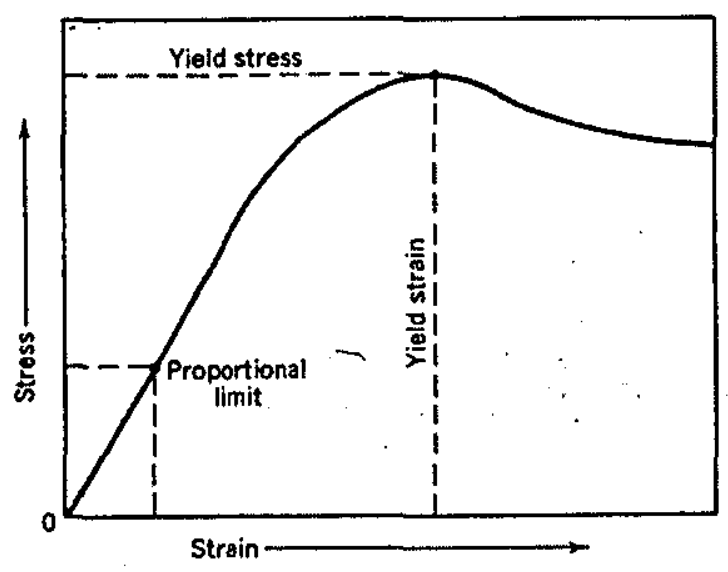

Figure 2.2: Typical stress-strain curve for ABS polymers. [31]

The impact toughness of ABS is a function of virtually all its material parameters, with greatest dependence upon those relating to the rubber phase: its volume fraction, graft or interfacial morphology, and degree of crosslinking. The impact toughness of ABS is relatively insensitive to the radius of the notch used, with sub-millimetre notch radii producing no significant loss in toughness. Notched impact values range from 105 to $440 \mathrm{~J} / \mathrm{m}$. The addition of rubber improves the strength of the SAN when impacted at high strain rates. Without the rubber phase, SAN is a brittle glassy polymer with an elongation to break of a few percent and a notched Izod impact strength of about $25 \mathrm{~J} / \mathrm{m}$. 
The presence of rubber particles enables the matrix to yield under plastic deformation by one of several energy-absorbing mechanisms [37]:
i. shear yielding (ductile),
ii. crazing (semi-brittle),
iii. cavitation (brittle).

Deformation consists of extensive shear deformation assisted by multiple crazing originating at the rubber particles and cavitation within the particles. Early work on creep and impact behaviour of HIPS and ABS [38] attributed the dilational component entirely to multiple crazing, but recent tests have shown that cavitation of the rubber particles precedes crazing and shear in both polymers. It was demonstrated that cavitation is responsible for the majority of the dilational strain in ABS. It also showed that changing the material parameters primarily affects the balance between shear and cavitation, while leaving the craze component relatively unaltered. Rubber particle cavitation creates plane stress conditions between closely spaced particles in the matrix material and allows ligaments to deform by yielding rather than cracking. Increased strain rate shifts the balance towards crazing and cavitation, from shear yielding at the lower strain rate [39].

The matrix styrene/acrylonitrile ratio has several effects on mechanical behaviour. A higher acrylonitrile content results in more ductile deformation, due to the matrix having a higher strand density, and this shifts the balance of deformation away from crazing towards shear. Shear is the more favourable of the two mechanisms since no voids are created in the process, unlike in a craze. High temperature, low strain rates and orientation all shift the deformation mode towards shear.

As the molecular weight of the SAN increases, for a given particle size, the impact performance increases and the flow decreases. It has also been observed that impact properties are improved when the acrylonitrile level in the graft SAN is less than that in the matrix SAN. 
The properties of ABS are sensitive to the morphology of the modifying phase. As well as the two major phases, the interface constitutes a third phase, which has a large effect with respect to overall properties. The interface must transfer stress from the matrix to the rubber in order to achieve reasonable mechanical properties. Particles not suitably bonded to the matrix behave as voids, resulting in reduced toughness.

\subsubsection{ABS Processing}

ABS is sold by numerous suppliers in grades with many different rubber contents, monomer contents (especially acrylonitrile levels), morphologies, molecular weights, weight distributions and different graft levels. These result in a family of polymers with a wide range of properties that are suitable for compounding and processing using a variety of equipment, most importantly compounders, extruders and injection moulders.

\subsubsection{Compounding}

ABS grades need to be compounded at relatively low temperatures (between $180^{\circ} \mathrm{C}$ and $250^{\circ} \mathrm{C}$ ) as exposure of the $\mathrm{ABS}$ to prolonged periods of either high temperature and/or high shear will increase the possibility of rubber particle agglomeration [40] or even degradation of the PB. Therefore care must be taken during extruder compounding not to leave the ABS in the barrel for excessive periods of time otherwise the polymer could become discoloured [20]. In extreme cases where excessive degradation occurs, brittleness, 'pockets' of degraded polymer or even smoke and fume emission can occur. In blends involving high rubber content $\mathrm{ABS}$ compounded with bulk $\mathrm{SAN}$, undue shear or heat history should be avoided through optimum use of extruder screw designs. Optimised use of co-rotating twin-screw extruders can further improve the processing conditions [41]. ABS can also be compounded at high rates due to its low viscosity (high flow). 


\subsubsection{Moulding}

The moulding process itself is as important as which type of ABS is chosen. Large mechanical property deviations can result, depending upon the flow direction as well as the moulding process stresses built into a moulded part.

ABS can be moulded at a slower injection rate, which will reduce the amount of shear. The orientation and gloss of the moulded part can also be altered if the injection rate is reduced. At slightly higher mould temperatures the orientation will be reduced and help to pack out the part even under slow injection rates. If high temperature or high shear are introduced discolouration can occur. To avoid this happening manufacturers generally suggest a shot size (volume) that is greater than half of the barrel volume.

Splay is a common visual defect (along with discolouration) usually caused by high water content, trapped air or volatile organic compounds. ABS is not as sensitive to water as some other thermoplastics (e.g. polycarbonate), but the levels of water should be reduced to 0.1 to $0.15 \%$.

\subsection{Fillers}

Fillers are finely divided solids added to a liquid, semisolid, or solid composition, to improve general properties, to introduce particular characteristics or to reduce the cost of the compound [42]. In more cases nowadays, fillers are used primarily as a means of modifying the composition (physical) properties, whilst minimizing the overall costs are an added secondary benefit [43]. The filler(s) used can be either a minor or a major part of a formulation depending on the required end properties. Filler particle structures range from precise geometrical forms (spherical, plate-like, or fibres) to irregular masses.

Fillers are characterised by a number of parameters that include origin of extraction (in the case of mineral fillers); particle size and size distribution [44] (or fibre length); density; purity; presence of any heavy-metal(s); water content; oil adsorption value or plasticiser adsorption value; whiteness; specific heat; and thermal conductivity. 
Consistency in filler properties, especially with respect to purity and particle size is an important criterion of quality. They are generally used for nondecorative purposes, although they may incidentally impart colour or opacity to a composition (as is found when using antimony trioxide).

The majority of fillers are used to improve or optimise certain mechanical properties of a system (e.g. impact resistance or modulus), but as well as these there are a large range of specialty fillers which are used to promote/improve other properties including those of flame retardancy and smoke suppression to name two.

\subsubsection{Properties of Fillers}

The overall value of a filler is a complex function of inherent material characteristics, e.g., true density, melting point, and chemical composition; as well as of process dependent factors, e.g., particle-size distribution, surface chemistry, purity, and bulk density. These values, often called functional properties, vary according to the nature of the application. A quantification of the functional properties per unit cost in many cases provides a valid criterion for filler comparison and selection.

The reinforcing effect of fillers depends on their chemistry, shape (fibres, flakes, spheres) and size (fibre length, particle size). The most important reinforcement effects are $[42,45,46]$ :

i. Increased strength, ultimate elongation, rigidity (modulus of elasticity) and in some cases impact strength,

ii. Improved heat distortion temperature and dimensional stability, reduced shrinkage, and improved stability of mechanical values at high temperatures and over extended times (fatigue),

iii. Modification of density (usually increased),

iv. Improved chemical resistance and lower water absorption,

v. Better surface quality and surface hardness,

vi. Good dispersion characteristics. 
Special fillers are used to obtain compounds with the following properties:
i. Low flammability
ii. Electrical conductivity and electromagnetic shielding
iii. Radiation and UV shielding
iv. Biodegradability
v. Noise suppression
vi. Good heat resistance.

\subsubsection{Methods of Filler Characterisation}

Current methods of characterisation of filler particles are listed below [47-49]:
i. Optical and electron microscopy
ii. Laser diffraction scattering
iii. Bulk density
iv. Oil absorption
v. Sieving
vi. Sedimentation

Of the methods listed above, the laser sizing method offers the best solution because results can be obtained fairly quickly and very small particle sizes can be measured on this piece of equipment, which is not possible with other methods. This method utilises the light scattering properties of particles as a means of detecting, counting and sizing particles. The scattering of light by particles depends on the size, shape, and refractive index of the particles; the wavelength of the light scattered and the angle with respect to the incoming beam of radiation at which scattered light is observed. Particle sizes are divided into three size intervals: $\mathrm{d}<0.1 \mu \mathrm{m}, 0.1<\mathrm{d}<25 \mu \mathrm{m}$ and $\mathrm{d}>25 \mu \mathrm{m}$. Particle sizes less than $0.1 \mu \mathrm{m}$ are difficult to detect due to the weak signal that they produce and generally optical equipment can measure particles $0.1 \mu \mathrm{m}$ or greater in size [48]. 
Scanning electron microscopy (SEM) and transmission electron microscopy (TEM) analysis of the fillers are available. Photomicrographs can be generated to analyse the size of the particles although precise measurement of the particles is difficult. Samples for TEM analysis consist of microtomed films taken from a larger sample. This cutting action can smear rather than cut through filler particles. Also if the particles are irregular shapes then theoretically different results could be obtained for identical geometries due to the angle of cutting with relation to the orientation of the particles. These techniques can be used to obtain a visual result of the filler particle size and shape (which enables assessment on their contributions to filler functions) and also to back-up other sizing techniques.

Bulk density analysis enables an understanding of a fillers packing capacity in a dry state, which therefore does not account for the possibility of improved packing when wetted by a suitable liquid. Nevertheless it is still of large relevance to the packing and storage conditions of the filler as high volume fillers would require larger packaging for a given weight, thereby requiring greater storage space. Costs incurred due to this would also be increased due to increased transit costs. High volume fillers can also cause problems during processing for example causing 'choking' in compounders at the feeder throat.

The oil absorption technique provides a quick and simple test to compare the respective packing of particles in polymers. Oil is added in drops to a filler until a point where the filler is just wetted-out by the oil. This point is described in the standards but is ultimately determined by the operator, depending on their level of expertise. Human error is therefore a large factor in the results.

Particle size is also measured by sieving; dry methods being used for large particles and wet methods for particle sizes below $150 \mu \mathrm{m}$ (100 mesh). Sieves can be used for measuring particles larger than about $40 \mu \mathrm{m}$ since sedimentation methods are imprecise above this value when water is used as the sedimentation medium [48]. 


\subsubsection{Agglomeration}

Agglomeration and flocculation both lead to a similar result, in that two or more particles join together to form a bigger one. Filler particles are composed mostly of primary particles but some consist of already formed aggregates (such as carbon blacks). Agglomeration adversely contributes to the dispersion stability of the fillers.

Interparticle forces, which cause bonding/adhesion between particles, can be grouped as follows:

i. bridging: sintering, melting, binders, chemical reaction

ii. adhesion and cohesion: viscous binders, adsorption layers

iii. attraction forces: van der Waals, hydrogen bonding, electrostatic and magnetic iv. interfacial forces: liquid bridges $\left(\mathrm{H}_{2} \mathrm{O}\right.$ - hydrogen bonding), capillary.

Agglomeration occurs mostly with smaller particles because of a high surface area of and the action of one of the attraction forces. The van der Waals force is significant for particles below $0.05 \mu \mathrm{m}$ in size [50]. Van der Waal's forces are mostly responsible for agglomeration of fillers during production and storage. These forces are especially important in considering the dispersion of fillers during mixing. The most important criterion of agglomeration has the following definition: the sum of all environmental forces (gravity, inertia, drag etc.) must be smaller than the forces between adhering partners:

$$
T_{a}=\frac{\sum B_{i}}{\sum E_{j}}>1
$$

where: $T_{a}$ is the tendency of adhesion, $B_{i}$ is the binding forces and $E_{j}$ is the environmental forces.

When the size of a particle of an inorganic powder decreases, the gravitational force acting on the particles also decreases. Therefore the adhesion forces attracting the particles become larger than the gravitational forces trying to separate them (as shown in 
the equation). At a limiting point, as a result of these surface forces, fine particles combine together resulting in the formation of strongly bonded aggregates or larger agglomerates.

The agglomeration forces can be measured by determining the tensile strength of compacted fillers. Tensile strength depends on the packing density and the type of filler. Tensile strength and agglomeration also depend on the type of mechanical processes used for filler dispersion.

Depending on the type of mechanism, agglomeration leads to formation of aggregates which can be weakly bonded or have very strong bonds, resisting even extensive grinding. The mechanism of bonding and the type of bonding forces present are related to:

i. particle size

ii. type of surface

iii. chemical groups available on the surface

iv. moisture level in the filler

v. effect of additional surface treatment

vi. method of filler production.

The mechanisms that can cause agglomeration are different in relative strengths. Mechanical interlocking is dependent on particle morphology and is the least strong of the attractive forces. Electrostatic forces originate from friction between particles that occur at various stages of use (in particular during feeding of the filler into the compounder). Van der Waal's forces originate from fluctuating dipoles in materials and are one order of magnitude greater than electrostatic adhesion forces. Liquid bridge forces are larger still than van der Waal's forces. These 'bridges' occur in moist fillers and where the presence of the liquid acts as an adhesive [51]. The 'bridges' progress from pendular (partly wet), through funicular to capillary state (total wetting). In the final state agglomerates with very fine particles can be highly compressed due to the high capillary pressure [52]. 
Agglomeration processes are complex in nature and therefore the best chances for their proper use (prevention or enhancement) are when the nature of agglomeration is studied before any preventive measures are taken. Several processes do benefit from agglomeration however and they include: wet mixing, suspending, rheological modification, drying, fluidised bed processes, clarification, briquetting, tabletting, pelletising and sintering. Processes negatively affected by agglomeration include: dispersion, dry grinding, screening, dry mixing, conveying and storage.

\subsubsection{Deagglomeration and dispersion of fillers}

Poor filler dispersion is due to the poor wetting of filler surfaces by the polymer melt which is affected by the presence of strong adhesion forces between particles within any agglomerates present in the system. This problem is largely influenced by the high surface energy of a filler. If this value can be reduced it will also reduce the adhesion. Dispersive mixing of fillers involves the breakdown of these agglomerates and is achieved in three significant stages. Firstly, wetting of the agglomerate particles by the polymer melt increases the gravitational forces acting near the surface. If suitably wetted these can become greater than the adhesive/attractive forces at the particle surfaces. Secondly, high shear stress zones during processing can be used to rupture the weakened agglomerates through induced internal stresses. Once ruptured further wetting must occur between the filler and polymer melt. The final stage involves the distribution of these ruptured agglomerate particles throughout the matrix. The nature of the forces acting in filled systems, filler wetting, charge distribution in the filled system and agglomeration are therefore essential for the discussion of filler dispersion.

Dispersion can be improved through the use of a variety of surface treatments or dispersants. Surface treatments can be used to create an improved interface between the filler surface and the polymer melt. The treatment creates a surface that is more compatible with the surrounding polymer. This is believed to be important as the ability to transfer stresses between the two without fracture occurring is increased. Dispersants (such as hydroxylated waxes) can also improve dispersion. These work initially by preferentially displacing the water at the filler surfaces that cause the agglomerates to 
form. These waxes act as wetting agents to disperse the particulates within the melt $[53]$.

Current methods of dispersion measurement include: optical microscopy, small-angle $\mathrm{X}$-ray scattering, viscosity measurement, electric resistivity, surface roughness and die swell. Scanning electron microscopy (SEM) can be used to enable observation of the breakdown of agglomerates and is therefore a very useful tool. The major problems interpreting results is related to the fact that the samples needed for SEM studies may contain a severely distorted structure. This is caused when the aggregates are pulled away, broken down or smeared during the ultramicrotome sectioning. Viewing of a very small surface area may also lead to a statistically invalid interpretation. Transmission electron microscopy observations give good results. Small angle X-ray scattering method is seldom used and results are only relevant when bigger agglomerates or coarser particles are observed.

\subsubsection{Properties of filled styrene plastics}

Filler particles present in ABS, or other styrenic polymers, limit the chain mobility and deformability of the matrix through mechanical hindrance. The properties, distribution and concentration of the filler as well as the characteristics of the matrix will determine the means of hindrance. The application of common particulate fillers with particle sizes of $1-10 \mu \mathrm{m}$ in concentrations of up to $25 \mathrm{wt} \%$ usually leads to only slight increases in the melt viscosity having little or no effect on the processability of the filled polymer. At higher filler concentrations the effect is more pronounced (above 40wt\%) [1].

The addition of a filler increases the elastic modulus. The filler modulus is higher than that of the polymer with the final modulus value usually lying between the two component values. The use of particulate fillers usually lead to a decrease in the tensile strength, although proper treatment of the filler particles can avoid this reduction.

Nearly all particulate fillers, as well as several fibre reinforcing agents reduce the impact strength of rubber-modified styrenics. For ABS polymers the presence of only $10 \mathrm{wt} \%$ can cause a drop in properties to $10 \%$ that of the unfilled impact strength [1]. The 
adverse effect of a filler on the impact properties increases with increasing particle size. Therefore it is preferable to choose as small a particle filler size as possible.

\subsection{Antimony Trioxide and Halogen Materials}

\subsubsection{Production and Properties of Antimony Trioxide}

Antimony oxide occurs naturally as three minerals, these being cervantite, senarmontite and valentenite. These originate from ores (stibnite or 'antimony sulphide' being the main type) or as oxidation products of other antimony minerals. These are found throughout the world with the major producing nations including (largest deposit first) China, South Africa, Bolivia and Russia. Other deposits are also found in Thailand, South America, Canada and Australia [54]. The most commercial antimony oxide, antimony trioxide $\left(\mathrm{Sb}_{2} \mathrm{O}_{3}\right)$, is a stable, white, crystalline mineral powder, which theoretically contains $83.53 \%$ antimony in the three valence state where the balance is oxygen. Other products include antimony pentoxide and sodium antimonite but antimony trioxide is considered more effective due to its higher antimony content (based on weight).

Naturally occurring antimony trioxide $\left(\mathrm{Sb}_{2} \mathrm{O}_{3}\right)$ is too impure to be used as found, and is usually manufactured from either antimony metal or the sulphide ore by oxidation in air between $600-800^{\circ} \mathrm{C}$. Waste products of both gaseous sulphur oxides as well as solid slag are formed when sulphide ore is used. However no waste products are formed when antimony metal is burned. Some antimony oxide is produced by a double fuming process, in which impure oxide is re-vaporised and recrystallised as a pure product suitable for commercial use. As well as this improvement in the purity another benefit can be the reduction of the particle size of the product. Particle size during manufacture is controlled by adjusting the temperature and rate at which the antimony vapours are precipitated. The lower the temperature and the slower the precipitation rate, the larger the particles. 
The particle size distribution of the three antimony trioxide grade ranges are [55]:

i. ultra fine: $0.25-0.45 \mu \mathrm{m}$

ii. high tint: $0.8-1.8 \mu \mathrm{m}$

iii. low tint: $1.9-3.2 \mu \mathrm{m}$.

Other properties are shown in Table $2.1[56]$.

Table 2.1: Typical properties of antimony trioxide materials.

\begin{tabular}{|l|l|}
\hline Molecular weight & 291.5 \\
\hline Refractive index & 2.087 (cubic); $2.18,2.35,2.35$ (rhombic) \\
\hline Particle size (range) & 0.25 to $3.2 \mu \mathrm{m}$ \\
\hline Specific gravity & 5.3 to 5.8 \\
\hline Acidity & Neutral \\
\hline Solubility & Dilute acids \& bases \\
\hline Surface area $\left(\mathrm{m}^{2} / \mathrm{g}\right)$ & 0.4 to 2.3 \\
\hline
\end{tabular}

Two crystal forms exist in antimony trioxide, these being senarmontite (cubic) and valentinite (rhombic). The cubic form is the most commonly found form in commercial grades as this is the stable low temperature form of antimony trioxide. The rhombic form is less common and forms at temperatures in excess of $570^{\circ} \mathrm{C}$ into needle-like structures. If the temperature falls below $570^{\circ} \mathrm{C}$, this rhombic form converts to the cubic form. Due to the slow conversion rate form rhombic to cubic, there are some traces of the needle-like structure in commercial grades. Both forms have a melting point of $656^{\circ} \mathrm{C}$ and a boiling point of $1550^{\circ} \mathrm{C}$.

Impurities present in the ore or metal are also found in the oxide in varying amounts from barely detectable traces to about $0.5 \mathrm{wt} \%$, due to the direct oxidation technique. Such contaminants include arsenic, lead, iron, copper, nickel, sulphur, tin as well as other trace elements (see Appendix A). The presence of these trace impurities do not appear to affect the efficiency of the antimony oxide as a flame retardant, however they may effect other properties (e.g. colour/tint). Despite the presence of traces of arsenic trioxide that are found with antimony in the natural form, $\mathrm{Sb}_{2} \mathrm{O}_{3}$ is not as toxic as would appear or has previously been suggested. Antimony trioxide is classified as a class 3 
carcinogen (via animal studies) however the extreme conditions of the test did not represent true working conditions [57]. Problems in the workplace have not occurred under normal use.

Particle size can affect flame retardancy efficiency, and it (along with weight percentage content) can have drastic effects on the mechanical properties of the polymer into which it is compounded [58]. The greater the reduction in size of the particles, the more the end properties can be maximized. The search for a suitable production method to reduce the size of the particles is a continual challenge for manufacturers. This problem is further complicated due to the difficulty maintaining good dispersion of the particles in the polymer matrix. This can be controlled through the use of dispersing agents and of most relevance to this work, carrier waxes. Other additives can also be used to aid the ease of production by reducing the amount of dust formed during handling. This can be achieved through the use of dustless grades, which have been treated with small amounts of ethylene glycol, mineral oil or plasticiser. As well as creating healthier working conditions (important due to the toxicity concerns), reducing the dust also reduces material losses.

Another method of binding particulate fillers, which gives the dual effect of dust control and property enhancement(s), is to incorporate the filler as part of a masterbatch concentrate. Property enhancements can be achieved if the carrier polymer is selected for compatibility with the polymer matrix into which it is to be dispersed [59]. However the masterbatch polymer chosen is often a different one to the polymer in which it is to be dispersed.

Antimony trioxide is a relatively inefficient flame-retarding agent when used alone in ABS and therefore tends to be used with halogenated materials. These two flame retardants combine synergistically even at low loadings. 


\subsubsection{Halogen Materials}

There are many different types of halogen materials that exist and the selection of the grade depends upon the required end properties (e.g. ABS, foamed PE [60]). Earlier work studied the use of chlorinated compounds [61] but more recently the brominated compounds have been more closely looked at and these are now widely used. Bromine containing compounds are on a mole basis significantly more effective than chlorine containing compounds $[62,63]$. The effectiveness of halogen-containing flame retardants increases in the order $\mathrm{F}<<\mathrm{Cl}<\mathrm{Br}<\mathrm{I}$ [64]. Fluorine and iodine based flame retardants are not used in practice because neither interferes with the combustion process at the right point. Fluorine has too strong a bond to carbon, iodine is too loosely bonded and both are also very expensive $[65,66]$. The polymer properties are highly affected due to this and the flame retardant effects are already lost in the temperature range of pyrolysis. Bromine is more effective than chlorine due to the fact that its weaker bonding to carbon enables it to interfere at a more favourable point in the combustion process.

The halogen materials can be classified into two generic groups; these being the additive and chemically reactive types. The additive type is generally added to the polymer during processing and is not chemically reacted with the matrix. The most important additive flame retardants used in the modification of polystyrenes are brominated aromatic and alicyclic compounds. The reactive types of halogens are chemically reacted into the polymer structure during the processing stage. Whilst this second type can induce better flame retardancy than the additive type, the detrimental effect they have on mechanical properties greatly reduces their use [1]. 


\subsubsection{Halogen Materials for ABS Polymers}

A wide variety of halogen materials are available and the grade selected is determined through the end use requirements of the finished compound. As the halogens are being used for their flame retardancy this is usually a high criterion for selection (i.e., which grade will impart best flame retardancy). The grade most suitable for flame retardancy will not always impart the best mechanical properties and it can be seen that they influence ABS in different ways. Several of these grades are discussed below.

\subsubsection{Decabromodiphenyl oxide}

Due to the high bromine content in decabromodiphenyl oxide (83\%) and the fact that it is widely available, this grade has been used for many years. The main problem with this grade is its high melting point of $305^{\circ} \mathrm{C}$, which means that it does not melt into the ABS. The DBDPO resides as considerably sized particles, which in turn leads to poor impact properties. This fact along with concerns over toxicity issues means that replacements for DBDPO are constantly being found and used [67].

\subsubsection{Bis(Tribromophenoxy)ethane}

Bis(tribromophenoxy)ethane (BTBPE) is a relatively expensive grade with a lower bromine content than DBDPO ( $69 \%)$. This is melt blendable in ABS and has less of an effect on impact properties than the previous grade. There are concerns over the toxic emissions from this product (namely decomposition products of the ether linkage) and a move away from this product is being seen.

\subsubsection{Tetrabromobisphenol A}

Due in part to its low cost, this product is widely used in the flame retarding of ABS. The fact that it is melt blendable into ABS is beneficial and its lower influence with respect to toxicity issues is also of importance. Detrimentally though this grade has less active bromine than the previous grades $(59 \%)$ and therefore more material is required within a compound to achieve the same levels of retardancy. 


\subsubsection{Halogen Flame Retardancy Mechanisms}

Pyrolysis products fed to the flame can be reduced by two methods. Evolution of volatile products, which inhibit the oxidation reaction in the flame ('gas phase' action) or modification of the pyrolysis products to reduce the amount of flammable products ('condensed phase' action), can both lead to flame extinction [68]. In vapour-phase reactions the decomposition products are less exothermic than the process of combustion itself. Two effects are significant: in the first, the flame retardants can function in the gas phase by producing free radical terminators (quenchers) when heated to the flame temperature. These radical chain terminators interfere with the free-radical chain reaction occurring in the flame and inhibit combustion. In the second, the flame retardant decomposes at the burning temperature, giving non-combustible vapours, which dilute the flammable gases evolved from the pyrolysed polymer to a concentration below the flammability limit. Such behaviour accounts for the low flammability exhibited by halogen containing polymers (such as PVC) and also the fire retarding properties of halogen containing species, especially in the presence of phosphorous or antimony compounds. $[69,17]$

Halogen containing flame retardants act by interfering with the radical chain mechanism occurring within the combustion process. The high energy $\mathrm{OH}$ and $\mathrm{H}$ radicals that are formed by chain branching are removed by the halogen containing flame retardant.

$$
\begin{aligned}
& \mathrm{H}^{\bullet}+\mathrm{O}_{2} \rightarrow \mathrm{OH}^{\bullet}+\mathrm{O}^{\bullet} \\
& \mathrm{O}^{\bullet}+\mathrm{H}_{2} \rightarrow \mathrm{OH}^{\bullet}+\mathrm{H}^{\bullet} \text { (Chain branching) }
\end{aligned}
$$

At first the flame retardant (assuming $\mathrm{Br}$ ) breaks down to the following:

$$
\mathrm{RBr} \rightarrow \mathrm{R}^{\bullet}+\mathrm{Br}^{\bullet}
$$


The halogen radical reacts to form the hydrogen halide:

$$
\mathrm{Br}^{\bullet}+\mathrm{RH} \rightarrow \mathrm{R}^{\bullet}+\mathrm{HBr}
$$

This in turn interferes with the radical chain mechanism:

$$
\begin{aligned}
& \mathrm{HBr}+\mathrm{H}^{\bullet} \rightarrow \mathrm{H}_{2}+\mathrm{Br}^{\bullet} \\
& \mathrm{HBr}+\mathrm{OH}^{\bullet} \rightarrow \mathrm{H}_{2} \mathrm{O}+\mathrm{Br}^{\bullet}
\end{aligned}
$$

The high energy $\mathrm{H}$ and $\mathrm{OH}$ radicals are removed by reacting with the bromine halide and then replaced with the lower energy Br radicals. The overall rate of propagation decreases owing to the lower reactivity of $\mathrm{Br}$ radicals, which regenerate $\mathrm{HBr}$ by reaction with volatile products of polymer degradation (Equation 2.5).

\subsubsection{Antimony Trioxide and Halogen Systems}

\subsubsection{Synergistic effects}

The concepts involved in synergism can be explained by reference to the kinetic diagram in Figure 2.3 [70], which depicts the decomposition of flame retardants. The ideal flame retardant is one characterised by a high activation energy and a high preexponential factor. Experience shows that this flame-retardant type could only be one that contains a low percentage of halogen, where auto catalytic effects would not occur, and thus would be impractical for use in real systems.

Systems that decompose readily can be depicted by the response of $F_{1}$ (flame retardant 1). This flame retardant has an adequate decomposition rate at the pyrolysis temperatures encountered, but it also has a high decomposition rate at processing. temperatures which makes it unsuitable for practical applications. This flame retardant can be stabilised against decomposition at the processing temperatures, through the use of stabilisers. This stabilised system must still be able to effectively release the halogen at the higher pyrolysis temperature action, which is difficult to achieve. In the majority 
of cases the halogen is not effectively released even though it is stabilised at the processing temperature. In the figure this corresponds to an inability to pivot the $\mathrm{FR}_{1}$ line around point $P_{1}$.

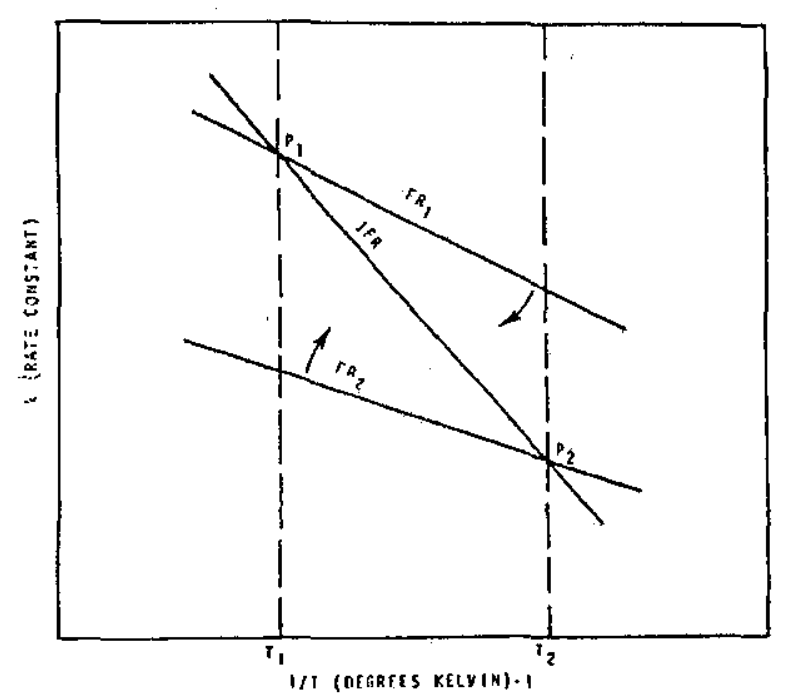

Figure 2.3: Rate constant expressions for ideal and real flame retardants.

i. IFR, ideal flame retardant decomposition;

ii. $\quad \mathrm{FR}_{1}$, highly effective flame retardant with poor processing stability;

iii. $\quad \mathrm{FR}_{2}$, ineffective flame retardant with excellent processing stability;

iv. $\mathrm{T}_{1}$, pyrolysis temperature;

v. $T_{2}$, processing temperature;

vi. $\mathrm{P}_{1}$, desired decomposition rate at pyrolysis temperature;

vii. $\mathrm{P}_{2}$, desired decomposition rate at processing temperature.

An alternate approach is to take a flame retardant like $\mathrm{FR}_{2}$ (stable at processing temperatures but with a low pyrolysis decomposition rate) and to encourage a more rapid release of halogen at the higher temperature. This corresponds to the $\mathrm{FR}_{2}$ line pivoting around point $\mathrm{P}_{2}$. Using a reactant to accomplish this can result in a degree of flame retardation that is well above that obtainable with the reactants alone. This is known as a "synergistic" system. This mechanism is the major route presently used in effecting flame retardation in polyolefins. The synergistic system must form volatile 
halides at appreciable rates at the pyrolysis temperatures without their formation at processing temperatures.

Antimony synergists are used almost exclusively with either brominated or chlorinated organic flame retardants, which synergistically combine to provide a highly effective flame retardant system. Antimony and the halogens react in the molten polymer at flame temperatures to form corresponding trihalide or oxyhalide of antimony [55]. One of the main objections to the chemical mechanism of inhibition by halogens however, is the necessity of introducing large quantities of flame retardant $(12-15 \% \mathrm{Br}$ and $\sim 20 \%$ $\mathrm{Cl}$ ) in order to noticeably reduce the flammability of a polymer. Due to the fact that the antimony compound must react with the halogen-bearing organic compound, the dispersion of these flame retardants within the polymer in an additive system is critical. Attaching the halogen directly to the polymer chain would provide the optimum conditions for reaction with the antimony compound.

Further insight into the antimony synergism has been found in the work of Schwarz [70]. Samples of flame-retardant PP containing antimony trioxide and a halogenated flame retardant were burned or subjected to a continuing ignition source. The percentage of antimony that escaped into the gas phase was determined by analysing the original sample and combustion products (char, drippings, etc.). It was found that with flame retardants that exhibit no synergism, the formation of volatile antimony halides was inhibited. Systems that exhibited good synergism appeared to lose antimony readily to the gas phase. These findings strengthen belief that the formation of volatile antimony halides is required for synergism.

\subsubsection{Inhibition}

The mole ratio of the two components used (halogen: antimony trioxide) is commonly 3:1 although it can vary from between $2: 1$ to $9: 1$ [1]. A study by Whiteley et al [71] used different ratios from 1:0 to $0: 1$ to analyse the effects of varying the mole ratio on fire properties. 
As mentioned previously, FR systems are effective during the growth of fires when they can inhibit the spread of flame, reducing the overall hazard. The Sb-X FR systems work in the vapour phase by "poisoning" or quenching the flame reactions, that is to say, they interfere with the free-radical combustion. Speculation by some workers [55] also highlights the importance of condensed phase reactions. These are less well documented and are still under investigation.

Reactions occurring in the $\mathrm{Sb}: \mathrm{X}$ system $(\mathrm{Br}$ or $\mathrm{Cl})$ are considered to be as follows:

$$
\begin{aligned}
& \mathrm{Sb}_{2} \mathrm{O}_{3}+2 \mathrm{HX} \stackrel{\sim 250^{\circ} \mathrm{C}}{\longrightarrow} 2 \mathrm{SbOX}+\mathrm{H}_{2} \mathrm{O} \\
& 5 \mathrm{SbOX} \stackrel{245-280^{\circ} \mathrm{C}}{\longrightarrow} \mathrm{Sb}_{4} \mathrm{O}_{5} \mathrm{X}_{2}+\mathrm{SbX}_{3} \uparrow \\
& 4 \mathrm{Sb}_{4} \mathrm{O}_{5} \mathrm{X}_{2} \stackrel{410-475^{\circ} \mathrm{C}}{\longrightarrow} 5 \mathrm{Sb}_{3} \mathrm{O}_{4} \mathrm{X}+\mathrm{SbX}_{3} \uparrow \\
& 3 \mathrm{Sb}_{3} \mathrm{O}_{4} \mathrm{X} \stackrel{475-565^{\circ} \mathrm{C}}{\longrightarrow} 4 \mathrm{Sb}_{2} \mathrm{O}_{3}+\mathrm{SbX}_{3} \uparrow
\end{aligned}
$$

The reactions give off $\mathrm{SbX}_{3}$, which acts as a radical interceptor similar to $\mathrm{HX}$ ( $\mathrm{HBr}$ or $\mathrm{HCl}$ ) at various temperature ranges. The phases shown above are all endothermic. It is also thought that $\mathrm{SbX}_{3}$ (as well as $\mathrm{SbOX}$ ) reduces the rate at which the halogen leaves the combustion zone, which increases its ability to react with the reactive species. Part of the success of Sb-X FR synergistic systems lies in the controlled release of the $\mathrm{SbX}_{3}$, by way of the intermediate oxyhalides, over a significantly wide temperature range. Here it is important to realise that surface temperatures for solids in fires may be around $500^{\circ} \mathrm{C}$ due to thermal feedback from the flames. Substrate temperatures will approach this value, and pyrolysis of the organic material takes place, yielding volatile fuels to feed the fire. At the same time, however, it can be seen that antimony oxyhalide dissociations are in the correct temperature range to yield volatile $\mathrm{SbX}_{3}$ for flame inhibition in the ways described: 
Also of importance is the fact that the $\mathrm{SbX}_{3}$ breaks down to form $\mathrm{HX}$, which then interferes in the manner described in equations 2.5 and 2.6.

$$
\begin{aligned}
& \mathrm{SbX}_{3}+\mathrm{H}^{\bullet} \longrightarrow \mathrm{SbX}_{2}+\mathrm{HX} \\
& \mathrm{SbX}_{2}+\mathrm{H}^{\bullet} \longrightarrow \mathrm{SbX}+\mathrm{HX} \\
& \mathrm{SbX}+\mathrm{H}^{\bullet} \longrightarrow \mathrm{Sb}+\mathrm{HX}
\end{aligned}
$$

$\mathrm{HX}$ is therefore produced over a wide range of temperature rather than a narrow range as is the case when the halogenated compound is used alone.

\subsubsection{Flame retarded $A B S$}

Low molecular weight flame retardants generally have a marked effect on the physical and mechanical properties of materials. When tetrabromobisphenol A (20 parts) and $\mathrm{Sb}_{2} \mathrm{O}_{3}$ (7 parts per 100 parts $\mathrm{ABS}$ ) are introduced into $\mathrm{ABS}$, the oxygen index of the material increases to $27.7 \%$ but, in this case, the viscosity decreases from 22.6 to 8.1 $\mathrm{kg} . \mathrm{cm} / \mathrm{cm}^{2}[72]$.

Song [73] looked at several bromine containing compounds namely decabromodiphenyl oxide (DBDPO), 1,2 bis(2,4,6-tribromophenoxy) ethane (TBPE), octabromodiphenyl oxide (OBDPO) and tetrabromobisphenol-A (TBBPA). These were chosen due to their wide commercial use. Except for the compound containing ODBPO these compounds exhibited poor impact properties. DBDPO and TBBPA exhibited good dispersing/mixing, whilst OBDPO was good and TBPE and ATO (antimony trioxide) were classed as poor.

The introduction of flame retardants changes the morphological structure of a two phase material. For flame retardants mixed with a polymer melt and interacting with individual polymer phases, the flame retardant distribution within these phases is an important factor. 


\subsection{Filled Polymer Systems}

Incorporation of fillers into thermoplastics modifies all properties of that material. Some changes will be beneficial and enhance the use of the compound, while some are detrimental. The extent to which the properties are affected will depend to a large extent on the nature of the filler that is being incorporated into the polymer. Also of great importance is the method by which the compound is processed.

\subsubsection{Influence of Processing on Properties of Filled Polymer Systems}

\subsubsection{Compounding}

The interrelationship between compounding route, compound microstructure and properties is not highly documented due partly to a limited understanding of what happens inside the compounder during processing. Previous work looking at masterbatches in single screw compounders $[8,74]$ explain some of the processes occurring, but do not necessarily compare well with those occurring in twin screw extruders. Incomplete characterization of the processed materials also prevents a fuller understanding. If a particulate filled compound is not processed sufficiently well the effects on various properties can be quite extreme. Mechanical properties (fracture toughness, strain to failure [tensile]) are sensitive to the size and dispersion of the filler particles. Functional filler effectiveness can be improved through optimisation of the compounding conditions. This may allow the content of additives such as flame retardants and property stabilizers to be reduced, whilst still retaining performance levels. The properties of the compounds are maximized when the additives are highly dispersed as well as being uniformly distributed within the polymer. Problems arise when the conditions needed to achieve this are so extreme that they start to degrade the polymer, which then results in a reduction in overall properties.

Investigations into the degradation of polystyrene by Hornsby and Sothern [75] have shown that twin-screw extrusion compounding does reduce the molecular weight of the polymer. Samples were subjected to increased residence times as well as several passes through the extruder. These had the effect of breaking the polymer chains, which gave the resultant reduction in molecular weight. Also of great importance was the fact that screw speed was found to have more of an influence on chain rupture than when the 
temperature profile was altered. These factors will have significant relevance when looking at ABS polymers in twin-screw extruders. However a study by Owen [76], which investigated the influence of changing screw speed (200rpm to 480rpm), did not show a significant change in impact properties. This suggested that the increased shear heat, lower residence time and torque differences did not influence the final properties. It also meant that direct comparisons of mechanical behaviour were valid for compounds produced at different speeds.

\subsubsection{Injection moulding}

Along with compounding, the injection moulding process can have a large influence on the properties of the moulded compound. There are many variables controlling the moulding cycle that can be used to influence the material properties, be it intentional or accidental. These changes can be slight or large depending on the variable and the manner in which it is altered.

Owen [76] looked at several of these variables including injection speed and mould temperature on the total impact energy and peak force values of unfilled ABS. Also investigated was the extent of conditioning (drying) prior to moulding. The moulding speed was increased from $40 \%$ to $90 \%$ and did not show clear trend on the resultant properties. The results were based on changes to the less influential secondary injection phase as changes to the primary phase caused excessive mould flash.

The mould temperature did alter properties, with the impact energy values increasing with increasing mould temperature. The mould was raised from $30^{\circ} \mathrm{C}$ to $80^{\circ} \mathrm{C}$, which raised impact values by $4 \%$. The change in mould temperature appeared to be the most influential parameter in the study. At the higher mould temperatures, the induced molecular orientation caused by the initial injection process was not frozen into the specimen. Molecular relaxation meant that a greater degree of homogeneity in the through thickness structure was possible. Skin effects were less of an influence on properties at the higher mould temperatures. Other studies looking at the rate of cooling of injection moulded ABS also found that the impact strength was not significantly affected by residual stresses and moulded in orientation [77]. 
Other work by Liang et al. [78], found similar effects with the impact strength varying with changing mould temperature, injection speed, injection and hold pressures. Amongst the findings were that at a mould temperature of $60^{\circ} \mathrm{C}$ the best impact strength of the moulded polymers occurred at an injection pressure of $190 \mathrm{MPa}$. The results showed the wide variance in properties that is possible with varying moulding conditions.

\subsubsection{Mechanical Properties of Filled Polymer Systems}

There have been several models produced to explain filled system properties and especially the mechanical properties of these systems [79]. Assumptions on the interaction between polymer and filler are usually used in the models, normally based on two extremes, either perfect or zero adhesion. In reality though, such conditions are not normally found around an inclusion embedded in a matrix. There are areas of imperfect 'bonding', mechanical stresses due to uneven shrinkage (because of differences in thermal expansions between polymer and filler), high stress gradients or even stress singularities due to the geometry of the inclusions, voids, microcracks, etc. The influence of these factors on various properties will now be discussed.

\subsubsection{Impact}

Usually the addition of a rigid filler to a thermoplastic results in a decrease in the plastics toughness, as measured by impact strength, while its rigidity is increased [80]. The greater the increase in rigidity, the lower the impact strength. However as the understanding of this has increased, it has been realized that a filled system does not have to experience a reduction in impact strength. Many parameters including filler size, shape, loading, interfacial adhesion, polymer type, glass transition temperature (in relation to test temperature) and even type of impact test (speed, temperature, type of impact) all influence the end properties.

These parameters can, in the whole, be measured but the main problems lie in determining the adhesion within the system and also the effect of the filler on the fracture mechanisms (compared to unfilled polymer). Impact strength is often used as the measure of toughness because it is a relatively simple test to perform and gives 
values that are easy to compare. However the wide variety of methods of impact testing $[81,82]$ add considerable complications in assessing toughness, especially in particulate-filled compounds. There is also a lack of correlation between impact strength and fracture energies in these composites due to the many mechanisms of energy absorption. One problem in predicting impact properties is related to the fact that filled plastics behave in a viscoelastic manner and their properties are therefore dependent on strain rate. Theories that are adequate at low strain rates are not necessarily appropriate at high strain rates.

The introduction of particulate filler into a polymer generally increases modulus but lowers the energy required to induce and propagate a catastrophic fracture. The assessment of the toughness has problems due to the mechanisms by which the matrix fractures: crazing for brittle or yielding for ductile plastics. A consequence of this is that any measurement of toughness will depend upon the temperature at which the test is made - above or below the glass transition temperature ( $\mathrm{Tg})$ of the polymer.

Failure in a filled plastic is often initiated by a flaw or defect, a feature most likely on a molecular or macromolecular level and caused by the fillers acting as stress concentration sites. These sites create potential sites for crack growth, a factor that is made even greater if debonding occurs between the matrix and the filler. The idea that particulate fillers can improve toughness in some systems by initiating multiple crazing [83] does not follow due to the limited adhesion between particulates and polymer matrix [84]. These cannot act as craze or crack terminators and thereby the filled system exhibits poorer toughness. Nakagawa et al. [80] make several recommendations regarding a filled polymer system and suggest that impact resistance can be improved by:

i. increasing the number of stress concentration points and their homogenous dispersion,

ii. dispersion of impact stress (wider distribution of the stress concentration sites),

iii. prevention of development from micro crack to macro crack,

iv. increase of micro plastic deformation ability in the matrix. 
Theories are deduced from thermodynamic arguments, which do not deal with these types of details. Empirically it can be considered that the energy required to initiate and propagate a crack through a filled plastic is the sum of all energies involved in the process. The usual approach to the effect that this has on fracture toughness is based on the Griffith's crack theory [85] (Equation 2.15):

$$
\sigma_{f}=\left[\frac{2 E \gamma_{f}}{\pi c}\right]^{1 / 2}
$$

where $\sigma_{\mathrm{f}}$ is the fracture stress, $\gamma_{\mathrm{f}}$ the energy required to form a unit area of fracture, $\mathrm{c}$ the size of the defect and $E$ the Young's modulus of the matrix. Therefore a particle or agglomerate above a certain size will reduce the stress needed to cause the composite to fracture and fail. This will also depend on the polymer type and its adhesion to the particle [45].

Particle shape is not evident in the Griffith equation but it is known that impact strengths are reduced dramatically by going from calcium carbonate to talc. High-aspect ratio particles, used to increase rigidity, decrease toughness and therefore the higher the rigidity, the lower the toughness. Conversely, to maximize toughness or impact resistance of a composite, spherical or low-aspect-ratio particles should be chosen.

It has been suggested that increases in toughness can be due to crack pinning by the particles inhibiting its propagation $[79,86]$. During fracture a moving crack front is momentarily pinned at a position of inhomogeneity within the matrix. This leads to a bowing out of the crack front from the pinned positions, thereby increasing the total length. Sizes and numbers of particles will affect the amount of pinning. The relative contribution of pinning to crack growth will depend on the strength of the filler polymer interaction and the toughness of the matrix. Increasing matrix toughness or reducing filler polymer interaction will reduce composite toughness.

The role of the polymer-filler interface in affecting impact strength has been investigated extensively and many publications have featured this aspect strongly. 
Some stress the need for strong adhesion, even through covalent bonding, but it is now widely accepted that, to improve the impact strength of a filled composites, a flexible energy absorbing bond is essential. This bond may be primary between particle and polymer, or secondary in that the filler and coating on it affect the structure of the polymer adjacent to the surface.

Introduction of a rubbery phase between the filler and polymer has been claimed to improve impact toughness for chalk filled polystyrene. Introduction of a gradient in modulus between filler and polymer by encapsulating the filler in a rubbery microencapsulant has been suggested for many years as a way of improving reinforcement and is used as a technique for relatively large fillers such as glass fibres and spheres.

The rubber phase increases the impact toughness of the SAN between one and two orders of magnitude. This results in the creation of a damage zone that is much bigger than the region immediately adjacent to the crack surface, and increases the energy dissipated before a critical crack can propagate. The crack tip is also blunted by this zone, further increasing the energy required for propagation. The large number and relative uniformity of the rubber particles relative to those of dilute, random stress concentrators such as impurities and voids, results in a well defined mean stress state around the particles. In commercial materials, the stress fields of individual particles overlap and interact and are further disturbed when the $\mathrm{Sb}_{2} \mathrm{O}_{3}$ is added.

\subsection{Effect of particle size on filled ABS}

Flame retardants can have a large effect on the mechanical properties of ABS according to the type of filler used and whether it acts as a filler or as a lubricant within the system. Those exhibiting filler properties will decrease the impact strength, sometimes down to one third of the original value. Those fillers with particle sizes in excess of $10 \mu \mathrm{m}$ are most unsuitable for ABS polymers (indeed all styrenic plastics). It is only when sizes approach $1 \mu \mathrm{m}$ in size, that property losses become more acceptable [1]. If particle sizes below $1 \mu \mathrm{m}$ could be employed then losses would be reduced further. 
Using colloidal antimony pentoxide instead of antimony trioxide, which consists of particles that can be less than $0.1 \mu \mathrm{m}$, can lead to improvements in properties. Bartlett [87] looked at compounds containing antimony pentoxide and several brominated materials and found that properties (such as tint strength) were superior to those found when using antimony trioxide. These effects were attributed to the improved dispersion of the filler, although particle size comparisons were not possible as the particle size of the $\mathrm{Sb}_{2} \mathrm{O}_{3}$ containing compound was not shown. Further investigation [88] failed to reveal the exact nature of the antimony trioxide grade.

The problem associated with the introduction of antimony trioxide into ABS compounds, namely the reduction of impact strength, has been counteracted by the use of finer particle size grades and also through the use of impact modifiers. One such modifier is chlorinated polyethylene (CPE) and several investigations have looked at it as a means of improving the properties of a filled ABS. Jue et al [89] used a combination of CPE ( $42 \%$ chlorine) with halogen flame retardants and antimony trioxide to attempt to find an optimum property level between impact and rigidity. The use of the CPE did improve impact properties but tensile strength and rigidity properties were reduced.

Uhlmann et al [90] systematically looked at the effect of a CPE impact modifier ( $36 \%$ chlorine) on the system properties of a flame retarded ABS system. Whilst the CPE was insoluble in the SAN phase of the ABS it still improved the impact properties of a fully flame retarded system by $100 \%$ at $15 \mathrm{wt} \% \mathrm{CPE}$ loading. This increase was significantly lower when compared to the original unfilled ABS ( $6 \%$ increase).

Other impact modifiers analysed included a high molecular weight ethylene polymer (Elvaloy EP4051) manufactured by DuPont, which improved properties by $60 \%$ when added at $6 \mathrm{wt} \%[91]$.

Methyl methacrylate and styrene grafted elastomers have also been used as a means of further improving the impact strength of ABS polymers [92]. 


\subsubsection{Flexural modulus}

One of the main reasons why mineral fillers are used in thermoplastics is to increase rigidity or stiffness, especially at higher than ambient working temperatures. Rigidity is usually measured as tensile (under tension) or flexural (bending) modulus. Tensile modulus is the ratio of stress to strain below the elastic limit whilst flexural modulus, as usually measured, does not separate plastic and elastic elements, and is therefore not a true elastic modulus.

For relatively simple systems such as glass spheres in a glassy matrix (such as SAN), elastic modulii can be predicted by continuum mechanics on the basis of elastic modulus and volume fraction of each component and perfect mechanical contact. In fact, the simple mixture rule (Equation 2.16), which has been used above to calculate several other physical properties, gives a reasonable approximation.

$$
E_{R}=(1-\phi) E_{m}+\phi E_{f}
$$

where $E_{R}, E_{m}$ and $E_{f}$ are modulus of elasticity of composite, matrix and filler, respectively, and $\phi$ is the volume fraction of the filler.

However, several other formulae have been developed to predict the modulus of filled polymers. The most widely used are those of Kerner [93] and Nielsen [94] which are both more sophisticated due to their consideration of inter-particle interactions, maximum fraction of filler as well as the relative modulus of the two constituents.

Kerner:

$$
E_{R}=\frac{\left.\left(G_{f} \phi /(7-5 v) G_{p}+(8-10 v) G_{f}\right]\right)+(\phi /[15(1-v)])}{\left(G_{p} \phi /\left[(7-5 v) G_{p}+(8-10 v) G_{f}\right]\right)+(\phi /[15(1-v)])}
$$

where $E_{R}$ is the relative modulus, $\phi$ is the filler volume fraction, $G_{f}$ is the filler shear modulus, $G_{p}$ is the polymer shear modulus, $v$ is Poissons ratio of polymer, $\phi_{m}$ is the filler maximum packing fraction. 
Nielsen:

$$
E_{R}=\frac{1+A \phi}{1-\left(1+\left[\left(1-\phi_{m}\right) / \phi_{m}{ }^{2}\right] \phi\right) \phi \phi}
$$

where $A$ is shape factor $f$ (geometry)

In these theories, modulus is independent of particle size. However it has been found that when the filler is strongly bonded to the plastic composite, modulus is affected by particle size. Neilson has modified Kerner's equations to some extent to allow for particle size effects by introducing an effective filler volume fraction.

Also relevant, when low concentrations of non-interactive spherical particles are present, is the basic Einstein equation for predicting the modulus.

$$
E_{R}=1+2.5 \phi
$$

The modulus of a filled polymer is usually increased upon the addition of a filler, with the increase being dependent on several factors. The filler loading fraction is of significant importance, as is filler reinforcement effects. This modulus increase is expected when looking at the rule of mixtures due to the fact that the filler modulus is greater than that of the filler. This increase is dependent on many variables with the exception of filler particle size. According to theory the Young's modulus is independent of the dispersed phase, with the local stresses within the composite being dependent on the ratio between particle dimensions and distance between particles.

Although difficult to measure it is almost universally accepted that particle shape plays a very important role in determining the rigidity of a filled thermoplastic. An example of this is where a study showed that in PP the modulus decreases in the order mica $>$ talc $>$ kaolin $>$ calcium carbonate. This was the order of their expected aspect ratios. A reasonable agreement has been found for PP filled with calcium carbonate (average particle diameter of $2.90 \mu \mathrm{m})$. A finer filler, with an average particle diameter of $1.54 \mu \mathrm{m}$, gave higher moduli. This is explained in terms of an immobilized matrix shell around the filler particles (hence the particle size dependency). 
Investigations by Vollenberg $[95,96]$ suggested this solidification effect resulting from locally activated hardening at the filler particle surface in cases where modulus was seen to increase with decreasing filler particle size. This led to preferential polymer orientation effects during cooling at the filler surface. This resulted in an enriched layer of high modulus and density polymer surrounding the filler surface, an effect known as the bound layer theory. Vollenberg suggested that this effect would lead to the creation of a higher density zone surrounding the filler particle with a lower density zone surrounding this zone. The creation of the lower density zone was effectively a depletion zone caused by transportation processes. In the case of fine particles $(<1 \mu \mathrm{m})$ these zones do not form around the particles but due to the large number of starting points for the thermal contraction process they actually create a near homogenous high modulus material. The particle size effects were dependent on the specific composite system.

\subsubsection{Tensile properties}

Under tension, modulus, tensile yield strength, tensile or ultimate strength and elongation at break are all important properties. Yield stress or strength is important in many applications ranging from engineering to films, giving information on the maximum allowable load without plastic deformation occurring. The elongation at yield is the strain allowable before plastic deformation occurs. Tensile yield stress values are used in assessing fracture toughness of a material. Tensile strength is the ultimate strength of the component and, while plastics are rarely used under loads approaching their ultimate strength, it is one of the most widely quoted properties. In practice, addition of particulate fillers usually reduces these properties and thus, as a consequence of a reduction in elongation in break, tensile strength becomes a more important parameter in a wider range of applications.

In the case of zero adhesion between filler particles and the continuous polymer phase, there is no load transfer to the filler and the total load is carried by the matrix. The material yield stress and ultimate strength depend, therefore, on the effective load bearing cross section and the strength of the unfilled polymer. 
Most particles have a shape so that the area fraction is different from volume fraction and also there will be some filler polymer interaction. Yield and tensile strengths can be improved by reducing particle size, increasing aspect ratio and improving adhesion between filler and polymer.

\subsubsection{Elongation at break}

Elongation at yield and break are normally reduced by the addition of filler when commercial loadings are used. As all the elongation has to take place in the matrix, its volume is reduced by the inextensible filler particle and the simple relationship given in the equation 2.20 holds as an approximation in systems where good adhesion occurs between phases:

$$
\varepsilon=\varepsilon_{0}\left(1-\phi^{1 / 3}\right)
$$

where $\varepsilon$ and $\varepsilon_{0}$ are the elongations at break of the composite and unfilled plastic. If there is no adhesion, then there is less relative elongation. Plastic composites elongate under three basic mechanisms: firstly there is elastic elongation; secondly; where deformation occurs at constant volume, then it will be a simple shear deformation of $45^{\circ}$; or a shear band. If the deforming material dilates, or it is anisotropic, then the angle of the shear band will increase; when this angle attains its limiting value of $90^{\circ}$ the deformation becomes a craze.

\subsubsection{Flammability/Combustion Characteristics}

Earlier sections discussed the conditions required for combustion to occur, namely the availability of oxygen, a fuel source and also a heat source and the interaction between these three components. Of most importance in this section is the fuel source, or material, and how the use of flame retardant fillers can enhance the fire characteristics of the polymer into which they are compounded. The geometry of the material (as well as its orientation when in use) is of great importance. These can be tested through a 
variety of methods, which include the more widely used Limiting Oxygen Index (LOI) [97, 98] and Underwriters Laboratories 94 (UL-94) [99] tests. The LOI test is used even though it has been found that the results of filled polymer systems do not correlate with other tests.

More useful larger scale tests include smoke box testing and the cone calorimeter [100102], which can both measure smoke emissions. The latter can also measure toxic gas emissions. These factors (smoke and gas emission) are increasingly more important as it is now widely believed that these are the greater factor in fire deaths. Due to the high emissions of smoke when ABS combusts, this is an important factor, even more so when flame retarded ABS is believed to be a greater producer of these by-products. The reason for the high smoke production is felt to occur due to the presence of aromatic nuclei.

\subsubsection{Influence of particle size}

An investigation by White and Docherty [103] looked at decreasing antimony trioxide particle size at $6 \mathrm{phr}$ loadings with $20 \mathrm{phr}$ OBDPO in ABS. Sizes of $\mathrm{Sb}_{2} \mathrm{O}_{3}$ used were $24.25,13.41,3.27,1.78,1.51,0.80$ and $0.75 \mu \mathrm{m}$. The more coarse grades $(13.41 \mu \mathrm{m}$ and $24.25 \mu \mathrm{m}$ ) had slightly lower LOI values than the other compounds. There was no significant difference seen for the UL-94 values at either $3.2 \mathrm{~mm}$ or $1.6 \mathrm{~mm}$ thickness. The sub-micron grades values did not appear to be any different to the values of the $1.5 \mu \mathrm{m}$ grade material. 


\section{EXPERIMENTAL PROCEDURES}

The work carried out in this thesis was mainly done in the laboratories and processing areas within IPTME at Loughborough University. All work was carried out individually except in those cases where the presence of a laboratory technician or experimental officer was necessary. The author was in close attendance when others carried out work in these situations. Analysis techniques, which were not carried out by the author were the particle sizing and titration work. These were carried out by the sponsoring company at sites both in Wallsend, Tyne and Wear (antimony trioxide) and in West Lafayette, Illinois (brominated materials). In these cases this work was necessary because of the need to use either specific test equipment or specific test methods.

The procedures and techniques were used to analyse the materials produced at each of three stages of work within the project. The first stage concerned the characterisation of the raw materials and made use of the facilities at the sponsoring company as mentioned above. The second stage looked at the processing of the formulations, especially the compounding and moulding procedures. The third stage looked at analysis of the compounded formulations.

\subsection{Materials Used}

\subsubsection{Polymers}

\subsubsection{ABS Polymer}

The grade of ABS polymer used as the base material for this work was Cycolac T manufactured by GE Plastics. This is a general-purpose injection mouldable grade with notched impact strength in the middle of the ABS range [104]. The quoted composition was $25 \mathrm{wt} \%$ acrylonitrile, $20 \mathrm{wt} \%$ butadiene and $55 \mathrm{wt} \%$ styrene. 


\subsubsection{Masterbatch Polymer}

Blendex 310(S), a high rubber content (61\%) ABS impact modifier from GE Specialty Chemicals was used in this work [105]. This was used as the base for several masterbatch compounds, in order to exploit its ability to produce improved impact performance when added at low loading levels.

\subsubsection{Antimony Trioxide}

Several different grades of antimony trioxide were used in this study, which were all supplied by Anzon Ltd (see Appendix A for technical data and product purity sheets). All grades had different average particle sizes and size distributions. Two of these were commercial grades and the rest were a range of a new experimental product.

\subsubsection{Timonox ${ }^{\circledR}$ Red Star}

The first grade of antimony trioxide was Timonox $\otimes$ Red Star (RS). This grade had an average particle size of $1.31 \mu \mathrm{m}$ and was the standard against which all others were measured [106]. This grade has been widely used in industry due partly to its relative cheapness compared to other grades.

\subsubsection{Microfine ${ }^{\circledR}$ A05}

The second commercial grade was Microfine A05 (A05) with an average particle size of $0.52 \mu \mathrm{m}$. Both these two commercial grades are manufactured by directly roasting and oxidising antimony metal in heated rotary kilns. The main difference is that the A05 product is produced under very carefully controlled conditions to ensure a very fine and consistent average particle size as well as a narrow particle size distribution [107].

\subsubsection{Anzon sub-micron (AZUB)}

The third grade of antimony trioxide was a milled sub-micron antimony trioxide grade supplied in masterbatch form using a proprietary castor wax carrier resin and classified as AZUB. This material was originally A05, which was milled to give a resulting average particle size of approximately $0.11 \mu \mathrm{m}$. The milled material was then 'flushed' 
from an aqueous medium into the castor wax binder resin and then dried using either a pan drying method (pAZUB) or a spray drying technique (sAZUB). The sizing data of the material was obtained prior to the introduction of the binder wax resin. The material was supplied in batches from between $1 / 2 \mathrm{~kg}$ to $1 \mathrm{~kg}$, with the $\mathrm{Sb}_{2} \mathrm{O}_{3}$ contents varying between $79 \mathrm{wt} \%$ and $85 \mathrm{wt} \%$. A grade of AZUB using milled Red Star material $\left(A Z \mathrm{UB}^{\mathrm{RS}}\right.$ ) was also supplied and was found to have an average particle size of $1.18 \mu \mathrm{m}$ [108].

\subsubsection{Brominated Materials}

Three commercial brominated materials were supplied by Great Lakes Chemical (Europe) Ltd. These were 1,2-bis(Tribromophenoxy)ethane (FF680 ${ }^{\mathrm{TM}}$ ), Tetrabromobisphenol A (BA59PTM) and Decabromodiphenyl Oxide (DE-83R ${ }^{\mathrm{TM}}$ ) [109].<smiles>Brc1cc(Br)c(OCCOc2c(Br)cc(Br)cc2Br)c(Br)c1</smiles>

Figure 3.1: Structure of 1,2-bis(Tribromophenoxy)ethane (BTBPETM).<smiles>CC(C)(c1cc(Br)c(O)c(Br)c1)c1cc(Br)c(O)c(Br)c1</smiles>

Figure 3.2: Structure of Tetrabromobisphenol A (TBBA $\left.{ }^{\mathrm{TM}}\right)$.<smiles>Brc1c(Br)c(Br)c(Oc2c(Br)c(Br)c(Br)c(Br)c2Br)c(Br)c1Br</smiles>

Figure 3.3: Structure of decabromodiphenyl oxide (DBDPO $\left.{ }^{\mathrm{TM}}\right)$. 
A milled sub-micron grade using decabromodiphenyl oxide (DE-83R) as the starting material was also supplied. This used the same milling, flushing and drying technique as used for the spray dried $\mathrm{Sb}_{2} \mathrm{O}_{3}$ AZUB material.

\subsection{Raw Material Characterisation}

\subsubsection{ABS}

TGA analysis was carried out on pellets of the supplied Cycolac $\mathrm{T}$ to determine the thermal stability of the material before compounding. TEM analysis was also carried out on these 'as supplied' pellets to determine the morphology prior to compounding. Analysis before and after compounding would then be possible and any changes in morphology due to the compounding process would then be able to be highlighted. This was achieved by cutting the pellets to a point and then mounting them in a cylindrical Spurr ${ }^{\mathrm{TM}}$ resin carrier. This enabled surface preparation of the sample using a microtome to be carried out prior to staining. Re-microtoming of the stained material gave the specimens for analysis.

\subsubsection{Particle Sizing}

Particle sizing of the Red Star and A05 antimony trioxide grades was carried out by Anzon using a Horiba LA-900 laser diffraction analyser and analysis of the AZUB materials was carried out using a Coulter counter. Within the laser diffraction apparatus the particles are analysed from the side and the rear in addition to the standard front scattering image, which means that particle size measurements can be made from 0.04 to $1000 \mu \mathrm{m}[110]$. This laser sizing system was used because it has a greater resolution than most alternatives [111] and was therefore capable of measuring finer particle sized fillers.

In order to avoid measuring agglomerates and aggregates of the primary particles, sonication was carried out prior to the sizing analysis. The amount of sonication carried out on the material prior to sizing analysis has previously been seen to have an effect on the particle size distribution [76]. The average particle size of the $\mathrm{Sb}_{2} \mathrm{O}_{3}$ decreased as the sonication time was increased from 1 minute to 15 minutes. A 5 minute sonication 
period was used for all materials as it was felt that this was the optimum time for breaking the agglomerates down. Any effects on the primary particles themselves were prevented by avoiding excessive agitation. The particles were dispersed in wetting agents, which included triethanol amine and ethanol. The complete size distribution, average particle size and standard deviation were shown using an appropriate software package.

Scanning electron microscopy was used to analyse all the materials with particular emphasis on the AZUB materials. The microscope was cooled using liquid nitrogen in order to avoid softening of the binder resin (see Section 3.4.4.1). Sizing analysis of the sub-micron particles was then possible, although accurate analysis was not possible due to charging effects caused by the presence of the binder resin. It was still possible however to measure approximate sizes of the particles.

The transmission electron microscope was also used to analyse the particle size of the materials making use of the scanning mode, which had a better resolution than the SEM. The results from the TEM were more accurate than those on the SEM and backed up the results obtained with both the Horiba and Coulter sizing instrumentation.

\subsubsection{Apparent Bulk Density}

The apparent bulk density (tap density) was carried out according to BS2782: Part 6 Method 621D [112]. The test was carried out on $100 \mathrm{~g}$ of the relevant material. Final measurements were those where successive readings differed by less than $2 \mathrm{ml}$ in the graduated column. The result quoted was the amount of tapped powder (g) compared to the final volume $(\mathrm{ml})$.

\subsubsection{Oil Absorption}

The oil absorption of the fillers by the spatula rubout method took place in accordance with standard ASTM D281-84 [113] using linseed oil ASTM D234-82 [114]. All samples used $10 \mathrm{~g}$ of dried material, except where the absorption was high and therefore $5 \mathrm{~g}$ of powder were used. The linseed oil was added to the powder drop by drop, with 
the combined oil and powder being rubbed with a spatula. This continued until a stiff, non-crumbly 'putty-like' paste was achieved.

\subsubsection{Thermogravimetric Analysis (TGA)}

Thermogravimetric analysis was carried out on both the supplied polymers and flameretardants to determine the thermal stability. TGA analysis technique is discussed in Section 3.4.7.

\subsection{Processing Method}

\subsubsection{Compounding}

Compounding was carried out using an APV MP30TC twin-screw co-rotating extruder with an L/D ratio of 30:1 and fitted with a four-strand die. The strands were then fed through a cooling water trough prior to entering a drying and pelletising unit. The screw configuration was kept constant for all the compounds formulated and the profile is detailed in Table 3.1. Also shown in the table is the barrel temperature profile for the majority of formulations, based on the recommended processing conditions for Cycolac $\mathrm{T}$ [104], as well as a temperature profile for a few select masterbatches. A screw speed of $170 \mathrm{rpm}$ and a mass flow rate of $12 \mathrm{~kg} / \mathrm{hr}$ was maintained for all formulations, except the masterbatches which used a screw speed of $100 \mathrm{rpm}$ and a mass flow rate of $4 \mathrm{~kg} / \mathrm{hr}$. All formulations were compounded on a constant mass flow rate basis.

The polymer and filler feed hoppers were Ktron Soder T20 type volumetric feeder units. The polymer feeder used long-pitch double spiral feed screws with a rotary agitator 'blade' whilst the filler feeder used long-pitch twin-concave profile screws with a similar agitator attachment. The agitator prevented 'bridging' of the material in both feeder hoppers but was more useful in the filler unit where 'bridging' was most likely to occur. Calibration of the output values of these units was carried out immediately before the processing of each compound. This was due to the fact that fluctuations in the feeder hopper equipment meant that it was not possible to produce a master calibration chart. 
Table 3.1: Screw configuration and barrel temperature profiles

\begin{tabular}{|c|c|c|c|c|c|c|}
\hline \multicolumn{7}{|l|}{ Screw configuration } \\
\hline \multicolumn{4}{|l|}{ Feed Screw } & \multicolumn{3}{|l|}{$5.5 \mathrm{D}$} \\
\hline \multicolumn{4}{|c|}{ Forwarding Paddles (Block) } & \multicolumn{3}{|l|}{$4 \times 30^{\circ}$} \\
\hline \multicolumn{4}{|l|}{ Forwarding Paddles } & \multicolumn{3}{|l|}{$8 \times 60^{\circ}$} \\
\hline \multicolumn{4}{|c|}{ Diameter Full Bore Orifice Plug } & \multicolumn{3}{|c|}{$\mathrm{D} / 2 \times 28.1 \mathrm{~mm}$} \\
\hline \multicolumn{4}{|l|}{ Feed Screw } & \multicolumn{3}{|l|}{$6 \mathrm{D}$} \\
\hline \multicolumn{4}{|l|}{ Forwarding Paddles } & \multicolumn{3}{|c|}{$12 \times 60^{\circ}$} \\
\hline \multicolumn{4}{|l|}{ Feed Screw } & \multicolumn{3}{|l|}{$4 \mathrm{D}$} \\
\hline \multicolumn{4}{|l|}{ Forwarding Paddles } & \multicolumn{3}{|l|}{$6 \times 60^{\circ}$} \\
\hline \multicolumn{4}{|c|}{ Diameter Full Bore Orifice Plug } & \multicolumn{3}{|c|}{$\mathrm{D} / 2 \times 28.1 \mathrm{~mm}$} \\
\hline \multicolumn{4}{|l|}{ Feed Screw } & \multicolumn{3}{|l|}{$4.5 \mathrm{D}$} \\
\hline \multicolumn{4}{|c|}{ Single Lead Discharge Screws } & \multicolumn{3}{|l|}{$1.5 \mathrm{D}$} \\
\hline \multicolumn{7}{|c|}{ Barrel temperatures $\left({ }^{\circ} \mathrm{C}\right)$} \\
\hline Compounds & Die & 2 & 3 & 4 & 5 & Throat \\
\hline General & 200 & 200 & 200 & 190 & 180 & 160 \\
\hline Select masterbatches & 210 & 200 & 200 & 190 & 180 & 170 \\
\hline
\end{tabular}

Due to the low loadings of the antimony trioxide grades in each compound (excluding masterbatches), it was difficult to feed the correct amount of material into the compounder. To avoid this problem, the $\mathrm{Sb}_{2} \mathrm{O}_{3}$ was premixed with the polymer in a large polyethylene bag, which was agitated for several minutes to achieve mixing. The contents were then fed into the 'polymer' feed hopper. Antimony trioxide material was often left in the bag (due to static effects) and was more noticeable for the smaller particle sized AZUB material. To avoid losses due to this phenomenon, the actual amount of material lost was noted in a control compound. Additional material (equal to that lost) was added to compensate in the next compound.

\subsubsection{Compounds}

The compounds created in this research work are shown in Table 3.2. These compounds were all created at different times during the research project but each one was formulated alongside one of six unfilled ABS controls for comparison. Nine 
compounds contained $\mathrm{Sb}_{2} \mathrm{O}_{3}$ only, four compounds contained brominated materials only and thirteen compounds contained both $\mathrm{Sb}_{2} \mathrm{O}_{3}$ and brominated material.

Table 3.2: List of compounds.

\begin{tabular}{|c|}
\hline ABS only \\
\hline Unfilled ABS ( 6 controls) \\
\hline Masterbatches \\
\hline $75 w t \%$ Blendex $310(S)+25 w t \%$ Cycolac T MB \\
\hline $75 \%$ (Blendex:Cycolac T MB) + 25\% Red Star \\
\hline $50 \%$ (Blendex:Cycolac T MB) +50\% Red Star \\
\hline $25 \%$ (Blendex:Cycolac T MB) $+75 \%$ Red Star \\
\hline $68 \%$ (Blendex:Cycolac T MB) $+32 \%$ AZUB \\
\hline ABS + polymer only \\
\hline $\mathrm{ABS}+1.33,4,12 \mathrm{wt} \%($ Blendex $310(\mathrm{~S})+$ Cycolac T MB) \\
\hline $\mathrm{ABS}+1.1 \mathrm{wt} \%$ castor wax binder resin \\
\hline $\mathrm{ABS}+\mathrm{Sb}_{2} \mathrm{O}_{3}$ \\
\hline $\mathrm{ABS}+4 \mathrm{wt} \% \mathrm{RS}$ (Timonox (8) Red Star) \\
\hline $\mathrm{ABS}+4 \mathrm{wt} \% \mathrm{~A} 05$ (Microfine A05) \\
\hline $\mathrm{ABS}+4 \mathrm{wt} \% \mathrm{Sb}_{2} \mathrm{O}_{3}\left(\mathrm{AZUB}{ }^{\mathrm{RS}}\right)$ \\
\hline $\mathrm{ABS}+4 \mathrm{wt} \%$ pan dried $\mathrm{Sb}_{2} \mathrm{O}_{3}(\mathrm{pAZUB})$ \\
\hline $\mathrm{ABS}+4 \mathrm{wt} \% \mathrm{Sb}_{2} \mathrm{O}_{3}(\mathrm{sAZUB})$ \\
\hline $\mathrm{ABS}+4 \mathrm{wt} \% \mathrm{RS}$ (diluted from $25 \%$ Red Star MB) \\
\hline ABS + 4wt $\%$ RS (diluted from $50 \%$ Red Star MB) \\
\hline ABS + 4wt $\%$ RS (diluted from $75 \%$ Red Star MB) \\
\hline $\mathrm{ABS}+4 \mathrm{wt} \% \mathrm{AZUB}$ (diluted from $32 \%$ AZUB MB) \\
\hline ABS + Brominated Material \\
\hline ABS $+20 w t \%$ bis(Tribromophenoxy)ethane (BTBPE) \\
\hline ABS + 20wt $\%$ Tetrabromobisphenol A (TBBA) \\
\hline ABS + 20wt $\%$ Decabromodiphenyl oxide (DBDPO) \\
\hline ABS + 20wt $\%$ spray dried Decabromodiphenyl oxide (sDBDPO) \\
\hline $\mathrm{ABS}+\mathrm{Sb}_{2} \mathrm{O}_{3}+$ Brominated Material \\
\hline $\mathrm{ABS}+4 \mathrm{wt} \%$ Red Star $+20 \mathrm{wt} \% \mathrm{BTBPE}$ \\
\hline $\mathrm{ABS}+4 \mathrm{wt} \%$ Red Star $+20 \mathrm{wt} \%$ TBBA \\
\hline $\mathrm{ABS}+4 \mathrm{wt} \%$ Red Star $+20 \mathrm{wt} \% \mathrm{DBDPO}$ \\
\hline $\mathrm{ABS}+4 \mathrm{wt} \% \mathrm{pAZUB}+20 \mathrm{wt} \%$ BTBPE \\
\hline $\mathrm{ABS}+4 \mathrm{wt} \% \mathrm{pAZUB}+20 \mathrm{wt} \%$ TBBA \\
\hline $\mathrm{ABS}+4 \mathrm{wt} \% \mathrm{sAZUB}+20 \mathrm{wt} \% \mathrm{BTBPE}$ \\
\hline $\mathrm{ABS}+4 \mathrm{wt} \% \mathrm{sAZUB}+20 \mathrm{wt} \% \mathrm{TBBA}$ \\
\hline $\mathrm{ABS}+4 \mathrm{wt} \% \mathrm{sAZUB}+20 w t \%$ DBDPO \\
\hline $\mathrm{ABS}+4 \mathrm{wt} \% \mathrm{sAZUB}+20 \mathrm{wt} \% \mathrm{sDBDPO}$ \\
\hline $\mathrm{ABS}+4 \mathrm{wt} \%(25 \%$ Red Star MB $)+20 w t \% \mathrm{BTBPE}$ \\
\hline $\mathrm{ABS}+4 \mathrm{wt} \%(25 \%$ Red Star MB $)+20 w t \%$ TBBA \\
\hline ABS + 4wt $\%(32 \%$ AZUB MB $)+20 w t \%$ BTBPE \\
\hline $\mathrm{ABS}+4 \mathrm{wt} \%(32 \% \mathrm{AZUB} \mathrm{MB})+20 \mathrm{wt} \% \mathrm{TBBA}$ \\
\hline
\end{tabular}


Five masterbatch compounds were formulated. Several other compounds looked at the effect of the masterbatch polymer only at loadings corresponding to the levels found in the compounds containing $\mathrm{Sb}_{2} \mathrm{O}_{3}$ from masterbatch material. One compound contained only castor wax binder at a level comparative to that found in the AZUB materials.

In order to ensure that as little contamination as possible occurred between compounds each series of work started with unfilled systems. The remaining compounds were then processed starting with the smallest particle sized material and then continued with increasing particle size. This ensured that any contamination that occurred would involve traces of finer particles in coarse grade compounds rather than the other way round, which was deemed to be unacceptable.

\subsubsection{Injection Moulding}

\subsubsection{Conditioning of compounds}

Prior to injection moulding all the formulations were conditioned in trays in a drying oven to remove as much water as possible. The material was kept to a maximum depth of $50 \mathrm{~mm}$ to ensure that all the material dried. The presence of water in the moulded component would affect the properties and drying is therefore recommended by the suppliers prior to compounding and injection moulding. Material that has not been dried properly may also lead to specimens containing splay-marks or other surface defects. This effect was seen when the author injection moulded ABS pellets that had some water remaining on the pellet surface.

A drying time of $80^{\circ} \mathrm{C}$ for 4 hours was used to remove excess amounts of water from all the formulations. This value was quoted by the company and had also been determined by both Dunham [115] and Owen [76]. Samples were dried for varying periods with the 4 hour drying time providing the optimal strength, with a gradual decrease in impact strength occurring after this point up to the 12 hour drying period. It was also noted that the surface finish of the material was dramatically improved after 4 hours of drying. An important factor raised by previous work was that raising the temperature could not reduce the drying time. 


\subsubsection{Injection moulder settings}

A Negri-Bossi NB62 injection moulding apparatus was used for moulding the compounds. The dimensions of the moulder are shown in the table below.

Table 3.3: Injection moulder dimensions [116].

\begin{tabular}{|l|l|}
\hline Screw diameter & $28 \mathrm{~mm}$ \\
\hline Screw length to diameter ratio & $23: 1$ \\
\hline Maximum injection rate & $66 \mathrm{~cm}^{3} / \mathrm{min}$ \\
\hline Maximum mould clamping force & $620 \mathrm{kN}$ \\
\hline Mould temperature & $60^{\circ} \mathrm{C}$ \\
\hline
\end{tabular}

The sprue and barrel heaters were set to give a melt temperature profile as shown in Table 3.4. These values were within the recommended processing window as recommended by the suppliers of the ABS Cycolac T grade [104].

Table 3.4: Injection moulding profile for impact and flexural specimen bars

\begin{tabular}{|l|l|}
\hline Sprue temperature & $230^{\circ} \mathrm{C}$ \\
\hline Nozzle temperature & $220^{\circ} \mathrm{C}$ \\
\hline Heater 1 temperature & $220^{\circ} \mathrm{C}$ \\
\hline Heater 2 temperature & $200^{\circ} \mathrm{C}$ \\
\hline Heater 3 temperature & $180^{\circ} \mathrm{C}$ \\
\hline \multicolumn{2}{|l|}{} \\
\hline 1st injection speed & $60 \%$ \\
\hline 2nd injection speed & $5 \%$ for $20 \mathrm{~mm}$ \\
\hline 1st Hold pressure & 30 bar for $10 \mathrm{sec}$ \\
\hline 2nd Hold pressure & 20 bar for $10 \mathrm{sec}$ \\
\hline
\end{tabular}

The overall cycle time was 52 seconds with 3 seconds for injection and 40 seconds for mould cooling. A $460 \mathrm{kN}$ applied force was used with a shot size of $88 \mathrm{~mm}$ for the impact bars and a shot size of $93 \mathrm{~mm}$ for the flexural bars. The barrel temperatures, injection speeds, hold pressures and all other conditions except shot size were kept the same for all the compounds. The mould temperature was set at $60^{\circ} \mathrm{C}$ since at this relatively high temperature the materials flowed well into the mould cavity, which made the filling phase easier, especially for the filled compounds. This setting enabled handling of the samples after ejection. For each compound the first twelve mouldings 
were discarded in order to purge the machine between each formulation and thereby avoid contamination. Testing of the 'purge' mouldings showed that at least eight specimens needed to be discarded to ensure no contamination. As with compounding, the order of moulding was carried out so that compounds containing the largest particles were produced last. This was in order to minimise any possibilities of contamination, which could affect the properties of the specimen bars.

Table 3.5: Injection moulding profile for LOI and UL-94 specimen bars

\begin{tabular}{|l|l|}
\hline Sprue temperature & $200^{\circ} \mathrm{C}$ \\
\hline Nozzle temperature & $200^{\circ} \mathrm{C}$ \\
\hline Heater 1 temperature & $190^{\circ} \mathrm{C}$ \\
\hline Heater 2 temperature & $185^{\circ} \mathrm{C}$ \\
\hline Heater 3 temperature & $180^{\circ} \mathrm{C}$ \\
\hline & \\
\hline 1st injection speed & $60 \%$ \\
\hline 2nd injection speed & $5 \%$ for $20 \mathrm{~mm}$ \\
\hline 1st Hold pressure & 30 bar for $10 \mathrm{sec}$ \\
\hline 2nd Hold pressure & 20 bar for $10 \mathrm{sec}$ \\
\hline
\end{tabular}

The overall cycle time was 50 seconds, which included 0.7 seconds for injection and 40 seconds for mould cooling. A $475 \mathrm{kN}$ applied force was used with a $20 \mathrm{~mm}$ material shot size. All other conditions were kept the same as for the impact and flexural bars.

\subsection{Analysis of Compounds}

\subsubsection{Antimony Content Analysis}

\subsubsection{Ashing}

Ashing was carried out on pellets of the compounded formulations at $550^{\circ} \mathrm{C}$ in a furnace. This temperature was selected because it was well below the melting point of antimony trioxide $\left(656^{\circ} \mathrm{C}\right)$ and thermogravimetric analysis (TGA) had shown that at this temperature the polymer residue was minimal. Another important factor was that the temperature did not exceed the point at which alleged volatilisation of the antimony trioxide occurred. Volatilisation of the material would result in a loss of some of the 
$\mathrm{Sb}_{2} \mathrm{O}_{3}$ and thereby give incorrect results. Comparisons between ashing and titration data (see Section 3.4.1.2) would not be possible therefore and as this problem would be exaggerated with higher $\mathrm{Sb}_{2} \mathrm{O}_{3}$ contents (masterbatches) any losses need to be avoided.

The standard procedure [117] requires measurement of the samples every 30 minutes but the author found that the results were not accurately reproducible when using this technique. To prevent possible losses occurring during removal of the samples from both the furnace and the weighing apparatus, as well as to give more reproducible results, the specimens were heated for 2 hours before being weighed. These results were more reproducible and the method was maintained for all formulations.

\subsubsection{Volumetric Titration Analysis}

The titration analysis procedure was supplied by Anzon and was carried out at the company facilities in Wallsend, Tyne and Wear [118].

i. Weigh out sample into $500 \mathrm{ml}$ Erlenmeyer flask fitted with splash trap

ii. Add $25 \mathrm{ml}$ of concentrated $\mathrm{H}_{2} \mathrm{SO}_{4}$ and heat gently for 10 minutes

iii. Heat strongly for 2 hours until $\mathrm{SO}_{3}$ fumes appear 1 inch below the neck

iv. Cool and add $\mathrm{H}_{2} \mathrm{O}$, rinse flask and add $5 \mathrm{ml} \mathrm{CuSO}_{4}$

v. Heat for 45 minutes on a hotplate with splash trap off

vi. Cool flasks under running water then add $100 \mathrm{ml}$ of $30 \% \mathrm{HCl}$

vii. Add amaranth indicator and titrate with $0.1 \mathrm{~N}$ potassium bromate until red colouration disappears

The titrated results were more reproducible than the ashing test results, with the latter tending to be significantly lower than expected suggesting losses during the ashing procedure. The average values of several tests for each compound were therefore used for the work from the titration results. 


\subsubsection{Bromine Content Analysis}

Determination of the total bromine content for those formulations containing a brominated compound was achieved using the Schöniger Flask Method [119]. This technique involves burning the sample in an oxygen-rich atmosphere in a specially designed flask where the bromine in the compound is converted into elemental bromine or hydrogen bromide. The gases are absorbed into a potassium hydroxide-hydrazine sulphate solution, in which the bromine is reduced to bromide. Bromide is then determined by potentiometric titration with standard silver nitrate.

i. Weigh appropriate amount of the powdered, dried and shredded sample into a tared sample capsule $(0.2 \mathrm{ml}$ cellulose acetate). The sample size is determined by the $\% \mathrm{Br}$ estimated in the sample. $2 \%$ to $10 \% \mathrm{Br}=50$ to $100 \mathrm{mg} ; 50 \%$ to $90 \% \mathrm{Br}=15$ to $20 \mathrm{mg}$.

ii. Place sample into platinum carrier and allow the tail section of the wrapper to hang freely.

iii. Add $25 \mathrm{ml}$ of $0.1 \mathrm{~N}$ hydrazine sulphate solution and $25 \mathrm{ml}$ of $2 \mathrm{~N} \mathrm{KOH}$ solution to the flask.

iv. Purge the flask with oxygen for 60 seconds and stopper flask ensuring it is secured for combustion process.

v. After complete combustion shake flask for 1 minute ensuring the walls are well wet.

vi. Permit combustion products to absorb in the hydrazine sulphate/potassium hydroxide solution for 30 minutes or until the visible vapours have disappeared.

vii. Quantitatively transfer the absorbed sample into a $300 \mathrm{ml}$ Berzelius type beaker, rinsing flask at least 3 times with distilled water.

viii. Add $0.5 \mathrm{ml}$ methyl orange indicator.

ix. Acidify with 1:1 nitric acid until indicator turns red, then cover and allow to stir.

x. Adjust the volume to about $200 \mathrm{ml}$ with distilled water.

xi. Titrate the sample potentiometrically on the recording titrator with $0.05 \mathrm{~N}$ silver nitrate using a titration rate of $0.5 \mathrm{ml} / \mathrm{min}$. 
xii. Endpoint is taken as the mid-point of the inflection in the titration curve. The volume of silver nitrate required is read to the nearest $0.0125 \mathrm{ml}$.

xiii. A reagent blank should be carried out through entire procedure.

Determination of the percentage of bromine present in the sample is then calculated using the following equation:

$$
\% \text { Bro } \min e=\frac{(A-B) N(7990)}{W}
$$

where $\quad \mathrm{A}=$ Volume of $\mathrm{AgNO}_{3}$ for the sample, $\mathrm{ml}$.

$\mathrm{B}=$ Volume of $\mathrm{AgNO}_{3}$ for the blank, $\mathrm{ml}$.

$\mathrm{N}=$ Normality of the $\mathrm{AgNO}_{3}$ solution.

$\mathrm{W}=$ Sample weight, $\mathrm{mg}$.

\subsubsection{Rheology}

\subsubsection{Haake Rheology}

A Haake Rheocord 90 instrument was used to analyse filler influence on the mixing torque and also to determine masterbatch formulations. The apparatus was equipped with a Rheomix 600 mixing head with two-roller type mixing rotors. Each test run was carried out for 10 minutes at $200^{\circ} \mathrm{C}$ with a test rotor speed of $100 \mathrm{rpm}$. The net chamber volume with roller rotors was $69 \mathrm{~cm}^{3}$ and it is advised by the manufacturers to have a fill level between 65 and $90 \%$ of this maximum for effective mixing. The equation used for determining the correct sample weight is shown below and is dependent on the net volume of the mixer chamber, which is in turn dependent upon the geometry of the motors used.

Sample weight $(\mathrm{g})=$ Bulk density $\left(\mathrm{g} / \mathrm{cm}^{3}\right) \times$ Net chamber vol. $\left(\mathrm{cm}^{3}\right) \times$ Filling vol. $(\%)$

Looking at the effect of the antimony trioxide on the mixing torque and also the effect of higher viscosity masterbatch carrier resins, the author ensured that the chamber was filled to $90 \%$ for each run. 


\subsubsection{Electron Microscopy}

\subsubsection{Scanning Electron Microscopy (SEM)}

\section{Sample Preparation}

Prior to analysis in the SEM it was necessary to coat the specimen with a thin $(10 \mathrm{~nm})$ conducting layer of gold or carbon to provide a good conducting flow path to earth. This is especially needed for non-conducting specimens such as polymers. Sputter coating with gold was used as it provided a quick and simple method for preventing surface charging which would otherwise produce a distorted image. A colloidal suspension of silver metal in an organic solvent known as 'silver dag' was used to provide a good earth for the sputtered specimens. All the specimens were mounted on aluminium stubs.

\section{Scanning Electron Microscopy}

A Cambridge/Leica Stereoscan 360 instrument was used to show the size and dispersion of the fillers in the ABS matrix as well as to analyse the impact fracture surfaces. In addition to these it was also used to look at the structure and morphology of the supplied AZUB materials. The scanning mode was used with a $10 \mathrm{keV}$ accelerating voltage to examine the morphology of the fillers. The backscattered mode was used at $20 \mathrm{keV}$ in order to distinguish between the matrix and the filler particles. The EM instrument was also equipped with an X-ray analyser and this was used for elemental analysis. This was particularly useful when unknown contaminants were located as their exact nature could then be determined.

\section{Backscattered Electron Microscopy}

Microtomed sections created from sectioned injection moulded impact specimens were analysed using the backscatter detector in the SEM. This method of analysis enabled determination of the extent of dispersion of the antimony trioxide within each sample. The backscattered electron image showed dispersion due to good contrast between the polymer matrix and the high density particles. This method was sufficient for the larger particle sizes but determining the size and distribution of the sub-micron grades proved 
to be far more difficult. Due to this problem it was necessary to use the TEM instrument to determine size and particle distribution.

\subsubsection{Transmission Electron Microscopy (TEM)}

\section{Sample Preparation (Staining and Microtoming)}

In order to see a contrast between the phases within polymer blends and block copolymers it is necessary to stain the samples, a fact that was first discovered by Kato [120]. He found that osmium tetroxide $\left(\mathrm{OsO}_{4}\right)$ vapour or a dilute $\mathrm{OsO}_{4}$ aqueous solution preferentially stains polymer molecules containing carbon-carbon double bonds, such as those in polybutadiene and polyisoprene. Prepared ABS specimens were immersed in a $2 \% \mathrm{OsO}_{4}$ aqueous solution for 72 hours, neutralised with sodium thiosulphate, rinsed with water and then dried prior to sectioning. As well as staining the double bond the $\mathrm{OsO}_{4}$ also hardens the elastomeric phase, enabling microtoming of specimens to about $500 \AA$ thickness. The hardened surface layer allows ultramicrotomy at room temperature without excessive section distorting or tearing. This staining process was used in order to determine the preferential location of the $\mathrm{Sb}_{2} \mathrm{O}_{3}$ in the $\mathrm{ABS}$. $\mathrm{OsO}_{4}$ is toxic and care must be taken not ingest or breath any vapours of the material. Other problems are that it has a low staining depth and takes at least 24 hours for adequate staining to take place.

A Cambridge/Huxley Mark 2 single pass ultramicrotome was used to prepare thin sections of materials for examination in the transmission electron microscope. Sections approximately $1 \mathrm{~mm} \times 1 \mathrm{~mm} \times 150 \mathrm{~nm}$ were prepared with this equipment. In this method a firmly mounted specimen is moved past an industrial diamond or fixed glass knife, in the case of this work a glass knife was used. The thin sliced sections were collected in a trough filled with distilled water. This allowed easier collection of the samples due to the fact that they floated on the surface. The presence of the water also reduced friction at the surface during the cutting process. Once cut the samples were then mounted on $3 \mathrm{~mm}$ copper discs with a 200 mesh size grid before being inserted in the microscope.

The samples prepared in this manner looked at two areas of the samples. The dispersion analysis of the particulate materials was tested using samples taken from the middle of 
the fractured impact specimen bar. Craze analysis samples were taken from within the stress whitened zone of each specimen, as close to both the fracture surface and the notch root as possible.

\section{Transmission Electron Microscopy}

A Jeol $100 \mathrm{CX}$ transmission electron microscope was used to analyse ultramicrotomed sections in order to look at the size and distribution of the antimony oxides. Using the TEM enables higher magnification than achievable in the SEM. The TEM enabled use of the staining methods described in the previous section in order to highlight the polybutadiene phase of the ABS. This meant that the location of the antimony trioxide in relation to both phases could be analysed. The examination looked at several sections of each compound in order to ensure that a true analysis of the samples was carried out. This was vital as the inherently small areas under observation could be misrepresentative of the whole and therefore be misleading.

The Jeol 100 CX TEM was also used in the SEM mode with an accelerating voltage of $100 \mathrm{keV}$, since it provided clearer images than the conventional SEM for analysing the morphology and size of the supplied materials. Methanol or toluene was used to disperse the particles and aid observation. The X-ray mapping facility on the TEM was used to determine the nature and origin of various inclusions, artifacts and other unknown particles. More importantly it was used to try and determine the location of the melt blendable bromines within the ABS matrix.

\subsubsection{Impact Testing}

Instrumented falling weight testing is becoming increasingly useful as a tool for obtaining information on the resistance to failure of polymers with a more realistic simulation of end-use abuse [121]. Over the years many studies have looked at impact testing using a variety of apparatus and test specimens (bars, plates, discs etc) [122127]. In this study a type 5 Rosand Instrumented falling weight impact machine equipped with a $26.2 \mathrm{~kg}$ mass and a Charpy geometry striker were used to measure the peak force, total impact energy, peak energy and peak and failure deflection. Notched 
and unnotched specimens were simply supported on a span of $40 \mathrm{~mm}$ with the notch (where applicable) being placed on the opposing side to the impact face. The injection moulded specimen dimensions were $63 \mathrm{~mm} \times 6.35 \mathrm{~mm} \times 12.6 \mathrm{~mm}$ with a $2.8 \mathrm{~mm}$ notch depth and a $0.25 \mathrm{~mm}$ root radius. An optimum impact velocity of $3 \mathrm{~ms}^{-1}$ [128] (as used in earlier studies $[76,129]$ ), giving an impact energy of $118 \mathrm{~J}$ was used with a $2.5 \mathrm{kHz}$ low pass filter frequency. All testing took place at room temperature. Eight specimens were tested per compound. The data was collected with the integral computer software using ASTM standard D3763-86 [130] as guidance for the work.

The basic layout of the falling weight column is shown in Figure 3.4.

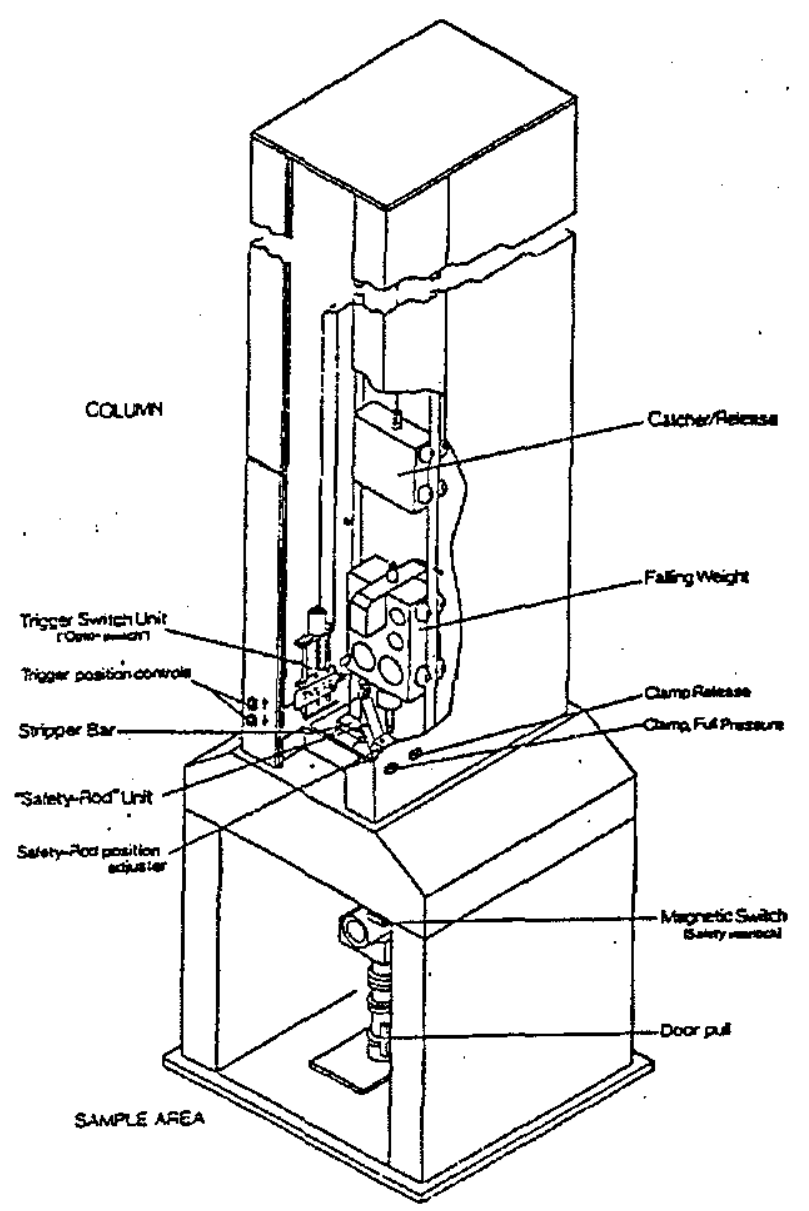

Figure 3.4: Rosand Instrumented Falling Weight Impact testing machine [131].

A Kistler transducer is positioned between the striker and the impact weight and when released the striker accelerates towards the specimen holder due to gravity. An optical sensor is positioned at a point where the striker just hits the surface of the specimen. 
This sensor activates a transient recorder, which then begins data collection of the force signal with time. The recorder collects the data points to record the behaviour of the material throughout the duration of the impact. The computer takes the force signal (which has been digitised) and converts them into force-deflection or force-time graphs. The energy values were calculated within the software by integration of the force-time co-ordinates.

Due to the nature of this test many vibrations are set up in the equipment when the test takes place. These vibrations can interfere with the signal generated by the fracture process and therefore need to be avoided or removed from the trace. This can be achieved by changing contact conditions [132] or by filtering, although the extent to which the filtering is used can also affect the fracture signal [133-136]. Excessive filtering can hide the real fracture behaviour characteristics completely. The correct filter value was determined by making use of the post filtering facility within the computer software. A specimen bar was impacted and the trace was then generated using a range of filter frequencies from 0.1 to $100 \mathrm{kHz}$. It was found that the low pass filter frequency selected significantly influenced the force/time and force/deflection signal produced. At $0.1 \mathrm{kHz}$ this resulted in a smooth symmetrical hemispherical shaped force/deflection trace, which meant that data had been removed. At $100 \mathrm{kHz}$ this gave a trace with many interference spikes and noise and was believed to be an unrealistic representation of the actual trace. Realistic traces were produced using between a 1.5 and $3 \mathrm{kHz}$ filter. The $2.5 \mathrm{kHz}$ filter was used because of this fact and which corresponded to findings in earlier work that used this filter [76]. Comparisons could therefore be made between this and earlier work if this filter arrangement was maintained.

\subsubsection{Flexural Testing}

A Lloyds type 2000R universal test machine was used at room temperature in the three point bending mode to determine the flexural modulus, flexural strength, peak deflection and work done of the compounds [137]. Rectangular sectioned dumbbell shaped injection moulded specimens, approximately $12.70 \mathrm{~mm}$ wide by $3.25 \mathrm{~mm}$ deep were used. Sample dimensions did alter slightly for the different formulations, although 
as stated in Section 3.3.2.2, the injection mouldings were kept constant for all the compounds. The experimental conditions used are shown in Table 3.6.

Each specimen had any excess mould flash removed and then conditioned at room temperature for 24 hours prior to testing. Dimensions of each specimen were measured to the nearest $0.01 \mathrm{~mm}$ just before testing using a micrometer. Testing.was done on specimen bars from the same position in the mould on eight samples from each of the compounded formulations. Specimens were selected from the same mould position to give more reproducible results.

Table 3.6: Flexural testing conditions

\begin{tabular}{|l|l|}
\hline Load cell and internal extensometer & $2.5 \mathrm{kN}$ \\
\hline Test rate & $5 \mathrm{~mm} / \mathrm{min}$ \\
\hline Span support width & $52 \mathrm{~mm}(16 \times$ specimen depth $)$ \\
\hline Central loading nose diameter & $25 \mathrm{~mm}$ \\
\hline Support diameters & $6.35 \mathrm{~mm}$ \\
\hline Secant modulus & $10 \mathrm{~N}$ to $80 \mathrm{~N}$ \\
\hline
\end{tabular}

\subsubsection{Thermogravimetric Analysis (TGA)}

A Rheometric Scientific type TG 760 apparatus and a TA Instruments high resolution modulated TGA 2950 unit were used to determine the thermal stability of the ABS compounds. Testing was conducted from room temperature to between 600 and $700^{\circ} \mathrm{C}$ with a heating ramp rate of $5{ }^{\circ} \mathrm{C} / \mathrm{min}$ in nitrogen. The masses of the samples were between 5 and $20 \mathrm{mg}$.

Initial work was carried out on the Rheometric Scientific TG-760 unit but the balance was extremely sensitive and static charges were affecting the results. An antistatic agent was applied to the glassware and the furnace assembly to reduce the effect of these charges. The data was recorded and annotated with a Rheometric Scientific Plus version 5.42 computer package. 


\subsubsection{Flame Testing}

\subsubsection{Limiting Oxygen Index (LOI) Flame Test}

The Limiting Oxygen Index (LOI) test is a significant technique in analysing the flame properties of a polymer system and originally developed in 1966 [138]. This test uses polymer specimens of a standard size placed into equipment where various oxygen concentrations in an oxygen-nitrogen mixture are used. The minimum amount that will just allow candle-like flaming combustion to continue is determined and it is this value, expressed as a percentage that is the Limiting Oxygen Index. The test is inexpensive, simple and uses small samples, which means that it is widely used in testing labs [139]. A paper by Weil et al [140], which questioned its correlation with other tests and real fire characteristics, did acknowledge its convenience and more importantly its precision.

In this test injection moulded specimens $120 \mathrm{~mm} \times 6.4 \mathrm{~mm} \times 3.0 \mathrm{~mm}$ were deburred and conditioned at $23{ }^{\circ} \mathrm{C}$ and $50 \%$ relative humidity. Reference lines $50 \mathrm{~mm}$ from the top surface were then marked on each sample. The samples were mounted vertically in the glass chimney of a Rheometric Scientific LOI instrument (Figure 3.5).

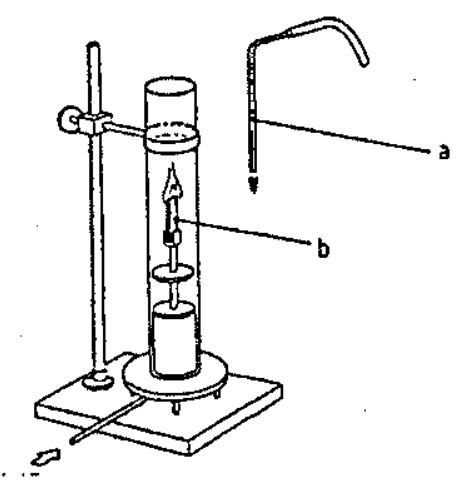

Figure 3.5: Limiting Oxygen Index apparatus [141].

The mixed gas flow of oxygen and nitrogen was set at a rate of $181 / \mathrm{min}$. The top of the specimen (b) was ignited using a butane gas burner (a) according to the standard [97]. The flame was held against the sample until steady combustion occurred. The sample was then allowed to burn either until the burning time exceeded three minutes, the burn length exceeded the $50 \mathrm{~mm}$ reference line or until the sample self extinguished. Generally an LOI value of 27 or above, which takes into account the convection effects 
in real fires, is considered to be a self-extinguishing material. The oxygen index testing does not measure or take account of flaming polymer drips, which become detached from the flame front. The author noted (as have others [140]) that many of the samples were prone to these drips, which ignited the sides of the sample. The results from these samples were not used in determining the LOI value for that material. Values were calculated using the Dixon up and down determination method shown in the standard and using final increments of $0.2 \%$ [76].

\subsubsection{Underwriters Laboratory (UL-94) Vertical Burn Test}

The UL-94 burn test uses a vertically clamped specimen with dimensions $127 \mathrm{~mm} \mathrm{x}$ $12.7 \mathrm{~mm} \times 1.6 \mathrm{~mm}$ to which a standardised gas flame is applied at the base of each sample (Figure 3.6). The injection moulded specimen bars were deburred and clamped $300 \mathrm{~mm}$ above a layer of cotton wool according to the standard. The flame was $19 \mathrm{~mm}$ long, angled at $45^{\circ}$ to prevent any flaming drips interfering with the testing procedure and initially applied to the specimen for 10 seconds. If no burning took place and the flame was extinguished, the gas flame was reapplied for a further 10 seconds. The flame behaviour was observed throughout both the flame applications and during any combustion that occurred. These observations were then used to determine the fire performance using ratings of V0, V2 or FAIL to describe the extent to which the sample is flame retardant. The full explanation of each rating is described in the standard but can be explained in that the classification is dependent on the time for flames to be extinguished and whether the material drips during the test. The best rating is the V0 grade and is given when the sample has little or no burning, has little or no afterglow and does not drip. All the testing was carried out in a chamber, which prevented any drafts affecting the results. An extraction unit removed the by-products of the testing, which was only used once the test had been completed. The following test was run once the extraction unit had been turned off and the air flow had stabilised. 


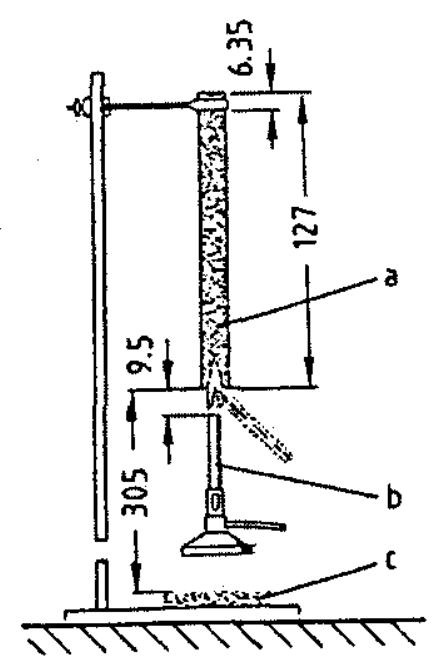

Figure 3.6: Underwriters Laboratory UL94 apparatus [142].

(a) Specimen, (b) Burner, (c) Surgical cotton.

Sample size is important for this test and the thinner the specimen size the harsher the test. Sample thicknesses that are most commonly used are 3.2 and $1.6 \mathrm{~mm}$. The latter has been used for this work, as it is more difficult for a formulation to achieve a V0 rating with the thinner specimen. 


\section{RESULTS}

The results of the work carried out have been separated into several sections, each dealing with a different aspect of the research program. Although the sections are shown separately all the results contained within them are comparable with each other. The results shown represent the influence of the various materials used in the ABS compounds.

\subsection{Analysis of Materials Used}

\subsubsection{Cycolac T (ABS) Polymer}

Pellets of the Cycolac T grade of ABS were tested prior to any method of processing or compounding. These 'as supplied pellets' were mounted in resin, stained, sectioned and then viewed using the TEM. Osmium tetroxide $\left(\mathrm{OsO}_{4}\right)$ was used to stain the polymer and which preferentially stained the rubbery particles within the ABS. This resulted in a clear contrast between the lightly stained SAN phase and the darkly stained butadiene phase (see Plate 4.1).

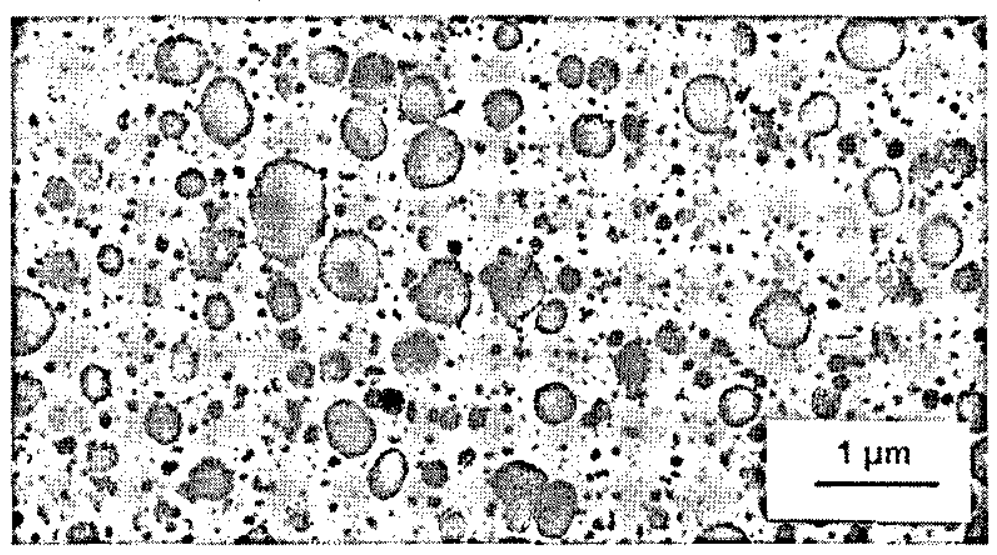

Plate 4.1: TEM image of Cycolac T ABS morphology.

The clear difference between phases enabled analysis of the individual size and size distribution of the particles as well as allowing observations on the dispersion of this phase. It also enabled confirmation of the polymerisation technique used to produce this material, which was emulsion polymerisation. This method resulted in a butadiene 
phase consisting of discrete particles with little or no inclusions of SAN within them. The range of particle size was estimated to be between 0.02 and $0.8 \mu \mathrm{m}$ with good dispersion of the butadiene particles throughout the sample.

TGA analysis looking at the thermal degradation characteristics of this polymer showed that the onset of mass loss occurred between 260 and $300^{\circ} \mathrm{C}$ with complete degradation occurring by $475^{\circ} \mathrm{C}$ (see Figure 4.2). The onset was difficult to determine due to a slight decrease from $170^{\circ} \mathrm{C}$. $\mathrm{T}_{5 \%}$ occurred at $362^{\circ} \mathrm{C}, \mathrm{T}_{10 \%}$ at $380^{\circ} \mathrm{C}$ and $\mathrm{T}_{50 \%}$ at $413^{\circ} \mathrm{C}$.

\subsubsection{Antimony Trioxide}

Several grades of antimony trioxide were used in this study (see Section 3.1.2): Timonox Red Star (RS), Microfine A05 (A05) and Anzon sub-micron (AZUB) material, which consisted of pan dried (pAZUB) and spray dried (sAZUB) grades. The particle sizes of these grades of material were measured using either a Horiba particle size distribution analyser or a Coulter counter apparatus. The results were measured as percentage frequency (Figure 4.1 and Table 4.1), which shows $\mathrm{d}_{50}$ (particle size below which $50 \%$ of all the particles fall) and standard deviation results. TEM was also used in the SEM mode to further investigate the morphology of the samples.

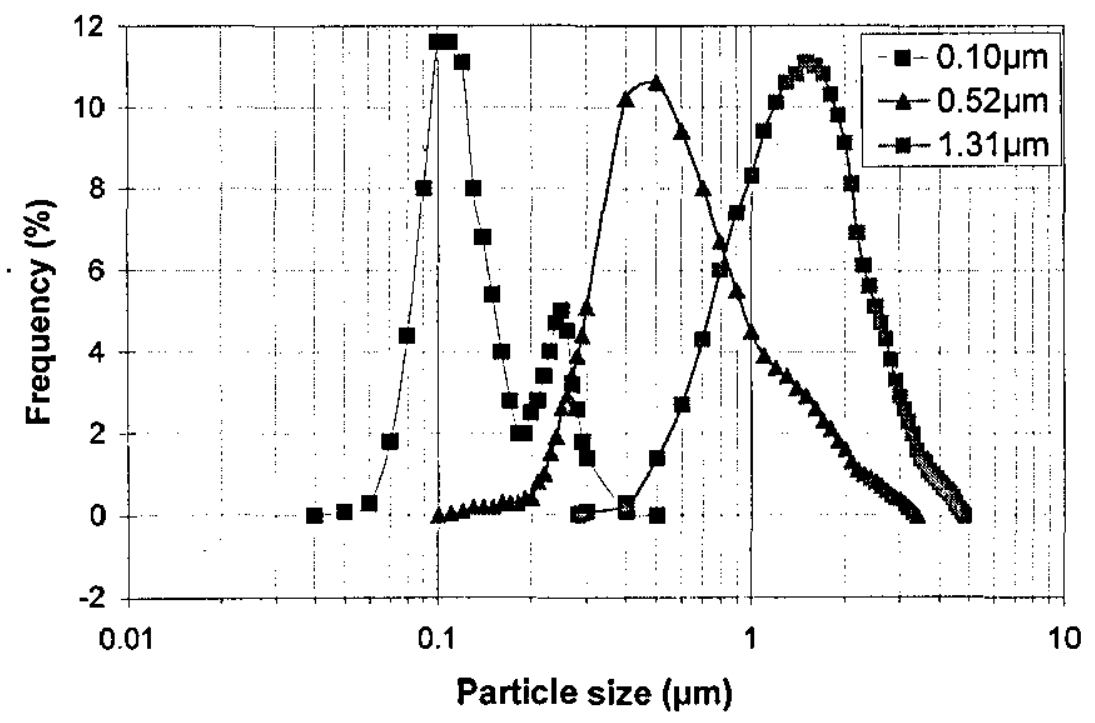

Figure 4.1: Antimony trioxide particle size distribution curves. 
Table 4.1: Particle sizing and packing properties of antimony trioxide grades.

\begin{tabular}{|l|c|c|c|}
\hline Antimony trioxide grade & $\begin{array}{c}\text { Particle size } \\
\mathrm{d}_{50} \mu \mathrm{m}(\mathrm{SD})\end{array}$ & $\begin{array}{c}\text { Bulk density } \\
(\mathrm{g} / \mathrm{ml})\end{array}$ & $\begin{array}{c}\text { Oil absorption } \\
(\mathrm{ml} / 100 \mathrm{~g})\end{array}$ \\
\hline Timonox Red Star & $1.31(0.69)$ & $1.88[1.87]$ & $15.3[15.1]$ \\
Microfine A05 & $0.52(0.47)$ & $1.25[1.25]$ & $17.8[17.6]$ \\
Anzon sub-miicron AZUB & $0.11(0.24)$ & $1.35[1.33]$ & $21.4[21.0]$ \\
\hline
\end{tabular}

The RS material had an average particle size of $1.31 \mu \mathrm{m}$ with a broad particle size distribution as shown in Figure 4.1. TEM analysis revealed that the RS consisted of roughly cubic shaped particles with some spherically shaped particles (see Plate 4.2). The larger particles were well defined and angular with the smaller particles being less well defined.

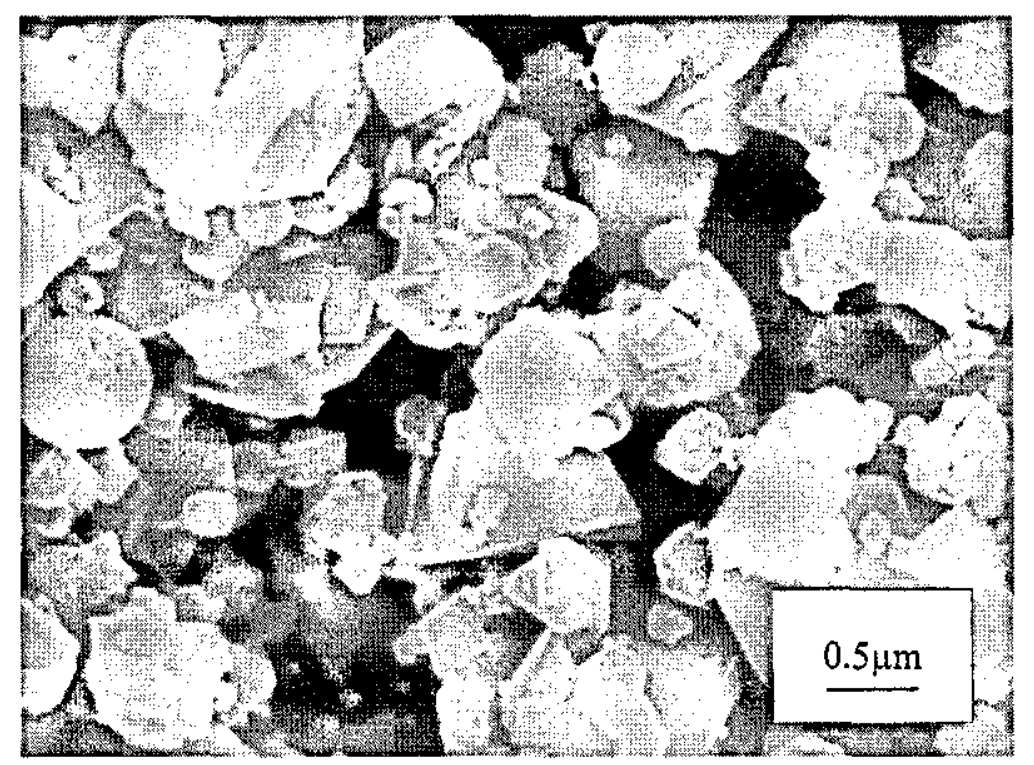

Plate 4.2: TEM image of Red Star antimony trioxide particles.

The A05 had an average particle size of $0.52 \mu \mathrm{m}$ with a smaller particle size distribution than the RS. The size distribution is 'skewed' towards the larger particle sizes however with the largest being similar in value to those at the upper end of the RS distribution curve, as can be seen in Figure 4.1. TEM analysis showed that the particles were similar 
in nature to the RS grade, being angular cubic forms with some spherical particles (Plate 4.3), although the image appears to show more of the smaller particles in this grade.

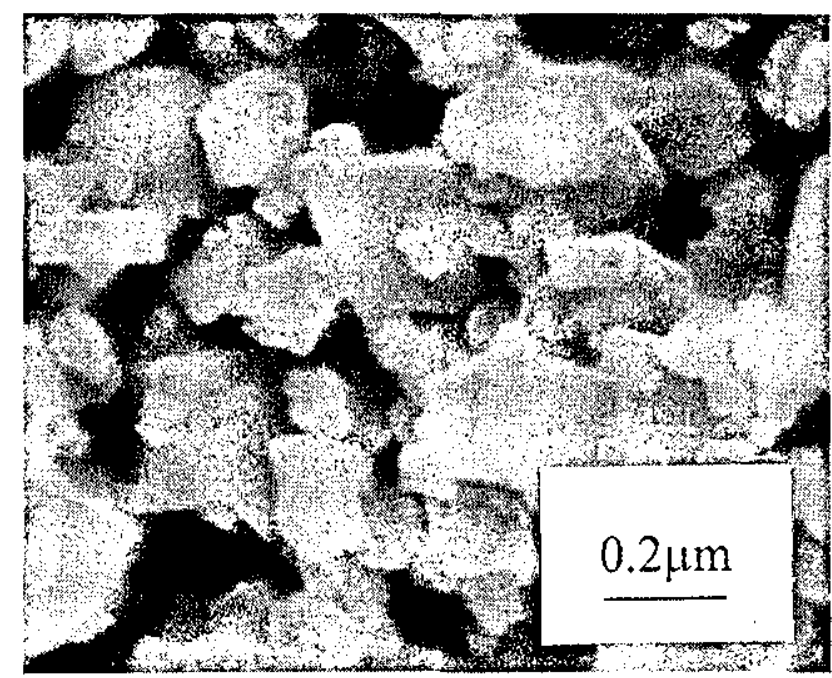

Plate 4.3: TEM image of Microfine A05 antimony trioxide particles.

The AZUB material had an average particle size of $0.10 \mu \mathrm{m}$. The sizing was carried out on material that was removed after milling but prior to the addition of the binder wax. Removing material at this stage created agglomerates and these can be seen in the second peak on the particle size curve (Figure 4.1). Larger agglomerates were also noted but have not been shown in the figure as the sizing process itself was later found to have created these agglomerates.

SEM analysis revealed that few of the larger agglomerates seen during sizing (approx. 1 $\mu \mathrm{m}$ diameter) were present in material that had been placed directly into the binder wax and then either pan or spray dried. In the case of the spray dried material it was shown that the binder wax usually formed as spheres and the antimony trioxide was located on the surface of these spheres (Plate 4.4). One of these spheres was isolated in the TEM (in SEM mode) and is shown in Plate 4.5. Higher magnification of the surface of this sphere reveals the presence of the sub-micron particles approximately $0.1 \mu \mathrm{m}$ diameter, as well as several larger particles $(0.2$ to $0.3 \mu \mathrm{m})$, which had been previously seen in Figure 4.1 (Plate 4.6). In contrast to the AZUB material is the image of a particle of flushed Red Star $\left(A Z U B^{R S}\right.$ ) as seen in Plate 4.7. The larger particles can be seen on the surface of the wax sphere. 


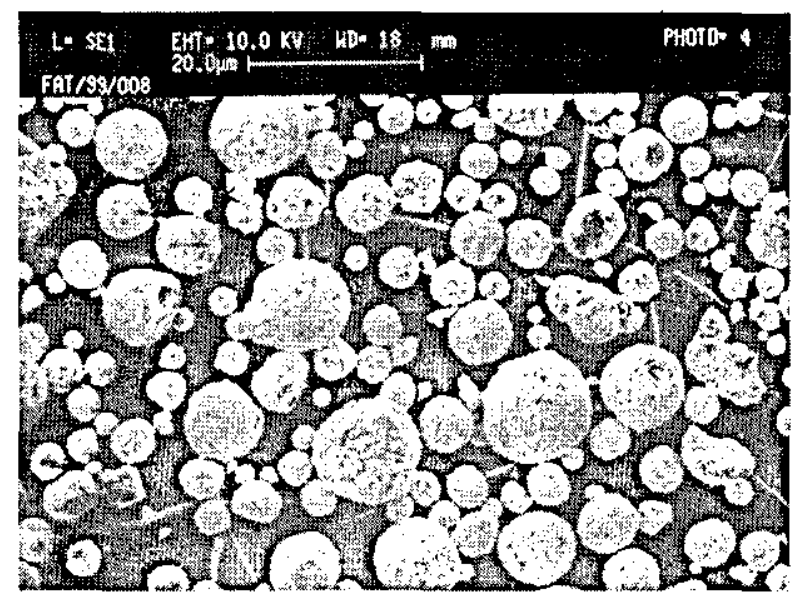

Plate 4.4: SEM image of spray dried AZUB material.

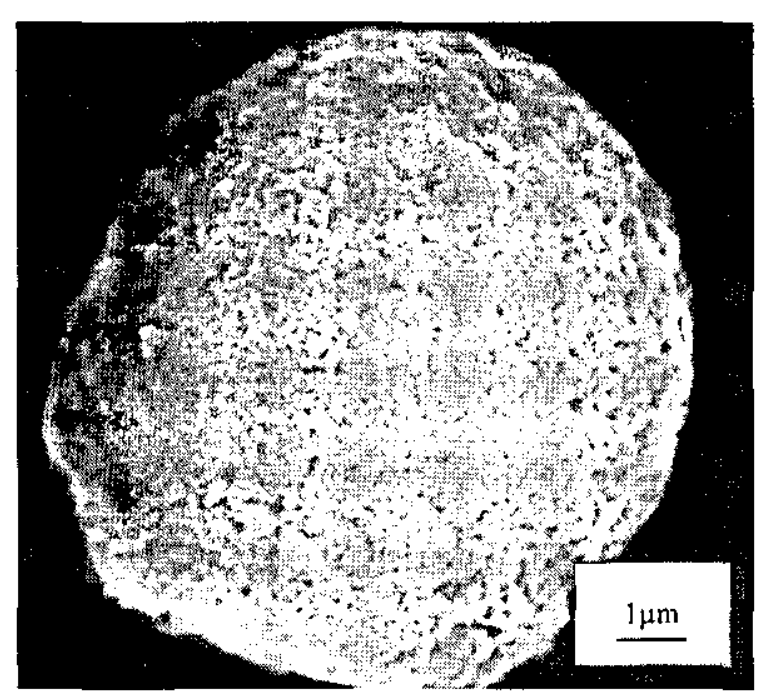

Plate 4.5: TEM image of a sphere of sAZUB material.

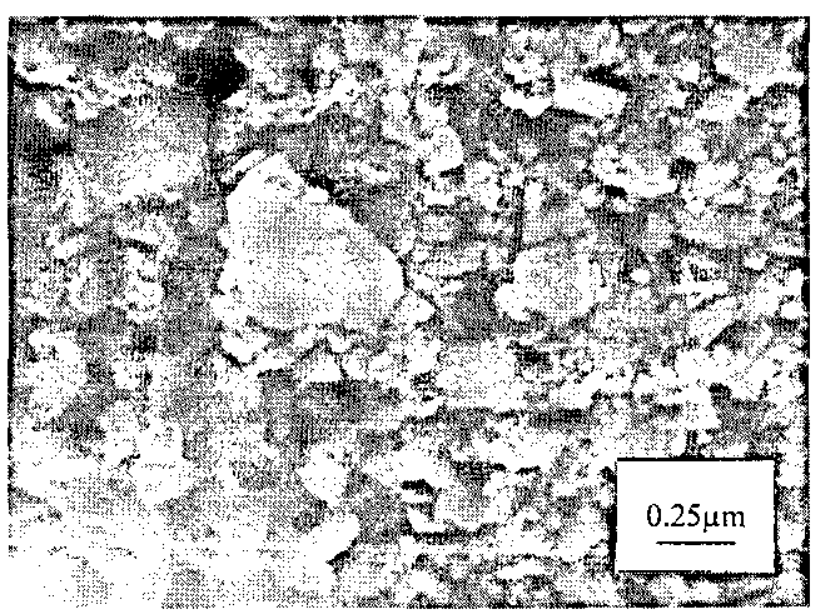

Plate 4.6: TEM image of sAZUB sphere surface. 


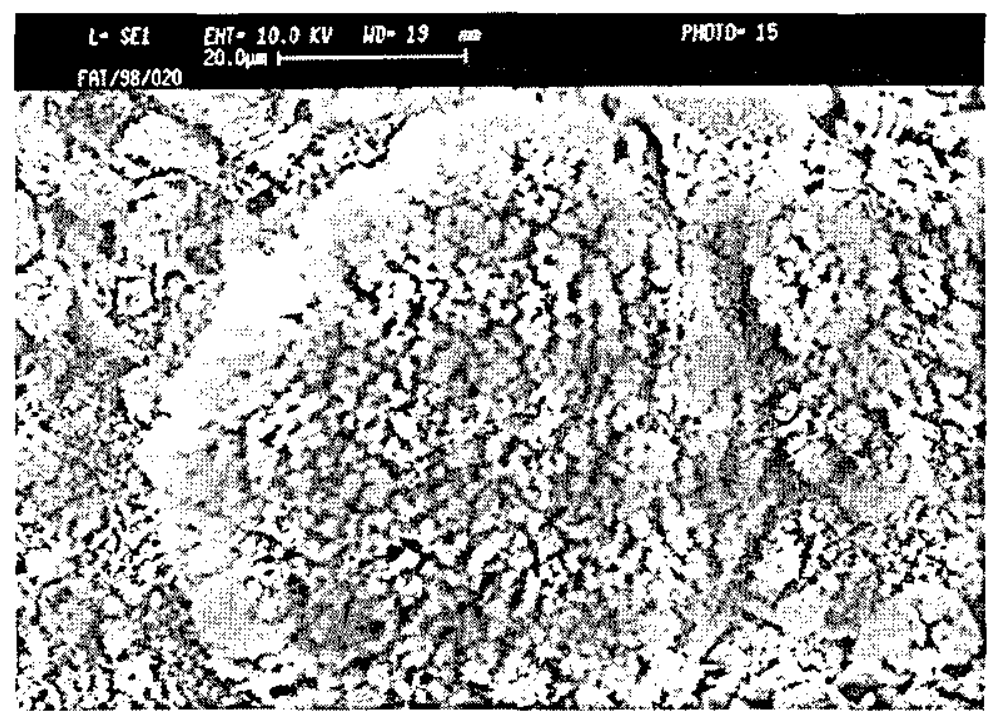

Plate 4.7: SEM image of particle of $A Z U B^{R S}$ material.

The spherical particles seen in Plates 4.4 to 4.6 were only typical of the spray drying process whilst the pan drying process produced more angular particles (Plate 4.8). At higher magnification in the TEM, the large irregular wax particle is also covered by submicron $\mathrm{Sb}_{2} \mathrm{O}_{3}$ with the particles appearing to be more embedded in the wax than $\mathrm{SAZUB}$ (Plate 4.9).

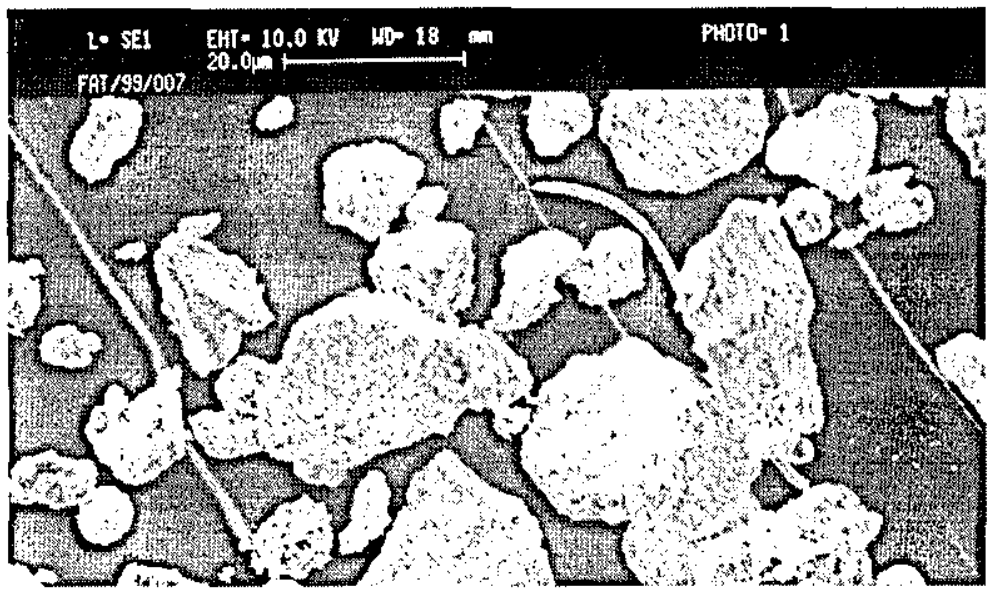

Plate 4.8: SEM image of pan dried AZUB material. 


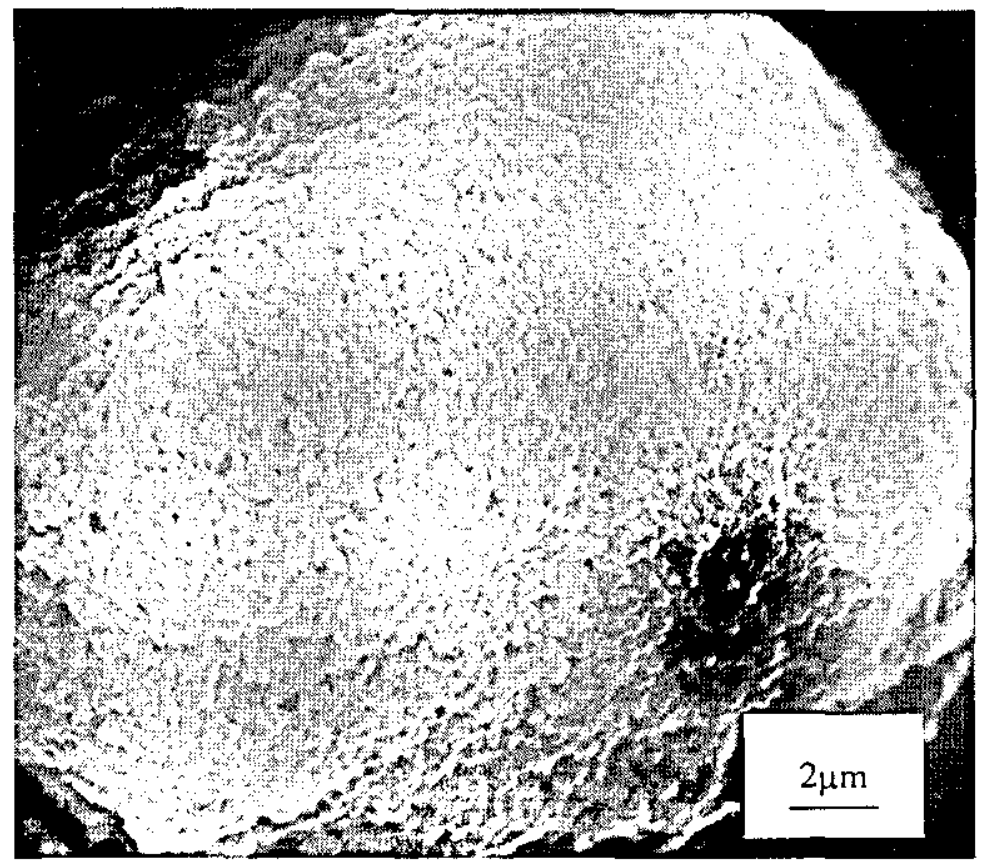

Plate 4.9: TEM image of pan dried AZUB material.

Imaging was difficult due to the size of the particles and the poorly defined edges. At higher magnifications it was still possible to see that the average size of the particles was approximately $0.1 \mu \mathrm{m}$, which agreed with the sizing data. SEM analysis of both the AZUB grades was also complicated by the fact that the soft wax led to charging of the sample due to penetration of the electrons into the sample.

The bulk density of the three grades (Table 4.1) did not appear to follow any trend. It must be noted that the AZUB material was tested using the material containing castor wax. Testing of this material was therefore not done under the same conditions as for the other antimony trioxide materials. The oil absorption results did show more of a trend with increasing absorption occurring with decreasing particle size.

\subsubsection{Brominated Halogens}

Four brominated materials have been used in this work and these were BTBPE FF-680, TBBA BA-59P, DBDPO DE-83R and a new milled DBDPO grade (sDBDPO). These have been analysed to look at the bromine content as well as the morphology and thermal degradation properties. Due to the fact that two of the bromines were melt 
blendable no particle sizing was carried out on these products. Earlier work by Owen [76], which previously looked at bulk density for these grades, is also quoted (Table 4.2). Both the work by Owen as well as the work in this thesis used material from the same bag(s).

Table 4.2: Characterisation of brominated halogen grades.

\begin{tabular}{|l|c|c|}
\hline $\begin{array}{l}\text { Brominated halogen } \\
\text { grade }\end{array}$ & $\begin{array}{c}\text { Bulk density }(\mathrm{g} / \mathrm{ml}) \\
\text { Loose (Tapped) [Owen] }\end{array}$ & $\begin{array}{c}\text { Specific gravity } \\
\text { (company data) }\end{array}$ \\
\hline BTBPE & $0.96(1.17)[1.19]$ & 2.6 \\
TBBA & $0.70(1.66)[1.68]$ & 2.2 \\
DBDPO & $1.07(1.72)[\mathrm{NA}]$ & 3.3 \\
\hline
\end{tabular}

Analysis of the active bromine contents of the four grades supplied was carried out to compare against the quoted values of the manufacturers. The literature values supplied were averages of all the batches produced by the company whilst the analysed values were specific to the batch used in the work. These are shown in Table 4.3 and it can be seen that there was slightly less bromine than expected in the supplied material for all the grades.

Table 4.3: Bromine contents of brominated halogen grades.

\begin{tabular}{|l|c|c|}
\hline $\begin{array}{l}\text { Brominated halogen } \\
\text { grade }\end{array}$ & $\begin{array}{c}\text { Bromine content } \\
(\%)\end{array}$ & $\begin{array}{c}\text { Bromine content (\%) } \\
\text { [literature] }\end{array}$ \\
\hline BTBPE & $68.3(-2.5 \%)$ & 70.0 \\
TBBA & $57.0(-3.2 \%)$ & 58.8 \\
DBDPO & $80.7(-2.6 \%)$ & 83.3 \\
sDBDPO & $80.7(-2.6 \%)$ & 83.3 \\
\hline
\end{tabular}

Morphological analysis of the DBDPO grades revealed the presence of large, angular

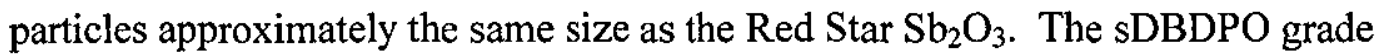
originated from the standard material but was milled in an attempt to reduce the particle size. SEM images showed that little or no reduction in size occurred with only the extreme edges of the original particles having been removed. The spray dried material formed spheres as with the SAZUB (Plate 4.10), but many of the DBDPO particles 
appeared to be surrounded by the castor wax. Some particles were still located on the surface (Plate 4.11).

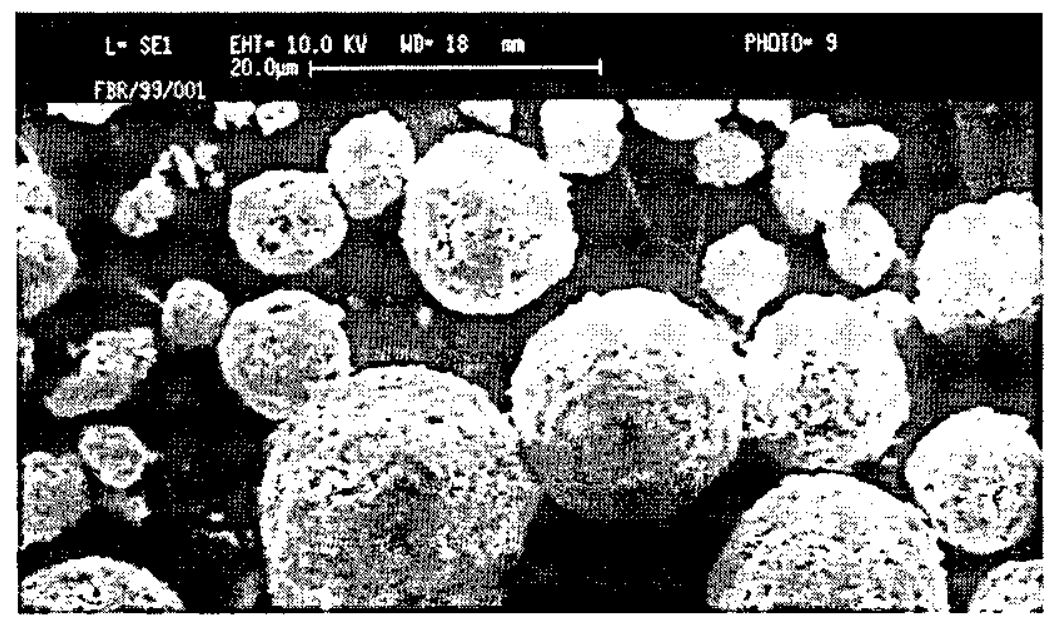

Plate 4.10: SEM image of spray dried DBDPO material.

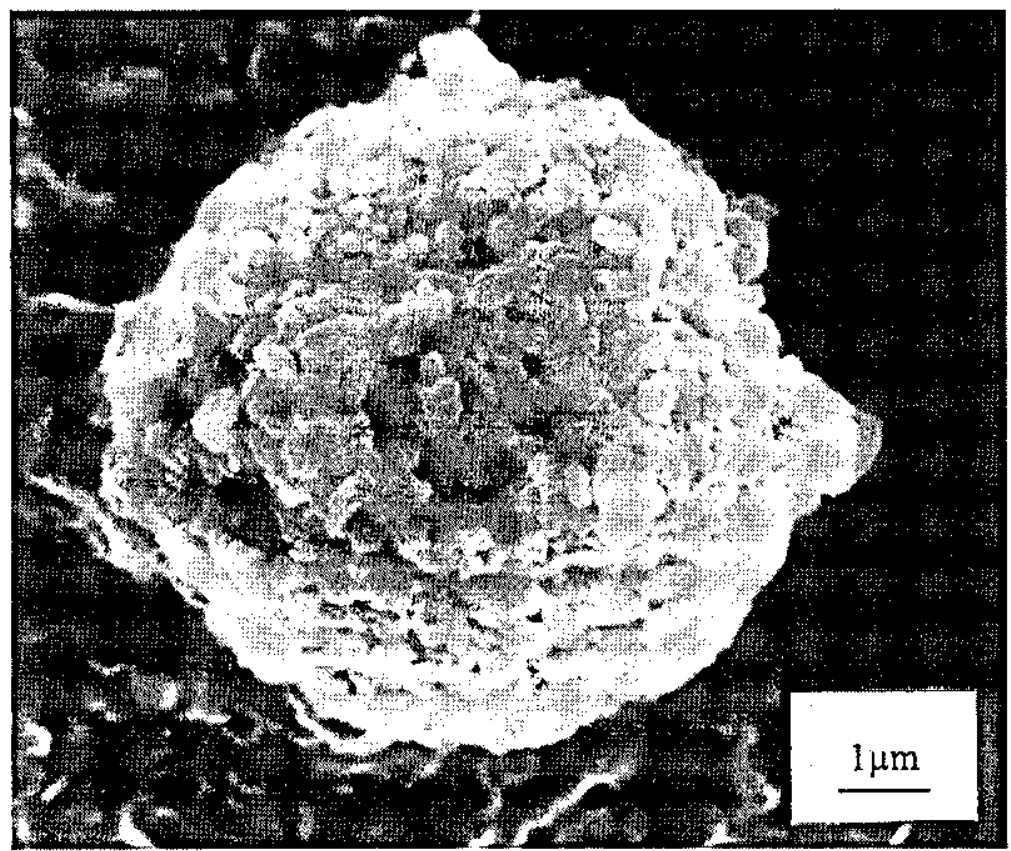

Plate 4.11: TEM image of a sphere with sDBDPO material. 
TGA analysis looked at the thermal degradation properties of the four bromines. The results are shown in Table 4.4 along with the manufacturers published values.

Table 4.4: TGA mass loss data for brominated halogen grades.

\begin{tabular}{|l|c|c|c|c|c|c|}
\hline $\begin{array}{l}\text { Brominated halogen } \\
\text { grade }\end{array}$ & \multicolumn{3}{|c|}{ Mass loss $\left({ }^{\circ} \mathrm{C}\right)$} & \multicolumn{3}{|c|}{$\begin{array}{c}\text { Mass loss }\left({ }^{\circ} \mathrm{C}\right) \\
\text { [literature] }\end{array}$} \\
\hline & $\mathrm{T}_{5 \%}$ & $\mathrm{~T}_{10 \%}$ & $\mathrm{~T}_{50 \%}$ & $\mathrm{~T}_{5 \%}$ & $\mathrm{~T}_{10 \%}$ & $\mathrm{~T}_{50 \%}$ \\
\hline BTBPE & 252 & 263 & 299 & 276 & 291 & 329 \\
TBBA & 215 & 227 & 260 & 244 & 261 & 304 \\
DBDPO & 293 & 304 & 342 & 326 & 341 & 384 \\
sDBDPO & 290 & 301 & 340 & - & - & - \\
\hline
\end{tabular}

It can be seen that for all the materials the manufacturers values were somewhat higher than the results for this research. The BTBPE was seen to be thermally stable to higher temperatures before onset of degradation. The mass loss curves are shown in Figure 4.2 .

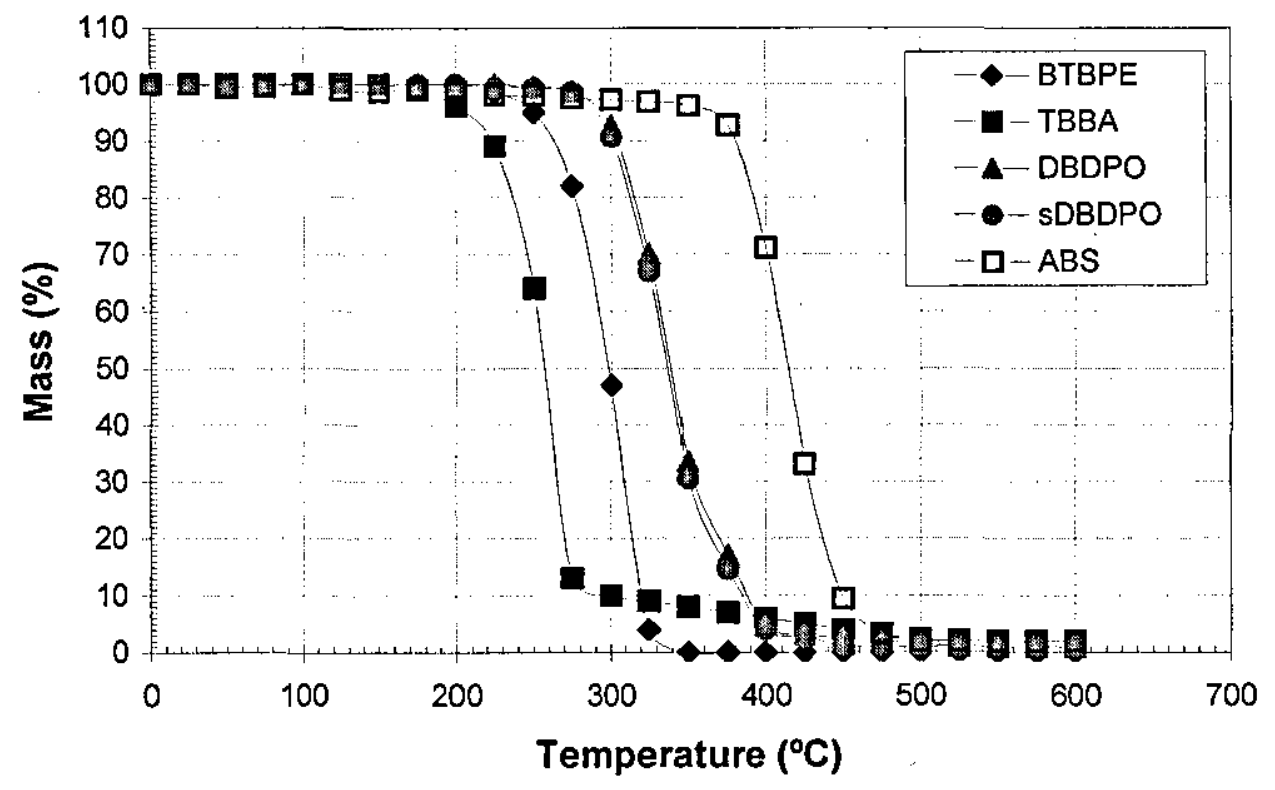

Figure 4.2: TGA curves for brominated materials (and ABS control). 


\subsection{Analysis of Unfilled ABS Compounds}

Each batch of formulations compounded during the project was produced alongside a control of unfilled ABS. These controls underwent identical processing and injection moulding conditions as described in Section 3.3 and are discussed in this section.

\subsubsection{Mechanical Properties}

Impact and flexural testing of notched bars from six unfilled controls gave peak force, peak energy, failure energy, flexural modulus and flexural strength values as shown in Table 4.5.

The results in Table 4.5 show that there were differences in values between the six unfilled ABS controls. The spread of results were not significantly different for the six controls, but differences were significant when the controls were compared to the rest of the compounds. This meant that it was not possible to use the average of the six controls as a reference to compare all other compounds against. All the compounds tested have therefore been compared against the relevant ABS control.

Table 4.5: Mechanical properties of unfilled ABS controls.

\begin{tabular}{|c|c|c|c|c|c|}
\hline Control & $\begin{array}{c}\text { Peak } \\
\text { Force } \\
(\mathrm{N})\end{array}$ & $\begin{array}{c}\text { Peak } \\
\text { Energy } \\
(\mathrm{J})\end{array}$ & $\begin{array}{c}\text { Failure } \\
\text { Energy } \\
(\mathrm{J})\end{array}$ & $\begin{array}{c}\text { Flexural } \\
\text { Modulus } \\
(\mathrm{MPa})\end{array}$ & $\begin{array}{c}\text { Flexural } \\
\text { Strength } \\
(\mathrm{MPa})\end{array}$ \\
\hline C1 & $924(23)$ & $0.80(0.05)$ & $1.09(0.05)$ & $2261(19)$ & $66.0(0.4)$ \\
C2 & $958(44)$ & $0.80(0.04)$ & $1.06(0.05)$ & $2144(48)$ & $65.2(0.7)$ \\
C3 & $979(37)$ & $0.84(0.04)$ & $1.11(0.05)$ & $2258(08)$ & $64.9(0.3)$ \\
C4 & $985(19)$ & $0.84(0.04)$ & $1.12(0.05)$ & $2223(44)$ & $67.4(0.8)$ \\
C5 & $969(51)$ & $0.81(0.04)$ & $1.08(0.06)$ & $2280(23)$ & $65.4(0.7)$ \\
C6 & $986(27)$ & $0.83(0.02)$ & $1.12(0.04)$ & $2145(63)$ & $63.3(0.3)$ \\
\hline AVG. & $967(34)$ & $0.82(0.04)$ & $1.10(0.05)$ & $2219(34)$ & $65.4(0.5)$ \\
\hline
\end{tabular}

Analysis of the fracture surfaces of these samples showed a relatively smooth surface with occasional large cavities (Plates 4.12 and 4.13). Stress whitening of the samples was seen across the face of the fracture surfaces. These varied in depth from $1 \mathrm{~mm}$ to 3 $\mathrm{mm}$. Scanning electron microscopic analysis showed ductile fracture behaviour in the samples. 


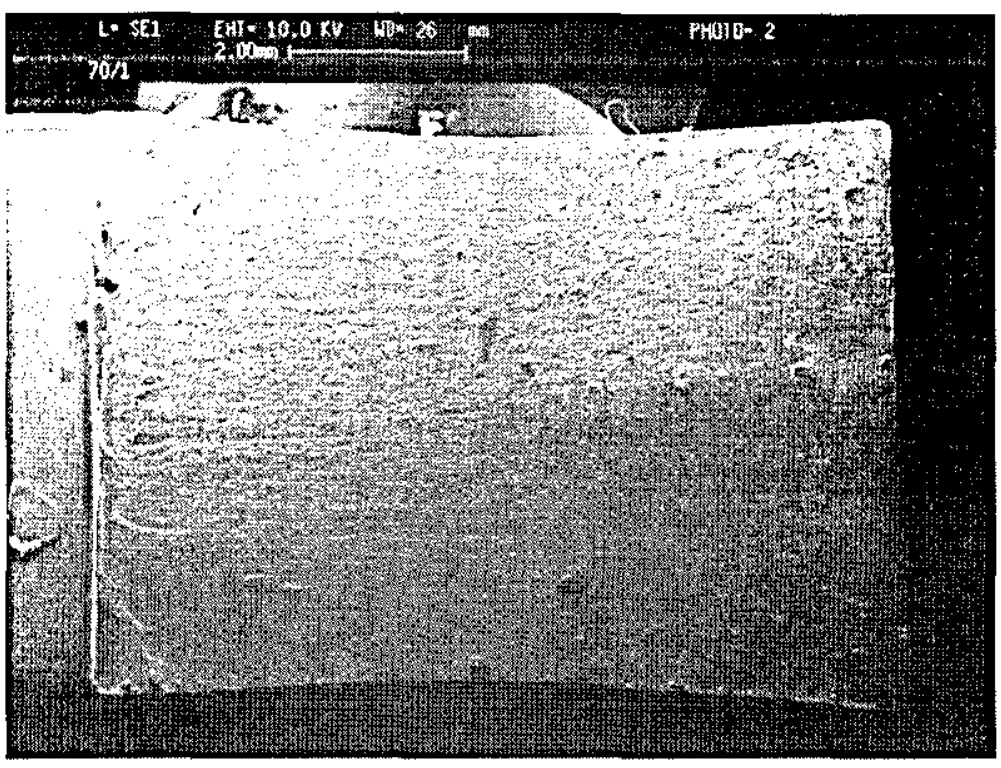

Plate 4.12: SEM image of unfilled ABS control.

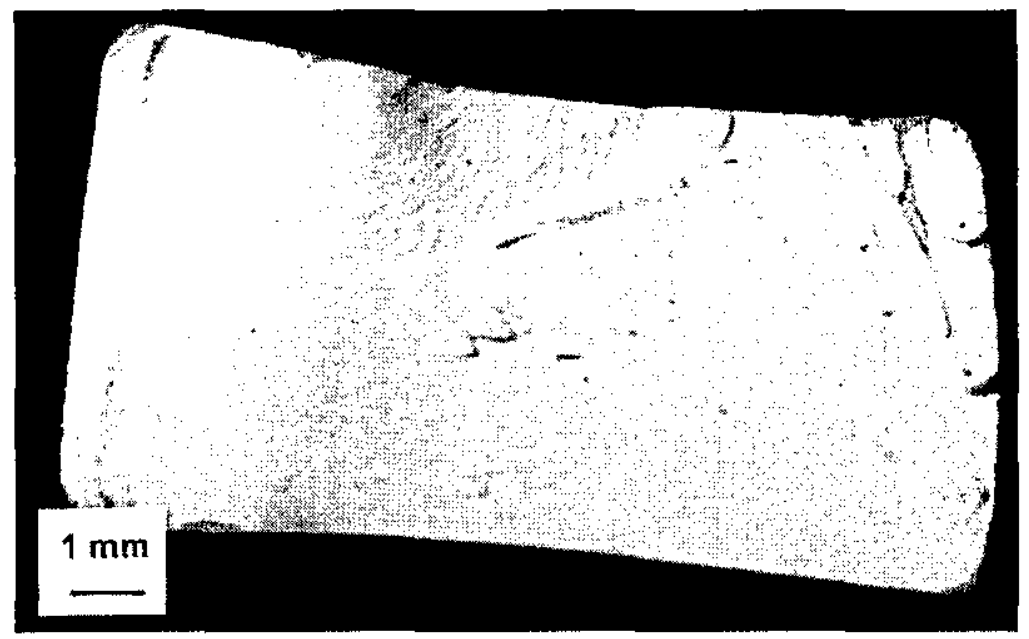

Plate 4.13: Optical microscope image of unnotched ABS control.

The optical microscope image (Plate 4.13) of an unnotched sample (sample impacted on the left side of the image; crack propagated from right) shows the large amount of plastic deformation occurring within the sample.

TEM analysis used stained sections from both within the stress-whitened area and away from the impacted zone. The first sectioning looked at the energy absorption mechanisms that occurred within this zone and crazing was seen throughout this sample 
(Plate 4.14). The crazes tended to originate from the larger particles but would terminate at any sized particle (Plate 4.15). Several crazes were seen to originate from some of the larger particles and appeared unaffected by the presence of the smaller butadiene particles (Plate 4.16). Cavitation of many butadiene particles was also seen throughout the sample. The sample taken from an area away from the stress whitened zone was used to compare against the sectioning of the 'as supplied' ABS pellets. The morphology of the compounded ABS was identical to that of the 'as supplied' ABS.

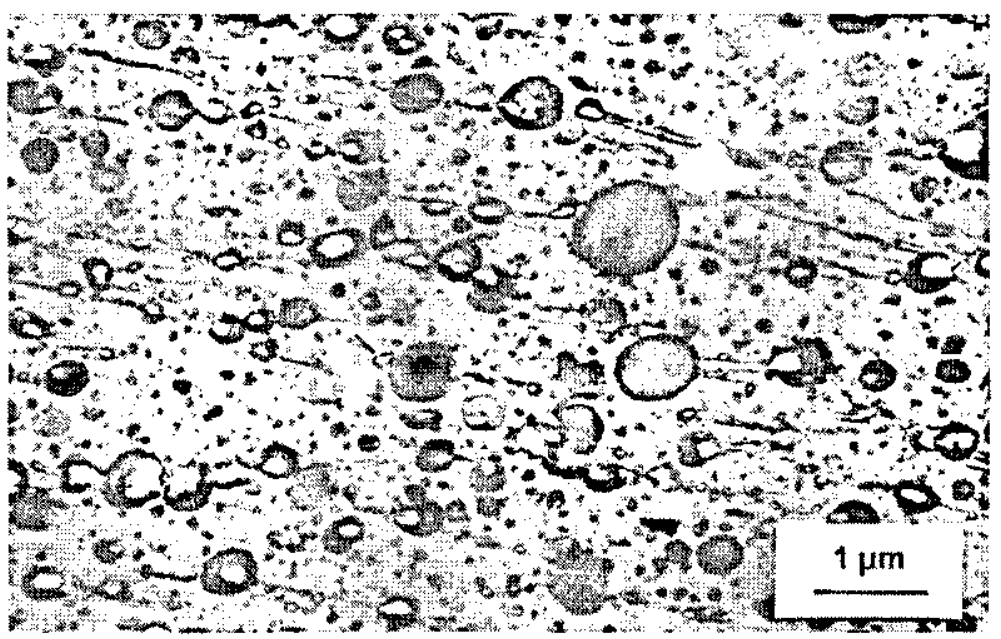

Plate 4.14: TEM image of stress-whitened zone in unfilled ABS.

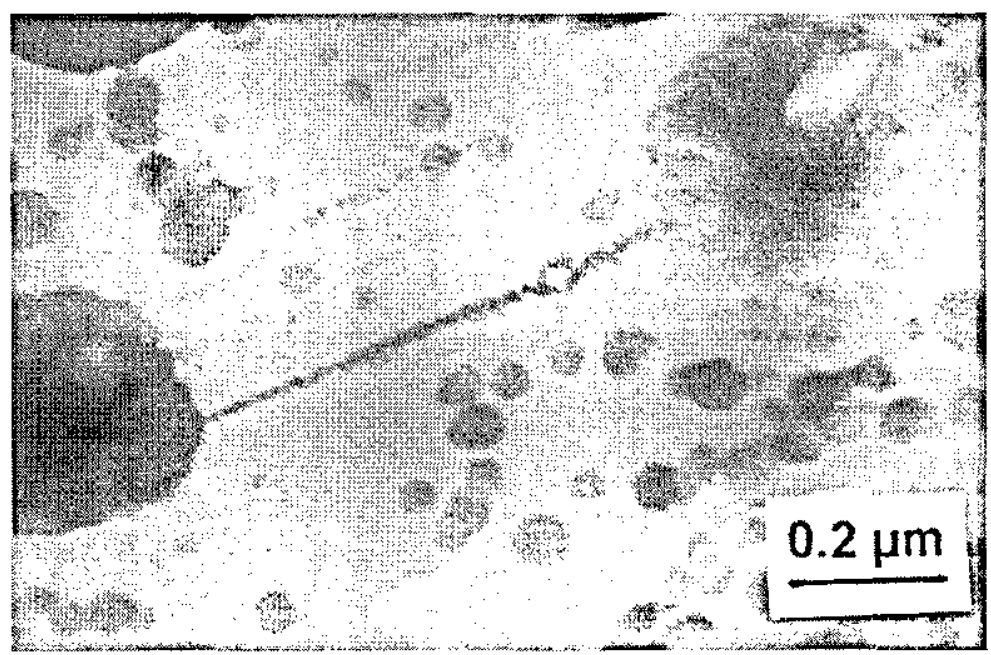

Plate 4.15: TEM image of crazing between larger butadiene particles. 


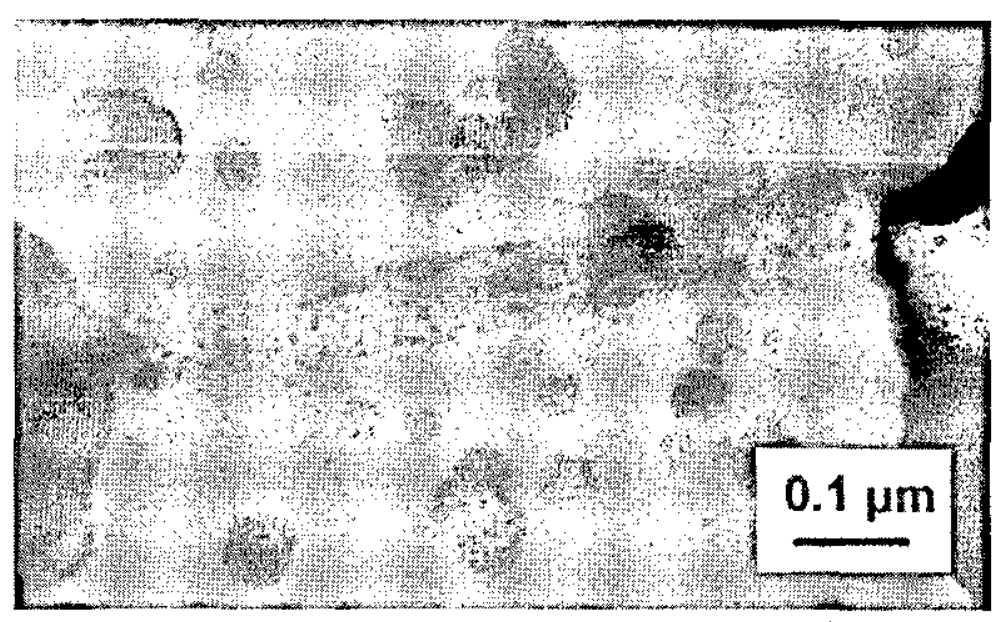

Plate 4.16: TEM image of crazing between larger butadiene particles.

\subsubsection{Thermogravimetric Analysis}

Figure 4.3 shows the thermograms for both the 'as supplied' ABS and the compounded unfilled ABS.

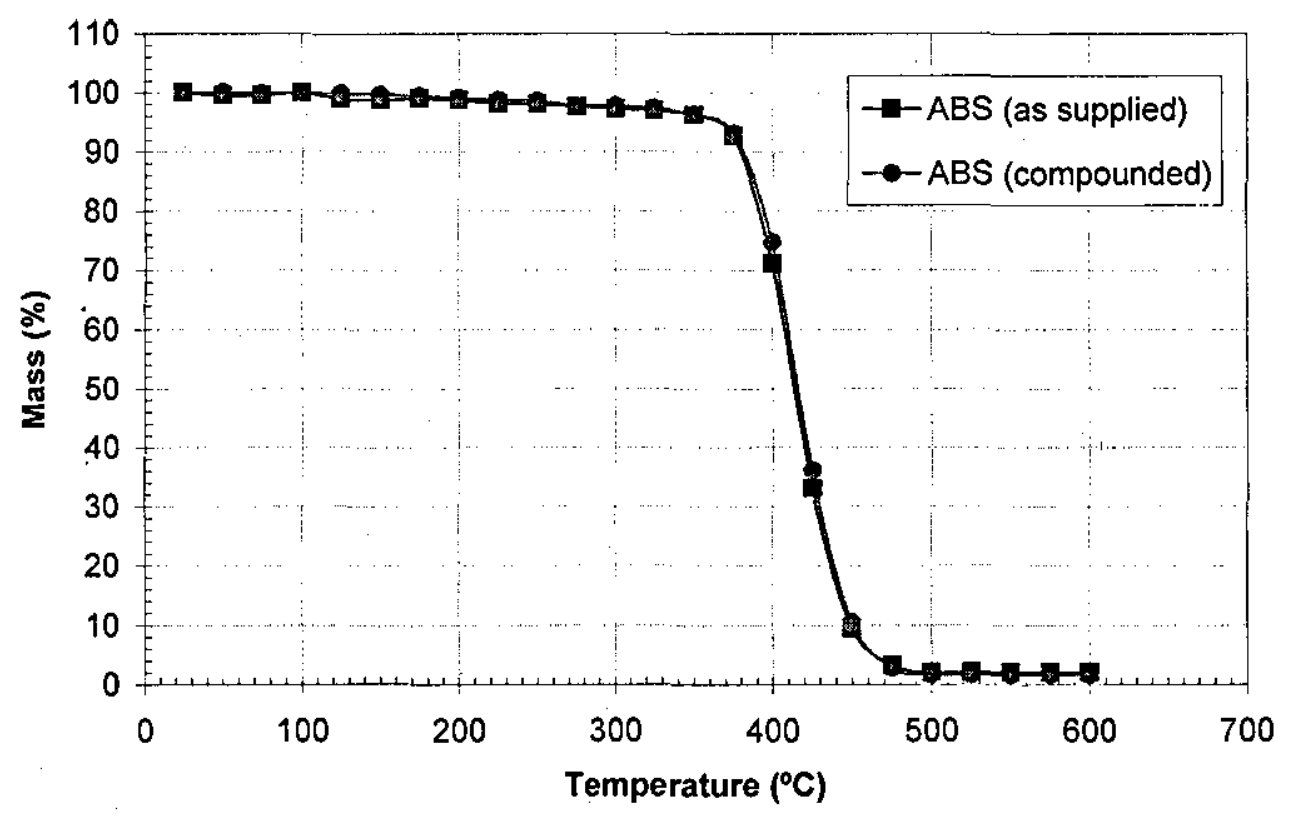

Figure 4.3: TGA curves for ABS before and after compounding.

The curves are identical with a $3 \%$ loss in weight at $300^{\circ} \mathrm{C}$. By $450^{\circ} \mathrm{C}$ there was an $80 \%$ loss in mass. Mass loss was completed by $500{ }^{\circ} \mathrm{C}$ in both samples. 


\subsubsection{Limited Oxygen Index (LOI)}

LOI testing was carried out for the ABS, which gave a result of 18.6. UL-94 testing was carried out with the ABS achieving a FAIL classification. The samples continued to burn after the first flame application and then engulfed the entire sample up to the clamp. Combustion ceased after all the sample below the clamp was fully burnt. In some cases the samples dripped, due to the sample softening and stretching under their own weight, which always then ignited the cotton wool. This was expected but testing was carried out to provide a basis with which to compare all other formulations.

\subsection{Influence of Antimony Trioxide Particle Size (direct addition)}

\subsubsection{Compounding}

Table 4.6 shows the results obtained during compounding of the formulations containing various grades of $4 \mathrm{wt} \% \mathrm{Sb}_{2} \mathrm{O}_{3}$, as well as a control containing castor wax only. This was loaded at a level comparable to that found in the AZUB materials. The differences seen were due to the compounds being processed at different times. Slight fluctuations from one series to another give the results seen in the table. There are no clear trends but there does appear to be slightly lower die pressures for the AZUB materials.

Table 4.6: Influence of $\mathrm{Sb}_{2} \mathrm{O}_{3}$ particle size (and castor wax) on compounding.

\begin{tabular}{|c|c|c|c|c|c|}
\hline No & $\begin{array}{c}\mathrm{Sb}_{2} \mathrm{O}_{3} \\
\text { grade }\end{array}$ & $\begin{array}{c}\text { Particle size } \\
\mathrm{d}_{50}(\mu \mathrm{m})\end{array}$ & $\begin{array}{c}\text { Torque } \\
(\%)\end{array}$ & $\begin{array}{c}\text { Die pressure } \\
(\mathrm{MPa})\end{array}$ & $\begin{array}{c}\text { Die pressure } \\
(\% \text { of ABS control) }\end{array}$ \\
\hline $\mathbf{1}$ & $\mathrm{RS}$ & 1.31 & 85 & 3.72 & $104 \%$ \\
$\mathbf{2}$ & $\mathrm{A} 05$ & 0.52 & 74 & 2.72 & $100 \%$ \\
$\mathbf{3}$ & $\mathrm{AZUB}^{(\mathrm{RS})}$ & 1.18 & 75 & 3.59 & $100 \%$ \\
$\mathbf{4}$ & $\mathrm{pAZUB}$ & 0.11 & 53 & 2.48 & $91 \%$ \\
$\mathbf{5}$ & sAZUB & 0.11 & 75 & 2.41 & $97 \%$ \\
$\mathbf{6}$ & Castor wax & - & 80 & 1.65 & $92 \%$ \\
\hline
\end{tabular}




\subsubsection{Mechanical Properties}

\section{Impact Properties}

Table 4.7 and Figure 4.4 show the effect that the different particle sized antimony trioxide grades had on the impact properties. The values have been generated as percentages of the values relative to the unfilled ABS control for each compound. The total impact failure energy of the compounds increased as the average particle decreased. The compounds containing $4 \mathrm{wt} \%$ (0.75 vol.\%) $1.31 \mu \mathrm{m}$ RS had failure energies approximately $30 \%$ lower than those of unfilled ABS. Addition of $0.52 \mu \mathrm{m}$ A05 resulted in a failure energy $25 \%$ lower than unfilled ABS. This compound had a higher percentage of $\mathrm{Sb}_{2} \mathrm{O}_{3}$ than others $(5.49 \mathrm{wt} \%)$ and this may have contributed to the fact that the properties were only slightly better than RS.

The AZUB materials all used A05 as the base material for their production except compound 3 which used Red Star $\left(\mathrm{AZUB}^{\mathrm{RS}}\right)$. The manufacturing process used a pan drying method for all compounds except for formulation 5 which used a spray drying technique (sAZUB).

Table 4.7: Impact properties of $\mathrm{Sb}_{2} \mathrm{O}_{3}$ filled compounds.

\begin{tabular}{|c|c|c|c|c|c|}
\hline No. & Description & $\begin{array}{c}\mathrm{Sb}_{2} \mathrm{O}_{3} \\
\text { content } \\
(\text { wt\%) }\end{array}$ & $\begin{array}{c}\text { Peak } \\
\text { Force } \\
(\%)\end{array}$ & $\begin{array}{c}\text { Peak } \\
\text { Energy } \\
(\%)\end{array}$ & $\begin{array}{c}\text { Failure } \\
\text { Energy } \\
(\%)\end{array}$ \\
\hline $\mathbf{1}$ & $\mathrm{RS}$ & 4.10 & $82(1)$ & $57(2)$ & $68(4)$ \\
$\mathbf{2}$ & $\mathrm{A} 05$ & 5.49 & $92(2)$ & $71(5)$ & $76(4)$ \\
$\mathbf{3}$ & $\mathrm{AZUB}^{(\mathrm{RS})}$ & 3.85 & $\mathbf{8 2}(2)$ & $63(11)$ & $73(4)$ \\
$\mathbf{4}$ & pAZUB & 4.93 & $98(2)$ & $94(6)$ & $93(4)$ \\
$\mathbf{5}$ & sAZUB & 3.45 & $99(4)$ & $99(5)$ & $98(4)$ \\
$\mathbf{6}$ & Castor wax & - & $98(3)$ & $98(4)$ & $99(4)$ \\
\hline
\end{tabular}

The AZUB ${ }^{(\mathrm{RS})}$ grade had similar failure energy values to the standard RS. Table 4.6 shows that the $A Z U B{ }^{(R S)}$ grade average particle size was approximately $1.18 \mu \mathrm{m}$. Four AZUB grades (A05 base) had failure energies between 93 to $95 \%$ that of unfilled ABS. The final grade of AZUB (5) using the spray drying method showed a drop in properties of only $2 \%$ with an $\mathrm{Sb}_{2} \mathrm{O}_{3}$ loading of $3.45 \mathrm{wt} \%$. The presence of the castor wax only (6) had no significant effect on the impact properties. 


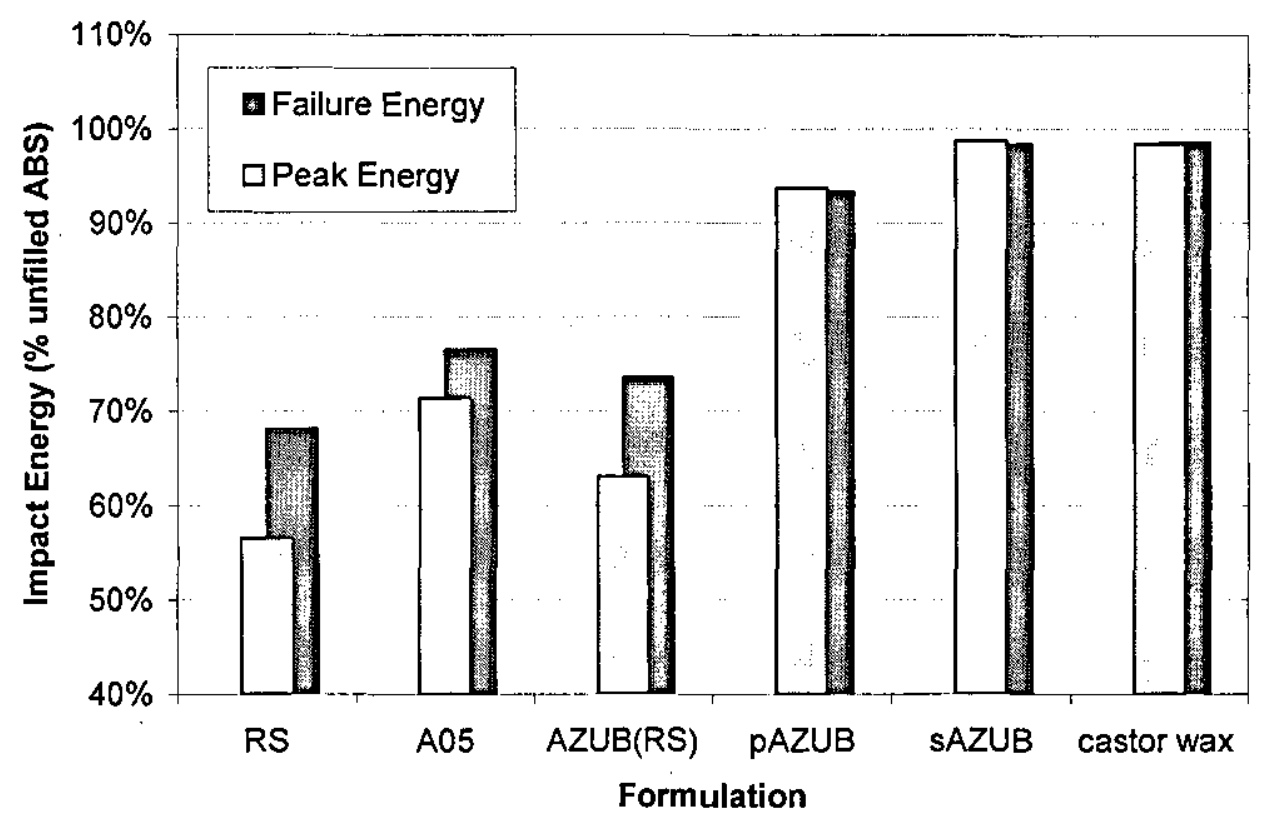

Figure 4.4: Influence of $\mathrm{Sb}_{2} \mathrm{O}_{3}$ particle size on impact properties (\% ABS)

\section{Flexural Properties}

The flexural modulus and strength values for these formulations are shown in Table 4.8 and Figure 4.5. The modulus of all the formulations fluctuated around the unfilled ABS value with no clear trends being seen. The RS compound had a similar modulus but reduced strength compared to unfilled ABS. The A05 had a slightly higher modulus than RS with a similar strength value.

Table 4.8: Flexural properties of $\mathrm{Sb}_{2} \mathrm{O}_{3}$ filled compounds.

\begin{tabular}{|c|c|c|c|c|c|}
\hline No. & Description & $\begin{array}{c}\mathrm{Sb}_{2} \mathrm{O}_{3} \\
\text { content } \\
\text { (wt\%) }\end{array}$ & $\begin{array}{c}\text { Deflection @ } \\
\text { max load } \\
(\mathrm{mm})\end{array}$ & $\begin{array}{c}\text { Flexural } \\
\text { Modulus } \\
(\%)\end{array}$ & $\begin{array}{c}\text { Flexural } \\
\text { Strength } \\
(\%)\end{array}$ \\
\hline $\mathbf{1}$ & $\mathrm{RS}$ & 4.10 & $101(26)$ & $101(0)$ & $92(1)$ \\
$\mathbf{2}$ & $\mathrm{A} 05$ & 5.49 & $94(7)$ & $100(1)$ & $96(1)$ \\
$\mathbf{3}$ & $\mathrm{AZUB}$ & $90(8)$ & $99(0)$ & $88(1)$ \\
$\mathbf{4}$ & pAZUB & 4.85 & $110(33)$ & $99(2)$ & $96(1)$ \\
$\mathbf{5}$ & sAZUB & 3.45 & $97(27)$ & $101(2)$ & $98(1)$ \\
$\mathbf{6}$ & Castor wax & - & $106(23)$ & $97(2)$ & $95(1)$ \\
\hline
\end{tabular}


The AZUB ${ }^{(\mathrm{RS})}$ formulation had a similar modulus value but a much lower flexural strength than the preceding compounds. Both the pan dried and spray dried AZUB materials had similar modulus and strength values as the A05 formulation. Analysis of the deflection at maximum load does not show any clear trend. Compounds 1,2 and 3 (with the larger particle sizes) appear to reduce the deflection more than the other compounds. However the large deviations do not allow any further analysis.

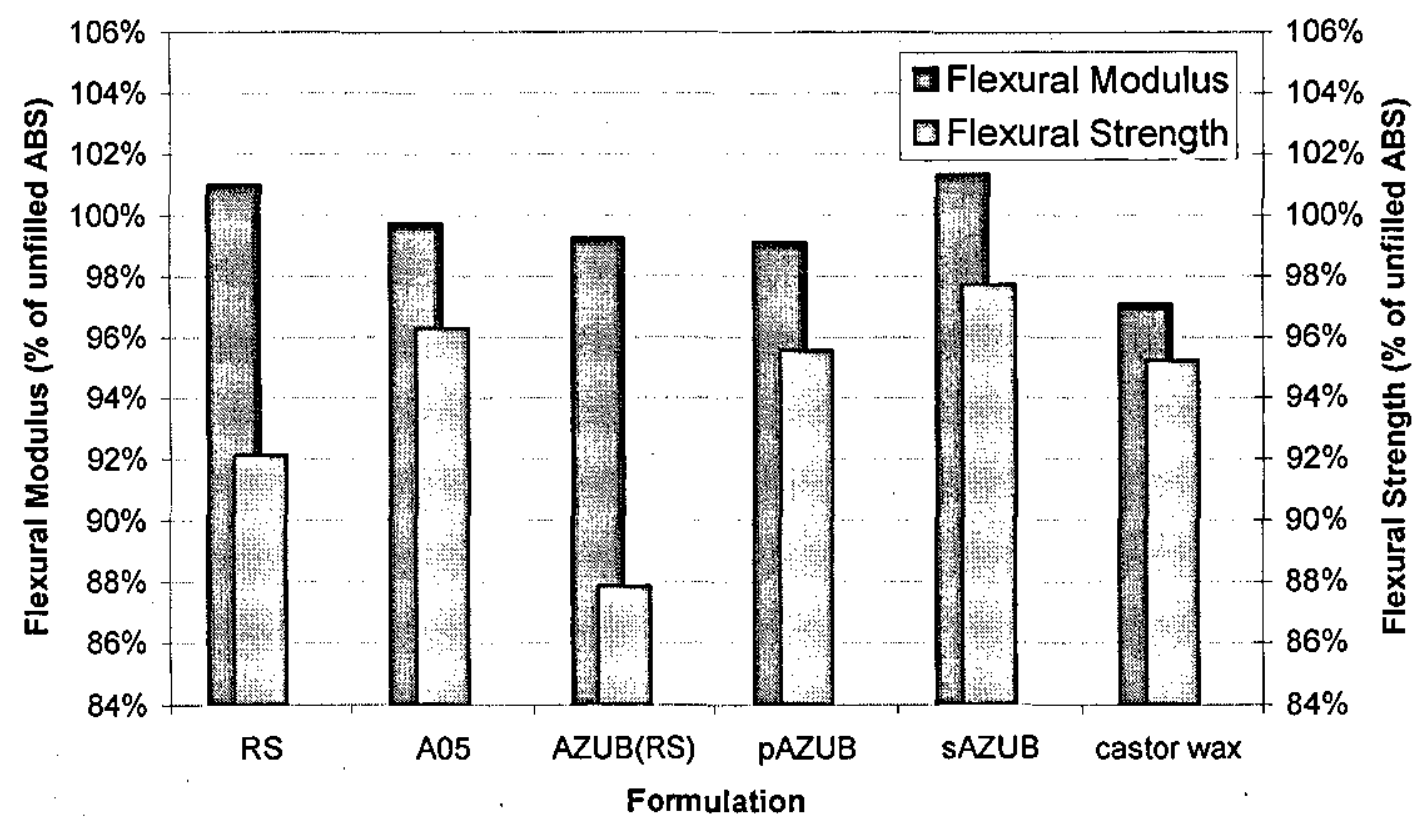

Figure 4.5: Influence of $\mathrm{Sb}_{2} \mathrm{O}_{3}$ particle size on flexural properties.

\subsubsection{Microscopy Analysis}

\section{Dispersion}

Samples from all the compounds were analysed on both the SEM and TEM and it was seen that generally the dispersion was good. Particles of the $\mathrm{RS}$ and $\mathrm{A} 05 \mathrm{Sb}_{2} \mathrm{O}_{3}$ grades could be seen on the fracture surfaces of the samples in the SEM using the back scattering electron analyser. Due to the much smaller size of the AZUB particles (excluding $\mathrm{AZUB}^{(\mathrm{RS})}$ ) it was more difficult to analyse individual particles using the back scatter method. A 'blanket' effect was seen across the sample indicating good dispersion, however analysis of individual particles was difficult due to the limiting SEM resolution. 


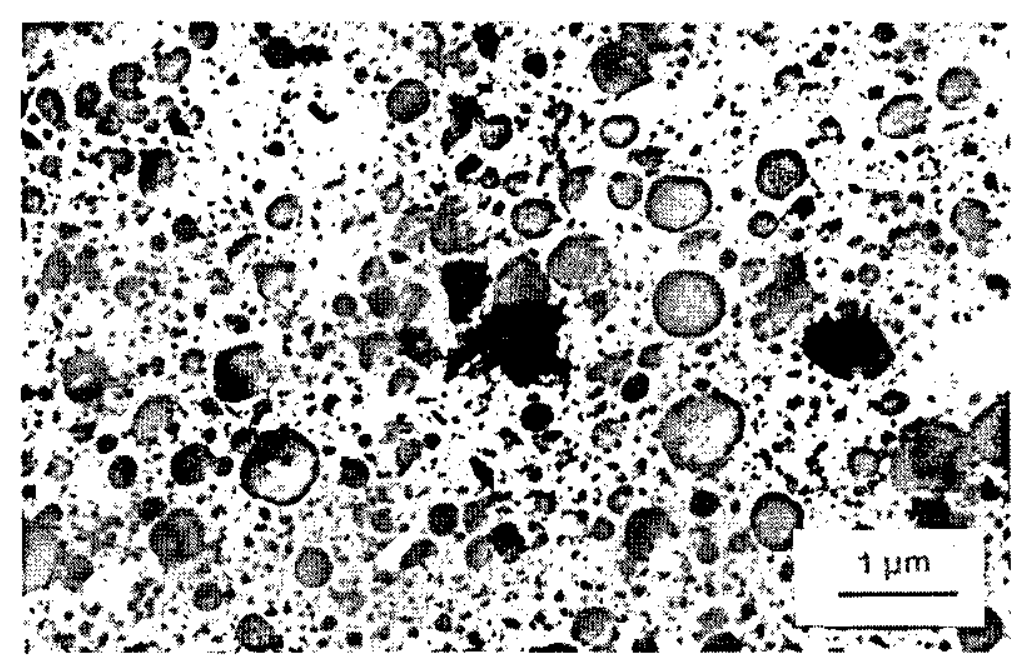

Plate 4.17: $T E M$ image of $A Z U B^{(R S)}$ dispersed in $A B S$.

TEM analysis of all the grades showed that the antimony trioxide was located in the SAN phase. Compounds were analysed across a large percentage of the sample to enable visual analysis of the particle dispersion and the effect of compounding on particle size. Plate 4.17 shows the $\mathrm{AZUB}^{(\mathrm{RS})}$ formulation and a slight reduction in size of the RS particles can be seen. The spray dried and pan dried AZUB materials appeared identical and an example of these can be seen in Plate 4.18. Both images show the presence of the antimony trioxide in the SAN phase.

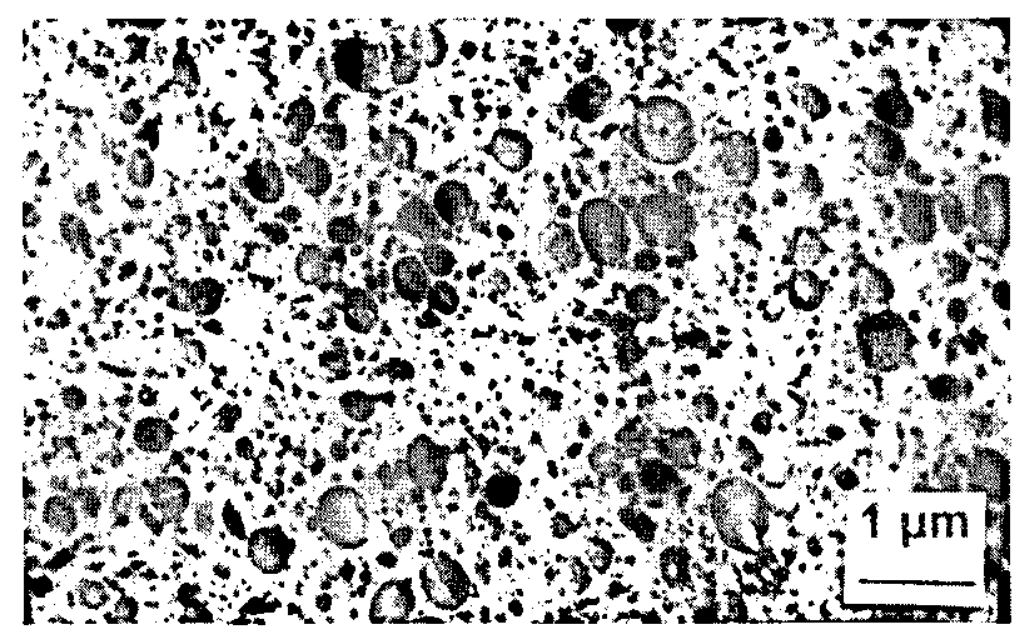

Plate 4.18: TEM image of sAZUB material dispersed in ABS. 


\section{Fracture}

Analysis of the fracture surfaces showed that the larger particle sizes created a coarser surface. In all cases the antimony trioxide particles did not appear to show any interaction with the polymer matrix. In the majority of cases the visible particles were located within cavities that had pulled away from the particle slightly. In some cases (most notably with compounds containing RS and A05) there were agglomerates of material located within parabolic craters. Plate 4.19 shows one of these agglomerates of A05 material.

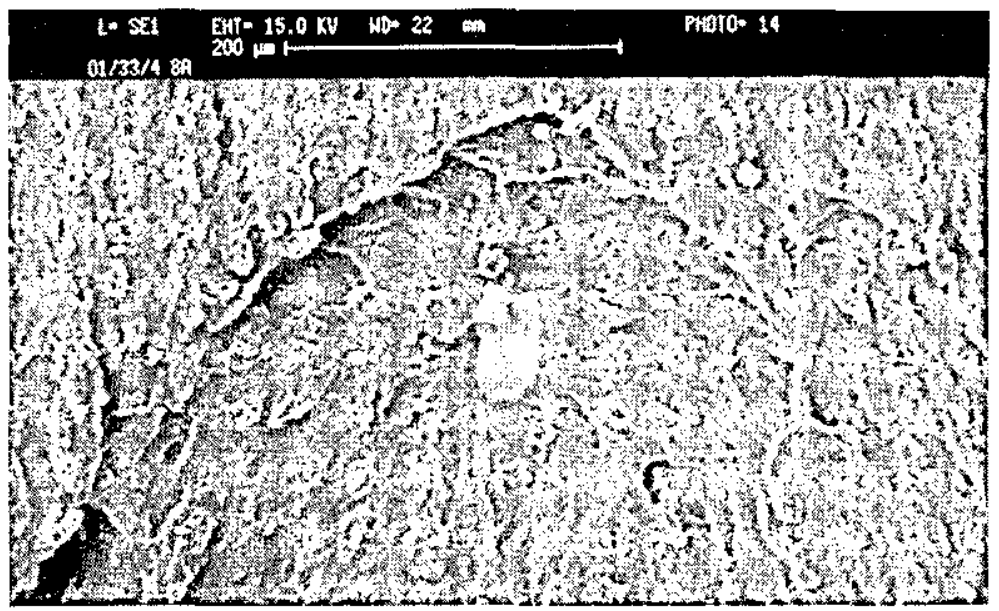

Plate 4.19: $\mathrm{SEM}$ image of $\mathrm{A} 05 \mathrm{Sb}_{2} \mathrm{O}_{3}$ agglomerate in parabolic crater.

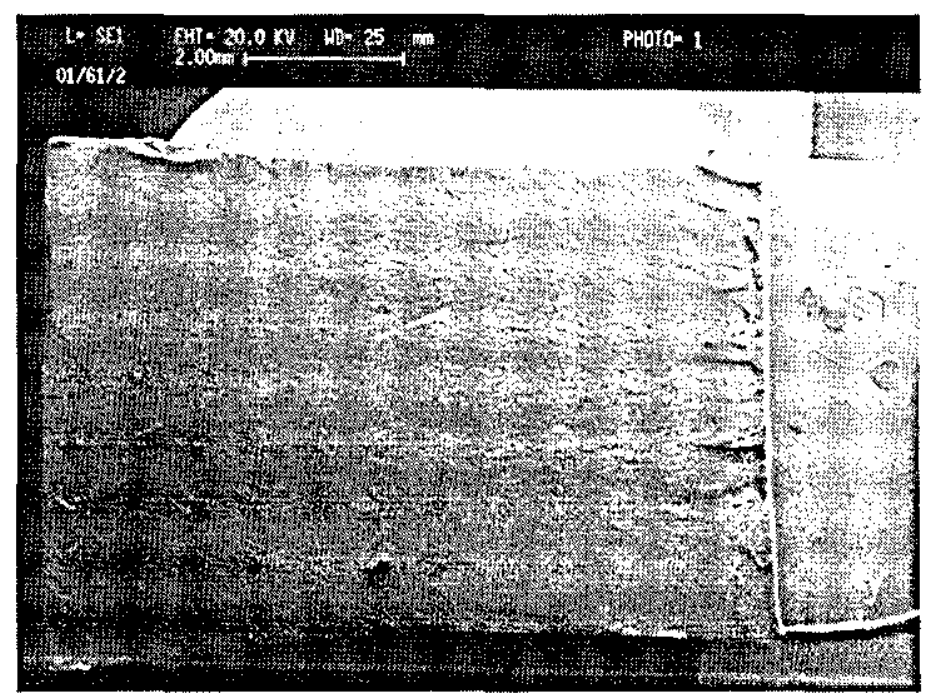

Plate 4.20: SEM image of fracture surface of sAZUB compound. 
The surfaces of the fractured bars were smoother on the samples containing the smaller particle sized material. Plate 4.20 shows the fracture surface of the sAZUB compound, which is near identical to that of the unfilled ABS specimen (Plate 4.12).

TEM analysis of the samples in the stress whitened zone showed the presence of crazing and cavitation as in the unfilled ABS samples. The craze length and width appeared to be similar in all the samples but with greater amounts being seen in the samples containing AZUB material. The amount of crazing appeared to correspond to the impact properties (i.e., highest number of crazes in compounds with highest impact energy retention).

\subsubsection{Flame Testing}

LOI testing carried out on these samples resulted in LOI values between 18.6 and 19.1 . These values were expected as $\mathrm{Sb}_{2} \mathrm{O}_{3}$ has poor flame retardant properties when used on its own. The slight increase in LOI value is most likely due to a dilution effect. UL-94 testing was carried out in order to compare against later compounds with full flame retardant packages.

Table 4.9: Flame properties of $\mathrm{Sb}_{2} \mathrm{O}_{3}$ filled compounds.

\begin{tabular}{|c|c|c|c|c|c|}
\hline No. & Description & $\begin{array}{c}\mathrm{Sb}_{2} \mathrm{O}_{3} \\
\text { content } \\
\text { (wt\%) }\end{array}$ & LOI & $\begin{array}{c}\text { UL-94 } \\
\text { value }\end{array}$ & $\begin{array}{c}\text { UL-94 Total } \\
\text { burn time } \\
(\mathrm{s})\end{array}$ \\
\hline $\mathbf{1}$ & $\mathrm{RS}$ & 4.10 & 18.7 & FAIL & 560 \\
$\mathbf{2}$ & $\mathrm{A} 05$ & 5.49 & 19.1 & FAIL & 495 \\
$\mathbf{4}$ & pAZUB & 4.93 & 19.0 & FAIL & 520 \\
$\mathbf{5}$ & sAZUB & 3.45 & 18.6 & FAIL & 590 \\
\hline
\end{tabular}

All the samples failed as expected with a decrease in total burn time when compared to unfilled ABS. The samples containing the higher amount of antimony trioxide had the lowest total burn time, which suggested a dilution effect. 


\subsection{Analysis of $\mathrm{Sb}_{2} \mathrm{O}_{3}$ Addition Using Masterbatches}

\subsubsection{Compounding}

Use of a masterbatch carrier resin to incorporate antimony trioxide into ABS was investigated during the work. Blendex 310(S) from GE Specialty, a high rubber content ABS, was obtained for the purpose of using its high impact properties to counter the detrimental effects of the antimony trioxide. This ABS grade contained $61 \mathrm{wt} \%$ polybutadiene and had an Izod value of $15.8 \mathrm{~kJ} / \mathrm{m}^{2}$ as compared to Cycolac $\mathrm{T}$ with $<4.0$ $\mathrm{kJ} / \mathrm{m}^{2}$.

Initial work compounding Blendex $310(\mathrm{~S})$ on the APV twin-screw extruder was difficult due to the high viscosity of the grade. The quoted processing range of 200 to $210^{\circ} \mathrm{C}[143]$ was far too low for the polymer. Batches were therefore mixed on the Haake Rheocord to investigate the possibility of formulating a mixture of Blendex 310(S) and Cycolac $T$ for use as the masterbatch carrier resin. Table 4.10 shows the five formulations compounded as well as the mean torque values generated from the stable region of the graph $(>240$ secs $)$.

Table 4.10: Haake Rheocord data for blends of Blendex 310(S) and Cycolac T.

\begin{tabular}{|l|c|c|c|}
\hline $\begin{array}{l}\text { Formulation } \\
\text { (Blendex : Cycolac T) }\end{array}$ & $\begin{array}{c}\text { Mean torque } \\
{[\mathrm{Nm}](\mathrm{SD})}\end{array}$ & $\begin{array}{c}\text { Mean torque } \\
\text { (\% Blendex 310S) }\end{array}$ & $\begin{array}{c}\text { Reduction in } \\
\text { torque }\end{array}$ \\
\hline Blendex 310(S) 100\% & $25.94(0.18)$ & $100 \%$ & $0 \%$ \\
$\mathbf{9 0 \% : 1 0 \%}$ & $23.63(0.20)$ & $91 \%$ & $-10 \%$ \\
$\mathbf{7 5 \%}: \mathbf{2 5 \%}$ & $18.91(0.12)$ & $73 \%$ & $-27 \%$ \\
$\mathbf{5 0 \%}: \mathbf{5 0 \%}$ & $13.91(0.12)$ & $54 \%$ & $-46 \%$ \\
Cycolac T 100\% & $7.87(0.10)$ & $30 \%$ & $-70 \%$ \\
\hline
\end{tabular}

For all the formulations the Rheocord chamber was filled to $70 \%$ (by volume). The highly viscous properties of Blendex $310(\mathrm{~S})$ at this temperature $\left(\sim 200^{\circ} \mathrm{C}\right)$ were indicated by the higher torque values. The effect of adding increasing amounts of Cycolac $T$ to the $310(\mathrm{~S})$ can be seen in the table as well as Figure 4.6, which indicate the reductions in torque that occur upon addition of Cycolac $\mathrm{T}$. 


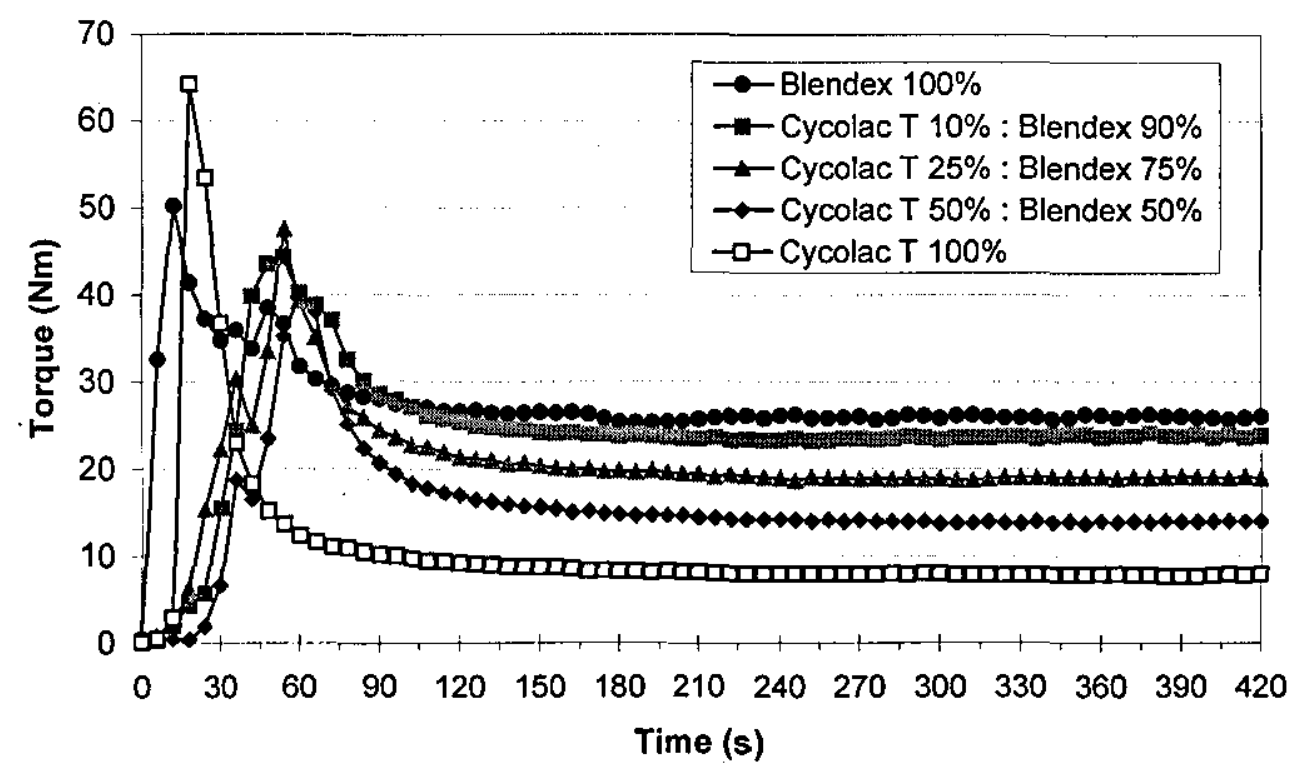

Figure 4.6: Haake Rheocord - torque versus time $\left(\mathrm{T}=200^{\circ} \mathrm{C}\right.$ at $\left.\mathrm{t}=0\right)$

A compromise between reducing the melt viscosity whilst attempting to maintain a high percentage of Blendex 310(S) in the formulation was needed. The 50:50 ratio had less Blendex than desired and the 90:10 did not reduce the viscosity sufficiently to allow easier compounding to take place. This meant that the best ratio for the APV from those tested was the $75 \%$ Blendex, 25\% Cycolac T blend (which contained 50wt $\%$ polybutadiene). The melt viscosity for this compound was $27 \%$ lower than the viscosity for Blendex 310 (S) only. Examination of the melt showed a significant improvement in properties, whereas the Blendex $310(\mathrm{~S})$ was crumbly in parts the $75: 25$ blend was smooth and processed well.

The results obtained in the Haake Rheocord were used to formulate the compounds shown in Table 4.11. The masterbatches were compounded with a feed rate of $4 \mathrm{~kg} / \mathrm{hr}$ and a screw speed of $115 \mathrm{rpm}$ to prevent the machine exceeding its maximum pressure limit of 8.65 MPa. The compounds were run with a feed rate of $12 \mathrm{~kg} / \mathrm{hr}$ and a screw speed of $170 \mathrm{rpm}$. 
Table 4.11: Blendex 310(S) masterbatches.

\begin{tabular}{|c|c|c|c|c|}
\hline Code & Compound description & $\begin{array}{l}\text { Torque } \\
(\%)\end{array}$ & $\begin{array}{l}\text { Pressure } \\
(\mathrm{MPa})\end{array}$ & $\begin{array}{l}\text { Pressure } \\
(\% \text { ABS })\end{array}$ \\
\hline MB1 & $75 \%$ Blendex $310 \mathrm{~S}+25 \%$ Cycolac T & 60 & 6.65 & $185 \%$ \\
\hline MB2 & $75 \mathrm{wt} \% \mathrm{RS}+25 \mathrm{wt} \%(\mathrm{MB} 1)$ & 55 & 6.17 & $172 \%$ \\
\hline MB3 & $50 \mathrm{wt} \% \mathrm{RS}+50 \mathrm{wt} \%(\mathrm{MB} 1)$ & 55 & 6.24 & $174 \%$ \\
\hline MB4 & $25 w t \% R S+75 w t \%(M B 1)$ & 50 & 6.38 & $178 \%$ \\
\hline MB5 & $32 w t \% A Z+68 w t \%(M B 1)$ & 70 & 6.34 & $177 \%$ \\
\hline 7 & $\begin{array}{l}\text { ABS }+1.33 w t \%[\text { Blendex }+ \text { Cycolac } \mathrm{T}] \\
\text { (using } \mathrm{MB} 1 \text { ) }\end{array}$ & 90 & 3.69 & $103 \%$ \\
\hline 8 & $\begin{array}{l}\text { ABS }+4 w t \%[\text { Blendex }+ \text { Cycolac } T] \\
\text { (using MB1) }\end{array}$ & 90 & 4.07 & $113 \%$ \\
\hline 9 & $\begin{array}{l}\text { ABS }+12 w t \%[\text { Blendex }+ \text { Cycolac } \mathrm{T}] \\
\text { (using } \mathrm{MB} 1 \text { ) }\end{array}$ & 95 & 4.34 & $121 \%$ \\
\hline 10 & $\mathrm{ABS}+4 \mathrm{wt} \% \mathrm{RS}$ (directly added) & 85 & 3.72 & $104 \%$ \\
\hline 11 & $\mathrm{ABS}+4 \mathrm{wt} \% \mathrm{RS}$ (using 5.33wt \% MB2) & 80 & 3.79 & $106 \%$ \\
\hline 12 & $\mathrm{ABS}+4 \mathrm{wt} \% \mathrm{RS}$ (using $8 \mathrm{wt} \% \mathrm{MB} 3$ ) & 85 & 3.93 & $109 \%$ \\
\hline 13 & $\mathrm{ABS}+4 \mathrm{wt} \% \mathrm{RS}$ (using $16 \mathrm{wt} \% \mathrm{MB} 4)$ & 85 & 3.99 & $111 \%$ \\
\hline 14 & $\mathrm{ABS}+5.1 \mathrm{wt} \% \mathrm{AZ}$ (directly added) & 75 & 3.72 & $104 \%$ \\
\hline 15 & $\mathrm{ABS}+5.1 \mathrm{wt} \% \mathrm{AZ}$ (using $16 \mathrm{wt} \% \mathrm{MB} 5$ ) & 85 & 1.93 & $108 \%$ \\
\hline
\end{tabular}

Compounds 7, 8 and 9 were reference compounds containing only the Blendex and Cycolac T mixture. Compounds 10 and 14 were reference compounds containing directly added antimony trioxide. The remaining compounds were formulated to contain $4 \mathrm{wt} \% \mathrm{Sb}_{2} \mathrm{O}_{3}$ using masterbatched material.

The high viscosity of the Blendex $310(\mathrm{~S})$ was apparent in the pressure readings of the masterbatches and the compounds. The Blendex:Cycolac T masterbatch (MB1) pressure reading was significantly higher than the ABS control $(185 \%)$, however this was not as high as that seen in the Haake (240\%). Increasing additions of antimony trioxide to the Blendex:Cycolac T mixture (in the masterbatches) decreased the pressure readings slightly. This trend was also seen in the compounds with those containing more Blendex having higher pressure readings. The addition of the Red Star antimony trioxide $(11,12$ and 13) lowered the pressure readings below those of the comparative formulations containing no antimony trioxide $(7,8$ and 9$)$. 


\subsubsection{Mechanical Properties}

\section{Impact Properties}

Table 4.12 and Figure 4.7 show the effect of letting down antimony trioxide at loadings of $4 \mathrm{wt} \% \mathrm{Sb}_{2} \mathrm{O}_{3}$ when incorporated in a high impact strength masterbatch. The impact values are again quoted as percentage values of unfilled ABS.

Table 4.12: Impact properties of masterbatched $\mathrm{Sb}_{2} \mathrm{O}_{3}$ compounds.

\begin{tabular}{|c|c|c|c|c|c|}
\hline Code & Compound description & $\begin{array}{c}\text { Actual } \\
\mathrm{Sb}_{2} \mathrm{O}_{3} \\
\text { content }\end{array}$ & $\begin{array}{c}\text { Peak } \\
\text { Force } \\
(\%)\end{array}$ & $\begin{array}{c}\text { Peak } \\
\text { Energy } \\
(\%)\end{array}$ & $\begin{array}{c}\text { Failure } \\
\text { Energy } \\
(\%)\end{array}$ \\
\hline MB2 & $75 w t \% R S$ & 73.00 & - & - & - \\
\hline MB3 & $50 w t \% \mathrm{RS}$ & 46.66 & - & - & - \\
\hline MB4 & $25 \mathrm{wt} \% \mathrm{RS}$ & 23.00 & - & - & - \\
\hline MB5 & $32 \mathrm{wt} \% \mathrm{AZ}$ & 19.50 & - & - & - \\
\hline 7 & $1.33 \mathrm{wt} \%$ (MB1) & - & $102(5)$ & $104(6)$ & $104(6)$ \\
\hline 8 & $4 \mathrm{wt} \%$ (MB1) & - & $103(3)$ & $109(5)$ & $110(5)$ \\
\hline 9 & $12 \mathrm{wt} \%(\mathbf{M B 1})$ & - & $101(1)$ & $112(10)$ & $123(4)$ \\
\hline 10 & $4 w t \%$ RS (direct) & 4.10 & $82(1)$ & $57(2)$ & $68(4)$ \\
\hline 11 & $5.33 \mathrm{wt} \%(\mathbf{M B 2})$ & 4.90 & $84(2)$ & $72(7)$ & $76(4)$ \\
\hline 12 & 8wt\% (MB3) & 4.00 & $84(3)$ & $72(10)$ & $78(4)$ \\
\hline 13 & $16 \mathrm{wt} \%$ (MB4) & 3.81 & $96(4)$ & $97(5)$ & $97(5)$ \\
\hline 14 & $5.1 w t \%$ AZUB (direct) & 4.11 & $96(3)$ & $94(3)$ & $94(3)$ \\
\hline 15 & $16 \mathrm{wt} \%$ (MB5) & 4.02 & $95(2)$ & $100(1)$ & $100(1)$ \\
\hline
\end{tabular}

The inclusion of increasing amounts of polybutadiene $(0.67 \mathrm{wt} \%, 2 \mathrm{wt} \%$ and $6 \mathrm{wt} \%$ in formulations 7,8 and 9 respectively) increased the impact energies of the compounds. Figure 4.8 shows the relationship between increasing amounts of additional PB in the compounds and the effect this had on the peak and failure impact energies. From the graph it can be seen that both sets of results showed a linear relationship with a high significance level, indicated by the high $\mathrm{r}^{2}$ values. This was valid for formulations 7,8 and 9, which did not include antimony trioxide. Incorporation of directly added $4 \mathrm{wt} \%$ RS dropped the impact energies by approximately $30 \%$. The inclusion of increasing amounts of polybutadiene, in the masterbatched RS compounds, improved the energies to a value approximately equal to that of unfilled ABS. 


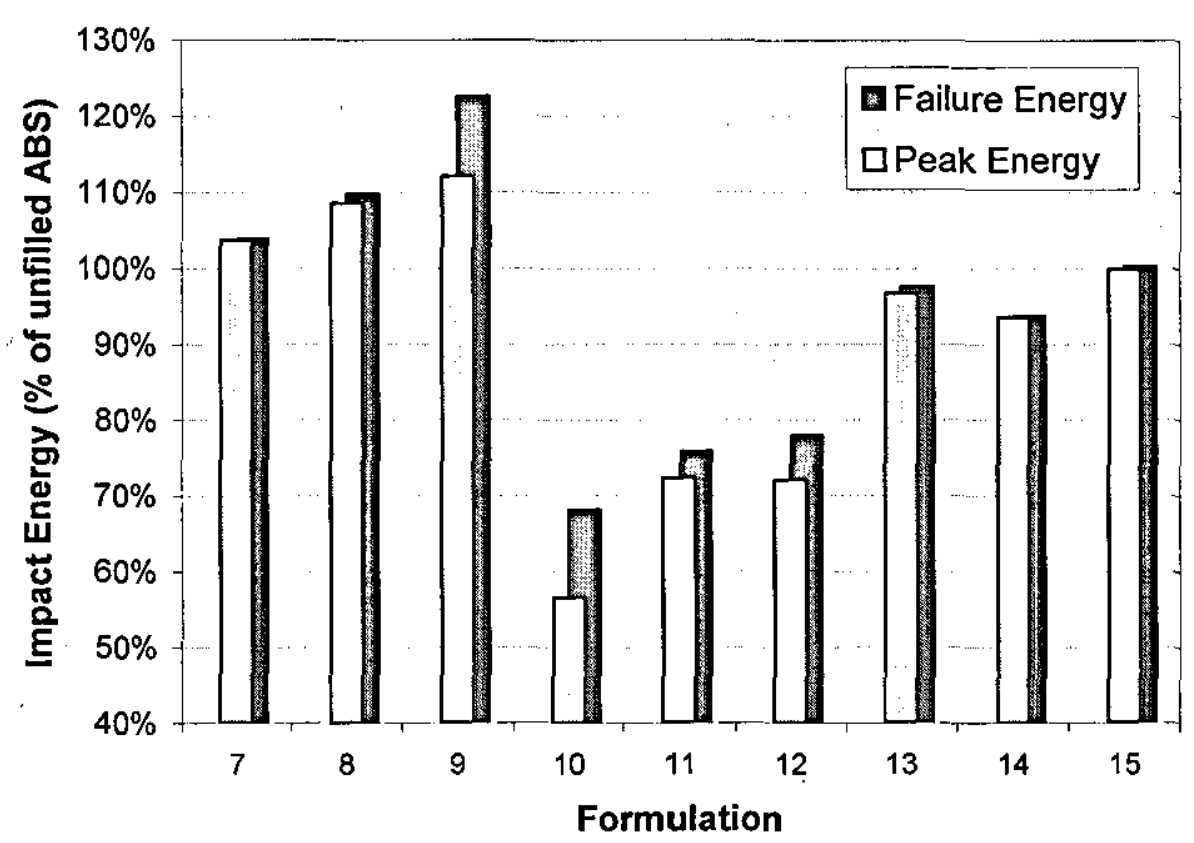

Figure 4.7: Impact properties of masterbatched $\mathrm{Sb}_{2} \mathrm{O}_{3}$ compounds (\% unfilled ABS)

However the increasing amounts of polybutadiene in the three $4 \mathrm{wt} \%$ masterbatched RS formulations did not exhibit a linear relationship when compared against impact energies.

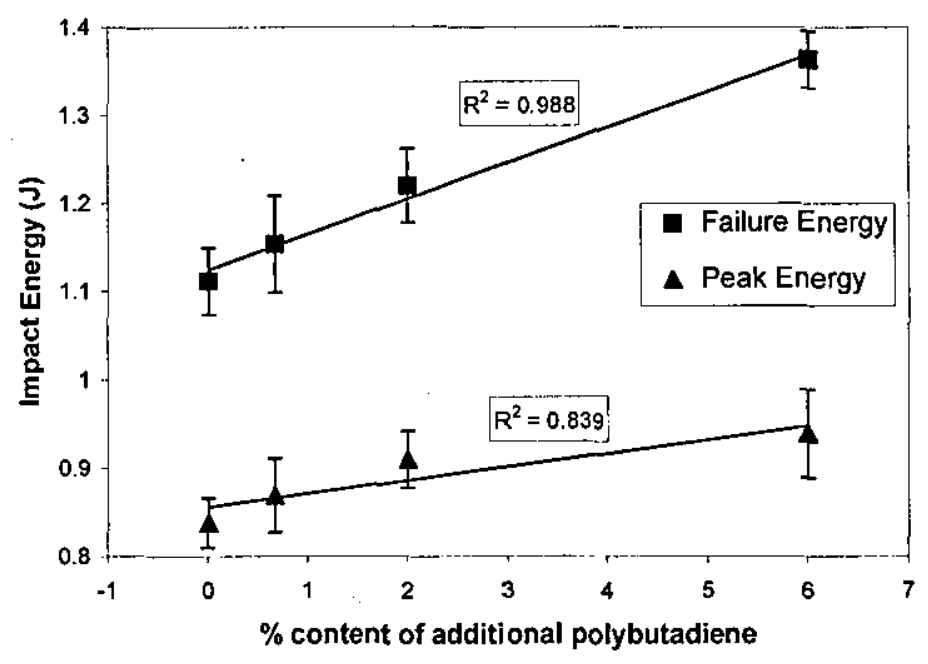

Figure 4.8: Relationship between increasing $\mathrm{PB}$ content and impact energies 
Masterbatching AZUB material. resulted in impact energies equal to those of unfilled ABS. The improvements in impact energies from directly added $4 w t \% R S(10)$ to masterbatched RS were greater than those in the comparative AZUB formulations.

\section{Flexural Properties}

The flexural modulus and strength values for these formulations are shown in Table 4.13 and Figure 4.9. Increasing additions of polybutadiene (7,8 and 9) lowered both the modulus and strength values of the compounds. Direct addition of $4 w t \%$ RS (10) raised the modulus above that of unfilled ABS but lowered flexural strength. The presence of the additional polybutadiene $(11,12$ and 13$)$ again lowered the flexural properties. The modulus values of the formulations containing masterbatched RS and PB were slightly lower than those with additional PB only. The strengths of all compounds containing antimony trioxide were much lower than unfilled ABS.

Table 4.13: Flexural properties of masterbatched $\mathrm{Sb}_{2} \mathrm{O}_{3}$ compounds

\begin{tabular}{|c|l|c|c|c|c|}
\hline No. & Compound description & $\begin{array}{c}\mathrm{Sb}_{2} \mathrm{O}_{3} \\
\text { content } \\
(\mathrm{wt} \%)\end{array}$ & $\begin{array}{c}\text { Deflection } \\
\text { @ max load } \\
(\mathrm{mm})\end{array}$ & $\begin{array}{c}\text { Flexural } \\
\text { Modulus } \\
(\%)\end{array}$ & $\begin{array}{c}\text { Flexural } \\
\text { Strength } \\
(\%)\end{array}$ \\
\hline $\mathbf{7}$ & $1.33 \mathrm{wt} \%(\mathrm{MB} 1)$ & - & $99(3)$ & $100(0)$ & $99(1)$ \\
\hline $\mathbf{8}$ & $4 \mathrm{wt} \%(\mathrm{MB} 1)$ & - & $101(5)$ & $97(0)$ & $96(1)$ \\
\hline $\mathbf{9}$ & $12 \mathrm{wt} \%(\mathrm{MB} 1)$ & - & $102(8)$ & $91(0)$ & $90(1)$ \\
\hline $\mathbf{1 0}$ & $4 \mathrm{wt} \% \mathrm{RS}$ (direct) & 4.10 & $101(26)$ & $101(0)$ & $92(1)$ \\
\hline $\mathbf{1 1}$ & $5.33 w t \%(\mathrm{MB} 2)$ & 4.90 & $96(8)$ & $100(1)$ & $93(1)$ \\
\hline $\mathbf{1 2}$ & $8 \mathrm{wt} \%(\mathrm{MB} 3)$ & 4.00 & $95(3)$ & $98(0)$ & $92(1)$ \\
\hline $\mathbf{1 3}$ & $16 \mathrm{wt} \%(\mathrm{MB} 4)$ & 3.81 & $95(5)$ & $91(0)$ & $87(1)$ \\
\hline $\mathbf{1 4}$ & $5.1 \mathrm{wt} \%$ AZUB (direct) & 4.11 & $90(7)$ & $99(1)$ & $89(1)$ \\
\hline $\mathbf{1 5}$ & $16 \mathrm{wt} \%$ (MB5) & 4.02 & $91(7)$ & $89(2)$ & $84(1)$ \\
\hline
\end{tabular}




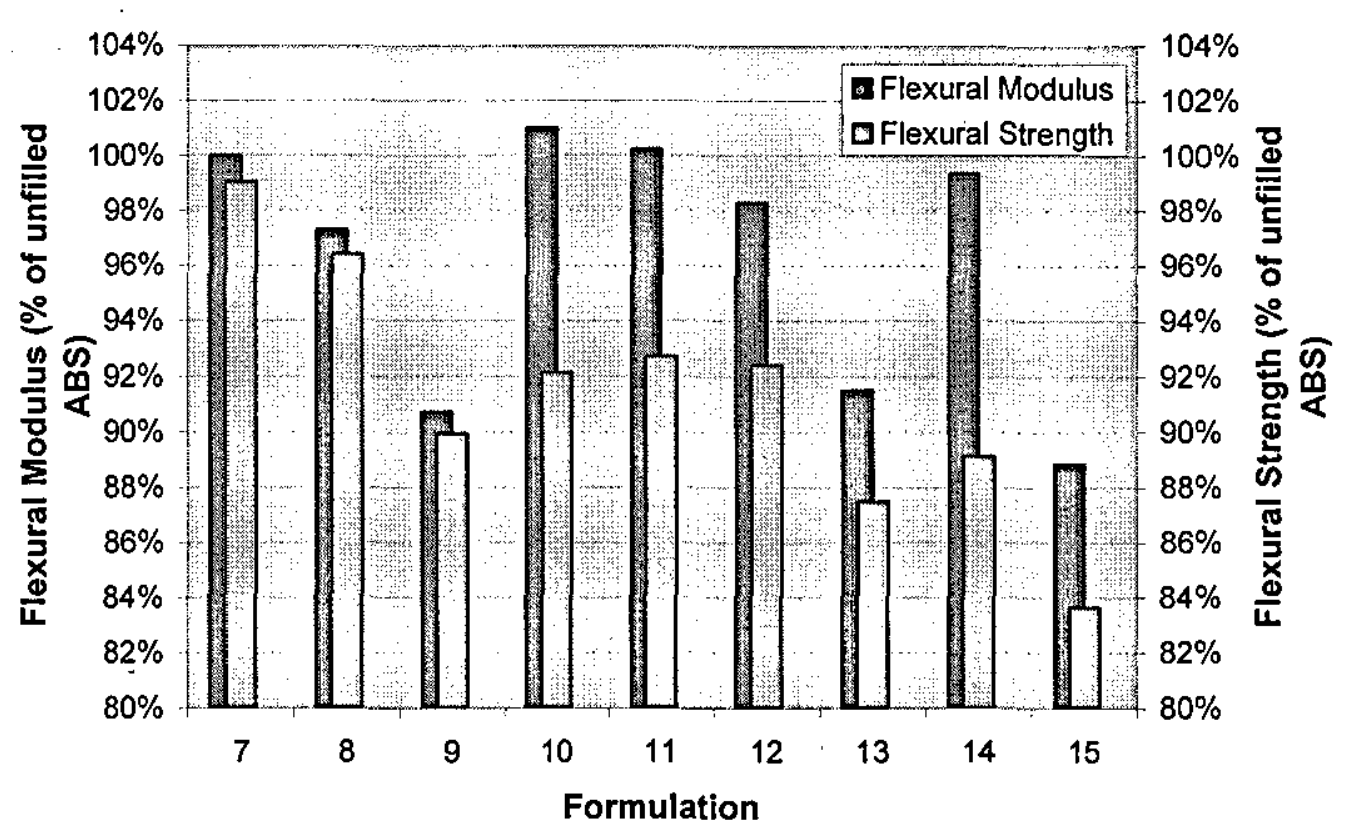

Figure 4.9: Flexural properties of masterbatched $\mathrm{Sb}_{2} \mathrm{O}_{3}$ compounds

\subsubsection{Microscopy Analysis}

\section{Dispersion}

Samples were analysed on both the SEM and TEM and dispersion of the antimony trioxide was generally good. At low magnifications the RS could clearly be seen as being well dispersed across the surface of a fracture plane. The smaller AZUB particles were too small to be defined at low magnifications but higher magnification also showed good dispersion. TEM analysis of all the grades confirmed the results obtained in the SEM with the antimony trioxide being located in the SAN phase. TEM analysis revealed that samples containing additional $\mathrm{PB}$ had butadiene particles that were considerably larger than the size range normally seen. These were most noticeable in samples from compound 12 and were indicative of excessive heating of the polybutadiene phase (Plate 4.21). 


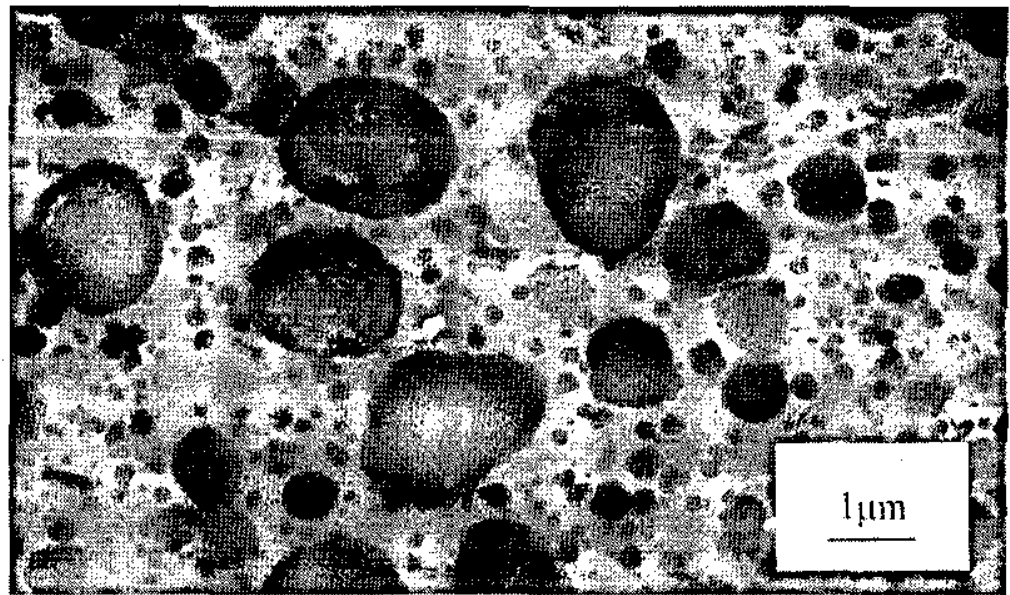

Plate 4.21: TEM image of enlarged polybutadiene particles (4wt $\% \mathrm{MB} 1)$.

\section{Fracture}

SEM analysis showed that the compounds containing RS had slightly coarser fracture surfaces than those containing AZUB. As previously seen in Section 4.3.3 the antimony trioxide particles did not appear to show any interaction with the polymer matrix. The compound with the greatest amount of additional PB (compound 9) had a smoother fracture surface than unfilled ABS (Plate 4.22).

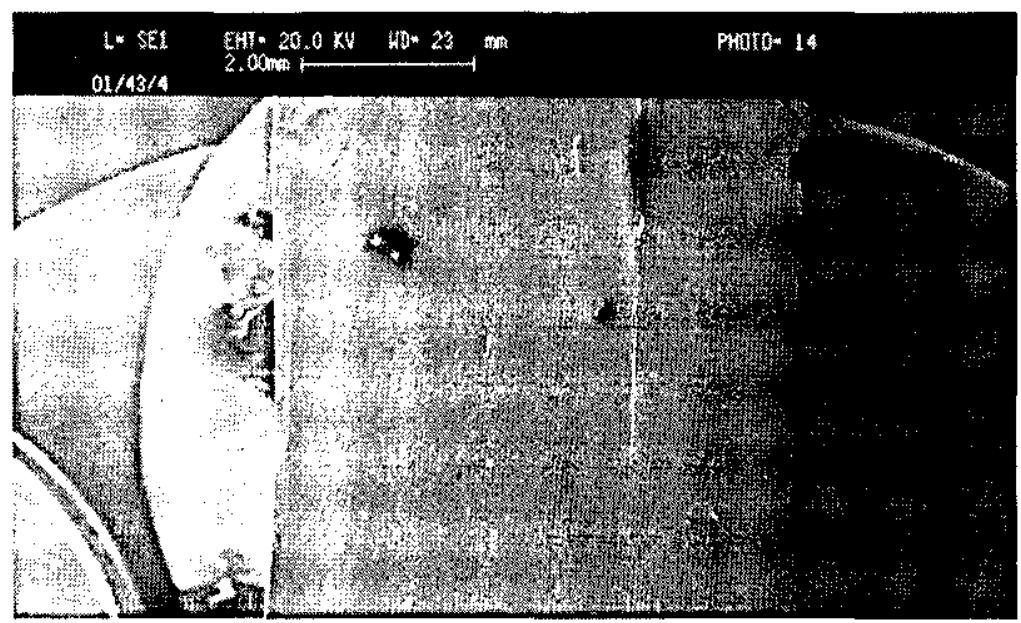

Plate 4.22:SEM image of compound 9 fracture surface (12wt\% MB1). 


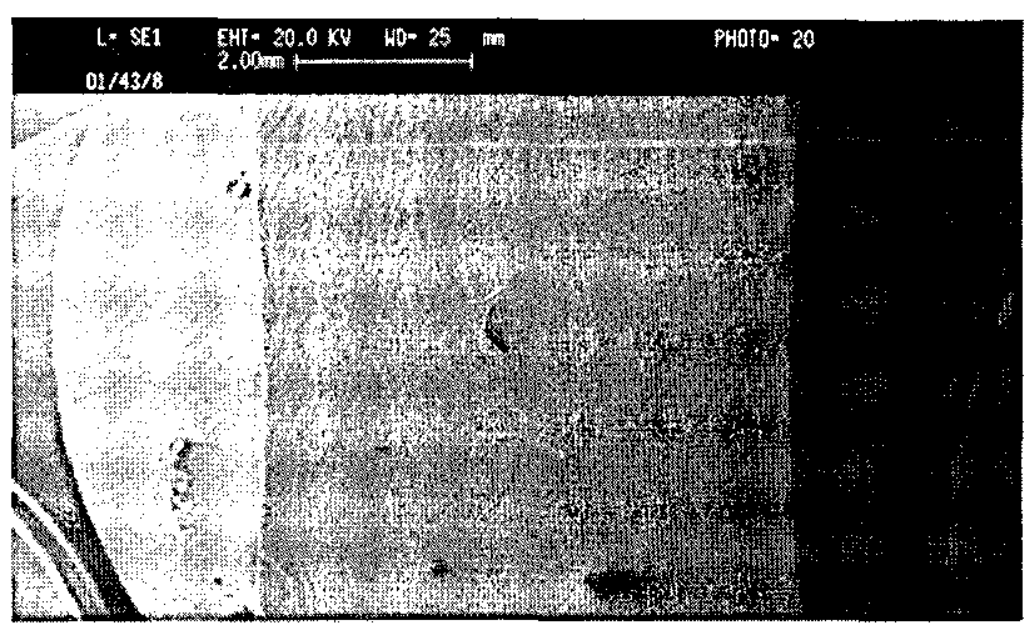

Plate 4.23: SEM image of compound 13 fracture surface (16wt\% MB4).

TEM analysis of the samples in the stress whitened zone showed the presence of crazing and cavitation as seen previously. The compounds containing additional PB only did not show a significant increase in the number of crazes (with increasing additions of polybutadiene) when viewed at higher magnifications. However analysis of the specimen in general gave the impression of increased numbers. The presence of antimony trioxide reduced the number of crazes but addition of increasing amounts of $\mathrm{PB}$ increased the number of crazes to a number similar to unfilled ABS.

\subsubsection{Flame Testing}

LOI testing carried out on these samples resulted in values identical to those seen for unfilled ABS (for compounds 7,8 and 9). The remaining compounds were similar to the values found in Table 4.9. These values were expected as direct additions of $\mathrm{Sb}_{2} \mathrm{O}_{3}$ had poor flame retardant properties. UL-94 testing again showed similar values to those seen in Table 4.9 for all samples. Direct addition compounds have been tested as mentioned in section 4.3.4. All the samples tested for these formulations failed as expected with a slight increase in burn time for compounds 7,8 and 9 (additional PB) compared to unfilled ABS. The compounds containing $\mathrm{MB} \mathrm{Sb}_{2} \mathrm{O}_{3}$ showed a decrease in total burn time when compared to unfilled ABS. 


\subsection{Influence of Bromine Additives}

\subsubsection{Compounding}

Four grades of brominated halogen flame retardant have been incorporated into ABS at optimum loadings of $20 \mathrm{wt} . \%$. The machine torque and die pressure readings are shown in Table 4.14 and clearly show reductions as compared to unfilled ABS for all four bromines. As mentioned earlier (Chapter 3 ) the bromines consisted of two melt blendable grades (BTBPE and TBBA) and two non-melt blendable grades of DBDPO. The spray dried DBDPO was a milled and flushed grade of the standard DBDPO material.

Table 4.14: Compounding data for $20 \mathrm{wt} \%$ bromine formulations.

\begin{tabular}{|l|l|c|c|c|}
\hline No & Sample description & $\begin{array}{c}\text { Torque } \\
(\%)\end{array}$ & $\begin{array}{c}\text { Pressure } \\
(\mathrm{MPa})\end{array}$ & $\begin{array}{c}\text { Pressure } \\
\text { (\% unfilled ABS) }\end{array}$ \\
\hline $\mathbf{1 6}$ & BTBPE & 70 & 2.79 & $84 \%$ \\
$\mathbf{1 7}$ & TBBA & 80 & 2.59 & $78 \%$ \\
$\mathbf{1 8}$ & DBDPO & 75 & 2.55 & $97 \%$ \\
$\mathbf{1 9}$ & Spray dried DBDPO & 65 & 1.72 & $69 \%$ \\
\hline
\end{tabular}

The compounds shown in Table 4.14 were compounded in three different series and the pressure readings for the unfilled ABS control was different for each series. The final column shows the pressure values as a percentage of the ABS control from the relevant series.

\subsubsection{Mechanical Properties}

\section{Impact Properties}

Table 4.15 and Figure 4.10 show the bromine contents of the compounds and the effect that these additions of bromine had on the impact properties. The bromine value quoted was the percentage of active bromine present in the compound. The actual amount of brominated material in all the compounds was approximately $20 \mathrm{wt} \%$ with the loadings 
shown in the table. The impact values are again quoted as percentage values of unfilled ABS.

Table 4.15: Impact properties of bromine containing compounds.

\begin{tabular}{|l|l|c|c|c|c|}
\hline No. & \multicolumn{1}{|c|}{ Description } & $\begin{array}{c}\text { Br } \\
\text { material } \\
(\text { wt\%) }\end{array}$ & $\begin{array}{c}\text { Peak } \\
\text { Force } \\
(\%)\end{array}$ & $\begin{array}{c}\text { Peak } \\
\text { Energy } \\
(\%)\end{array}$ & $\begin{array}{c}\text { Failure } \\
\text { Energy } \\
(\%)\end{array}$ \\
\hline $\mathbf{1 6}$ & BTBPE & 19.8 & $89(4)$ & $69(12)$ & $82(5)$ \\
$\mathbf{1 7}$ & TBBA & 21.0 & $86(2)$ & $58(4)$ & $65(3)$ \\
$\mathbf{1 8}$ & DBDPO & 20.1 & $59(2)$ & $23(1)$ & $31(1)$ \\
$\mathbf{1 9}$ & Spray dried DBDPO & 21.4 & $61(1)$ & $27(1)$ & $35(1)$ \\
\hline
\end{tabular}

Looking at the table and also Figure 4.10 the two compounds containing melt blendable grades, BTBPE and TBBA, had better impact properties than the two DBDPO grades which remained as particulates in the compounds. The BTBPE reduced failure energies by $18 \%$, while TBBA dropped the value by $35 \%$.

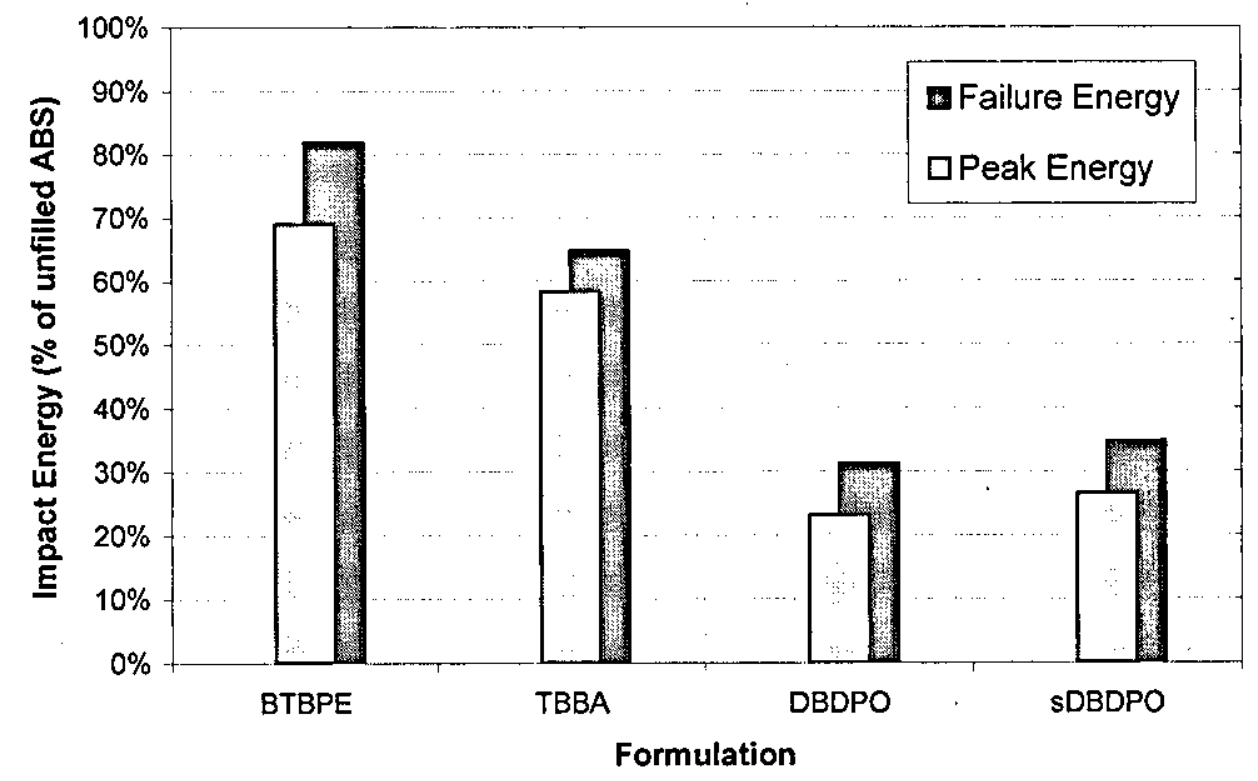

Figure 4.10: Impact properties of bromine only compounds (\% ABS) 
DBDPO had the greatest effect on properties and reduced the failure energy by $69 \%$. The spray dried DBDPO, which contained smaller particle sized material and low viscosity carrier wax, had slightly better values than the standard DBDPO. Failure energy dropped by $65 \%$ using this material.

\section{Flexural Properties}

The flexural modulus and strength values for these formulations are shown in Table 4.16 and Figure 4.11.

Table 4.16: Flexural properties of bromine containing compounds and references.

\begin{tabular}{|l|l|l|c|c|c|}
\hline No. & Description & $\begin{array}{c}\text { Br } \\
\text { material } \\
(\text { wt\%) }\end{array}$ & $\begin{array}{c}\text { Deflection @ } \\
\text { max. load } \\
(\% \text { ABS })\end{array}$ & $\begin{array}{c}\text { Flexural } \\
\text { Modulus } \\
(\% \text { ABS) }\end{array}$ & $\begin{array}{c}\text { Flexural } \\
\text { Strength } \\
(\% \text { ABS) }\end{array}$ \\
\hline $\mathbf{1 6}$ & BTBPE & 19.8 & $97(9)$ & $99(2)$ & $92(1)$ \\
$\mathbf{1 7}$ & TBBA & 21.0 & $96(7)$ & $119(1)$ & $103(1)$ \\
18 & DBDPO & 20.1 & $107(12)$ & $108(2)$ & $100(2)$ \\
19 & sDBDPO & 21.4 & $76(4)$ & $102(1)$ & $86(1)$ \\
\hline
\end{tabular}

The addition of BTBPE caused a reduction in flexural strength $(-8 \%)$ but had no effect on modulus. The three remaining bromines caused an increase in flexural modulus with TBBA having the greatest effect (19\%). The DBDPO and spray dried DBDPO grades caused increases of $8 \%$ and $2 \%$ respectively. The spray dried DBDPO grade reduced the strength of the compound in a similar manner to BTBPE causing a $14 \%$ drop. DBDPO had no effect on strength. Unlike the other three grades addition of the TBBA material resulted in a flexural strength $3 \%$ higher than unfilled ABS. 


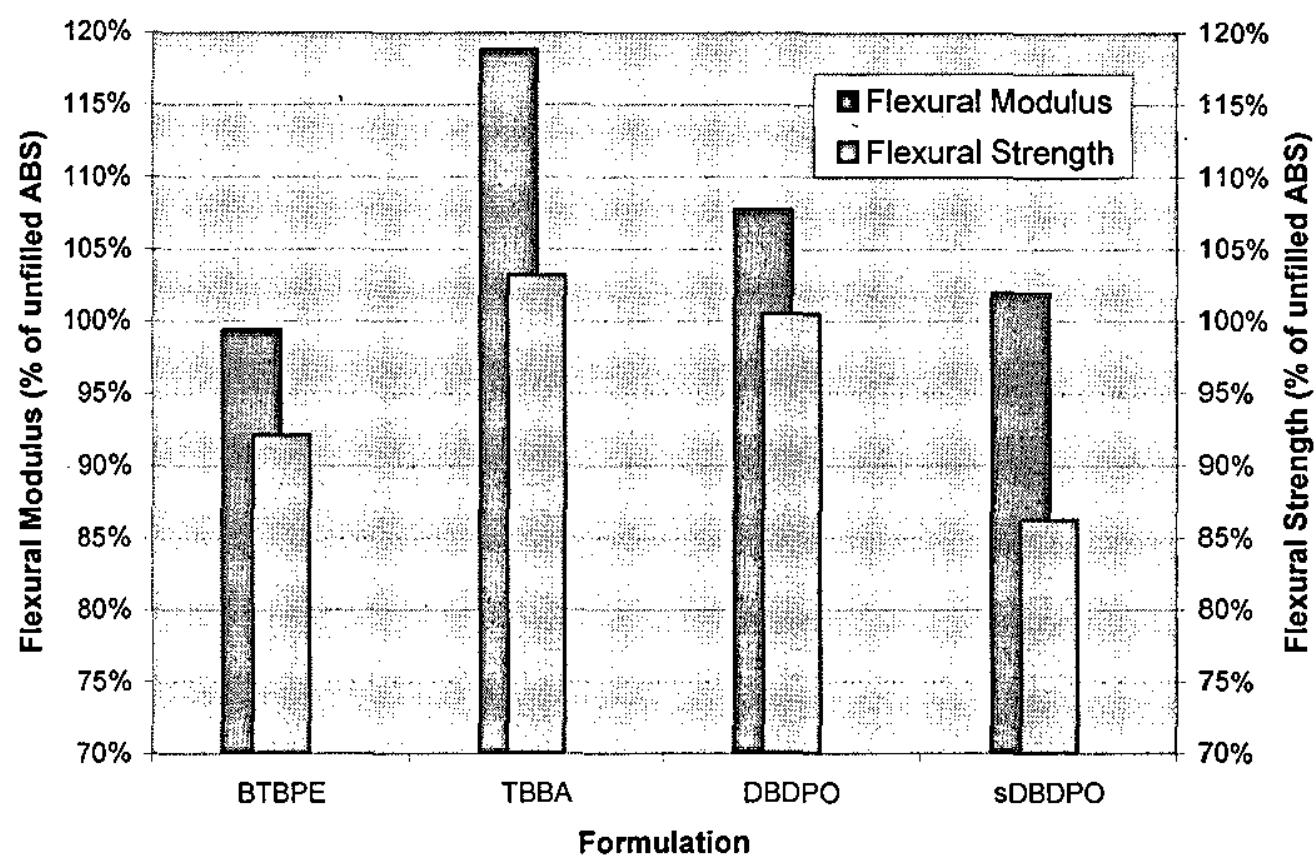

Figure 4.11: Flexural properties of bromine containing compounds

\subsubsection{Microscopy Analysis}

\section{Dispersion}

Samples were analysed on both the SEM and TEM but dispersion of the bromine was difficult to determine in the compounds containing the melt blended BTBPE and TBBA. TEM analysis using both osmium tetroxide as well as a more aggressive staining agent, ruthenium tetroxide [144-147] failed to determine the location. STEM analysis and Xray mapping were carried out at several locations in sections of the compounds containing the two bromines. Results suggested a blanket effect of bromine across the samples with a slight increase in concentration at the butadiene/SAN interface.

The location within the respective samples of the two DBDPO bromines was easily determined as these grades were not melt blendable (Plates 4.24 and 4.25). As seen with antimony trioxide the particles were located in the SAN phase and were well dispersed. Due to the milling procedure the particles were smaller in the spray dried DBDPO although only a slight reduction in size was achieved. 


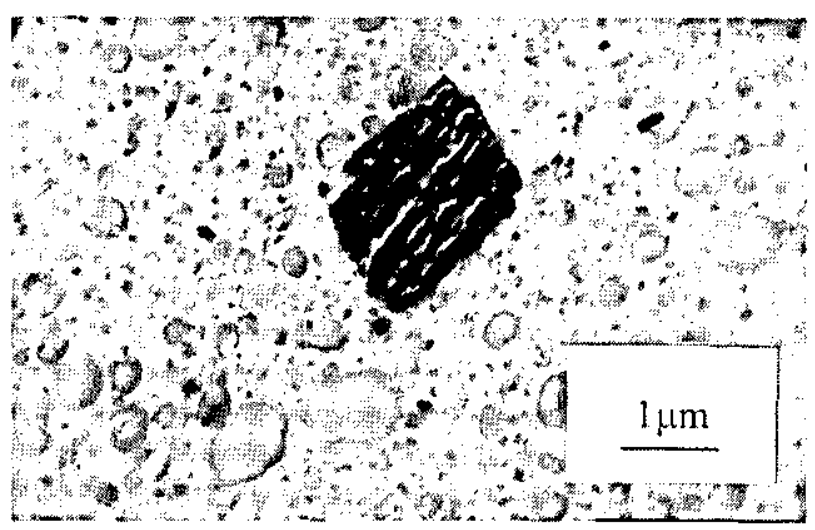

Plate 4.24: TEM image of DBDPO particle in ABS.

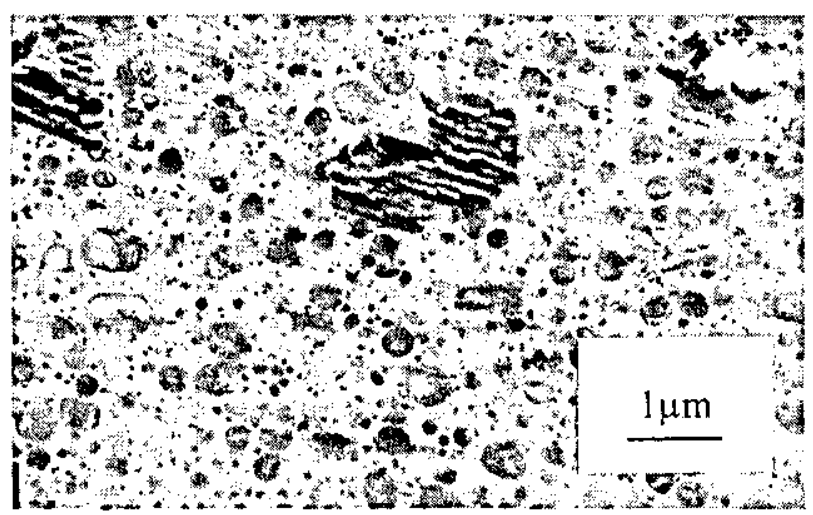

Plate 4.25: TEM image of sDBDPO particles in ABS (inc. crazing).

\section{Fracture}

SEM analysis showed that the compound containing BTBPE had a smooth impact surface similar to unfilled ABS (Plate 4.26). Stress whitened areas within the samples could not be identified due to the pigmenting effect of the bromine. TBBA and DBDPO containing compounds had a more coarse fracture surface than the unfilled ABS (Plates 4.27 and 4.28 ). The crack propagation gave an initial moderately rough surface followed by a coarse 'teared' surface. Slight stress whitening was seen near the crack tip of the TBBA compound but none was seen in the two DBDPO compounds. The DBDPO particles were well dispersed in both compounds but they did not appear to show any interaction with the polymer matrix. 


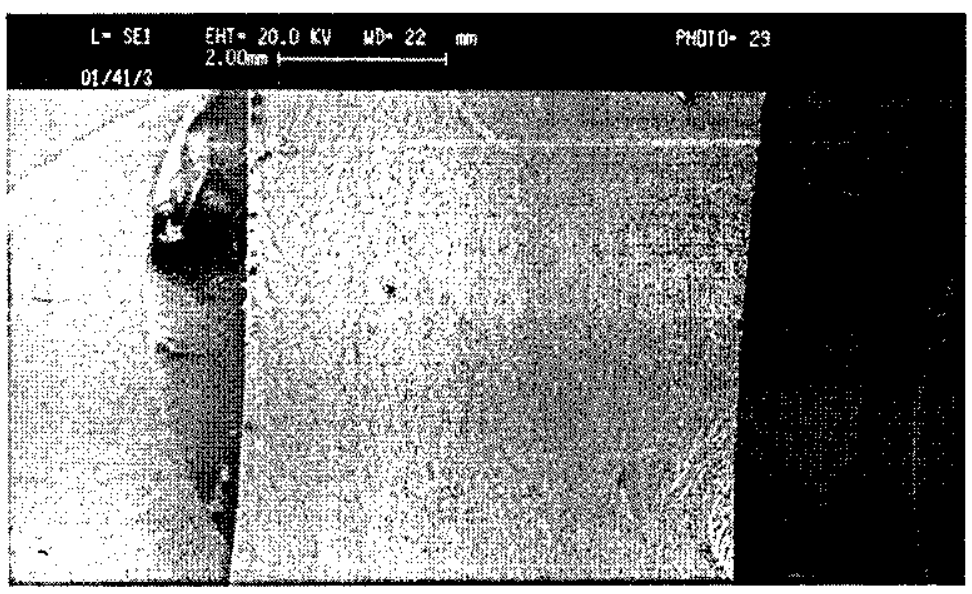

Plate 4.26:SEM image of BTBPE compound fracture surface.

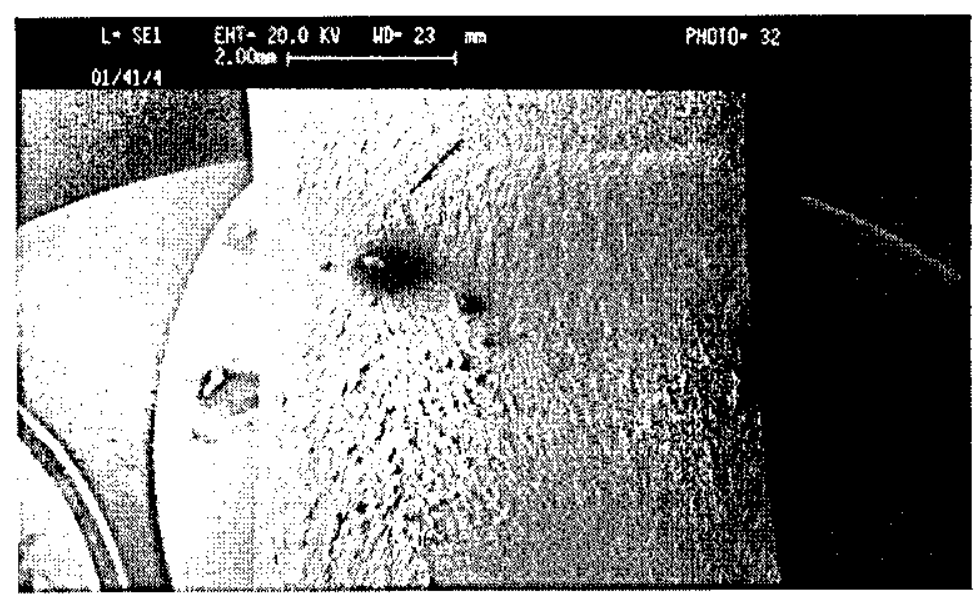

Plate 4.27:SEM image of TBBA compound fracture surface.

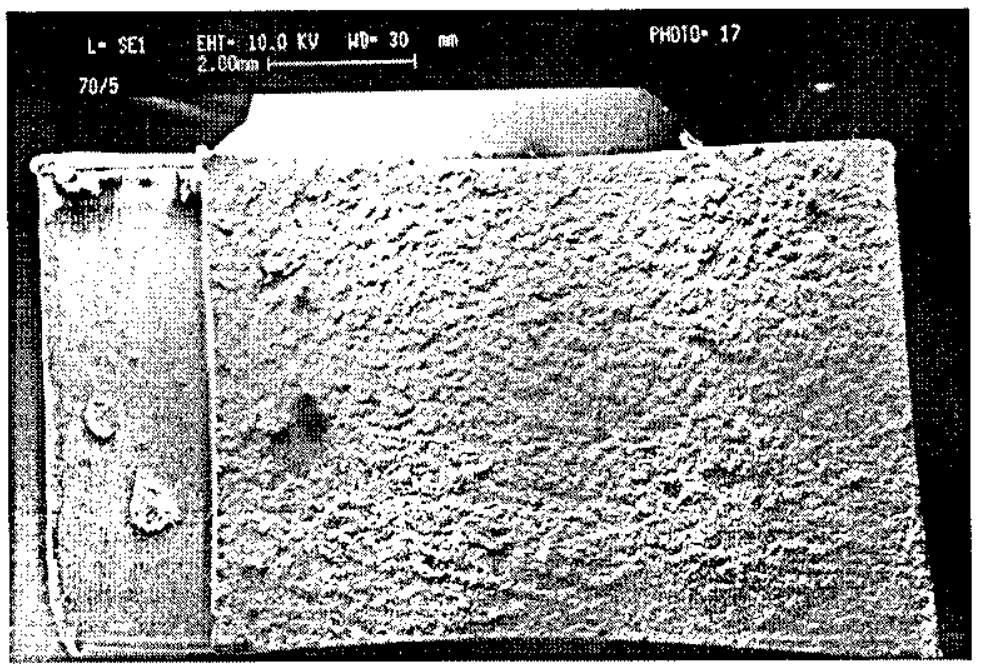

Plate 4.28: SEM image of DBDPO fracture surface. 


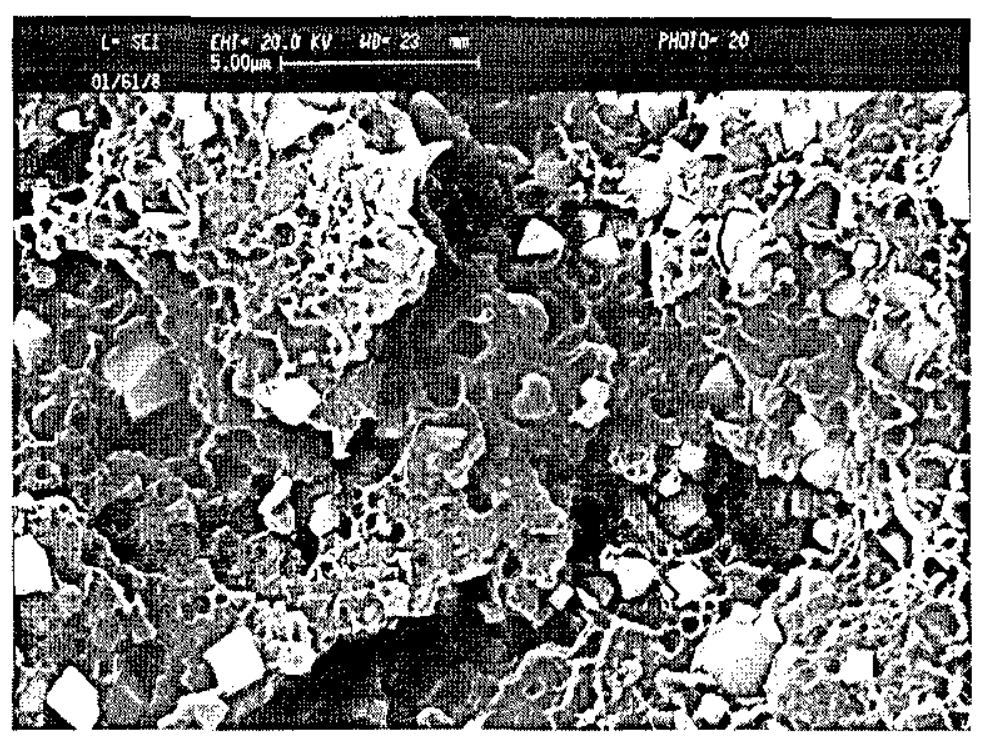

Plate 4.29: SEM image of sDBDPO compound fracture surface.

TEM analysis of the samples in the stress whitened zone (assumed in the case of those compounds containing pigmenting material) showed little presence of crazing and cavitation. The compound containing BTBPE showed the presence of some cavitation and crazing. Samples containing TBBA had little or no cavitation and crazing. Both the DBDPO grades appeared to have no cavitation or crazing but closer examination revealed the presence of some crazing between larger particles (see Plates 4.24 and 4.25).

\subsubsection{Flame Testing}

Table 4.17 shows the results of both LOI and UL-94 flame tests on the four bromine containing compounds.

The LOI results were significantly higher than the results for both unfilled ABS and $4 \mathrm{wt} \% \mathrm{Sb}_{2} \mathrm{O}_{3}$ compounds. The four grades performed differently with the order of effectiveness being DBDPO $>$ sDBDPO $>$ BTBPE $>$ TBBA. The order differs to previous work [76] and this could be due to the different loading levels of the bromine materials. 
Table 4.17: Influence of bromine material on flame properties of ABS.

\begin{tabular}{|l|l|c|c|c|c|}
\hline No. & Description & $\begin{array}{c}\mathrm{Br} \\
\text { content } \\
(\mathrm{wt} \%)\end{array}$ & LOI & $\begin{array}{c}\text { UL-94 } \\
\text { value }\end{array}$ & $\begin{array}{c}\text { UL-94 Total } \\
\text { burn time } \\
(\mathrm{s})\end{array}$ \\
\hline $\mathbf{1 6}$ & BTBPE & 13.55 & 22.5 & $\mathrm{~V}-2$ & 95 \\
$\mathbf{1 7}$ & TBBA & 11.95 & 22.1 & $\mathrm{~V}-2$ & 125 \\
$\mathbf{1 8}$ & DBDPO & 16.20 & 24.1 & $\mathrm{~V}-2$ & 73 \\
$\mathbf{1 9}$ & Spray dried DBDPO & 14.70 & 23.3 & $\mathrm{~V}-2$ & 40 \\
\hline
\end{tabular}

Looking at the UL-94 values, the DBDPO grade had a V-2 rating due to some of the samples dripping and igniting the wool. This carried the flame away from the sample (which extinguished) but still ignited the wool. The spray dried DBDPO failed the UL94 test due to extended burning of the samples and the high number of flaming drips which again ignited the wool. The spray dried grade contained castor wax and this was likely to be responsible for the high number of flaming drips. The remaining grades also dripped but continued to burn for a greater period of time.

\subsection{Influence of Bromine and $\mathrm{Sb}_{2} \mathrm{O}_{3}$ Addition}

\subsubsection{Compounding}

The four grades of brominated halogen flame retardant discussed in Section 4.5 were incorporated into ABS at optimum loadings of $20 \mathrm{wt} \%$ with two grades of antimony trioxide. Red Star (RS) and AZUB (AZ), in both pan dried and spray dried forms, were added at $4 \mathrm{wt} \%$ loadings. The machine torque and die pressure readings are shown in Table 4.18 and show reductions in both values for all four bromines. As mentioned earlier the bromines consisted of two melt blendable grades (BTBPE and TBBA) and two non-melt blendable grades of DBDPO. The spray dried DBDPO (sDBDPO) was a milled and flushed grade of the standard DBDPO material.

The compounds shown in Table 4.18 were compounded in four different series and the pressure readings for the unfilled ABS control was different for each series. The final column shows the pressure values as a percentage of the ABS control from the relevant series. 
Table 4.18: Compounding data for formulations containing bromine and $\mathrm{Sb}_{2} \mathrm{O}_{3}$.

\begin{tabular}{|c|c|c|c|c|}
\hline No. & Sample description & $\begin{array}{c}\text { Torque } \\
(\%)\end{array}$ & $\begin{array}{l}\text { Die pressure } \\
(\mathrm{MPa})\end{array}$ & $\begin{array}{c}\text { Die pressure } \\
\text { (\% of unfilled ABS) }\end{array}$ \\
\hline \multicolumn{5}{|c|}{$4 w t \%$ RS + 20wt $\%$ Bromine } \\
\hline 20 & $\mathrm{RS}+\mathrm{BTBPE}$ & 70 & 2.79 & $84 \%$ \\
\hline 21 & $\mathrm{RS}+\mathrm{TBBA}$ & 75 & 2.59 & $78 \%$ \\
\hline 22 & $\mathrm{RS}+\mathrm{DBDPO}$ & 70 & 2.41 & $92 \%$ \\
\hline 23 & $\mathrm{RS}(\mathrm{MB} 4)+\mathrm{BTBPE}$ & 70 & 1.24 & $69 \%$ \\
\hline 24 & $\mathrm{RS}(\mathrm{MB} 4)+\mathrm{TBBA}$ & 70 & 1.17 & $65 \%$ \\
\hline \multicolumn{5}{|c|}{$4 w t \%$ AZUB + 20wt $\%$ Bromine } \\
\hline 25 & pAZUB + BTBPE & 60 & 1.65 & $67 \%$ \\
\hline 26 & $\mathrm{pAZUB}+\mathrm{TBBA}$ & 55 & 1.48 & $60 \%$ \\
\hline 27 & sAZUB + BTBPE & 60 & 1.59 & $64 \%$ \\
\hline 28 & sAZUB + TBBA & 55 & 1.52 & $61 \%$ \\
\hline 29 & sAZUB + DBDPO & 70 & 2.48 & $95 \%$ \\
\hline 30 & sAZUB + sDBDPO & 70 & 2.21 & $84 \%$ \\
\hline 31 & $\mathrm{AZ}(\mathrm{MB} 5)+\mathrm{BTBPE}$ & 70 & 1.45 & $81 \%$ \\
\hline 32 & $\mathrm{AZ}(\mathrm{MB} 5)+\mathrm{TBBA}$ & 70 & 1.14 & $64 \%$ \\
\hline
\end{tabular}

\section{Red Star + Bromine}

Comparing these results against those in Table 4.14 (Bromine only compounds) it can be seen that the pressure values for both BTBPE and TBBA did not alter with the addition of $4 \mathrm{wt} \% \mathrm{Sb}_{2} \mathrm{O}_{3}$, although the torque value was slightly lower for RS + TBBA. The pressure dropped from $97 \%$ to $92 \%$ for RS + DBDPO with the torque value also dropping.

Masterbatched RS additions to both BTBPE and TBBA significantly dropped pressure values, by a further $15 \%$ and $13 \%$ respectively (compared to $\mathrm{Br}$ only values). Torque was unaffected for BTBPE whilst TBBA was reduced by $10 \%$.

\section{$A Z U B+$ Bromine}

Addition of AZUB to BTBPE and TBBA had a greater effect than the RS with the pressure dropping by $17 \%$ and $18 \%$ respectively. Torque readings dropped by $10 \%$ and $25 \%$ respectively. Using spray dried AZUB caused a slight drop in pressure for BTBPE with no significant effect for TBBA. Torque values did not change compared to 
standard AZUB (pAZUB). For DBDPO the presence of the sAZUB had less of an effect than the RS as the pressure was reduced by $2 \%$ and the torque by $5 \%$. Use of the sAZUB with spray dried DBDPO resulted in an increase from $69 \%$ (sDBDPO only) to $84 \%$ (sAZUB + sDBDPO) whilst also increasing torque by $5 \%$. Masterbatched AZUB (MB32AZ) with BTBPE reduced pressure by only $3 \%$ compared to $15 \%$ for RS. Torque was unaffected. Use of MB32AZ with TBBA had a larger effect with pressure dropping by $14 \%(\mathrm{RS}=-13 \%)$. Torque reduced by $10 \%$ as also seen for $\mathrm{RS}$.

\subsubsection{Mechanical Properties}

\section{Impact Properties}

Table 4.19 and Figures 4.12 and 4.13 show the antimony trioxide and bromine contents of the compounds and the effect that these additions had on the impact properties (expressed as a percentage of ABS values).

Table 4.19: Impact properties of compounds containing bromine and $\mathrm{Sb}_{2} \mathrm{O}_{3}$.

\begin{tabular}{|c|c|c|c|c|c|c|}
\hline No. & Description & $\begin{array}{c}\mathrm{Sb}_{2} \mathrm{O}_{3} \\
\text { content } \\
\left(\mathrm{wt}^{\circ} \%\right)\end{array}$ & $\begin{array}{c}\mathrm{Br} \\
\text { content } \\
(\%)\end{array}$ & $\begin{array}{c}\text { Peak } \\
\text { Force } \\
(\%)\end{array}$ & $\begin{array}{c}\text { Peak } \\
\text { Energy } \\
(\%)\end{array}$ & $\begin{array}{c}\text { Failure } \\
\text { Energy } \\
(\%)\end{array}$ \\
\hline \multicolumn{7}{|c|}{$4 \mathrm{wt} \% \mathrm{RS}+20 \mathrm{wt} \%$ Bromine } \\
\hline 20 & $\mathrm{RS}+\mathrm{BTBPE}$ & 4.10 & 14.7 & $78(1)$ & $52(4)$ & $57(3)$ \\
\hline 21 & $\mathrm{RS}+\mathrm{TBBA}$ & 3.98 & 11.25 & $72(4)$ & $46(7)$ & $52(5)$ \\
\hline 22 & $\mathrm{RS}+\mathrm{DBDPO}$ & 4.06 & 19.2 & $42(8)$ & $16(3)$ & $20(3)$ \\
\hline 23 & RS (MB4) + BTBPE & 4.40 & 13.6 & $84(5)$ & $84(5)$ & $83(5)$ \\
\hline 24 & $\mathrm{RS}(\mathbf{M B} 4)+\mathrm{TBBA}$ & 4.50 & 10.6 & $77(3)$ & $54(3)$ & $59(4)$ \\
\hline \multicolumn{7}{|c|}{$4 w t \%$ AZUB + 20wt \% Bromine } \\
\hline 25 & pAZUB + BTBPE & 3.82 & 15.1 & $88(3)$ & $58(1)$ & $67(5)$ \\
\hline 26 & $\mathrm{pAZUB}+\mathrm{TBBA}$ & 4.34 & 8.3 & $92(4)$ & $61(4)$ & $68(4)$ \\
\hline 27 & SAZUB + BTBPE & 3.50 & 15.0 & $84(3)$ & $57(2)$ & $64(4)$ \\
\hline 28 & sAZUB + TBBA & 3.60 & 11.4 & $76(2)$ & $50(1)$ & $56(2)$ \\
\hline 29 & sAZUB + DBDPO & 4.03 & 17.3 & $48(6)$ & $18(2)$ & $23(2)$ \\
\hline 30 & sAZUB + sDBDPO & 5.15 & 16.7 & $58(4)$ & $22(2)$ & $29(3)$ \\
\hline 31 & $\mathrm{AZ}(\mathbf{M B 5})+\mathrm{BTBPE}$ & 3.50 & 14.1 & $91(5)$ & $93(6)$ & $92(6)$ \\
\hline 32 & $\mathrm{AZ}(\mathbf{M B 5})+\mathrm{TBBA}$ & 3.70 & 11.7 & $75(3)$ & $50(2)$ & $55(2)$ \\
\hline
\end{tabular}


The bromine value quoted was the percentage of active bromine present in the compound. The actual amount of brominated material in all the compounds was approximately $20 \mathrm{wt} \%$ with the loadings shown in the table. The impact values are again quoted as percentage values of unfilled ABS.

The addition of both additives into the ABS polymer resulted in a further decrease in impact energy than with either $\mathrm{Sb}_{2} \mathrm{O}_{3}$ or bromine alone. The order of energy retention by the filled ABS compounds were the same order as seen when only bromines were added to ABS: BTBPE $>$ TBBA > DBDPO.

Table 4.20 compares the predicted impact reduction to the actual impact energy reductions (using an additive prediction theory). When compounded with RS the compounds containing BTBPE showed additive reductions whilst the TBBA and DBDPO compounds did not show this trend. The use of masterbatched RS led to additive reductions for TBBA as well as BTBPE. The compounds using AZUB material generally showed additive reductions for all the bromine grades.

Table 4.20: Failure impact energy properties of $\mathrm{Br}$ and $\mathrm{Sb}_{2} \mathrm{O}_{3}$ compounds.

\begin{tabular}{|c|c|c|c|c|c|c|}
\hline No & Description & $\begin{array}{c}\mathrm{Sb}_{2} \mathrm{O}_{3} \& \\
(\mathrm{Br}) \\
\text { contents }\end{array}$ & $\begin{array}{c}\text { Reduction } \\
\text { by } \mathrm{Sb}_{2} \mathrm{O}_{3} \\
(\%)\end{array}$ & $\begin{array}{l}\text { Reduction } \\
\text { by } \mathrm{Br}(\%)\end{array}$ & $\begin{array}{l}\text { Predicted } \\
\text { additive } \\
\text { loss }(\%)\end{array}$ & $\begin{array}{l}\text { Actual } \\
\text { loss } \\
(\%)\end{array}$ \\
\hline \multicolumn{7}{|c|}{$4 w t \%$ RS $+20 w t \%$ Bromine } \\
\hline 20 & $\mathrm{RS}+\mathrm{BTBPE}$ & $4.10(14.7)$ & $32(4)$ & $18(5)$ & $50(9)$ & $43(3)$ \\
\hline 21 & $\mathrm{RS}+\mathrm{TBBA}$ & $3.98(11.3)$ & $32(4)$ & $35(3)$ & $67(7)$ & $48(5)$ \\
\hline 22 & $\mathrm{RS}+\mathrm{DBDPO}$ & $4.06(19.2)$ & $32(4)$ & $69(1)$ & $101(5)$ & $80(3)$ \\
\hline 23 & $\mathrm{RS}(\mathrm{MB} 4)+\mathrm{BTBPE}$ & $4.40(13.6)$ & $3(5)$ & $18(5)$ & $21(10)$ & $17(5)$ \\
\hline 24 & $\mathrm{RS}(\mathrm{MB} 4)+\mathrm{TBBA}$ & $4.50(10.6)$ & $3(5)$ & $35(3)$ & $38(8)$ & $41(4)$ \\
\hline \multicolumn{7}{|c|}{$4 w t \%$ AZUB + 20wt $\%$ Bromine } \\
\hline 25 & pAZUB + BTBPE & $3.82(15.1)$ & $7(4)$ & $18(5)$ & $25(9)$ & $33(5)$ \\
\hline 26 & $\mathrm{pAZUB}+\mathrm{TBBA}$ & $4.34(8.3)$ & $7(4)$ & $35(3)$ & $42(7)$ & $32(4)$ \\
\hline 27 & SAZUB + BTBPE & $3.50(15.0)$ & $2(4)$ & $18(5)$ & $20(9)$ & $36(4)$ \\
\hline 28 & sAZUB + TBBA & $3.60(11.4)$ & $2(4)$ & $35(3)$ & $37(7)$ & $44(2)$ \\
\hline 29 & sAZUB + DBDPO & $4.03(17.3)$ & $2(4)$ & $69(1)$ & $71(5)$ & $77(2)$ \\
\hline 30 & sAZUB + sDBDPO & $5.15(16.7)$ & $2(4)$ & $65(1)$ & $67(5)$ & $71(3)$ \\
\hline 31 & $\mathrm{AZ}(\mathrm{MB} 5)+\mathrm{BTBPE}$ & $3.50(14.1)$ & $0(1)$ & $18(5)$ & $18(5)$ & $8(6)$ \\
\hline 32 & $\mathrm{AZ}(\mathrm{MB} 5)+\mathrm{TBBA}$ & $3.70(11.7)$ & $0(1)$ & $35(3)$ & $35(3)$ & $45(2)$ \\
\hline
\end{tabular}




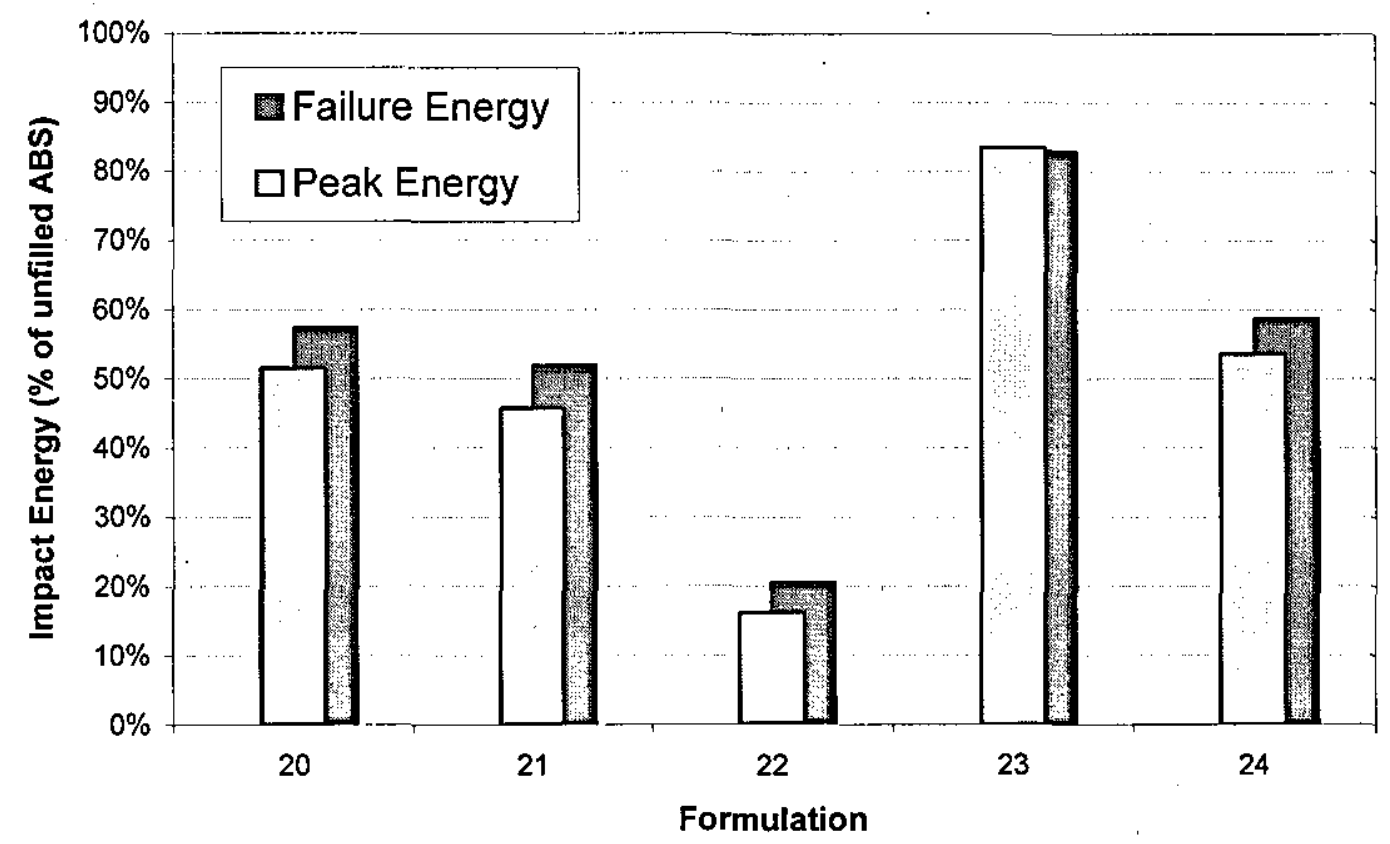

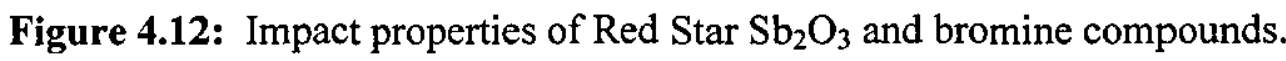

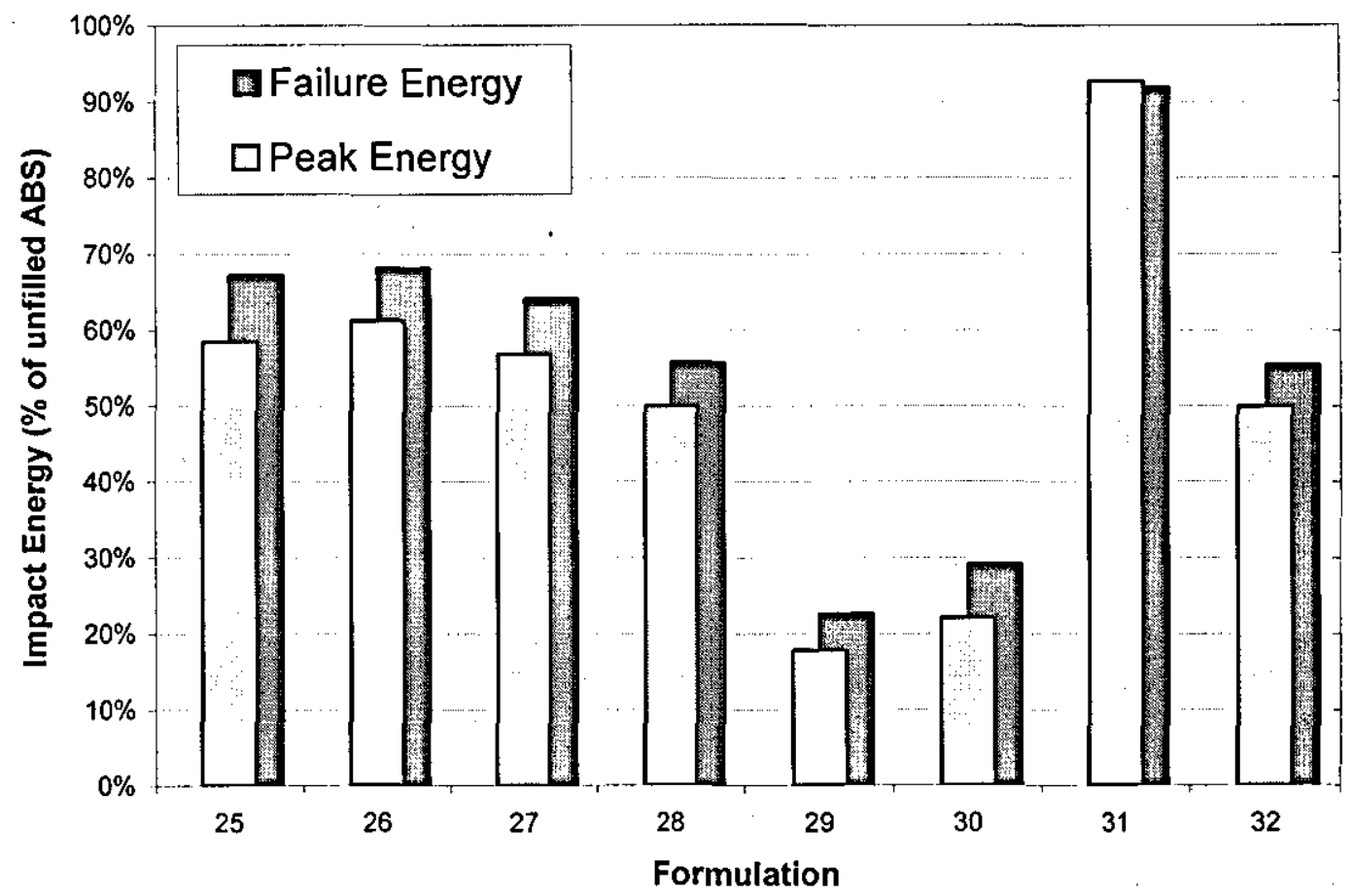

Figure 4.13: Impact properties of $\mathrm{AZUB} \mathrm{Sb}_{2} \mathrm{O}_{3}$ and bromine compounds. 


\section{Flexural Properties}

The flexural modulus and strength values for these formulations are shown in Table 4.21 and Figures 4.14 and 4.15. All the compounds had an increased flexural modulus, except for the two compounds containing BTBPE and masterbatched $\mathrm{Sb}_{2} \mathrm{O}_{3}$, which were significantly lower than the rest.

The flexural strengths of these compounds varied and did not follow a clear trend for all the compounds. The compounds containing TBBA did tend to have a higher strength value than unfilled ABS (as was seen when TBBA was added on its own in the previous section). As with the modulus values, the presence of masterbatched $\mathrm{Sb}_{2} \mathrm{O}_{3}$ with BTBPE significantly lowered the strength. Analysis of the peak deflection did not reveal any clear trends.

Table 4.21: Flexural properties of masterbatched $\mathrm{Sb}_{2} \mathrm{O}_{3}$ compounds and references.

\begin{tabular}{|c|c|c|c|c|c|}
\hline No & Description & $\begin{array}{c}\mathrm{Sb}_{2} \mathrm{O}_{3} \& \\
(\mathrm{Br}) \\
\text { contents }\end{array}$ & $\begin{array}{l}\text { Deflection } \\
@ \text { max load } \\
(\% \mathrm{ABS})\end{array}$ & $\begin{array}{l}\text { Flexural } \\
\text { Modulus } \\
(\% \text { ABS }) \\
\end{array}$ & $\begin{array}{l}\text { Flexural } \\
\text { Strength } \\
(\% \mathrm{ABS}) \\
\end{array}$ \\
\hline \multicolumn{6}{|c|}{$4 w t \%$ RS + 20wt $\%$ Bromine } \\
\hline 20 & $\mathrm{RS}+\mathrm{BTBPE}$ & $4.10(14.7)$ & $98(33)$ & $100(1)$ & $88(3)$ \\
\hline 21 & $\mathrm{RS}+\mathrm{TBBA}$ & $3.98(11.3)$ & $88(9)$ & $122(2)$ & $101(1)$ \\
\hline 22 & $\mathrm{RS}+\mathrm{DBDPO}$ & $4.06(19.2)$ & $92(9)$ & $103(1)$ & $90(1)$ \\
\hline 23 & RS (MB4) + BTBPE & $4.40(13.6)$ & $112(34)$ & $86(2)$ & $79(1)$ \\
\hline 24 & RS (MB4) + TBBA & $4.50(10.6)$ & $161(9)$ & $106(2)$ & $93(2)$ \\
\hline \multicolumn{6}{|c|}{$4 w t \%$ AZUB + 20wt \% Bromine } \\
\hline 25 & pAZUB + BTBPE & $3.82(15.1)$ & $90(28)$ & $104(1)$ & $90(1)$ \\
\hline 26 & $\mathrm{pAZUB}+\mathrm{TBBA}$ & $4.34(8.3)$ & $79(1)$ & $113(2)$ & $100(1)$ \\
\hline 27 & $\mathrm{sAZUB}+\mathrm{BTBPE}$ & $3.50(15.0)$ & $103(35)$ & $102(1)$ & $91(1)$ \\
\hline 28 & $\mathrm{sAZUB}+\mathrm{TBBA}$ & $3.60(11.4)$ & $80(1)$ & $123(1)$ & $108(1)$ \\
\hline 29 & sAZUB + DBDPO & $4.03(17.3)$ & $105(11)$ & $108(1)$ & $95(1)$ \\
\hline 30 & sAZUB + sDBDPO & $5.15(16.7)$ & $92(4)$ & $107(1)$ & $91(1)$ \\
\hline 31 & $\mathrm{AZ}$ (MB5) + BTBPE & $3.50(14.1)$ & $87(9)$ & $85(1)$ & $76(1)$ \\
\hline 32 & AZ (MB5) + TBBA & $3.70(11.7)$ & $124(39)$ & $105(1)$ & $90(1)$ \\
\hline
\end{tabular}




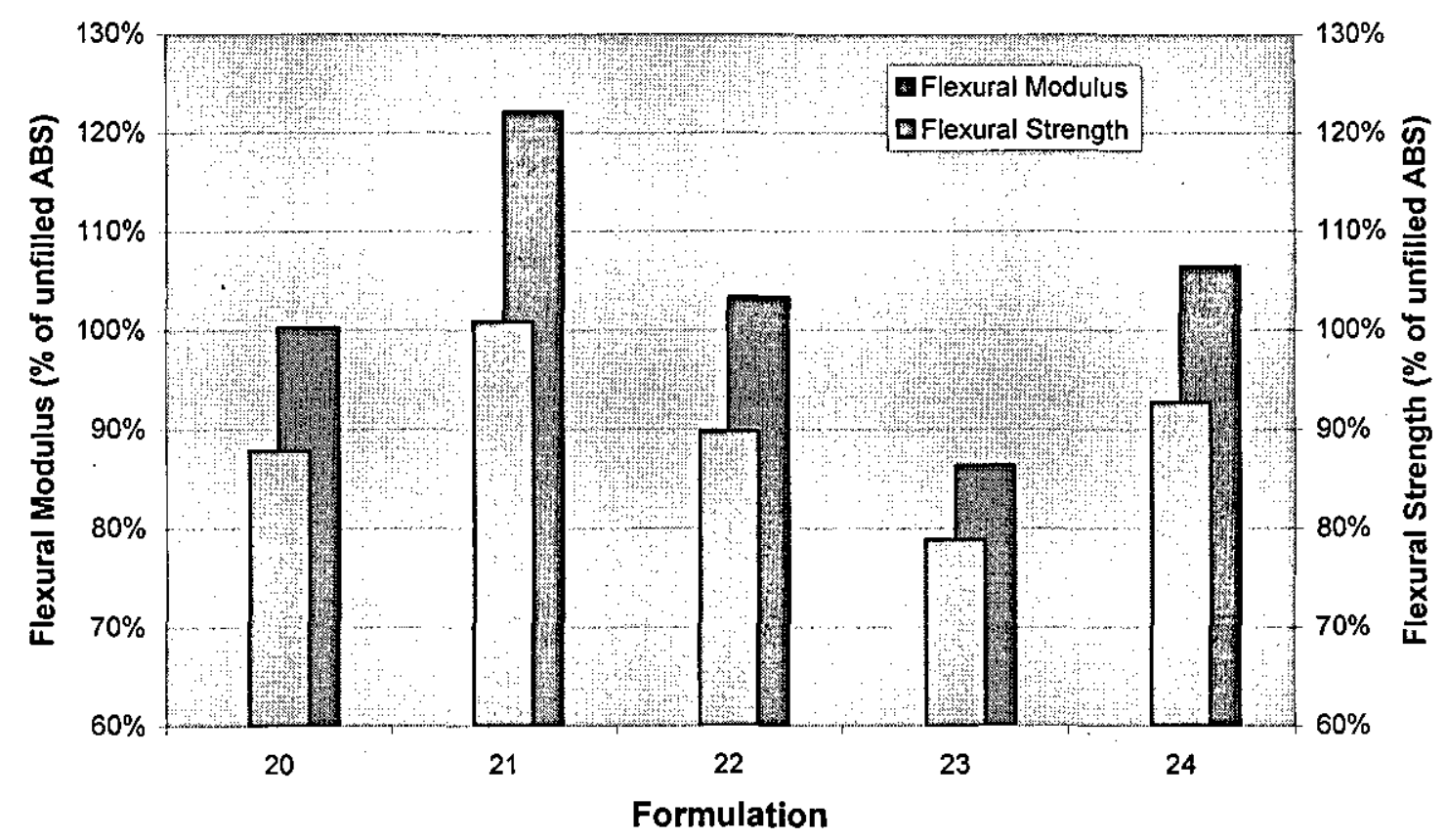

Figure 4.14: Flexural properties of Red Star and bromine compounds.

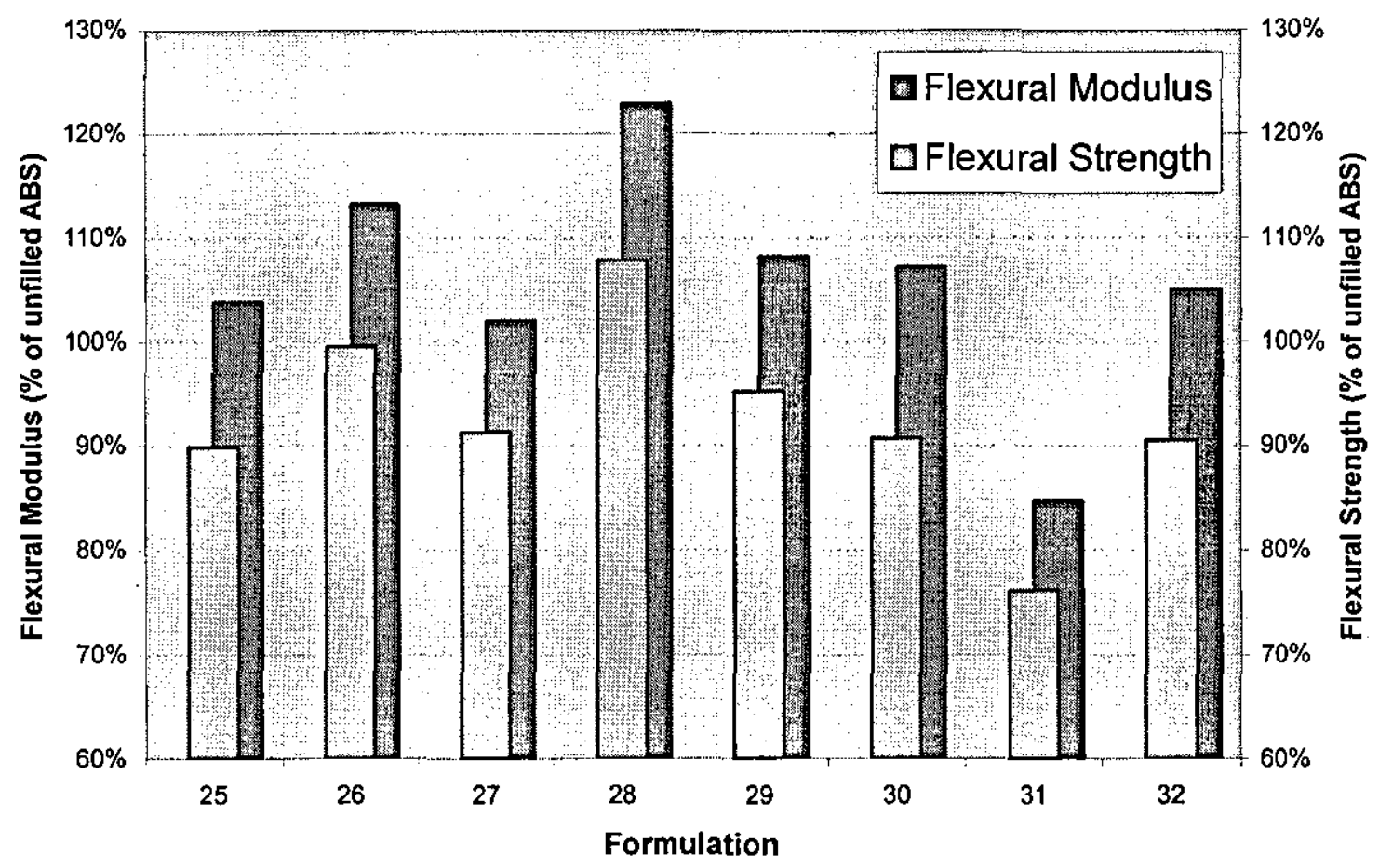

Figure 4.15: Flexural properties of AZUB and bromine compounds 


\subsubsection{Microscopy Analysis}

\section{Dispersion}

The previous section showed that the melt blended BTBPE and TBBA could not be located using either osmium tetroxide or ruthenium tetraoxide staining. STEM analysis and X-ray mapping carried out at several locations in sections of the compounds containing the two bromines did suggest a blanket effect of bromine across the samples with a slight increase in concentration at the butadiene/SAN interface. This was also the case for the samples in this section.

The location within the respective samples of the two DBDPO bromines was easily determined as these grades were not melt blendable. As seen with antimony trioxide the particles were located in the SAN phase and were well dispersed. In compound 29 (sAZUB + DBDPO) dispersion was generally good (Plate 4.30), but some agglomerates were seen. Closer examination of these agglomerates (Plate 4.31) using elemental analysis revealed them to be agglomerates of antimony trioxide.

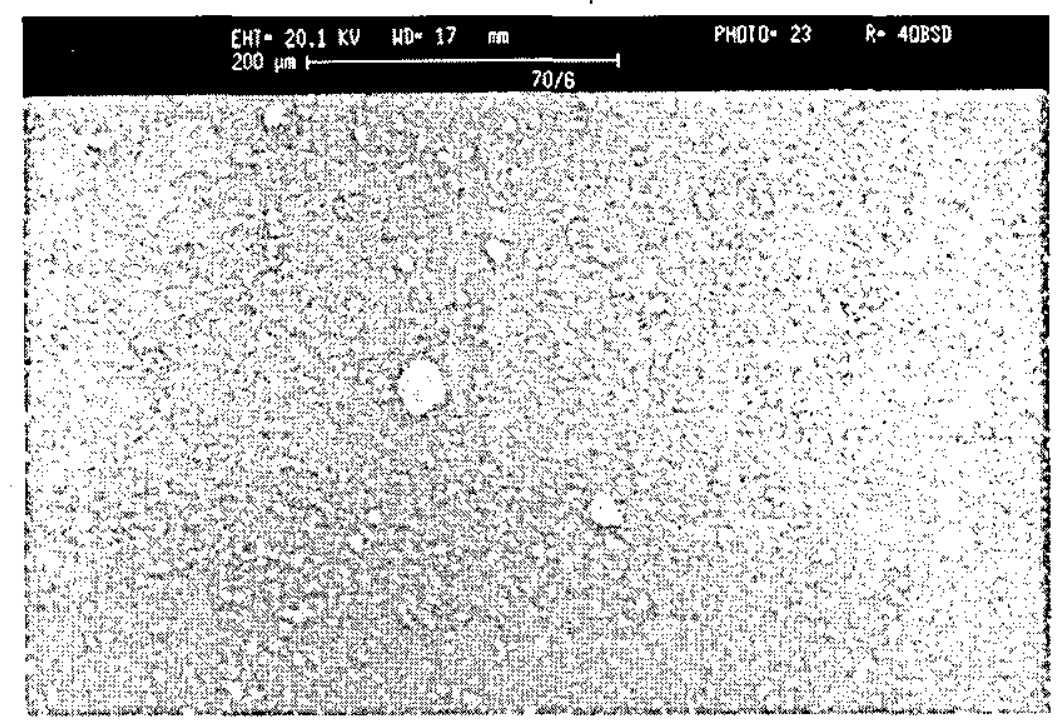

Plate 4.30: Back scattered electron image of SAZUB and DBDPO particle dispersion. 


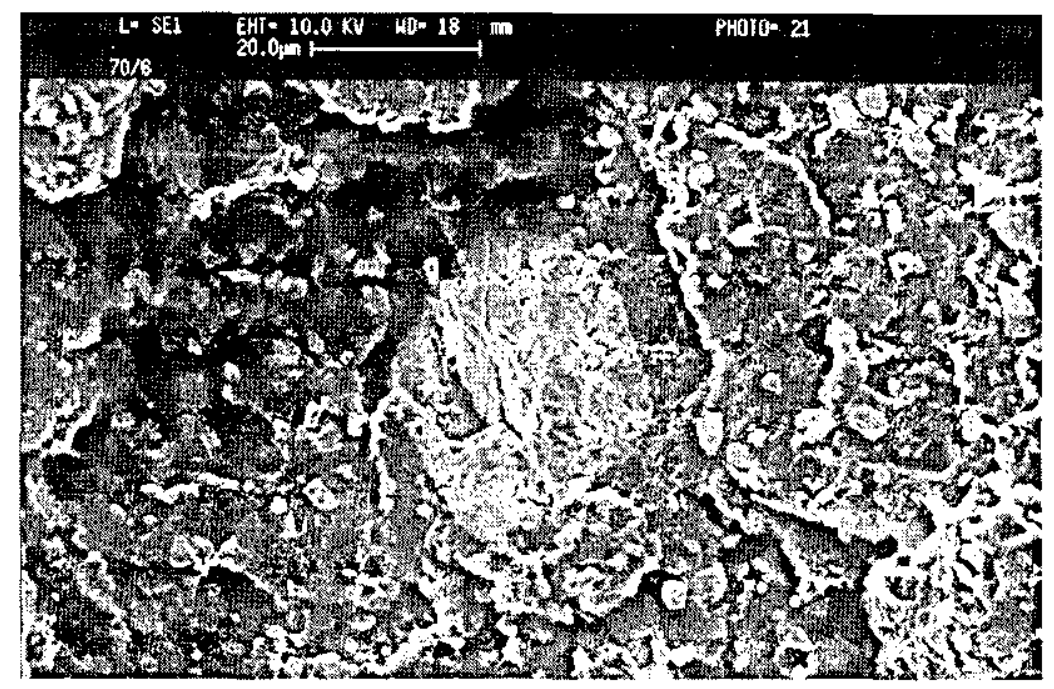

Plate 4.31: $\mathrm{SEM}$ image of $\mathrm{SAZUB} \mathrm{Sb}_{2} \mathrm{O}_{3}$ agglomerate (and DBDPO particles).

\section{Fracture}

Fracture surfaces were increasingly coarser with decreasing impact energy retention. Plates 4.32 and 4.33 show fracture surfaces of MB RS + BTBPE and MB RS + TBBA respectively. The smoother surface of the BTBPE can clearly be seen. The fracture mechanism seen across the bulk of the specimen also appears to continue to the point of failure (far left). The TBBA sample however appears to have two distinctly different fracture surfaces with the latter (far left) appearing to be indicative of brittle failure.

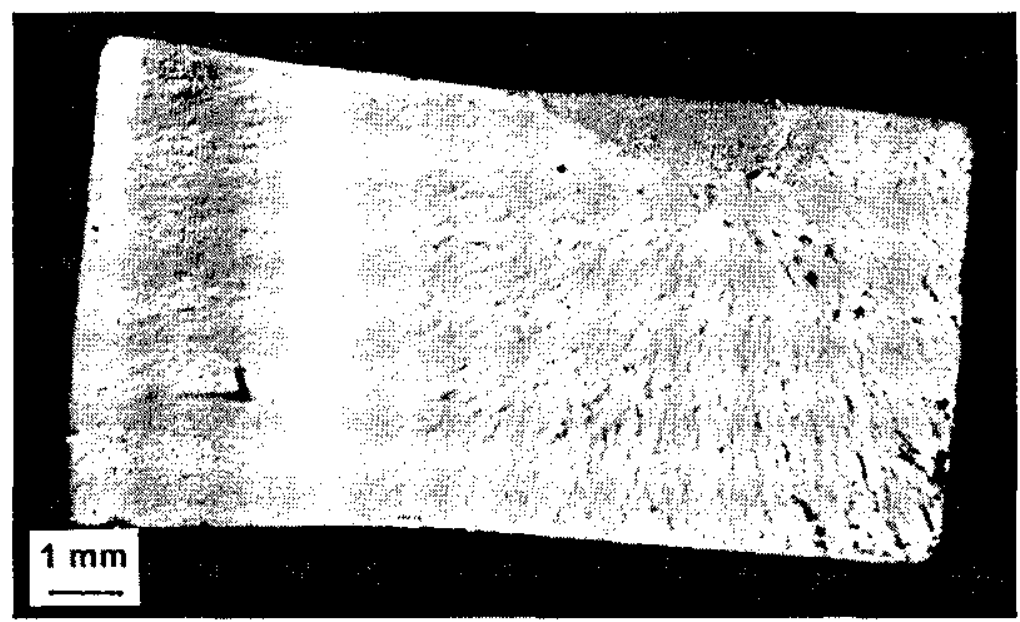

Plate 4.32: Optical microscope image of MB RS + BTBPE fracture surface. 


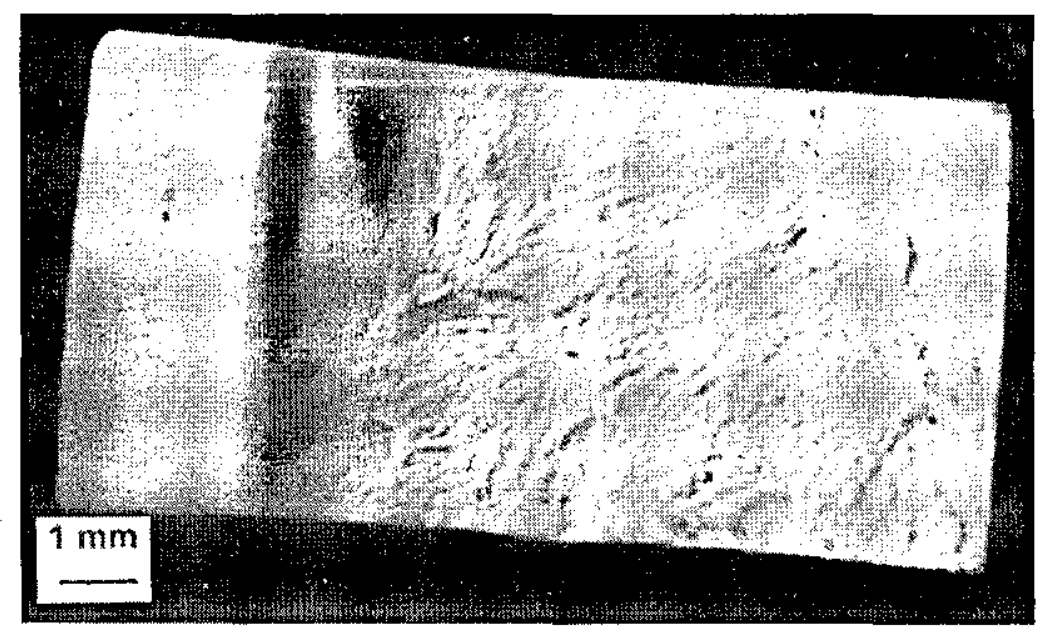

Plate 4.33: Optical microscope image of MB RS + TBBA fracture surface.

\subsubsection{Flame Testing}

Table 4.22 shows the results of both LOI and UL-94 flame tests on the compounds containing both $4 \mathrm{wt} \% \mathrm{Sb}_{2} \mathrm{O}_{3}$ and $20 \mathrm{wt} \%$ bromine. The presence of both the additives raised the LOI values of the compounds further than the values seen previously for either antimony trioxide or bromine only. The increases in performance (when compared to the bromine only values) were: BTBPE $(6.0,8.1,5.5,5.0$ and $4.5 \%)$, TBBA (6.1, 7.5, 2.8, 4.8 and 6.0\%), DBDPO (5.5 and 4.6\%) and SDBDPO (6.4\%). These are all significantly higher increases than the increase seen for antimony trioxide grades only, which indicates the synergistic relationship between the two additives.

The UL-94 tests showed that the BTBPE compound tended to drip, which resulted in a $\mathrm{V}-2$ rating. This also occurred for the TBBA material, but not for DBDPO hence the V0 reading. The combination of the BTBPE as well as the increased percentage of polybutadiene in compound 23 again lead to drips igniting the wool. MB RS + TBBA did not exhibit any dripping.

The presence of the wax in the AZUB material lead to dripping of the polymer in many of the AZUB formulations, which meant that many of the compounds received a V-2 rating. 
Table 4.22: Influence of bromine material on flame properties of ABS.

\begin{tabular}{|c|c|c|c|c|c|c|}
\hline No. & Description & $\begin{array}{c}\mathrm{Sb}_{2} \mathrm{O}_{3} \\
\text { content } \\
(\mathrm{wt} \%) \\
\end{array}$ & $\begin{array}{c}\mathrm{Br} \\
\text { content } \\
(\mathrm{wt} \%) \\
\end{array}$ & LOI & $\begin{array}{l}\text { UL-94 } \\
\text { value }\end{array}$ & $\begin{array}{c}\text { UL-94 Total } \\
\text { burn time } \\
\text { (s) }\end{array}$ \\
\hline \multicolumn{7}{|c|}{$4 w t \%$ RS $+20 w t \%$ Bromine } \\
\hline 20 & $\mathrm{RS}+\mathrm{BTBPE}$ & 4.10 & 14.7 & 28.5 & $\mathrm{~V}-2$ & 60 \\
\hline 21 & $\mathrm{RS}+\mathrm{TBBA}$ & 3.98 & 11.3 & 28.2 & $\mathrm{~V}-2$ & 50 \\
\hline 22 & $\mathrm{RS}+\mathrm{DBDPO}$ & 4.06 & 19.2 & 29.6 & $\mathrm{~V}-0$ & 1 \\
\hline 23 & $\mathrm{RS}(\mathrm{MB} 4)+\mathrm{BTBPE}$ & 4.40 & 13.6 & 30.6 & $V-2$ & 65 \\
\hline 24 & $\mathrm{RS}(\mathrm{MB} 4)+\mathrm{TBBA}$ & 4.50 & 10.6 & 29.6 & $\mathrm{~V}-0$ & 10 \\
\hline \multicolumn{7}{|c|}{$4 w t \%$ AZUB + 20wt \% Bromine } \\
\hline 25 & pAZUB + BTBPE & 3.82 & 15.1 & 28.0 & $\mathrm{~V}-2$ & 33 \\
\hline 26 & $\mathrm{pAZUB}+\mathrm{TBBA}$ & 4.34 & 8.3 & 24.9 & FAIL & 228 \\
\hline 27 & sAZUB + BTBPE & 3.5 & 15.0 & 27.5 & $\mathrm{~V}-0$ & 23 \\
\hline 28 & sAZUB + TBBA & 3.6 & 11.4 & 26.9 & $\mathrm{~V}-2$ & 41 \\
\hline 29 & sAZUB + DBDPO & 4.03 & 17.3 & 28.7 & V-0 & 3 \\
\hline 30 & sAZUB + sDBDPO & 5.15 & 16.7 & 29.7 & $\mathrm{~V}-2$ & 19 \\
\hline 31 & $\mathrm{AZ}(\mathrm{MB} 5)+\mathrm{BTBPE}$ & 3.5 & 14.1 & 27.0 & $\mathrm{~V}-2$ & 80 \\
\hline 32 & $\mathrm{AZ}(\mathrm{MB} 5)+\mathrm{TBBA}$ & 3.7 & 11.7 & 28.1 & $\mathrm{~V}-0$ & 18 \\
\hline
\end{tabular}




\section{DISCUSSION}

\subsection{Analysis of Materials Used}

\subsubsection{Cycolac T (ABS) Polymer}

The ABS microstructure was studied using the TEM, which revealed that the polymer structure consisted of grafted polybutadiene particles within the SAN matrix (see Plate 4.1). These were discrete within the SAN giving a homogenous system. The particles were well dispersed and had little or no occluded SAN, which suggested that the polymer was processed using emulsion polymerisation techniques. This confirmed the supporting data sent by the suppliers. The butadiene particles ranged in size from 0.02 to $0.8 \mu \mathrm{m}$ (within the optimum particle size range [33]) as mentioned in Section 4.1.1. The particles were roughly spherical but tended to become more elliptical due to the sectioning process. The longer axis of the ellipse tended to be parallel to the sectioning direction. As this grade was a medium impact grade this range of particles was within the optimum size to give impact properties in the middle of the ABS range [149]. Sizes greater than $1 \mu \mathrm{m}$ were not expected as that size of particle would have resulted in coagulation of the butadiene particles during the polymerisation process. No particles of this size were seen in the supplied material. Comparisons between unprocessed and processed Cycolac $\mathrm{T}$ will enable analysis of the effect of processing on the butadiene phase and thereby allow assessment of its impact effectiveness.

\subsubsection{Antimony Trioxide}

\subsubsection{Particle sizing}

Particle sizing of the three grades was carried out using both laser sizing and Coulter counter equipment. Both the RS and A05 grades presented few problems during the sizing analysis. Good correlation was seen between the sizing data and the SEM and TEM sizing analysis. The RS particles were seen to be regular cubic shaped with no indication of needle-like particles (orthorhombic phase). Owen [76] found that X-ray diffraction studies showed the presence of trace amounts of this phase $(<5 \%)$ with visual investigations also failing to reveal their presence. 
The sub-micron particles of the AZUB material presented a problem due to the tendency of smaller particles to agglomerate unless suitably dispersed. The wax binder used to prevent undue agglomeration could not be used to disperse particles prior to sizing as any measurement would then be measuring both wax and antimony trioxide. This problem is shown in Appendix A where the effect of poor dispersion and agglomeration is clearly seen in the sizing results. The sizing of the AZUB showed some larger particles, which were actually agglomerates of the finer particles. This was an obvious complication to the sizing procedure. TEM work on spray dried AZUB material did reveal the presence of some agglomerates on the surface but a lower amount than was suggested by the sizing procedure. The particles were angular and appeared similar to those of A05, the material from which all the AZUB grades were manufactured (excluding AZUB ${ }^{(\mathrm{RS})}$ which was developed from Red Star).

\subsubsection{Packing characteristics}

The bulk density for a series of powders usually follows a trend of increasing in value as the average particle size increases, due largely to the ability of the smaller particles to fill the spaces between the coarse particles. This was not seen in this work where the bulk density for the AZUB material $(0.11 \mu \mathrm{m})$ was greater than that of the A05 material $(0.52 \mu \mathrm{m})$. This was most probably due to the presence of the castor wax in the AZUB material affecting the dry state packing. The presence of the wax binder meant that the effect of dry powder particle size could not be directly related.

It is worth noting that the bulk density property of a filler can have an influence on the feeding properties of the powder into extrusion equipment and thereby is a limiting factor. This fact is of less significance in this work due to the small loading levels used. The bulk density becomes more significant with increased filler loadings.

The oil absorption values showed an increase in value with decreasing particle size. This test is dependent on the surface area of the filler (as well as particle size, shape and size distribution). The oil absorption usually increases with decreasing particle size due to the increase in available surface area. Previous BET surface area analysis work on 
the same materials showed that RS and A05 (AZUB not available) had values of 2.72 and $7.31 \mathrm{~N}_{2} \mathrm{~m}^{2} / \mathrm{g}$ respectively [76]. This increase with decreasing particle size was seen in the oil absorption readings, although not by as large an increase as suggested by the BET values.

The oil absorption of the AZUB material was significantly higher than the other values, most likely due to the small particle size (and assumed high surface area). The presence of the wax would also have an influence on the absorption. The action of rubbing with the spatula could break down some of the agglomerates seen in the sizing data, thereby creating more available surface for absorption.

\subsubsection{Brominated halogens}

Particle sizing of the brominated materials was only relevant for the two DBDPO grades as the other two bromines were melt blendable. TEM analysis revealed that the DBDPO particles were similar in size to the Red Star particles $(1.31 \mu \mathrm{m})$. The sDBDPO material had been milled from this DBDPO material, although analysis showed that little reduction in size occurred.

The thermal degradation properties of the two materials were significantly lower in value than those figures supplied by the manufacturers. The values differed by over $50^{\circ} \mathrm{C}$ in most cases. This large difference could perhaps be due to different testing conditions (such as heating rate and gas supply used which were not quoted in the literature) or perhaps the quality of the material tested. If the material tested by the suppliers was a high purity 'ideal case' sample then large differences could be present between that and a sample taken from a mass-produced commercial grade. Earlier work on identical material suggests that this is the case as the results between that study and this are far more consistent. (N.B. A representative of the supplying company stated that the testing conditions led to the higher values [155]). 
The BTBPE was seen to be more thermally stable than the TBBA which correlates with melting temperatures: TBBA $\left(179-181^{\circ} \mathrm{C}\right)$ and BTBPE $\left(223-228^{\circ} \mathrm{C}\right)$. This does not follow for other bromines and perhaps this fact is less significant. More significant may be the temperature range from onset to end of degradation. BTBPE degraded completely over a range of 120 to $130{ }^{\circ} \mathrm{C}$ whilst TBBA degraded to $5 \%$ mass left over a range of 320 to $330^{\circ} \mathrm{C}$.

\subsection{Analysis of Unfilled ABS Compounds}

\subsubsection{Processing}

The Cycolac $\mathrm{T}$ ABS polymer was fed into the extruder from a polymer feed hopper.

The material was taken straight from the sealed supplied bag(s) where possible in order to avoid any contamination. The polymer was not dried prior to compounding, as ABS is not susceptible to excessive moisture retention. Drying the quantities of polymer needed for the compounds would also have been logistically difficult to accomplish. Feeding of the polymer was easy and extrusion was made easier through the use of a vacuum unit to remove any volatilised products. This had a noticeable effect on the melt properties, reducing the amount of melt strand breakage.

\subsubsection{Thermal Properties}

TGA analysis showed that the two curves of as supplied and compounded ABS were near identical. This suggests no detrimental effects on the thermal properties of the polymer from the compounding procedure.

\subsubsection{Impact and Fracture Properties}

Impact properties of the compounded ABS were as expected based on results from earlier work using this polymer grade [76]. Analysis of the fracture surfaces of the samples initially revealed the presence of one or two craters in some samples (Plate 4.13). These corresponded to slightly lower impact energy values. These craters appeared to be formed due to the presence of either processing inclusions (either 
porosity or a material impurity) or a point of weakness within the polymer structure. Cycolac $T$ contains a small quantity of excess monomer (due to its production method), which could cause these localised weaknesses. This problem could be avoided (or minimised) by improving the polymerisation procedure for the ABS. More modern ABS polymers, with similar impact strength but lower residual monomer have been created. These make use of separate production routes for the polybutadiene and SAN phases, which are then reacted together. The G100 ABS grade by GE Plastics is one example of a polymer produced by this technique [36].

A stress-whitened zone was seen from the fracture surface down to a depth of between 1 $\mathrm{mm}$ and $3 \mathrm{~mm}$ for each sample, which was indicative of the failure mechanisms within the polymer. Craze yielding was the predominant mechanism with cavitation and shear yielding also occurring to lesser extents. Crazing was seen in the stained sections. It initiated predominantly at the points of maximum principal strain (i.e., at the equator) of the polybutadiene particles $[150,151]$. The crazes ran in directions normal to the applied stress with the craze fibrils forming in the stress direction. Crazing was seen to occur mostly between the larger particles with little or no crazing occurring in areas of the sample devoid of larger particles (Plates 4.14, $15 \& 16$ ).

Cavitation within the polybutadiene phase was also observed in the stress-whitened zone (Plate 4.14) but not in the area away from this zone. This suggested that the effect was caused by some energy absorption mechanism rather than as an effect of sectioning the material. Generally the butadiene cavitated in particles greater than or equal to a diameter of approximately $0.1 \mu \mathrm{m}$. No cavitation was seen for particles less than this except in the case where a craze passes through a smaller particle between larger particles (Plate 4.15).

Amongst the authors who have studied this field, Donald et al [156] have found that this combination of multiple crazing of the matrix and cavitation of the elastomer particles occurred. The ABS grade that was used had particles in the $1 \mu \mathrm{m}$ range (which was slightly larger than many of the butadiene particles seen in the Cycolac $\mathrm{T}$ grade). Notably though the elastomer phase in the ABS used by Donald had occluded matrix polymer within them, which was not found in this study. 


\subsubsection{Flexural Properties}

The three-point bend testing of the six unfilled ABS compounds gave average results of $2219 \mathrm{MPa}$ for the flexural modulus and 65.4 MPa for the flexural strength. These agreed closely with those values quoted by the manufacturers (2200 and $64 \mathrm{MPa}$ respectively) [104]. The samples in this study were tested at $5 \mathrm{~mm} / \mathrm{min}$ compared to 2 $\mathrm{mm} / \mathrm{min}$ for the manufacturers values. This could partly explain the differences seen between the two sets of data. Sixteen samples were tested to a maximum deflection of $12 \mathrm{~mm}$ and no samples were seen to break.

\subsubsection{Flame Properties}

LOI testing gave a result of 18.6. This value was in agreement with previous data, which stated a range of 18.3 to 18.8 for $\mathrm{ABS}$ [157]. For this grade of ABS it is clear that this value is below that of oxygen in air (20.8) and would therefore burn in normal atmospheric conditions once ignited. UL-94 testing was carried out with the ABS achieving a FAIL classification. This result was expected but testing was carried out to provide a basis with which to compare all other formulations containing Cycolac $\mathrm{T}$.

\subsection{Influence of Antimony Trioxide Particle Size (direct addition)}

\subsubsection{Compounding}

Compounding of the formulations containing $4 \mathrm{wt} \%$ direct addition did not cause any problems and all melts exhibited good strength. Melt strengths of these compounds were slightly better than for unfilled ABS with none of the strands thinning or breaking (as occasionally occurred for ABS only). A small difference could be seen between the formulations containing the RS and the AZUB materials with the melts containing the larger particles being slightly more brittle. Readings taken during the compounding did not reveal any clear trends except in the case of the AZUB materials. The lower die pressures recorded for these compounds could be attributed to the presence of the small percentage of low viscosity binder wax in these compounds. 
Previous work [76] stated that TEM analysis of the compounded antimony trioxide grades showed that the compounding resulted in particle size reductions of between 0.1 and $0.2 \mu \mathrm{m}$. Analysis of the samples showed smaller particles than the stated averages (for the RS grade) although it was not clear as to whether compounding had caused any size reduction. The process of sectioning could also have affected the particle size. Some of the larger particles tended to crumble and break during analysis so exact measurement of their dimensions was difficult.

\subsubsection{Impact Properties}

The reduction in impact properties when the different grades of antimony trioxide were added to ABS can first be explained through dilution effects. Incorporation of a filler reduces the amount of polymer available to absorb the impact energy and therefore impact properties can be reduced. The particles act as stress concentration points which will tend to de-bond with the matrix under loading, thereby creating voids and interfering with the normal polymer fracture mechanisms. The amount of antimony trioxide was approximately the same in each compound $(4 \mathrm{wt} \% \approx 1 \mathrm{vol} \%)$ but the results varied with particle size suggesting that this property had a large effect on the end results. Larger particles raise stress within compounds and thereby lower the ability to absorb impact energies [45]. Lowering the particle size has been seen to improve this situation, although at low particle sizes $(<0.2 \mu \mathrm{m})$ agglomerates can form due to the high particle / particle attractive forces [59]. These agglomerates then result in a decrease in impact energy absorption. In the case of the AZUB material this problem was avoided through use of the binder resin wax.

In addition to the average size of the particles, the size distribution can also have a large significance on the results. Figure 4.1 shows the particle size distribution curves for RS, A05 and AZUB. The RS and A05 have broader curves than the AZUB as well as having some larger particles over $2 \mu \mathrm{m}$. Due to their size these large particles will lend themselves to greater reductions in impact properties [45]. Figure 4.4 clearly shows the drop in impact energy when the RS and A05 grades are added to ABS. The slight 
reduction in particle size of the $\mathrm{RS}(1.31 \mu \mathrm{m})$ material in the $\mathrm{AZUB}^{(\mathrm{RS})}$ grade $(1.18 \mu \mathrm{m})$ shows that decreasing the particle does improve increase impact energy retention.

Overall the use of the $0.11 \mu \mathrm{m}$ AZUB materials resulted in a large improvement in the total impact energy absorbed by the samples. The use of a finer particle size grade incorporated with a suitable carrier resin has clearly shown to be appropriate for improving impact properties over the $0.52 \mu \mathrm{m}$ and $1.31 \mu \mathrm{m}$ grades. Whilst the smaller particle size was a large factor, the carrier wax also affected properties slightly (Figure 4.4). The addition of a small amount of castor wax (equivalent to that found in the AZUB material when loaded to give $4 \mathrm{wt} \% \mathrm{Sb}_{2} \mathrm{O}_{3}$ ) lowered impact energy absorption although by only $1 \%$. The castor wax was a low molecular weight $\left(M_{w}=1000\right)$ material with excellent lubricating properties [152]. These lubricating effects could be occurring at the interface between the filler and polymer or between the polymer chains to enable chain movement and thereby enable increased energy absorption. Through use of this new material it is now possible to produce an $\mathrm{ABS}$ containing $4 \mathrm{wt} \% \mathrm{Sb}_{2} \mathrm{O}_{3}$ with very little detrimental effects on compound impact properties.

\subsubsection{Flexural Properties}

The flexural properties did not appear to have any dependence on particle size. The modulus values were similar to unfilled ABS with both the RS and SAZUB compounds having slightly higher values. No trend was therefore apparent for changes in particle size. The bound layer theory of Vollenberg et al. [95], which suggests an increase in modulus with decreasing filler size due to the interaction of dense 'bound layers' around a filler particle, does not appear to be relevant in this case. This is probably due to the low volumetric loadings used in this work. At higher loadings the closer interaction of the filler particles (and their bound layers) would be more likely to increase modulus values.

As with the modulus the flexural strength did not follow any clear trend although the two compounds with the larger particles (RS and $\mathrm{AZUB}^{(\mathrm{RS})}$ ) had the lowest strengths. All other compounds had flexural strengths 3 to $4 \%$ lower than the unfilled ABS value. 
Significant effects on flexural strength would have been unusual due to the relatively low volumetric loading levels of the antimony trioxide.

Peak deflection results for these compounds also failed to reveal any trend relating to particle size.

\subsubsection{Dispersion}

Dispersion of the antimony trioxide in the samples was determined using thin microtomed sections in the TEM as well as samples 'polished' using the glass knife microtome in the SEM. Polishing the SEM surface was carried out in order to eliminate the likelihood of a misrepresentative fracture surface on the sample. If fracture propagation occurred through (or near) the larger particles then these would be seen in the surface analysis. All the samples appeared to be better in the TEM sections as these avoided smearing of the antimony trioxide. Samples analysed in both the TEM and SEM were seen to generally have good dispersion for all particle sizes. This dispersion was aided by the fact that the surface of the antimony trioxide was virtually unreactive after the manufacturing process. This heating process created a 'dead-burned' product due to roasting and re-roasting. If there was little interaction between particles there was therefore less chance of agglomerates forming. The unreactive surface also prevented excessive water absorption, which would also lead to agglomeration. In the case of the RS and A05 the mixing achieved within the compounder (and to some extent the injection moulder) was sufficient to achieve good dispersion. The fine particles in the AZUB materials were introduced to the compounding process in a wetted form (using the wax binder), which prevented agglomerates forming. This method also prevented re-agglomeration of the antimony trioxide occurring and this was seen in the sectioned samples.

Some large particles were seen within samples of RS and A05 compounds and analysis of these revealed that these were not agglomerates but single large particles that were present from the coarse end of the particle size distribution. 
Analysis of the samples in the TEM microtomed sections also showed that the antimony trioxide was located in the SAN phase of the ABS. This was most likely to occur due to the fact that the energy required to incorporate the $\mathrm{Sb}_{2} \mathrm{O}_{3}$ into the $\mathrm{SAN}$ phase was far lower than that required to incorporate into the butadiene phase.

\subsubsection{Fracture}

When the antimony trioxide was incorporated into the ABS matrix it was seen that the particles had little or no interaction with the matrix. During crack propagation these (coarse) particles represent weaknesses within the matrix and offer a route for further propagation. This is due to the fact that the particle cannot deform in the same manner as the surrounding polymer matrix which will then usually result in debonding at the particle / matrix interface. This effect would be greater with more coarse particles as the larger cavity created would be more likely to reach and exceed the critical crack size required for further propagation. Similar debonding with fine sized particles would be less likely to reach the critical crack size. In compounds with fine particle sizes the small voids created by their presence may be less influential and damaging because surrounding butadiene particles would be able to distort in order to accommodate the stress.

These factors affect the topography of the fracture surface. The larger particle sizes create a more coarse fracture surface than the surface seen for fine particle compounds. The coarse surface occurs because the crack propagates from large particle to large particle across relatively large distances (due to there being less particles in the direct fracture path). Fracture propagation in the compounds containing fine particles does not occur across large distances between critical stress points. Instead it travels shorter distances to move between particles and gives a resultant smoother surface. In the fine particle compound there should be more fine particles at the fracture surface due to this process. 
The fracture process for all grades of antimony trioxide was seen to be failure by debonding around the particles. This is the route that requires the least amount of energy. Evidence is shown in Plate 5.1 and clearly shows whole particles at peaks or troughs of deformation craters along the fracture surface. If particles are present at both the peak and relevant trough (of the opposite fracture surface) then this would indicate intergranular failure, which was not present in these compounds.

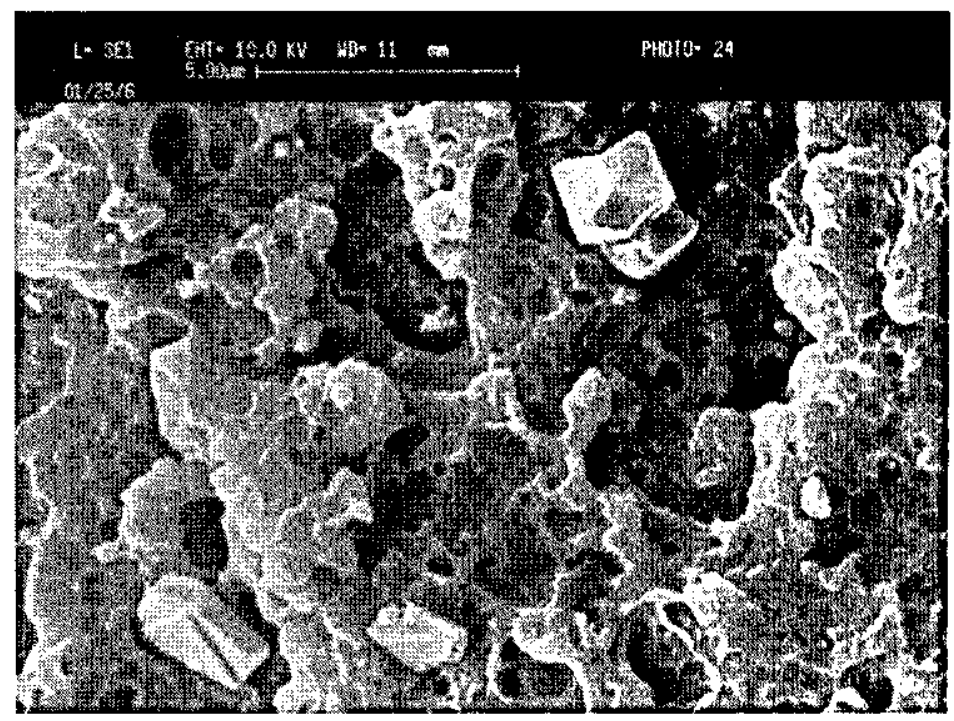

Plate 5.1: SEM image showing RS particles embedded in fracture surface.

Although the different antimony trioxide grades were generally well dispersed, fracture surface analysis did reveal some agglomerates in the A05 compound (Plate 4.19). These agglomerates were visually observed due to the formation of the elliptical crater around them, which forms when localized yielding occurs ahead of the crack front. Due to the reduced amount of polymer available to dissipate the energy the crater forms. Once past the stress concentration point the crack propagation proceeds as normal and the crater 'disappears' (see Plate 5.2). 


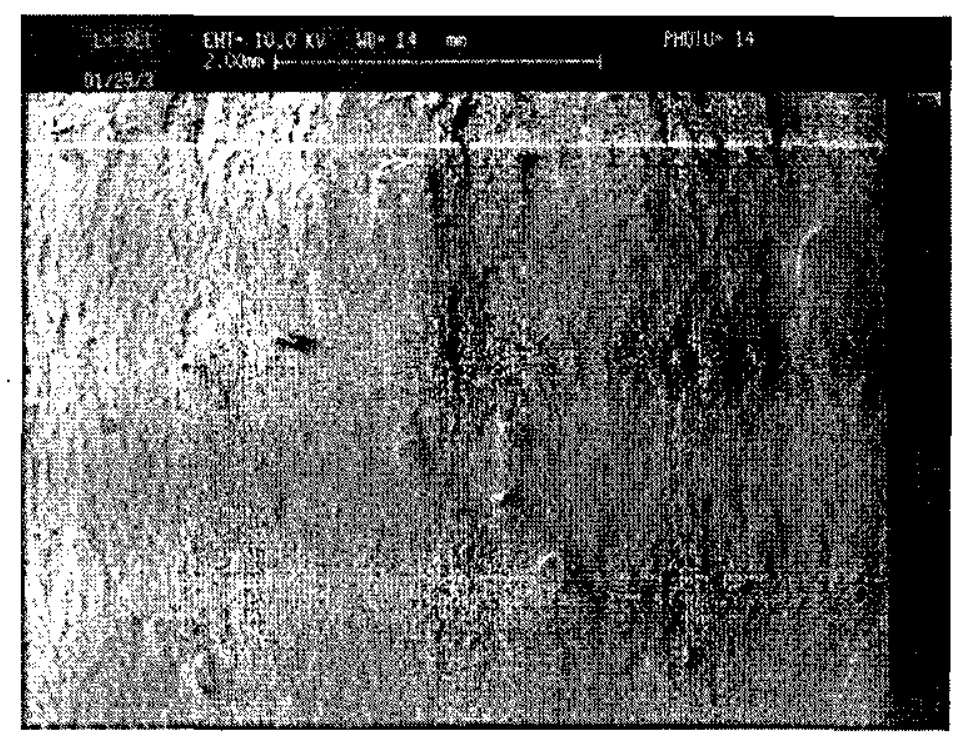

Plate 5.2: SEM image of fracture surface of RS compound.

Analysis of the crazing and cavitation phenomena showed that the amount of crazing was greatest in the compounds containing AZUB and reduced with increasing particle size. Crazing occurs ahead of the crack tip to dissipate the subjected energy as well as deforming the material in the crack tip region. Work by Bucknall [38] looking at crazing shows that the impact absorption is directly linked to the amount of crazing within the sample. This ties in with the results found in this work. The crazes seen were of similar dimensions in all the samples. The only difference was the number of crazes with the greatest number being in the AZUB samples. The amount of crazes dropped considerably from the AZUB to the RS sample, indicating that the reduction in energy absorption of the RS grade was predominantly due to this phenomenon. This is difficult to quantify however as it is difficult to ensure that the samples were taken from exactly the same depth and location in each sample. This is essential as the density of the crazes alters as a function of distance from the surface.

\subsubsection{Flame Properties}

LOI testing of all the samples showed a spread of results from 18.6 to 19.1. There was no clear trend regarding particle size but there was a near linear trend dependent on the amount of antimony trioxide within the samples (see Figure 5.1). This would suggest a dilution effect. This relationship is valid for these compounds but does not extrapolate back to zero. 


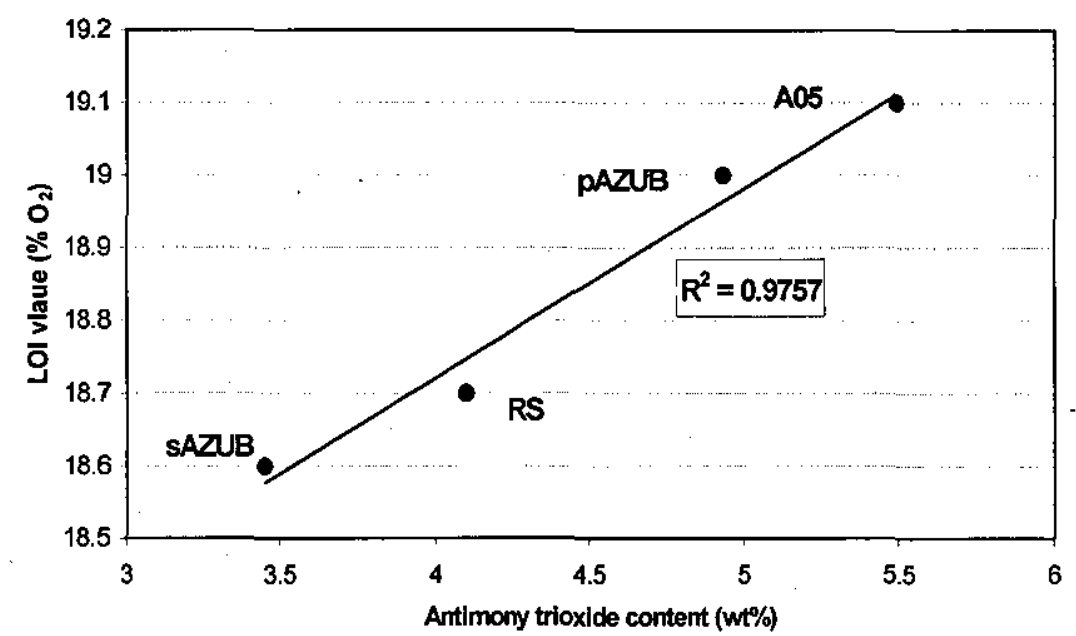

Figure 5.1: Graph showing relationship between LOI value and $\mathrm{Sb}_{2} \mathrm{O}_{3}$ loading.

UL-94 testing was also carried out in order to create further references with which to compare later fully flame retarded formulations. All the samples failed (as expected) with the total burn time decreasing slightly from the value(s) obtained for unfilled ABS. These results also followed a linear trend with those samples containing more antimony trioxide having a slightly lower total burn time.

\subsection{Analysis of $\mathrm{Sb}_{2} \mathrm{O}_{3}$ Addition Using Masterbatches}

\subsubsection{Compounding}

Initial work on the APV twin-screw extruder using the high rubber content ABS grade Blendex 310(S) from GE Specialty proved difficult. Initially Blendex $310(\mathrm{~S})$ was compounded on its own (from powder to pellet form) in order to relate its properties to those of Cycolac T. 
The Blendex 310(S) was compounded according to settings given by a representative of GE Specialty [143] but was found to be highly viscous and caused a pressure overload, which stopped the machine. The extrudate was solid on exiting the die and exhibited a darkening in colour toward the centre of the melt. Altering temperatures, input feed rates and screw speeds to various combinations did not improve the quality of the melt, indeed further degradation was seen to occur. Due to these problems it appeared that the only remedy to aid processing would be to combine the Blendex with another polymer. Cycolac $\mathrm{T}$ was used with the blend ratio being determined by the work on the laboratory Haake Rheocord.

Due to the problems with the Blendex $310(\mathrm{~S})$ polymer the processing conditions had to be altered to enable processing. The blend of Blendex and Cycolac, as well as the three masterbatches were all run at $4 \mathrm{~kg} / \mathrm{hr}$. At higher feed rates the pressure at the die head exceeded the cut off point for the APV compounder, which would then automatically switch off to avoid damage to the pressure transducer. The torque values were lower than normal to reduce the amount of shear heating within the melt.

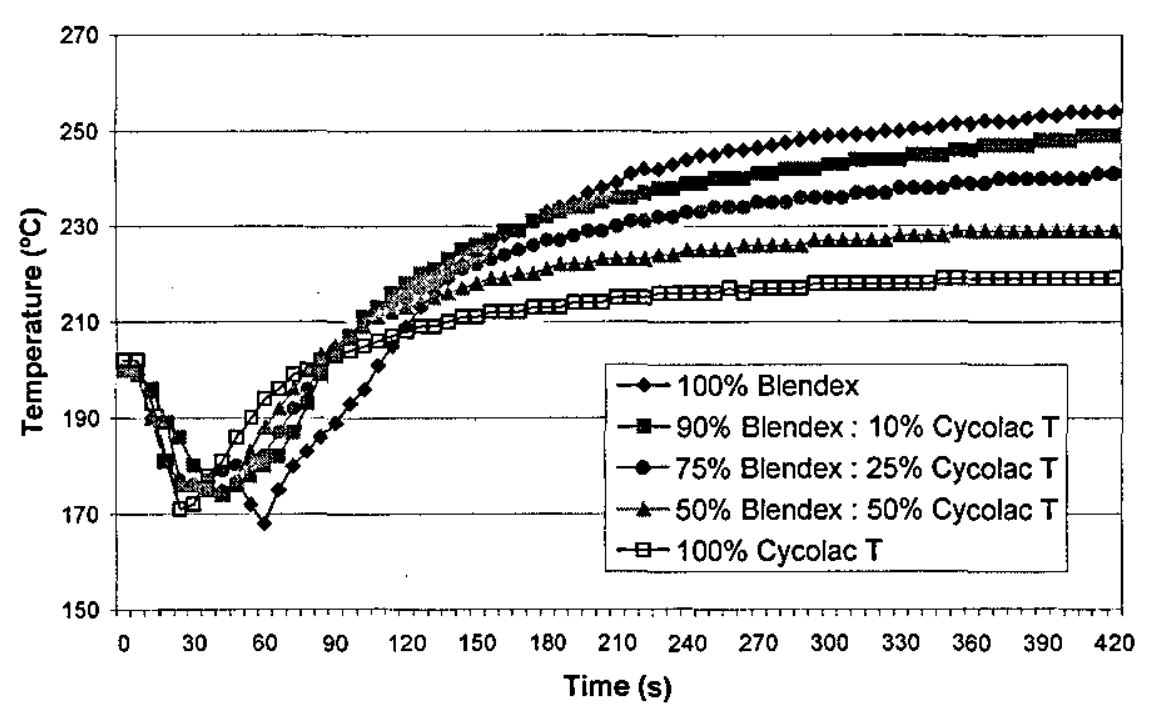

Figure 5.2: Haake Rheocord data showing temperature increase with time.

From the Haake work it appeared that the Blendex $310(\mathrm{~S})$ was prone to excessive heat build-up (Figure 5.2). The figure shows the temperature profiles in the Haake Rheocord after the polymers (and polymer blends) were added to the chamber (at $t=0$ ). The 
chamber had been stabilized at $200^{\circ} \mathrm{C}$ prior to the addition of the polymer(s). The initial dip in temperature occurred after the material was introduced to the chamber. The higher temperatures seen for the high Blendex content blends compares well with the higher torque readings seen in Figure 4.6. The high temperatures reached by the 100\% Blendex sample led to degradation of the polymer inside the Haake Rheocord chamber.

Compounding the formulations containing additions of the Blendex:Cycolac $\mathrm{T}$ mixture on the twin-screw extruder did not cause the problems found when compounding the Blendex grade on its own and all melts exhibited good strength. Compounding the masterbatch RS and AZUB compounds proved to be slightly easier due to the lubricating effect from the presence of the antimony trioxide. Lower die pressures were recorded for the AZUB compounds, which were most likely due to the presence of the castor wax resin in these compounds, acting as a lubricant.

\subsubsection{Impact Properties}

The main point that was noted with the peak and failure energies was the improvement seen with increasing additions of polybutadiene (achieved using Blendex + Cycolac $T$ blend) over the unfilled ABS properties. It can be seen that an addition of $12 \mathrm{wt} \% \mathrm{MB} 1$ (75\%Blendex : $25 \%$ Cycolac $\mathrm{T}$ ), which was the equivalent of a $6 \mathrm{wt} \%$ addition of $\mathrm{PB}$, gave an improvement in failure energy of nearly $23 \%$ over Cycolac T. Even small additions of this compound gave small improvements to the energy values. The increase in impact energy values followed significant linear relationships for both peak and failure energy with the latter being the most significant (Figure 4.8). This was expected as previous work discussed the benefits of additional PB (or elastomeric phase) within a filled polymer system to improve impact properties [1].

Looking at the compounds that contained the antimony trioxide it can be seen that in compound 11 the presence of $5.33 \mathrm{wt} \%$ (MB2) had little effect on the poor impact properties associated with $\mathrm{Sb}_{2} \mathrm{O}_{3}$. Little improvement in properties was seen when $8 \mathrm{wt} \%$ (MB3) was incorporated (compound 12). However when $16 \mathrm{wt} \%$ (MB4) blend was added (compound 13) the impact values approached that of unfilled ABS. Unlike 
the compounds with additions of only the Blendex + Cycolac T blend (compounds 7, 8 and 9), these results did not follow a linear trend with increasing added polymer blend.

Using the AZUB masterbatch MB5 (32\%AZUB) improved impact properties to a value equal to that of unfilled ABS. Comparisons with the RS grade MB4 (25\%RS) suggested that even higher values were expected in the masterbatched AZUB, but this was not the case.

\subsubsection{Flexural Properties}

The flexural modulus of the compounds was seen to decrease with increasing additions of Blendex + Cycolac $\mathrm{T}$ blend. The additions of lower modulus rubbery butadiene particles reduced the rigidity of the compounds (as would be expected). The direct

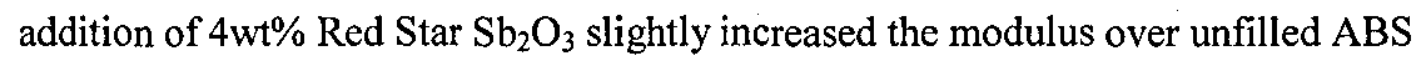
. (1\%) as seen previously (Section 4.3.2). The subsequent additions of the antimony trioxide (using masterbatches) again reduced the modulus values. The additions of extra polybutadiene in these compounds were identical to those of compounds 7,8 and 9 (Blendex:Cycolac T blend only), which was perhaps expected, as the RS on its own did not significantly affect modulus.

Directly added AZUB gave a lower modulus than directly added RS, most probably due to the presence of the castor wax resin. The castor wax is believed to act as a lubricant and will therefore enable some movement of polymer chains. This movement will allow more flexibility and thereby reduce the modulus. The masterbatched AZUB compound had the lowest modulus of the formulations due to the effects of both the additional PB as well as the castor wax resin.

As with the modulus the flexural strength also decreased with increasing additions of polybutadiene. A difference with the masterbatched RS compounds was the similarity of values to directly added RS. The compounds using MB2 (75\% RS) and MB3 (50\% RS) had similar strength values. MB4 (25\% RS) had a lower strength due to the higher percentage of additional polybutadiene in the compound. 
Flexural strength of the direct AZUB compound was lower than direct RS, which was most likely due to the castor wax present in the AZUB. Masterbatched AZUB further reduced the strength.

\subsubsection{Dispersion}

Dispersion of the antimony trioxide in the samples was determined using thin microtomed sections in the TEM as well as 'polished' microtomed samples in the SEM. All the samples were better in the TEM sections as these avoided smearing of the antimony trioxide. Samples analysed in both the TEM and SEM were seen to have good dispersion for all compounds.

A noticeable property of the masterbatched Red Star and AZUB compounds was the presence of large butadiene particles in the final compound. This would have been due to the high heat history of the masterbatch polymer blend due to having been passed through the extruder three times. Conditions were set to avoid these problems (lower screw speed and less material) but some butadiene particles did coagulate. As butadiene particles have a critical maximum size for best impact properties (Section 5.2.3) these larger particles will have a detrimental effect on properties. These were seen most in formulation 12 (using MB3 50\% RS) where a larger amount of large particles were seen. This was reflected in the impact properties, which were lower than expected.

\subsubsection{Fracture}

Analysis of the fracture surfaces of the compounds containing $0.67 \mathrm{wt} \%, 2 \mathrm{wt} \%$ and $6 \mathrm{wt} \%$ added PB showed little difference between compounds. The compounds containing masterbatched material showed debonding of the particles from the matrix. The extra butadiene particles appeared to have little effect in compound 59 and 58. However with the increased quantity of polybutadiene in compound 57 the fracture surface appeared less brittle. 
The compounds containing AZUB and masterbatched AZUB were no different in appearance from each other. Due to the size of the antimony trioxide particles the interaction with the matrix was difficult to determine.

Analysis of the crazing and cavitation phenomena showed that the amount of crazing was greatest in the compounds containing Blendex:Cycolac $\mathrm{T}$ blend only and decreased with decreasing impact energy.

\subsubsection{Flame Properties}

LOI testing carried out on these samples resulted in LOI values between 18.6 and 18.9. The compounds with Blendex:Cycolac T polymer blend only $(7,8$ and 9$)$ were identical to unfilled ABS. The compounds containing masterbatched RS (11, 12 and 13) were identical to the values seen with directly added RS. These values were expected as direct additions of $\mathrm{Sb}_{2} \mathrm{O}_{3}$ had poor flame retardant properties and the additional $\mathrm{PB}$ did not affect flame properties. UL-94 testing of all samples resulted in FAIL classifications. All the samples tested for formulations 7,8 and 9 failed with total burn times identical to unfilled ABS. This trend was also seen for the compounds containing $\mathrm{MB} \mathrm{Sb} b_{2} \mathrm{O}_{3}$ which had near identical burn times to directly added RS and AZUB and as expected with a decrease in total burn time when compared to unfilled ABS.

\subsection{Influence of Bromine Additives}

\subsubsection{Compounding}

All four bromine grades reduced the die pressure in the compounder, together with a slight decrease in torque. Although the weight output was kept constant for all the compounds, the volume output altered due to the additions of the bromines. This was due to a diluent effect in the ABS of the low molecular weight brominated materials. Compared against unfilled ABS those compounds with bromine had a lower percentage of both PB and SAN, the latter being the more influential to the flow properties. 
Melt blendable BTBPE with a melting point approximately that of the compounding temperature reduced the pressure to $84 \%$. TBBA melt blended at $180^{\circ} \mathrm{C}$ and lowered the die pressure further (78\%). The BTBPE and TBBA bromines exist as molecular chains within their compounds and it would be assumed that these would have a beneficial effect on the flow properties compared to large particulate solids within the melt. The high melting points of the DBDPO grades results in the bromine being present in particulate form. This would provide greater resistance to flow compared to the melt blendable grades. The presence of the bromines in greater quantities than antimony trioxide would suggest that the effect on flow properties would be greater. This was seen in the die pressure readings for the standard DBDPO. The non-melt blendable DBDPO had a higher die pressure and torque than the melt blendable grades, a value close to that of unfilled ABS. This indicates little overall effect to the polymer melt properties compared to unfilled ABS, although it suggests that the drop in pressure expected due to dilution of the melt is offset by the presence of the particles. The spray dried DBDPO, had the lowest die pressure. This lower pressure was most likely due to the presence of a relatively high amount of the low viscosity castor wax (5wt\%), which would have acted as a lubricant, thereby improving flow within the extruder.

\subsubsection{Impact Properties}

The BTBPE and TBBA melt blendable grades appeared to be compatible with the ABS (after analysing the stained sections in the TEM) whilst the DBDPO grades contained particulate solids, which showed no compatibility. These solids will act as stress raisers in a similar manner to the antimony trioxide with a greater effect on properties because the DBDPO bromines were present in a higher amount. The diluting effect of the brominated materials in the ABS again meant that the compounds had a lower percentage of the constituent phases of the ABS. A reduction in the number of polybutadiene particles in a given compound would result in less crack arresting points and therefore give lower impact properties. The addition of $20 \mathrm{wt} \%$ bromine material reduces the original $\mathrm{PB}$ content by $4 \%$. The previous section has already shown the benefits possible with $6 \mathrm{wt} \%$ additional $\mathrm{PB}$, which increased the total impact energy by $23 \%$. If $\mathrm{PB}$ is effectively removed then a drop of $16 \%$ could occur based solely on this 
factor. The combination of increased stress raisers and reduced energy absorption material can describe the effect of the DBDPO grades. The presence of the castor wax in the spray dried DBDPO (as well as the slightly reduced particle size) improved the impact properties slightly. However both grades had very poor results.

TBBA showed compatibility with the ABS but the compound had poor impact properties, which could have been due to several factors. Hindrance of the polymer energy absorption mechanisms by the presence of the bromine molecule structure may be one explanation. This would affect the ability of the ABS to plastically deform. The molecules of this bromine grade could also act as stress raisers due to differential thermal cooling between the bromine and the surrounding polymer matrix.

The BTBPE had better impact properties than the TBBA, which is due to a more mobile and flexible $\mathrm{Br}$ molecule due to a greater freedom of rotation within its structure. This grade of bromine had a melting range similar to that of the melting range of the ABS.

\subsubsection{Flexural Properties}

The bromines had a larger effect on flexural modulus and strength than the addition of the antimony trioxide material. This was expected due to the fact that the loadings were greater. The TBBA compound had a higher modulus than unfilled ABS indicating an increased rigidity due to the presence of the low flexibility of the bromine molecule. These molecules promoted a brittle response yet the flexural strength was higher than unfilled ABS. This phenomenon has been seen previously [155], but a clear explanation of why this occurs has not been determined.

The BTBPE did not significantly lower the modulus compared to ABS, but did drop flexural strength by $8 \%$. The fact that there was little change in the modulus indicated that the BTBPE molecules were less rigid than those in TBBA. This greater flexibility (through rotation between the carbon - oxygen bond) appeared to induce yielding at a lower load thereby reducing the flexural strength. The slight reduction in peak deflection also lends weight to this theory. 
Standard DBDPO raised the modulus slightly (but not significantly) due to the high percentage of solid particulates, which restricted polymer molecular movement. The $3 \%$ reduction in flexural strength was most likely due to the poor interaction between the bromine solids and polymer matrix, as well as the reduction of available polymer matrix due to the presence of the DBDPO. The spray-dried grade had a near identical modulus to unfilled ABS, which indicated that the presence of the castor wax had a plasticising effect. The flexural strength did drop significantly, with the deflection at maximum load value dropping by $24 \%$. The presence of the castor wax appeared to affect the compound by lowering the yielding point (peak deflection was reduced by $24 \%$ ). The high loading of carrier wax in the sDBDPO grade appears to allow some polymer chain movement. The movement means that yielding occurs at a lower force and enables greater yielding prior to fracture. This is reflected in the higher work done values of the spray dried DBDPO (Appendix C).

\subsubsection{Dispersion}

The location of the two melt blendable grades could not be determined using either osmium tetroxide or the more aggressive ruthenium tetroxide staining agents. Indeed the ruthenium was less effective as the SAN phase was also stained resulting in reduced contrast between PB and SAN. X-ray mapping of the samples (using the TEM) did show a blanket effect of both the TBBA and BTBPE across the SAN phase with an increase at the $\mathrm{PB} / \mathrm{SAN}$ interphase. Bromine levels in the polybutadiene did vary from particle to particle with loadings ranging from low to none (compared to levels in SAN). This indicated good dispersion in the SAN but little or none in the PB, which follows the results found for antimony trioxide. BTBPE appeared to have as good dispersion as TBBA even though its melting range was at the higher end of the ABS processing temperature range. This factor may otherwise have reduced its ability to be adequately dispersed. This good dispersion indicates high miscibility and good compatibility within the polymer matrix. 
Due to the particulate nature of the two DBDPO grades the location of these bromines was easy to determine. As seen with the antimony trioxide the two bromines were located in the SAN phase. Some particles appeared to overlay polybutadiene particles but due to poor contrast at the edge of the bromine particles it was difficult to determine exactly what was happening. The standard DBDPO grade had good dispersion of particles but occasional clustering was seen. The spray-dried grade had slightly better dispersion most likely aided by the presence of the wax. This improved dispersion with the spray dried DBDPO (along with a slight reduction in particle size) reflects the slightly better impact properties of this compound (compared to the standard grade).

\subsubsection{Fracture}

SEM analysis showed that the compound containing BTBPE had a smooth impact surface similar to the unfilled ABS (Plate 4.26). Stress whitened areas within the samples could not be identified due to the pigmenting effect of the bromine. TBBA and DBDPO containing compounds had a more coarse fracture surface than the unfilled ABS (Plates 4.27 and 28). The crack propagation gave an initial smooth surface followed by a coarse 'teared' surface for the TBBA with slight stress whitening seen near the crack tip of the TBBA compound. None was seen in the two DBDPO compounds. The DBDPO particles did not appear to show any interaction with the polymer matrix, as with antimony trioxide particles, and the matrix in which they were located show little or no deformation (Plate 4.29).

TEM analysis of the samples in the stress whitened zone (assumed in the case of those compounds containing pigmenting material) showed little presence of crazing and cavitation. The compound containing BTBPE showed the presence of some cavitation and crazing. Samples containing TBBA had little or no cavitation and crazing. Both the DBDPO grades appeared to have no cavitation or crazing but closer examination revealed the presence of some crazing between larger particles in the sDBDPO grade (see Plate 4.25). 


\subsubsection{Flame Properties}

The bromines varied in their effectiveness as flame retarding agents in the order DBDPO $>$ sDBDPO $>$ BTBPE $>$ TBBA. This order of merit corresponds to the bromination level of each compound: DBDPO (81\%), sDBDPO (81\%), BTBPE $(68 \%)$ and TBBA (57\%). N.B. The values quoted for the bromines are the values determined by analytical methods for samples of the batches used in this study, and all differ from the manufacturers published values. Previous studies [148] have shown DBDPO to be a flame retardant that imparts good flame retardancy to a system, thereby giving high LOI values.

The DBDPO grade had a V-2 rating due to some of the samples dripping and igniting the wool. These drips carried the flame away from the sample, which then extinguished. The spray dried DBDPO failed the UL-94 test due to extended burning of the samples and the high number of flaming drips which again ignited the wool. The spray dried grade contained $4 \mathrm{wt} \%$ castor wax and this was most likely responsible for the high amount of flaming drips. Another reason for the lower flame properties was also the lower amount of bromine in the spray dried compound.

Most noticeable during the testing of these samples was the amount of smoke generated, which is due to the incomplete combustion of the ABS polymer. This factor has not been investigated in this work (due to lack of facilities), however its influence in fire deaths is significant and therefore needs to be investigated. 


\subsection{Influence of Bromine and $\mathrm{Sb}_{2} \mathrm{O}_{3}$ Addition}

\subsubsection{Compounding}

The incorporation of both additives did not cause any severe problems during processing. The only difficulties that arose were due to problems with the more brittle compounds. The melt strands often broke prior to the cooling bath, which caused some problems in collecting these compounds. Problems with the haul-off unit were later discovered (namely speed fluctuations and roller slippage) and these fluctuations in performance may have added to the problems of the strands breaking. The die pressure values for the compounds containing Red Star and a bromine were most similar to the compounds containing bromine only. This suggests that the bromines had a greater effect in lowering die pressure values than the $\mathrm{RS} \mathrm{Sb}_{2} \mathrm{O}_{3}$, which had very little effect when added on its own. This was perhaps expected due to the larger percentage (by weight) of the bromines in the compounds. This lowering of the pressure was also seen in the compounds containing AZUB material, but the drop was greater than for RS. This was most likely due to the presence of the castor wax, which had previously been seen to lower the die pressure (Table 4.6).

\subsubsection{Impact Properties}

\subsubsection{Red Star}

The failure impact energy of the RS and BTBPE compound approximately equalled that of a predicted additive value based upon the impact energies of the two components when tested individually (Figure 5.3). This suggested that the individual failure mechanisms created by each component were both present in this compound. Analysis of the fracture surface showed this to be true. The TBBA and DBDPO compounds did not exhibit additive effects and these compounds had actual failure energies significantly lower than the predicted values. This suggested that one of the components in these compounds had a greater effect on the impact properties. 


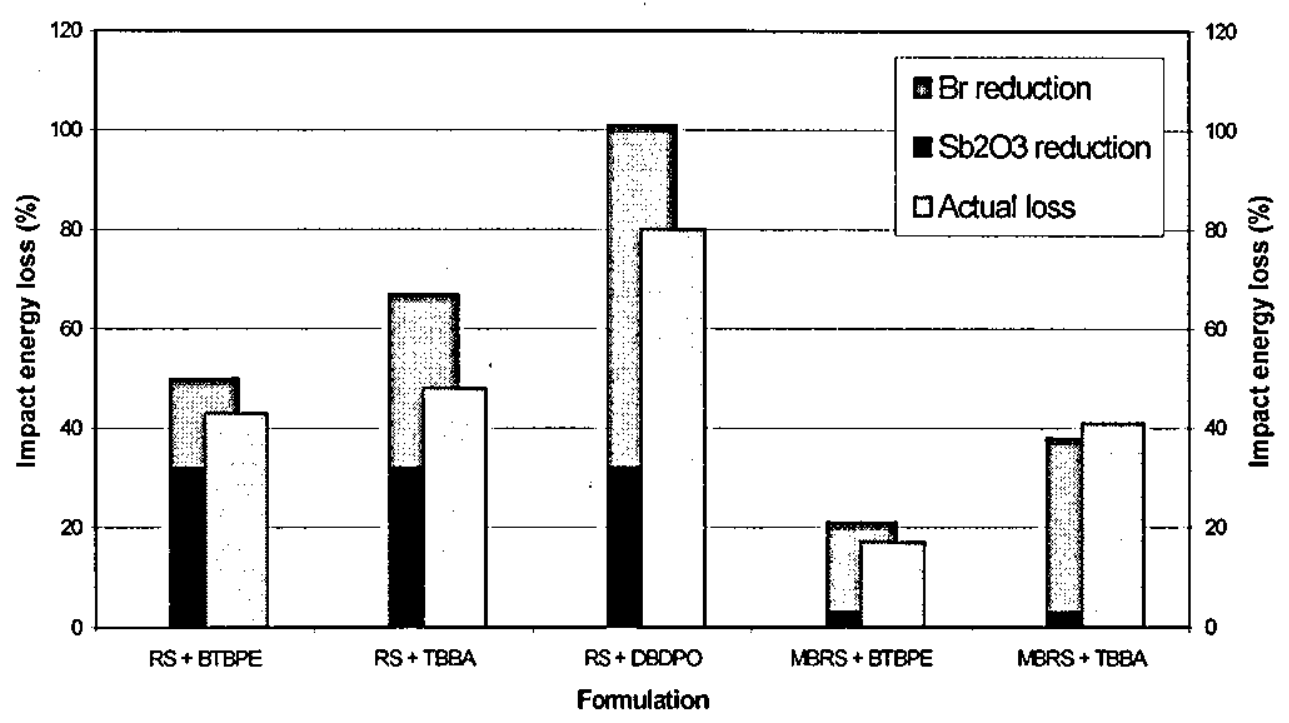

Figure 5.3: Predicted and actual energy losses ( $\mathrm{RS}+\mathrm{Br}$ compounds).

The TBBA appeared to be the more dominant component as the fracture surface around the antimony trioxide particles exhibited few voids, debonding or shear yielding. The normal mechanism of energy absorption attributed to $\mathrm{Sb}_{2} \mathrm{O}_{3}$ was greatly reduced, affected by the presence of the TBBA. The bromine is believed to affect the ability of the matrix to deform under loading conditions. This effect is more dominant than the stress concentration sites created by the $\mathrm{Sb}_{2} \mathrm{O}_{3}$.

In the case of DBDPO the effect of the high number of larger solid particulates appeared to overwhelm the RS particles. Little or no debonding was seen for any of the particulates of either the antimony trioxide or the bromine and this was reflected in the highly brittle nature of the compound.

The two compounds using masterbatched material had additive impact reductions, although the MB RS had little effect on properties individually and the dominant factor still appeared to be the bromines. 


\subsubsection{2 $A Z U B$}

The near additive effect was again seen for the BTBPE + pAZUB, but not for the spray dried AZUB (Figure 5.4). The latter had a greater loss than predicted although both compounds had a similar overall reduction in impact properties. Fracture surface analysis did not show any significant difference between the two compounds,

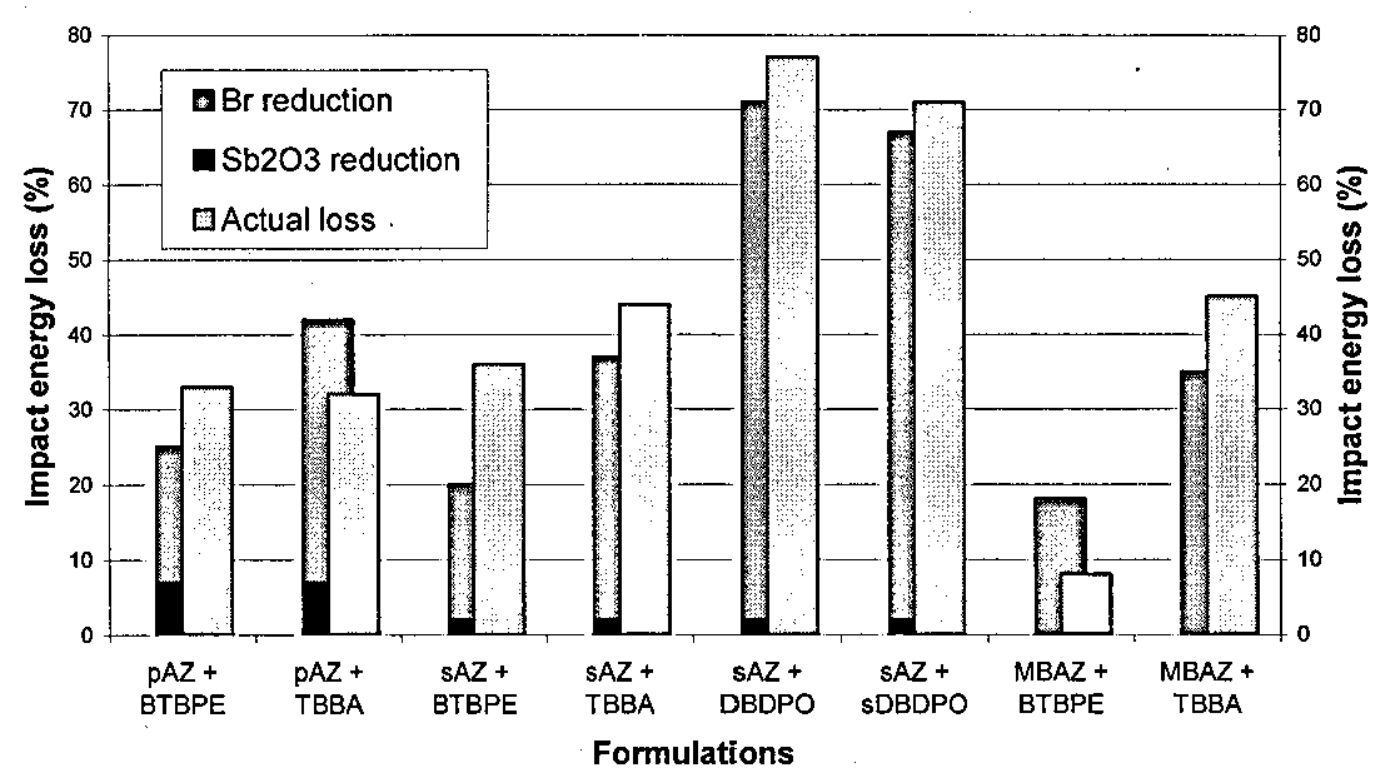

Figure 5.4: Predicted and actual energy losses ( $\mathrm{AZ}+\mathrm{Br}$ compounds).

The TBBA and sAZUB appeared to show an additive reduction but the effect of the AZUB was so small that sample deviations could have accounted for this. The DBDPO again had the overriding effect on impact reductions, this time with sAZUB. The presence of castor wax in the spray dried DBDPO, in addition to that in the spray dried AZUB improved impact properties slightly over the standard DBDPO compound. The fracture surfaces of both the DBDPO compounds appeared identical to the compound containing DBDPO only. The presence of the AZUB material improved impact properties over RS compounds for all of the four bromines.

Overall the impact properties appear to be dominated by the bromine materials, and in many cases the actual loss in an AZUB + Br system is greater than the predicted losses, which in many cases are attributable to the spread of results. Despite this the losses in AZUB compounds are predominantly lower than the losses incurred with the RS 
compounds, indicating that despite the effect of the bromines the AZUB material can be used to reduce impact energy losses in flame retarded compounds.

\subsubsection{Flexural Properties}

The flexural modulii of all the compounds were greater than the unfilled ABS modulus except for the two compounds containing BTBPE with either MB RS or MB AZUB. These were significantly lower than all other compounds. This was most likely due to the presence of the additional polybutadiene of the masterbatch material, which was expected to reduce the modulus as described earlier in this section. Compounds containing TBBA had the highest modulus values and the use of the SAZUB grade did not significantly alter properties compared to the RS compound. This again suggests that the TBBA is the dominating additive and its retardation of matrix compliance is dominant at the slower test speed of bend testing. The modulus was reduced by the presence of masterbatched antimony trioxide material as had also been seen with the BTBPE compounds. This was expected due to the large amount of additional rubbery elastomer phase in this compound. The AZUB material raised the modulus over RS ' when used with the DBDPO grades. The extra castor wax in the sDBDPO grade had no significant effect over the standard DBDPO grade.

The flexural strengths of all the compounds dropped by approximately $10 \%$ compared to unfilled ABS, except in the case of those containing TBBA. These compounds had strengths equal to or greater than unfilled $\mathrm{ABS}$, except for the two masterbatched compounds. The presence of the masterbatch again lowered properties but not as much as for the masterbatched BTBPE compounds, which had significantly lowered flexural strengths (-21\% for RS/BTBPE and $-24 \%$ for AZUB/BTBPE).

The maximum load deflection results do not offer clear trends but it can be seen that BTBPE was generally the least brittle with both TBBA and DBDPO being considerably more brittle. The masterbatched compounds again contradicted this general rule, particularly the two containing TBBA. 


\subsubsection{Dispersion}

Dispersion of the melt blendable BTBPE and TBBA grades was again difficult to determine, however analysis of the dispersion of the antimony trioxide in these compounds (for both RS and AZUB) showed identical dispersion compared to the compounds containing $\mathrm{Sb}_{2} \mathrm{O}_{3}$ only. As the antimony trioxide was well dispersed, it was also assumed that the bromines were equally well dispersed. Analysis of the compounds containing the masterbatched antimony trioxide showed some clustering of particles. Dispersion may have been hindered slightly due to the presence of the additional polybutadiene in these compounds. This could explain the poor flexural strength of both masterbatch compounds containing BTBPE. It is possible that the additional PB in these compounds prevented sufficient dispersion of the BTBPE, which then affected the flexural strength of the compounds.

The dispersion of the non-melt blendable DBDPO grades could easily be determined and these were both noted as being well dispersed. The sDBDPO particles were again seen to be slightly smaller than the standard grade. Agglomerates were noted however in the AZUB and DBDPO compounds and when analysed were found to be antimony trioxide. This was surprising as the spray dried AZUB had not been seen to agglomerate in previous compounds. The agglomerates found were in close proximity to several DBDPO particles and the presence of these particles may have been a factor in creating the agglomerate. The AZUB material could have been prevented from dispersing and once free from its binder wax may have then agglomerated. This factor is of concern as the binder resin is used in order to prevent this agglomeration process from occurring.

\subsubsection{Fracture}

The impact fracture surfaces of the compounds containing BTBPE and TBBA appeared similar to those of the fracture surfaces in the previous section (bromines only). The presence of either the RS or AZUB did not appear to have any significant effect. The TBBA surface again displayed a far more brittle topography than the BTBPE (see Plates 4.32 and 4.33). 
TBBA and DBDPO containing compounds had a more coarse fracture surface than the unfilled $\mathrm{ABS}$ when viewed at low magnifications (10x). At these low magnifications localized craters were evident as in unfilled ABS, but on a larger scale (Plate 4.33). The crack propagation appeared to initiate at a defect at the top right hand of the image. Initially the crack propagation gave a smooth surface, which was followed by a coarse 'teared' surface. Finally the last third of the sample is very smooth indicative of a brittle fracture. Comparing this image with Plate 4.13, the difference in dimensions is immediately noticeable. The unfilled ABS sample underwent considerable plastic deformation (resulting in an 'anvil' shaped test piece). The sample in Plate 4.33 has undergone little or no plastic deformation, which indicates a more brittle fracture. Slight stress whitening was seen near the crack tip of the TBBA compound but none was seen in the two DBDPO compounds. The DBDPO particles did not appear to show any interaction with the polymer matrix.

TEM analysis of the samples in the stress whitened zone (assumed in the case of those compounds containing pigmenting material) showed little presence of crazing and cavitation again indicative of brittle fracture processes. The compound containing BTBPE showed the presence of some cavitation and crazing. Samples containing TBBA had little or no cavitation and crazing. Both the DBDPO grades appeared to have no cavitation or crazing but closer examination revealed the presence of some crazing between larger particles in the sDBDPO grade. The smaller particles and lubricating nature of the carrier wax again appear to be influential in enhancing the impact properties of this system.

\subsubsection{Flame Properties}

The presence of the synergistic flame retardants had the effect of significantly raising the LOI values above those compounds containing only bromines in the previous section. All the formulations had similar LOI values except for compound 26 (pAZUB + TBBA). The lower level of bromine in this formulation could be the reason for this significantly lower value. Generally the compounds containing AZUB material have a slightly lower LOI value than the RS compounds. This trend does not necessarily 
follow on to the UL-94 values however, and the problem of dripping due to the lower viscosity castor wax appears to have less of an influence. The notable exception is compound 26 , which was the TBBA compound with the lower bromine content. The fire chemistry in this formulation will not have been as optimal as the others. The presence of additional castor wax in formulation 30 (sAZUB + sDBDPO) did drop properties compared to formulation 29 (sAZUB + DBDPO). The flaming dripping of the low molecular weight additive resulted in a V-2 rating for this compound. 


\section{SUMMARY}

The beneficial properties of ABS such as its ease of processing and excellent impact strength were overwhelmed when both the $\mathrm{Sb}_{2} \mathrm{O}_{3}$ and brominated materials were added. The addition of $\mathrm{Sb}_{2} \mathrm{O}_{3}$ did not significantly influence the compounding properties of the ABS compounds. The brominated materials had a more dominant effect on the ABS compounding than the $\mathrm{Sb}_{2} \mathrm{O}_{3}$ (lowering die pressures by up to $30 \%$ ), although the influence was dependent on the specific brominated material used. A large influence was also the amount of castor wax material, which had a lubricating effect during compounding but suffered with a tendency to build up in the feeder throat and thereby affect feeder output. The greatest effect on compounding properties (particularly die pressure) was with low melting point TBBA, which significantly lowered pressure. DBDPO had the least effect on properties due to its high melting point and incompatibility in ABS, which offset any dilution effects.

Three point flexural bend testing showed that the flexural strength, flexural modulus and peak deflection values were not significantly affected although the flexural modulus was seen to marginally increase in the $\mathrm{Sb}_{2} \mathrm{O}_{3}$ filled compounds. This increase did not relate to the $\mathrm{Sb}_{2} \mathrm{O}_{3}$ particle size and could not even be related to increases in volume fraction.

The brominated materials altered the flexural properties of ABS more than $\mathrm{Sb}_{2} \mathrm{O}_{3}$. Compounds containing TBBA significantly increased both the flexural modulus and flexural strength yet exhibited the most ductile behaviour as shown by the work done at failure. The BTBPE had little effect on modulus but lowered strength and was more brittle than TBBA emphasized by the lower work done at failure. DBDPO raised both modulus and strength (to a lesser extent than TBBA) but was far more brittle. The presence of the wax in the sDBDPO grade had a plasticising effect and was slightly more ductile than the standard grade. When $\mathrm{ABS}$ contained both $\mathrm{Sb}_{2} \mathrm{O}_{3}$ and the brominated materials, the flexural modulus generally increased further which reflected the additive individual contributions from each. 
The impact testing (high strain rate testing with sharp notched impact specimens) showed that the impact failure energy absorbed by the $\mathrm{Sb}_{2} \mathrm{O}_{3}$ filled compounds decreased when compared to unfilled ABS. This decrease was dependent on the average $\mathrm{Sb}_{2} \mathrm{O}_{3}$ particle size with large decreases of approximately $30 \%$ seen when using a $1.31 \mu \mathrm{m} \mathrm{Sb} b_{2} \mathrm{O}_{3}$ filler at $4 \mathrm{wt} \%\left(\approx 1\right.$ vol. \%) loading. The use of a finer $(0.52 \mu \mathrm{m}) \mathrm{Sb}_{2} \mathrm{O}_{3}$ grade led to slightly higher impact values but those compounds containing the finest grades offered the best impact energy retention. These sub-micron grades had little or no effect on failure energy at $4 \mathrm{wt} \%$ loading. The use of a wax carrier for a fine particle size $\mathrm{Sb}_{2} \mathrm{O}_{3}$ grade (AZUB) improved performance and was due to the fine particles having less of a detrimental influence on the existing fracture mechanisms. Localized stress intensities were reduced allowing conventional yielding and crazing to take place in the ABS; as seen by SEM and stained sections viewed in the TEM.

Ultramicrotomed osmium tetroxide stained sections analysed by TEM showed that processing of the compounds appeared to marginally reduce the average particle size of the larger grades $(1.31 \mu \mathrm{m}$ and $0.52 \mu \mathrm{m})$, although this could also have been an effect of sectioning the samples. The fine particle size of the AZUB grades did not reveal whether any further size reductions occurred. DBDPO particles were also reduced slightly during compounding. These sections also revealed the fact that all the particles (including DBDPO) were located in the SAN phase of the ABS polymer. The location of the TBBA and BTBPE could not be determined visually but STEM analysis suggested that they were present in a blanket effect across each sample. The readings were higher in the SAN phase than the butadiene phase but an increase was seen in the SAN/butadiene interphase region.

Ultramicrotomed specimens taken from inside the stress whitened area at the impact fracture surface revealed that the number of crazes dropped with decreasing impact energy properties, which related to increased $\mathrm{Sb}_{2} \mathrm{O}_{3}$ particle size. The crazes were seen to mainly originate from the 'equator' of the largest butadiene particles. The higher the impact energy properties the more crazing occurred from increasingly smaller butadiene particles. 
Use of a high rubber content masterbatch to incorporate the $\mathrm{Sb}_{2} \mathrm{O}_{3}$ into the ABS polymer resulted in better impact properties than unfilled ABS. The dispersion and distribution of antimony trioxide in these compounds was as good as directly added $\mathrm{Sb}_{2} \mathrm{O}_{3}$ when samples were viewed using the $\mathrm{SEM}$, although the repeated passing through the compounder of the masterbatch material did cause an increase in butadiene particle size. This was due to the high heat history causing smaller butadiene particles to coagulate. This could lead to degradation of the rubber phase and thereby affect compound properties.

All compounds containing brominated materials had reduced impact energy as compared with the unfilled ABS. The compounds containing BTBPE had superior impact energy properties than compounds containing TBBA or DBDPO. It was believed that the BTBPE was compatible in the ABS and that the reductions were mainly due to dilution effects. Compounds containing TBBA exhibited more brittle behaviour even though it was believed that TBBA was compatible in ABS. Unlike BTBPE it did not act as a plasticiser and thereby effectively restricted molecular motion. DBDPO was clearly incompatible in ABS as it did not melt blend and remained as large particles, which resulted in extremely low impact strength.

The impact fracture surface (surface topology and shear yielding) of compounds containing BTBPE was similar to that of the unfilled ABS explaining why the impact strength of these compounds was relatively good. The amount of stress whitening in compounds containing BTBPE was also relatively similar to that of the unfilled ABS. The presence of TBBA and DBDPO produced a fracture surface with little evidence of shear yielding and only a slight amount of crazing (seen as stress whitening).

When both the $\mathrm{RS} \mathrm{Sb}_{2} \mathrm{O}_{3}$ grade and brominated materials were compounded into ABS, the absorbed impact energy decreased. An additive decrease was noted when the $\mathrm{Sb}_{2} \mathrm{O}_{3}$ was incorporated with BTBPE with both additives contributing to the reductions. When the antimony trioxide was compounded with TBBA or DBDPO the reductions were less than would have been predicted by simple addition. The brominated materials were seen to have dominated the fracture process in these compounds. This theory did not 
follow for those compounds containing masterbatched antimony trioxide, where an additive effect for TBBA was also noted.

An additive effect was displayed when the AZUB grades were incorporated with all four of the bromine grades. This was perhaps due to the fact that the AZUB material had little effect on mechanical properties when used alone and therefore the effect of the bromine would always therefore be dominant.

The respective LOI results showed that $\mathrm{Sb}_{2} \mathrm{O}_{3}$ provided a synergistic action with the brominated materials to enhance the flame performance. There was no direct correlation between LOI and UL-94 test methods. Flame retardancy as measured by both LOI and UL-94 was more dependent on the brominated material loading in ABS. No trend could be seen for the different bromine materials suggesting the values were not dependent on the degree of bromination of the bromine molecule. The greatest LOI values were obtained with compounds containing DBDPO although the presence of wax in the sDBDPO grade did leave the compounds prone to dripping in the UL-94 test. Compounds containing TBBA performed worst during both LOI and UL-94 vertical burn testing. This was most likely due to the lower amount of bromine in these compounds. Compounds containing BTBPE had relatively good flame retardancy except in the masterbatched compounds. 


\section{CONCLUSIONS}

i. The beneficial properties of ABS (ease of processing and excellent impact strength) were detrimentally affected upon the addition of both the $\mathrm{Sb}_{2} \mathrm{O}_{3}$ and brominated materials.

ii. Addition of the $\mathrm{Sb}_{2} \mathrm{O}_{3}$ grades did not significantly affect compounding results whether compounded alone or with bromine material, although the presence of the castor wax in the AZUB grades did lower the die pressure slightly.

iii. The brominated materials lowered die pressure, with the low melting point TBBA having the most effect and the high melting point DBDPO having the least effect.

iv. Injection moulding properties were similar for all compounds (including unfilled ABS) except in the compounds containing RS and either BTBPE or DBDPO, which displayed more short shots.

v. Compared to unfilled $\mathrm{ABS}$, the $\mathrm{Sb}_{2} \mathrm{O}_{3}$ filled compounds did not significantly affect flexural values. The slight changes to flexural strength, flexural modulus and peak deflection values did not relate to particle size.

vi. The brominated materials had a greater effect than $\mathrm{Sb}_{2} \mathrm{O}_{3}$ on the flexural modulus of $\mathrm{ABS}$, raising values over unfilled $\mathrm{ABS}$ by between $2 \%$ and $19 \%$. Most noticeable was the compound containing TBBA, which had a significantly higher modulus values $(+19 \%)$ and slightly higher flexural strength. Compounds containing DBDPO were most brittle. Flexural strength values did not follow any clear trend for the remaining bromines.

vii. The impact failure energy absorbed by the $\mathrm{Sb}_{2} \mathrm{O}_{3}$ filled compounds decreased when compared to unfilled ABS and was dependent on the average particle size, except for the spray dried AZUB grade, which did not significantly alter impact properties. 
viii. All compounds containing brominated materials had significantly reduced impact energy values when compared with the unfilled ABS in the order BTBPE $>$ TBBA $>$ DBDPO and SDBDPO.

ix. When both $\mathrm{Sb}_{2} \mathrm{O}_{3}$ and brominated materials were compounded into $\mathrm{ABS}$, the absorbed impact energy decreased and generally appeared to be dominated by the bromine material. Compounds containing BTBPE exhibited an additive effect.

x. Sections taken from the stress-whitened areas of all compounds showed a decrease in the number of crazes with decreasing impact energy absorption. Some small traces of crazing were also found in compounds with poor impact properties (i.e., DBDPO and SDBDPO).

xi. Incorporating $\mathrm{Sb}_{2} \mathrm{O}_{3}$ into $\mathrm{ABS}$ using a high rubber content masterbatch significantly improved impact properties; the additional butadiene content did not appear to affect dispersion.

xii. The wax carrier used in the fine particle size $\mathrm{Sb}_{2} \mathrm{O}_{3}$ grades (AZUB) enabled excellent dispersion to be achieved in $\mathrm{ABS}$ leading to an equivalent impact energy to that of unfilled ABS at $4 \mathrm{wt} \%$ loading.

xiii. Ultramicrotomed sections taken from several areas of the samples showed that both the $\mathrm{Sb}_{2} \mathrm{O}_{3}$ and DBDPO material were located in the SAN phase and well dispersed. The melt blendable grades were analysed using STEM analysis and were also located in the SAN phase with a slight increase at the SAN/butadiene interface.

xiv. The investigation revealed that dispersion was important in the link between impact strength and degree of dispersion in determining the final compound impact strength and was as influential as either the scatter in filler loading or the particle size used. 
xv. Compounds containing only antimony trioxide raised the LOI value by less than $0.5 \%$ compared to unfilled ABS.

xvi. Flame retardancy of the compounds (using LOI measurements) was dependent on the brominated material loading in ABS but the degree of bromination in the molecule did not appear to be a factor.

xvii. Compounds containing DBDPO appeared to have the best flame properties, followed by BTBPE and TBBA although differences in loading levels of both $\mathrm{Sb}_{2} \mathrm{O}_{3}$ and bromine in each compound prevented a true trend analysis.

xviii. There was no direct correlation between LOI and UL-94 test methods. 


\section{FUTURE WORK}

This investigation has shown that the impact strength of ABS can be improved by using sub-micron grades in a wax carrier (AZUB) in the place of traditional $\mathrm{Sb}_{2} \mathrm{O}_{3}$ grades. This new grade of antimony trioxide was at the experimental stage when this project started and was produced in small batches but has been optimized and moved into larger scale production. Further investigations are therefore necessary to determine the effect of using the material produced by the larger scale and whether the production methods influence the properties. Further investigation into the effects that the wax may have on the flame retardant properties would also be a possibility.

A problem encountered whilst compounding the AZUB grades was the build-up of this material on the feed hopper walls and especially on (and under) the feeder screws. The AZUB material tended to compact, which resulted in losses of material. An improved feeding method for this material needs to be investigated in order to reduce the losses incurred.

As the brominated materials were seen to dominate the effects on the impact strength, as well as other properties, an investigation looking specifically at ways of improving or enhancing the properties of the bromines would be useful. A spray-dried grade of DBDPO was used in this work and further analysis could be carried out to look at whether the particle size could be further reduced.

The systems used in this work were relatively simple and further work could look at the effect of additives such as antioxidants, anti-drip agents and other stabilizers on the mechanical and physical properties.

This work was concerned mainly with the effect of the antimony trioxide and bromines on the impact properties of ABS but used only one type of impact specimen. Instead of using only Charpy specimens with a moulded notch stress concentration, the impact behaviour of samples with other dimensions could be investigated. This could include bars in which the notch is cut in after moulding or flat plate analysis. Use of monitoring 
equipment (video recorder etc.) could be used to analyse crack initiation and propagation in the samples.

Nowadays the rules regarding materials used in flame retardant products are increasingly more stringent, especially in the case of emissions from fires (smoke, toxic gases etc.). More sophisticated analysis of the flame process would give greater understanding of these emissions and the use of equipment such as the Cone Calorimeter would allow such an investigation. As well as being a method for measuring heat release rates it can also measure smoke, carbon dioxide and carbon monoxide output over a measured time period. Specialist equipment can be used to look for other gases in the by-products.

Alternate flame-retardants to halogenated materials are being increasingly investigated. Flame-retardants such as alumina trihydrate and magnesium hydroxide, which release less toxic emissions during the combustion process, are being used as replacements for antimony trioxide and halogens. The current problem when using these in ABS polymers is their large detrimental effect on mechanical properties, as they need to be incorporated at loadings of approximately 50 to $60 \mathrm{wt} \%$ for full flame retardancy. Future work looking at ways of improving mechanical properties of ABS compounds using these alternative flame retardants could be investigated. The milling and flushing technology employed with the AZUB grades in this work may also be used with the alternate FR's. 


\section{REFERENCES}

1. Švec, P., Rosík, L., Horák, Z. \& Večerka, F., Styrene-Based Plastics and their Modification, Ellis Horwood, (1989).

2. Nelson, G. L., Fire and Polymers II: Materials and Tests for Hazard Prevention, American Chemical Society, (1995).

3. Woolley, W. D., Fardell.P.J, Polymer Degradation and Stability, 30, p123140, (1990).

4. Lahaye, J., Polymer Degradation and Stability, 30, p111-121, (1990).

5. Flisi, U., Polymer Degradation and Stability, 30, p153-168, (1990).

6. Principles of Flame-Retardancy and Test Methods, Anzon Technical Memorandum 1 + 2, Anzon Ltd., Wallsend, Tyne and Wear, UK, (1996).

7. Aseeva, R. M., Zaikov, G. E., Combustion of Polymer Materials, Hanser Publishers, (1981).

8. Grassie, N., Polymer Degradation and Stability, 30, p3-12, (1990).

9. Becker, W. H. K., Polymer Degradation and Stability, 30, p141-152, (1990).

10. Calcraft, A. M. \& Maries, K., Plast. Polm., 42, p162, (1974).

11. Pal, G. \& Macskásy, H., Plastics - their behaviour in fires., Research Institute for the Plastics Industry, Budapest; Elsevier, (1991).

12. Troitzsch, J., Kunststoffe - German Plastics, 74, 10, p627-630, (1984).

13. Yehaskel, A., Fire and Flame Retardant Polymers, Noyes Data Corp., (1979).

14. Rogers, J. K., Modern Plastics International, p57-60, (1992).

15. Billington, K., Griffiths, J., West, G., Plastics and Rubber International (Report from 'Flame Retardants 92' Conference), p6-9, (1992).

16. White, R. J., Lazear, N. R., Antec 1992, p2401-2402, (1992).

17. Bogas.P, Plastics Technology, 7, p56-59, (1984).

18. Ng, W., Modern Plastics International, 24, 10, p84, (1999).

19. Anon., Plastics and Rubber Weekly, 1, p7, (2000).

20. Casale, A., Salvatore, O., Pizzigoni, G., Polymer Engineering and Science, 15, 4, p286-293, (1975).

21. Hough, M. C., Allan, S. J., Dolbey, R., The Plastics Compendium - Volume 2, Comparative Materials Selection Data, RAPRA, 2, 1, p137-147, (1998). 
22. Hough, M. C., Dolbey, R., The Plastics Compendium - Volume 1, Key Properties and Sources, RAPRA, 1, 1, p1-10, (1998).

23. Anon., European Chemical News, p11, (1997).

24. Frank, H., Kunststoffe - German Plastics, 74, 10, p559-564, (1984).

25. Savenije, H. B., Kunststoffe - German Plastics, 83, 10, p763-766, (1993).

26. Anon., Kunststoffe - German Plastics, 79, 10, p913-914, (1989).

27. Adams, M. E., Buckley, D. J., Colborn, R. E., England, W. P. \& Schissel, D. N., Rapra Review Reports No. 70, Acrylonitrile-Butadiene-Styrene Polymers, 6, 10, (1993).

28. Halasa, A. F., Massie, J. M., Encyclopedia of Chemical Technology, $3^{\text {rd }}$ Ed., Kirk-Othmer, 8, p1031-1045, (1979).

29. Hyungsu, K., Keskkula, H., Paul, D. R., Polymer, 32, 8, p1447-1455, (1991).

30. Anon., Encyclopedia of Chemical Technology, $4^{\text {th }}$ Ed., Kirk-Othmer, 1, p370-390, (1993).

31. Pillichody, C. T., Kelley, P. D., GE Plastics, Technology Centre, Parkersburg, WV, USA.

32. Traugott. T. D., Encyclopedia of Polymer Science and Technology, 16, p72$88,(1989)$

33. Radian Corporation, Polymer Manufacturing: Technology and Health Effects, Noyes Data Corporation, p74-93, (1986).

34. Zahn. A., Kunststoffe, 87, 3, p314-318, (1997).

35. Earhart, N. J., ANTEC '97, p2963-2966, (1997).

36. Kaspersma, J., Anzon Ltd., Personal Communication, (Dec 1997).

37. Braglia, R., Casiraghi, T., Journal of Materials Science, 19, p2643-2650, (1984).

38. Bucknall, C. B., Toughened Plastics, Applied Science Publishers, (1977).

39. Bernal, C. R., Frontini, P. M., Sforza, M., Bibbó, M. A., Journal of Applied Polymer Science, 58, p1-10, (1995).

40. Chang, M. C. O., Nemeth, R. L., Journal of Polymer Science B: Polym. Phys., 35, p553-562, (1997).

41. Dillon, M. J., Plastics, Rubber and Composites Processing and Applications, 24, 5, p267-270, (1995). 
42. Ritchie, P. D. (ed.); Plasticisers, Stabilisers and Fillers, The Plastics Institute, (1972).

43. Falcone Jr, J. S., Encyclopedia of Chemical Technology, $4^{\text {th }}$ Ed., 10, p745761, (1993).

44. Kauly, T., Keren, B., Siegmann, Narkis, M., Journal of Materials Science, 32, p693-699, (1997).

45. Rothon, R. (ed.), Particulate-Filled Polymer Composites, Polymer Science and Technology Series, (1995).

46. Plastics, Additives (Flame Retardants), in: Ullmann's Encyclopaedia of Industrial Chemistry, A20, p483-507, (1992).

47. Wake, W. C., Fillers for Plastics, The Plastics Institute, (1971).

48. Katz, H. S. \& Milewski, J. V., (Editors), Handbook of Fillers and Reinforcements for Plastics, Van Nostrand Reinhold Company, (1978).

49. Murphy, C. H., Handbook of Particle Sampling and Analysis Methods, Verlag Chemie International, (1984).

50. German, R. M., Particle Packing Characteristics, Metal Powder Industries Federation, (1989).

51. Wypych, G., Fillers, ChemTec Publishing, (1993).

52. Botsaris, G. D., Study notes (Devine, S.), p1-13, (1999).

53. Bigg, D. M., Polymer and Plastics Technology and Engineering, 23, 2, p133$168,(1984)$.

54. Michell, E. W. J., Morley, J. C., Antimony Oxide and its Derivatives, in: Plastics Additives and Modifiers Handbook, Ed. Edenbaum, J., Van Nostrand Reinhold, New York, Chapter 7, p1034-1049, (1992).

55. Touval.I, Encyclopedia of Chemical Technology, $4^{\text {th }}$ Ed., 10, p930-953, (1993).

56. Bartlett, J., Fire Retardant Chemicals Association, p1-23, (1997).

57. Docherty, A., Personal Communication, Anzon Ltd., Wallsend, Tyne and Wear, UK (Nov 1996).

58. Horák, Z., Vecerka, F., Plaste und Kautschuk, 24, 8, p564-564, (1977).

59. Ahmed, M., Coloring of Plastics, Van Nostrand Reinhold Co., New York (1979).

60. Weßling, B., Kunststoffe - German Plastics, 86, 4, p518-520, (1996). 
61: Costa.L, Goberti.P, Paganetto.G, Camino.G, Polymer Degradation and Stability, 30, p13-28, (1990).

62. McAllister.D.L, Brominated Flame Retardants: Current Issues and Future Prospects, Great Lakes Chemical Corporation, West Lafayette, IN, USA.

63. Deanin, R. D., Normandin, R. O., Ouellette, G. J., ACS - Division of Organic Coatings and Plastics Chemistry Reprints, 36, 2, p469-473, (1976).

64. Hussain, S., A History of Halogenated Flame Retardants, in: History of Polymeric Composites, Proceedings of the $192^{\text {nd }}$ ACS National Symposium, CA, USA, (Sep 1986).

65. Pettigrew, A., Encyclopedia of Chemical Technology, $4^{\text {th }}$ Ed., 10, p954-976, (1993).

66. Anon, Combustion of Plastics (Assorted Overheads) from Devine, S., Great Lakes Chemicals, (Sep 1999).

67. Pillai, C. K. S., Prasad, V. S., Menon, A. R. R., Sudha, J. D., Journal of Applied Polymer Science, 66, p2157-2173, (1997).

68. Luda di Cortemiglia, M. P., Camino, G., Costa, L., Roma, P., Journal of Analytical and Applied Pyrolysis, 11, p511-526, (1987).

69. Aminabhavi, T. M., Cassidy, P. E., Polymer Plastics Technology and Engineering, 28, 7, p717-751, (1989).

70. Schwartz, R. J., Fire Retardation of Polyethylene and Polypropylene, in: Flame Retardancy of Polymeric Materials, Marcel Dekker, New York, p110119, (1973)

71. Whiteley, R. H., Sawyer, M. D., McLoughlin, M. J., Raychem Fire Science Laboratory Paper, (1994).

72. Bair, H. E., Polymer Engineering and Science, 14, 3, p202-205, (1974).

73. Song, J. H., Engineering Plastics, 9, 3, p196-204, (1994).

74. Benkreira, H., Britton, R. N., International Polymer Processing, 9, 3, p205210, (1994).

75. Hornsby, P. R., Sothern, G. R., Polymer Degradation During Twin-Screw Extrusion Compounding, Plastics and Rubber Processing and Applications, 4, p165, (1984).

76. Owen, S. R., PhD Thesis, Loughborough University, (1998).

77. Akay, M., Ozden, S., Journal of Materials Science, 30, p3358-3368, (1995). 
78. Liang, X., McNally, G., Spedding, P. L., Crawford, R. J., Journal of Materials Science Letters, 9, p1478-1480, (1990).

79. Ahmed, S., Jones, F. R., Journal of Materials Science, 25, p4933-4942, (1990).

80. Nakagawa, H., Sano, H., Polymer Preprints, 26, 2, p249-250, (1985).

81. 10, Gutteridge, P. A., Hooley, C. J., Moore, D. R., Turner, S., Kunststoffe German Plastics, 72, 9, p543-547, (1982).

82. Lacost Berna, J. M., Ensayos de impacto de los materiales plasticos, Revista de Plasticos Modernos, 66, 448, p381-389, (1993).

83. Collyer, A. A., Rubber Toughened Engineering Plastics, Chapman and Hall, (1994).

84. Evans, A. G., Williams, S., Beaumont, P. W. R., Journal of Materials Science, 20, p3668-3674, (1985).

85. Griffith, A. A., Phil Trans Roy. Soc., 163, A221, (1920).

86. Lange, F. F., Radford, K. C., Journal of Material Science, 6, p1 197, (1971).

87. Bartlett, J., Colloidal antimony pentoxide in flame retarded ABS, Fire Retardant Chemicals Association, pl-23, (1997).

88. Bartlett, J., Personal Communication, at: EuroFillers '97, Manchester, UK, (Sep 1997).

89. Jue, N. C., Young, W. L., Antec 1977 (Montreal Conference), p19-22, (1977).

90. Uhlmann, J. G., Oelberg, J. D., Sikkema, K. D., Nelb, R. G., Plastics Compounding, 16, 3, p38-46, (1993).

91. Nyland, B., Conference Proceedings, Antec 1992, p2124-2126, (1992).

92. 085, Keskkula, H., Paul, D. R., McCreedy, K. M., Henton, D. E., Polymer, 28, 12, p2063-2069, (1987).

93. Kerner, E. H., Proceedings of Physics Society, London, B69, p808, (1956).

94. Nielsen, L. E., Journal of Applied Physics, 4, p4626, (1970).

95. Vollenberg, P. H. T., Heikens, D., Polymer, 30, p1656-1662, (1989).

96. Vollenberg, P. H. T., de Haan, J. W., van de Ven, L. J. M., Heikens, D., Polymer, 30, p1663-1668, (1989). 
97. D2863-77, Standard Method for Measuring the Minimum Oxygen

Concentration to Support Candle-like Combustion of Plastics (Oxygen Index), ASTM Committee on Standards, p627-634, (1977).

98. Macaione, D. P., Dowling II, R., Flammability Assessment Tests for Organic Materials - The Oxygen Index / Temperature Index Concept, AMMRC Polymer and Chemistry Division, 1, p1-8, (1977).

99. Anon, UL94-1979 Standard for Tests for Flammability of Plastic Materials for Parts in Devices and Appliances, Underwriters Laboratories Inc., (1980).

100. Hill, M., Redfern, J.P., PL Thermal Sciences Ltd, Laboratory Practice, 40, No. 9, p11-16.

101. Redfern, J.P., Technical Information paper no. CC/ 10.88/5101 'Cone Calorimeter'; Stanton Redcroft Ltd., (1992).

102. Hill, M., Rolls, T., Aldridge, R., Wetton, R., 'The PL-Stanton Cone Calorimeter - A new instrument for assessing fire behaviour', PL Thermal Sciences Ltd., Technical paper.

103. White, S., Docherty, A., Flame Retardant Technical Service Report, Ref: AD2316, Cookson Group Plc., (Feb 1994).

104. Anon, Cycolac T ABS resin, Product Information Sheet, GE Plastics Ltd,, Sale, Cheshire, UK (1995).

105. Anon., Blendex 310(S) High Efficiency ABS Impact Modifier, Product Information Sheet, GE Specialty Chemicals Inc., (2000).

106. Timonox Red Star Antimony Trioxide, Technical Specification Sheet, Anzon Ltd., Wallsend, Tyne and Wear, UK, (Nov 1996).

107. Microfine A05 Antimony Trioxide, Technical Data Sheet, Anzon Inc., Philadelphia, PA, USA, (2000).

108. Devine, S., Personal Communication, Anzon Ltd., Wallsend, Tyne and Wear, UK, (May 1998).

109. Flame Retardant Selection Guide, Great Lakes Chemical Corporation, West Lafayette, IN, USA, (1997).

110. Horiba LA-900 series Laser Particle Sizing Operating Manual, Appendix B + C.

111. Murphy, C. H., Handbook of Particle Sampling and Analysis Methods, Verlag Chemie International, (1984). 
112. BS2782: Part 6, Method 621D: 1978, ISO 1068 - 1975, Determination of Compacted Apparent Bulk Density of PVC resins, (1978).

113. ASTM D281-84 (Reapproved 1989), Standard Test Method for Oil Absorption of Pigments by Spatula Rub out, (1989).

114. ASTM D234-82, Standard Specification for Raw Linseed Oil, (1982).

115. Dunham, J., The Effects of Drying Time on Hydroscopic Polymers, ANTEC Conference Proceedings Pt. 2, (1994).

116. Negri Bossi NB62 Injection Moulder Operation Manual, 16, Negri Bossi, Milan, Italy, (1996).

117. Anon, BS2782 (ISO 3451/1-1981 (E)) Plastics -Determination of Ash. Part 1: General Methods, International Standard, p1-3, (1981).

118. Anon, The Determination of Antimony in Masterbatches by Titration with Potassium Bromate, Anzon, p1-3, (1984).

119. Watson, L. K., O'Callaghan, M. P., Halogenated Organic Compounds, Determination of Total Bromine (Schoniger Flask Method), Great Lakes Chemical Corp Analytical Method, p1-5, (1982).

120. Kato, K., Polymer Engineering and Science, 7, 1, p38-39, (1967).

121. Bibeau, A. A., Polymer Engineering and Science, 15, 4, p294-298, (1975).

122. Sjoerdsma, S. D., Boyens, J. P. H., Mooij, J. J., Polymer Engineering and Science, 25, 4, p250-255, (1985).

123. Wnuk, A. J., Ward, T. C., McGrath, J. E., Polymer Engineering and Science, 21, 6, p313-324, (1981).

124. Younan, H., Hodgkinson, J. M., Williams, J. G., Plastics and Rubber Processing and Applications, 8, 4, p227-233, (1987).

125. Jones, D. P., Leach, D. C., Moore, D. R., Plastics and Rubber Processing and Applications, 6, 1, p67-79, (1986).

126. Klunder, J., Kunststoffe - German Plastics, 72, 9, p548-553, (1982).

127. Casiraghi, T., Castiglioni, G., Ajroldi, G., Plastics and Rubber Processing and Applications, 2, 4, p353-360, (1982).

128. Aggag, G., Takahashi, K., Polymer Engineering and Science, 36, 17, p22602266, (1996).

129. Turner, S., Reed, P. E., Money, M., Plastics and Rubber Processing and Applications, 4, 4, p369-378, (1984). 
130. D3763-86, Standard Test Method for High-Speed Puncture Properties of Plastics Using Load and Displacement Sensors, ASTM Standards, p178-182, (1986).

131. Rosand Instrumented Impact Test Systems, Company Manual for Drop Weight Tester 5, (1986).

132. Mills, N. J., Zhang, P. S., Journal of Materials Science, 24, p2099-2109, (1989).

133. Chivers, R. A., Moore, D. R., Measurement Science and Technology, 1, p313-321, (1990).

134. Chivers, R. A., Moore, D. R., Polymer Preprints, 29, 2, p152, (1988).

135. Cain, P. J., Instrumented Impact Testing of Plastics and Composites, ASTM STP 936, p81-102, (1987).

136. Reed, P. E., Plastics, Rubber and Composites Processing and Applications, 17, 3, p157-163, (1992).

137. ASTM D790-91 Standard Test Methods for Flexural Properties of Unreinforced and Reinforced Plastics and Electrical Insulating Materials, ASTM Standards, p269-278, (1991).

138. Fenimore, C. P., Martin, F. J., Combustion and Flame, 10, p135-139, (1966).

139. Anon, Oxygen Index, Raychem document, Raychem Ltd., Swindon, Wilts, UK, p1-9, (1978).

140. E.D.Weil, E. D., Hirschler, M. M., Patel, N. G., Said, M. M., \& Shakir; S., Fire and Materials, 16, p159-167, (1992).

141. Sutker, B. J., Ullmann's Encyclopedia of Industrial Chemistry, $5^{\text {th }}$ Ed., A.11, p123-139, (1988).

142. Doumen, C., Flammability Tests Information Sheet, Great Lakes Chemical Europe, p1-159, (1997).

143. GE Specialty Chemicals representative, Personal Communication, (May 1998).

144. Hosoda, S., Kojima, K., Polymer Communications, 30, 3, p83-85, (1989).

145. Trent, J. S., Scheinbeim, J. I., Couchman, P. R., Journal of Polymer Science: Polymer Letters Edition, 19, p315-319, (1981).

146. Brown, G. M., Butler, J. H., Polymer, 38, 15, p3937-3945, (1997). 
147. Trent, J. S., Scheinbeim, J. I., Couchman, P. R., Macromolecules, 16, p589598, (1983).

148. Antonov, A. V., Gitina, R. M., Novikov, S. N., Polymer Science U.S.S.R., 32, 9, p1809-1815, (1990).

149. Bucknall, C. B., Plastics, Rubber and Composites Processing and Applications, 17, 3, p141-145, (1992).

150. Ni, B. Y., Li, C. M., Berry, V. K., Polymer, 32, 15, p2766-2770, (1991).

151. Rink, M., Ricco, T., Lubert, W., Pavan, A., Journal of Applied Polymer Science, 22, p429-443, (1978).

152. Anon, Castor Oil and its Chemistry, Information Sheet, CasChem, Inc, p427.

153. Martin, S. B. \& Kanury, A. M., McGraw-Hill Encyclopedia of Science and Technology $7^{\text {th }}$ Ed., 7, (1992).

154. Anon., Chemical Additives for the Plastics Industry, Radian Corporation, Noyes Data Corp., (1987).

155. Kaspersma, J., Personal Communciation, Great Lakes Chemicals (Europe), (Nov 1998).

156. Donald, A. E., Kramer, E. J., Journal of Materials Science, 17, 6, p17651772, (1982).

157. Carty, P., White, S., Applied Organometallic Chemistry, 5, p51-56, (1991). 


\section{APPENDiX A: MATERIAL CHARACTERISATION}

- Cycolac T ABS polymer - processing conditions and properties

- Blendex 310S ABS impact modifier - properties

- Antimony trioxide - physical properties

- Castor wax - physical properties

- BTBPE FF680 - data sheet

- TBBA BA59P - data sheet

- DBDPO DE83R - data sheet

- Antimony trioxide - particle sizing data 


\section{Product Information} COMMERCIAL

\section{CYCOLAC}

\author{
ABS Resins
}

$T$

CYCOLAC T is a multipurpose Injection moulding grade affering a versatile balance of properties such as ultra high gloss. good impact, stiffness and flow. It is widely used in appliances.

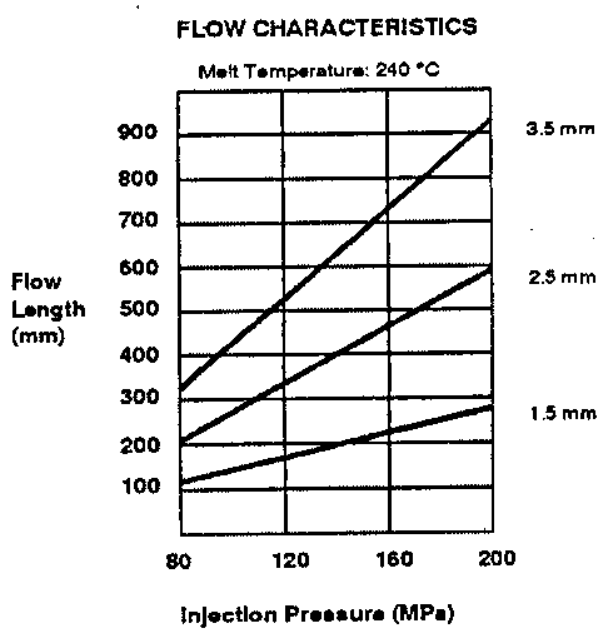

PROCESSING CONDITIONS
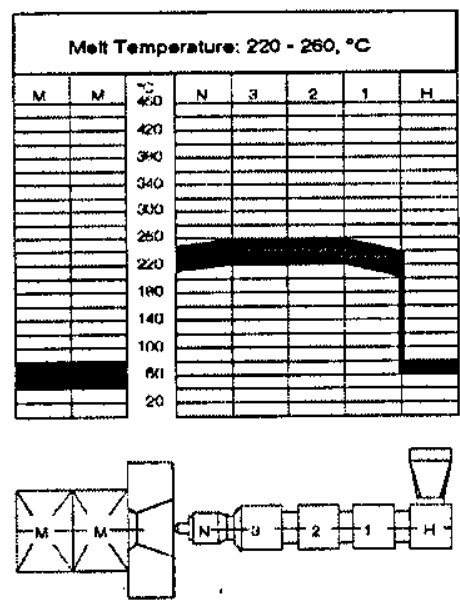

\footnotetext{
Pred rying temperaturetime $\quad: 85 \cdot 95^{\circ} \mathrm{C} / 2-4 \mathrm{hr}$ Fecommended melt tomperature $\quad: 220 \cdot 260^{\circ} \mathrm{C}$ $\begin{array}{ll}\text { Recommended molh tomperaturo } & : 220 \cdot 260^{\circ} \mathrm{C} \\ \text { Recommonded mould tomperaturn } & : 40.00^{\circ} \mathrm{C}\end{array}$
}

\begin{tabular}{|c|c|c|c|}
\hline TVPICAL PROPERTIES') & TYPICAL VALUE & UNIT & STANDARD \\
\hline 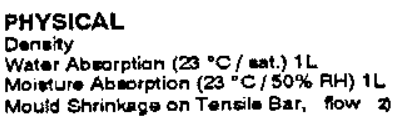 & $\begin{array}{l}1.04 \\
1.00 \\
0.20 \\
0.5-0.7\end{array}$ & $\begin{array}{l}g / \mathrm{cm}^{*} \\
\% \\
\% \\
\%\end{array}$ & $\begin{array}{l}\text { ISO } 11 \% 3 \\
\text { DIN } 53445 \\
\text { DIN } 53495 \\
\text { ASTM DS55 }\end{array}$ \\
\hline $\begin{array}{l}\text { RHEOLOGICAL } \\
\text { Ment Flow Rate, MFR } 220^{\circ} \mathrm{C} / 10 \mathrm{~kg} \\
\text { Mett Voluma Rate, MVR } 220^{\circ} \mathrm{C} / 10^{\mathrm{kg}}\end{array}$ & $\begin{array}{l}25 \\
26\end{array}$ & $\begin{array}{l}g / 10 \text { min. } \\
\mathrm{cm} / 10 \mathrm{~min} .\end{array}$ & $\begin{array}{l}\text { iso } 1133 \\
\text { ISO } 1133\end{array}$ \\
\hline
\end{tabular}




\section{Product Information} COMMERCIAL

\section{CYCOLAC $^{\circledast}$}

ABS Resins

$T$

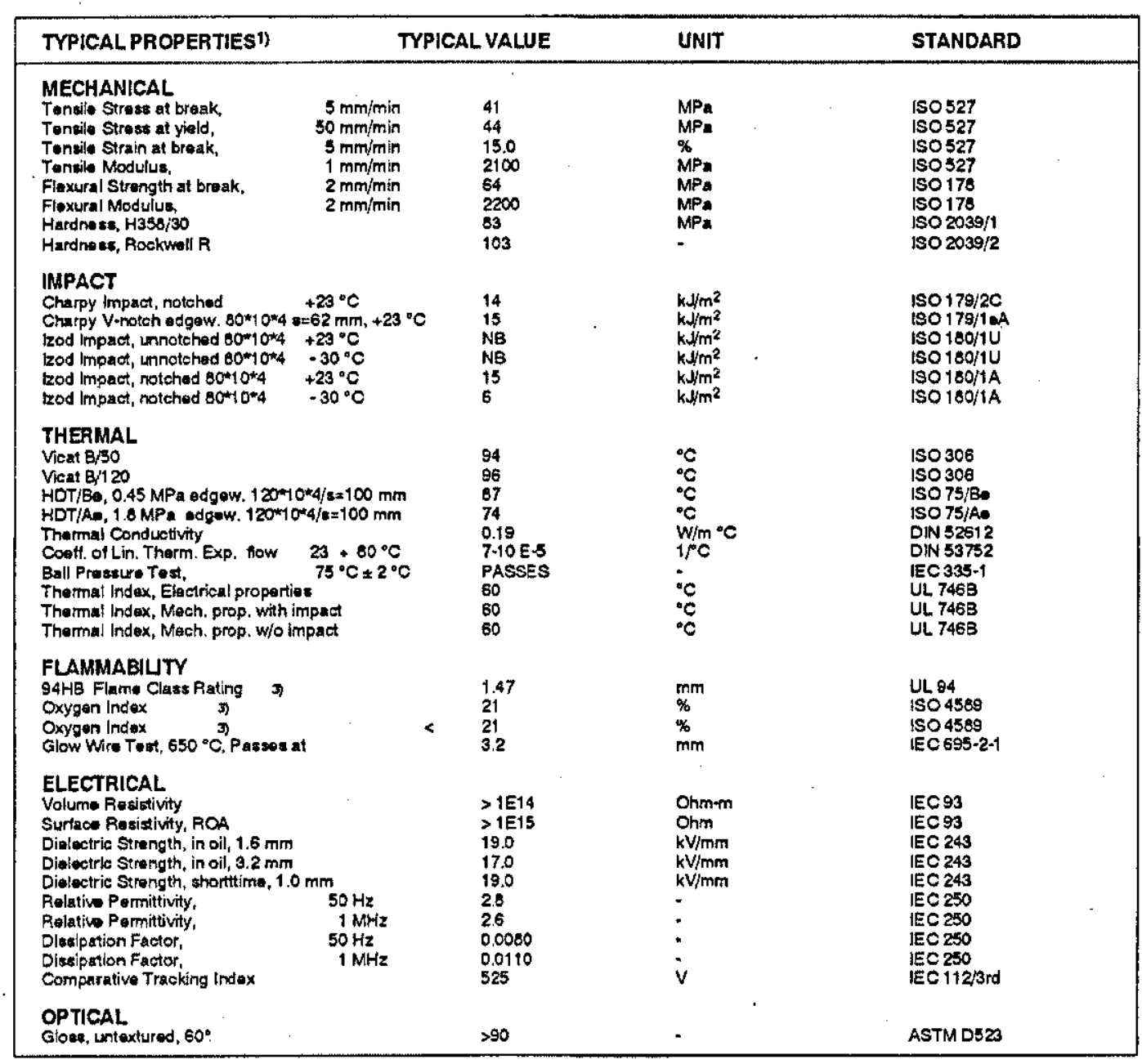

1) Typical vakus only. Variations within normel trferancets are pxesibh fot various colours. All valuea afs moaguted at loast alter 48 hours atorage at $23^{\circ} \mathrm{C} / 50 \%$ selative humidity. The samples fos HDT and Vicat are stored on silicagel diteclly after moulding. Al properties, except the met volurtio rate. are mesarured in injection mouldod sarmplese.
2) Only typical data for maborial selection purposes. Nol to be uned for part or tool derign.

3) Tha rating is not intended to reflect hazurdy presuread by this or any other material under actual fire conditione.

4) Own moasurement arcording to UL. 


\section{BLENDEX ${ }^{\circledR}$ Modifier Resins}

\section{BLENDEX 310(S) \\ DESCRIPTION \\ APPEARANCE \\ TYPICAL PROPERTIES}

\section{D176-1-795}

High Efficiency Opaque ABS Impact Modifier

Free Flowing White Powder

Butadiene (\%)

Specific Gravity.... 61

Bulk Density. $0.99 \mathrm{~g} / \mathrm{m}^{3}$

Hardness, Rockwell D. $290 \mathrm{~kg} / \mathrm{m}^{3}\left(18.1 \mathrm{lb} / \mathrm{ft}^{3}\right)$

IZOD Impact .155

Tensile Strength $15.8 \mathrm{~kJ} / \mathrm{m}^{2}\left(7.52 \mathrm{ft}-\mathrm{lb} / \mathrm{in}^{2}\right)$

Tensile Modulus $.7 \mathrm{MPa}(1020 \mathrm{psi})$

VICAT $10 \mathrm{~N}$ $0.5 \mathrm{GPa}(70,000 \mathrm{psi})$

Heat Deflection Temperature. $96^{\circ} \mathrm{C}\left(205^{\circ} \mathrm{F}\right)$ $87^{\circ} \mathrm{C}\left(189^{\circ} \mathrm{F}\right)$

\section{ADVANTAGES}

- Versatile, high efficiency impact modifier

- Extends room and low temperature abuse/impact resistance

\section{APPLICATIONS}

- Can be used at low loading levels to produce improved impact performance at a broad range of temperatures in PVC compounds including calendered, extruded and molded products.

- Provides a balance of properties including excellent impact and temperature resistance at low loading levels in most thermoplastic polymer applications

\section{REGULATORY STATUS}

USA (FDA) 21 Code of Federal Regulations Par. 177.2460.

Eur. Union EU Directive 90/128/EEC of 23.02.1990 as amended.

Germany (BGA) -Lebensmittel- und Bedarfsgegenständegesetz of 08.07.1993

Netherlands Food Packaging and Utensils Decree of 01.10.1979 as amended.

France - Min. Decree of 14.09.1992 - Brochure 1227 (January 1994).

Italy - Min. Decree of 21.03.1973 as amended - Min. Decree No. 200 of 26.04.1993.

Spain - Royal Decree 211/1992 or 06.03.1992 - Royal Decree 1769/1993 of 09.10.1993.

Belgium Royal Decree of 11.05.1992 as amended.

United Kingdom - Letter from British Plastics Federation of 20.12.1989.

- The Plastic Materials and Articles in Contact with Food Regulations

1992 (S.I. No. 3145) as amended.

Testing performed under ISO conditions.

This product is available in Europe.

HTS Harmonized Tariff Schedule number as of printing date 3902.90.0050

\section{GE Specialty Chemicals, Inc.}




\title{
Microfine AO5 Antimony Trioxide

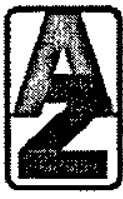

\section{DESCRIPTION}

Microfine AO5 Antimony Trioxide is a sub-micron particle size antimony oxide with an average particle size of 0.5 microns. This product is produced under very carefully controlled conditions to ensure not only a very fine and consistent average particle size but also a narrow particle size distribution with the absolute minimum of coarser particles above one micron. The product is predominantly senarmontite (cubic crystal form), with a high tintorial strength and a bright white powder colour. This product is available in both standard and high purity grades designated Microfine AO5 and Microfine AO5-HP respectively.

\section{PHYSICAL PROPERTIES}

\begin{tabular}{|l|l|}
\hline Appearance & $\begin{array}{l}\text { Very Fine White } \\
\text { Powder }\end{array}$ \\
\hline Specific Gravity & 5.5 \\
\hline Refractive Index & 2.1 \\
\hline Bulk Density (aerated) & $26-28 \mathrm{lbs} / \mathrm{cu} . \mathrm{ft}$. \\
\hline Bulk Density (packed) & $38-40 \mathrm{lbs} / \mathrm{cu} . \mathrm{ft}$. \\
\hline $\begin{array}{l}\text { Fineness thru 325 mesh sieve } \\
\text { Average particle size } \\
\text { (Sediograph) }\end{array}$ & $99.995 \%$ \\
$\begin{array}{l}\text { Surface Area (BET) } \\
\text { Tinting Strength \% of } \\
\text { standard }\end{array}$ & $0.4-0.6 \mathrm{microns}$ \\
\hline
\end{tabular}

\section{CHEMICAL PROPERTIES}

\begin{tabular}{|c|c|c|c|}
\hline Chemical & Symbol & $\begin{array}{c}\text { Microfine } \\
\text { A05 }\end{array}$ & $\begin{array}{c}\text { Microfine } \\
\text { AO5-HP }\end{array}$ \\
\hline $\begin{array}{l}\text { Antimony } \\
\text { Trioxide }\end{array}$ & $\mathrm{Sb} 203$ & $99.3 \% \mathrm{Min}$ & $99.5 \% \mathrm{Min}$ \\
\hline Arsenic & As & $0.3 \%$ Max & $0.1 \% \operatorname{Max}$ \\
\hline Lead & $\mathrm{Pb}$ & $0.2 \% \mathrm{Max}$ & $0.1 \% \mathrm{Max}$ \\
\hline Iron & $\mathrm{Fe}$ & $0.01 \% \mathrm{Max}$ & $0.003 \%$ Max \\
\hline Copper & $\mathrm{Cu}$ & $0.005 \%$ Max & $0.001 \%$ Max \\
\hline Nickel & $\mathrm{Ni}$ & $0.005 \% \mathrm{Max}$ & $0.001 \% \operatorname{Max}$ \\
\hline $\begin{array}{l}\text { Moisture, } 2 \\
\text { hrs } @ 1050 \mathrm{C}\end{array}$ & & $0.1 \% \mathrm{Max}$ & $0.1 \% \operatorname{Max}$ \\
\hline Water Soluble & & $0.25 \% \mathrm{Max}$ & $0.25 \%$ Max \\
\hline $\begin{array}{l}\text { Acidity, as } \\
\text { (II2SO4) }\end{array}$ & & $0.15 \% \operatorname{Max}$ & $0.04 \% \operatorname{Max}$ \\
\hline
\end{tabular}

\begin{abstract}
APPLICATIONS
Microfine AO5 finds application as a flame retardant, when used in combination with a source of halogen. In rigid and plasticized PVC compounds, the addition of controlled amounts of Microfine AO5 will confer excellent flame-retardant properties. In other plastics, paints and textiles which do not contain halogen, a suitable chlorinated or brominated compound must be added with the Microfine AO5 in order to obtain the required flame-retardant properties. Microfine AO5 is especially recommended in coating applications (paint, paper, textiles and adhesives) where it's very fine particle size can give benefits of improved suspension stability, smoother surface finish and improved physical properties along with it's high white pigmentary power. Microfine AO5 also finds application in thermoplastic compounds where tensile and impact properties are critical or in very thin wall applications to improve surface finish and electrical properties. Microfine also finds application as a catalyst and chemical reactant. The very fine particle size provides an improved reactivity over other grades of antimony trioxide. In this application Microfine AO5-HP is usually the product of choice due to its higher chemical purity.
\end{abstract}

\section{HYGIENE}

Avoid inhalation and ingestion. Air purity should be controlled in conformance with OSHA standards. Material Safety Data Sheets available on request.

\section{PACKAGES}

The standard package is a multiwalled $25 \mathrm{lb}$ paper sack, shrunk wrapped $2,000 \mathrm{lbs}$ to a skid. Alternate packages are available on request. 


\section{CEFTIFICATE OF ANAIXSIS}

\section{To Richred sedow}

\section{Customer:}

Customer's order no.

Anzon order no.

Material:

Quantity:

Batch number ( $s$ )

Date of manufacture

ofAntimony (as Sb203)

oAntimony tetroxide (as Sb204)

ofrsenic (as As)

ofron (as $\mathrm{Fe}$ )

\&Lead ( $\mathrm{as} \mathrm{Pb}$ )

ofidity (as H2SO4)

Fisher Number

응+53 microns

Colour

\section{Loughborough University}

Timonox ket-star

$4 \times 25 \mathrm{~kg}$.

$$
\begin{aligned}
96-689 \\
19-\text { Nov- } 96
\end{aligned}
$$

99.7

0.49

0.12

0.0008

0.04

0.001

$1.31 \mathrm{um}$

0.001

W/S

For Anzon Ltd.

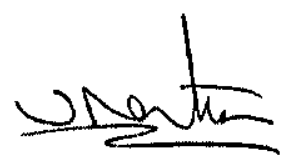

V.Denton (Mrs.)

Laboratory Manager 
Information on castor wax materials as used in Anzon sub-micron 'AZUB' products.

\section{HYDROXY WAXES}

The addition of hydrogen changes castor oil to a hard britle wax known as Castorwax or Opalwax. The saturation of double bonds converts each hydroxyoleic chain to bydroxystearic.

\section{Characteristics}

- Available with several melt points

- Resistant to water, oils and fats, crude petroleum and derivatives.

- Narrow melting range due to the high purity of castor's structure, $90 \%$ ricinoleic acid

- Soluble in hot solvents; subject to solidification on cooling

- Generally reduce melt viscosity

- Non-toxic, tasteless and release no undesirable odors

- Improve distribution of anti-perspirant actives and enhance pay-off in stick products

- Compatible with silicone fluids and most natural and animal waxes

- Do not yield to rancidity

\section{Uses and Applications}

- Metal drawing lubricants

- Packing and Sealants

- Processing aid for rubber and plastics

- Strippable coatings

- Dielectric compounds

- Camauba wax substitute

- Wax polishes

- Cosmetics and toiletries

- Investment casting

- Pencils and crayons

- Tableting - controlled release binder

- Lipstick

- Anti-perspirant sticks

- Potting compounds

\begin{tabular}{|c|c|c|c|c|c|c|c|}
\hline PRODUCT NAME & $\begin{array}{l}\text { ACID } \\
\text { VALUE }\end{array}$ & $\begin{array}{l}\text { IODINE } \\
\text { VALUE } \\
\text { (WLS) }\end{array}$ & $\begin{array}{l}\text { HYDROXYL } \\
\text { VALUE }\end{array}$ & $\begin{array}{l}\text { SAPON. } \\
\text { VALUEE }\end{array}$ & $\begin{array}{c}\text { SPECIFIC } \\
\text { GRAVTrY } \\
\left(25^{\circ} \mathrm{C} / 25^{\circ} \mathrm{C}\right)\end{array}$ & $\begin{array}{l}\text { PENETRATION } \\
\text { HARDNESS }\end{array}$ & $\begin{array}{l}\text { MELTING } \\
\text { POINT } \\
\text { ("C) }\end{array}$ \\
\hline \multicolumn{8}{|c|}{ 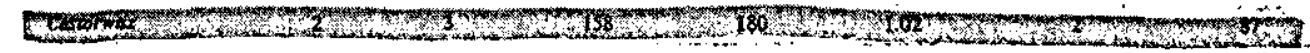 } \\
\hline Castorwax NF & 2 & 3 & 158 & 180 & 1.02 & 2 & 87 \\
\hline Ceseonwer MP-80 & 2 & 29 & $158^{\circ}$ & 180 & 0.98 & 9 & 80 \\
\hline Castomarar MP-70 & 2 & 38 & 158 & 180 & 0.98 & 42 & 70 \\
\hline
\end{tabular}

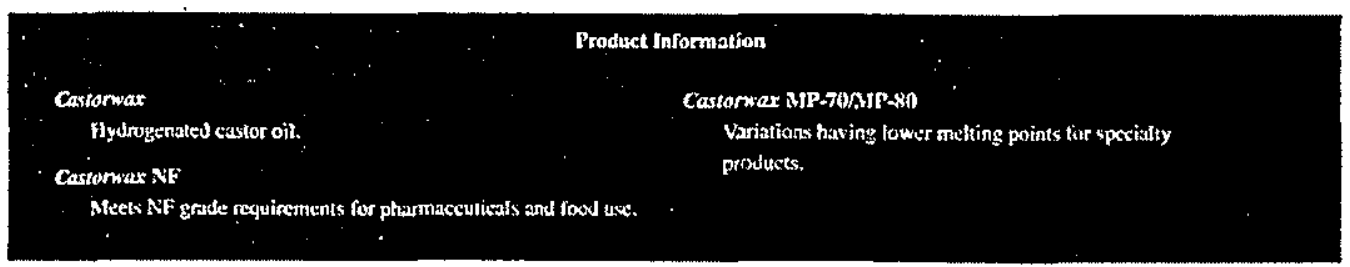




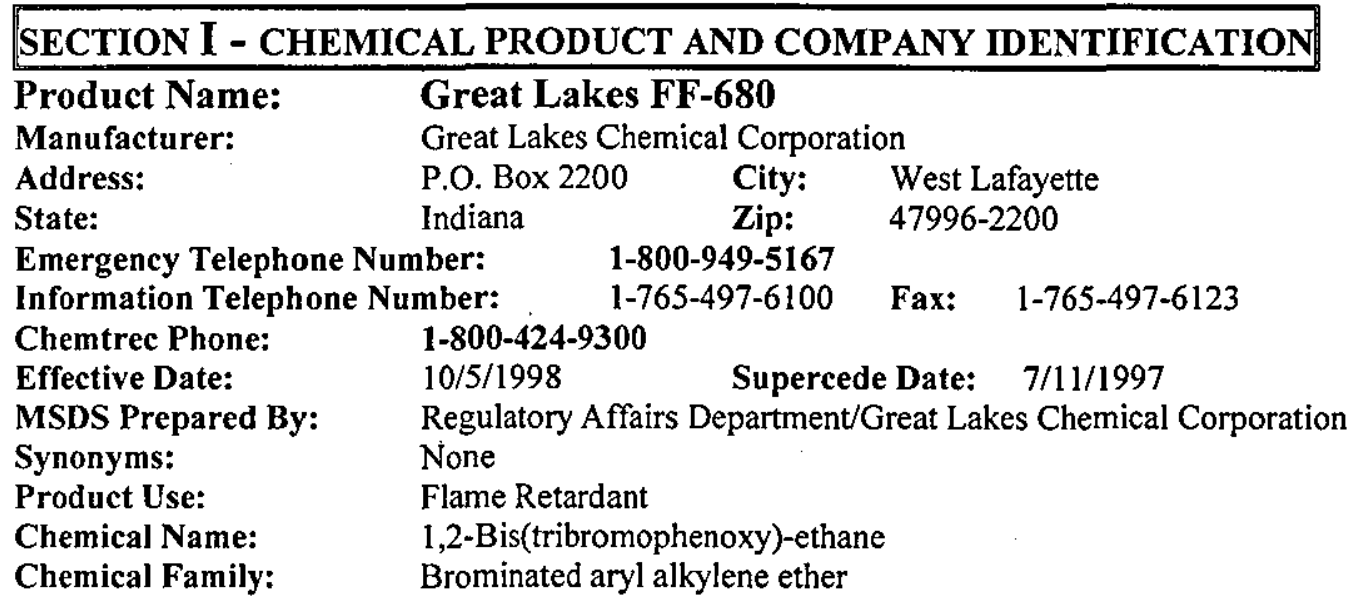

\section{SECTION IX - PHYSICAL \& CHEMICAL PROPERTIES}

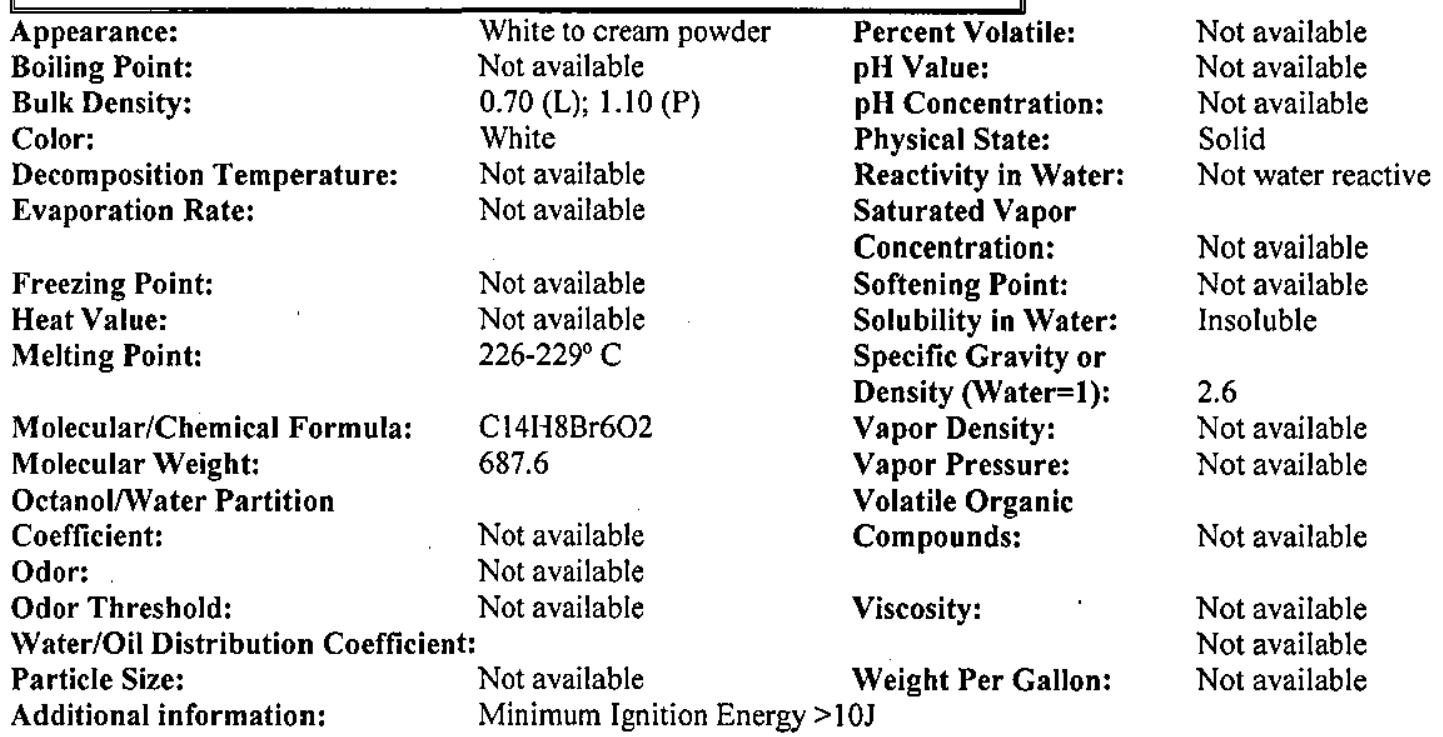

\section{SECTION XI - TOXICOLOGICAL INFORMATION}

\begin{tabular}{|l|l|l|l|}
\hline VALUE (LD50 OR LC50) & ANIMAL & ROUTES & COMPONENTS \\
\hline$>36.68 \mathrm{mg} / \mathrm{L}$ & Rat & Acute Inhalation & FF-680 \\
\hline$>2 \mathrm{~g} / \mathrm{kg}$ & Rabbit & Acute Dermal & FF-680 \\
\hline$>10 \mathrm{~g} / \mathrm{kg}$ & Rat & Acute Oral & FF-680 \\
\hline
\end{tabular}

Toxicological Information:

This material has been determined not to be a primary eye irritant in rabbits. This material has been determined not to be a primary skin irritant in rabbits. In a 90 day dietary study no treatment related changes were observed in rats fed $0.1 \%$ or $1.0 \%$ FF- 680 . At $10 \%$, minimal liver cell enlargement was observed. Other acute and chronic health hazards, as well as target organs, are unknown. As with all dusts, inhalation of air concentration levels above the PNOR may cause irritation and adverse lung effects. 


\title{
SECTION I - CHEMICAL PRODUCT AND COMPANY IDENTIFICATION
}

\author{
Product Name: \\ Great Lakes BA-59P and BA-59PC \\ Manufacturer: \\ Address: \\ Great Lakes Chemical Corporation \\ State: \\ P.O. Box 2200 \\ City: \\ West Lafayette \\ Indiana \\ Zip: \\ 47996-2200 \\ Emergency Telephone Number: \\ 1-800-949-5167 \\ Information Telephone Number: $\quad 1-765-497-6100$ \\ Fax: $\quad 1-765-497-6123$ \\ Chemtrec Phone: \\ 1-800-424-9300 \\ Effective Date: \\ $12 / 29 / 1999$ \\ Supercede Date: 4/28/1998 \\ MSDS Prepared By: Regulatory Affairs Department/Great Lakes Chemical Corporation \\ Synonyms: \\ Tetrabromobisphenol A, TBBPA, 4,4'-Isopropylidene-bis(2,6- \\ Product Use: \\ dibromophenol), Compacted BA-59P \\ Chemical Name: \\ Chemical Family: \\ Flame Retardant \\ 4,4'-(1-Methylethylidene)bis[2,6-dibromo-]phenol \\ Halogenated bisphenol A
}

\section{SECTION IX - PHYSICAL \& CHEMICAL PROPERTIES}

\begin{tabular}{|c|c|c|c|}
\hline Appearance: & White crystals or powder & Percent Volatile: & Not available \\
\hline Boiling Point: & $601^{\circ} \mathrm{F}$ & pH Value: & Not available \\
\hline Bulk Density: & $0.96(\mathrm{~L}) ; 1.36(\mathrm{P})$ & pH Concentration: & Not available \\
\hline Color: & White & Physical State: & Solid \\
\hline Decomposition Temperature: & Not available & Reactivity in Water: & Not water reactive \\
\hline Evaporation Rate: & Not available & $\begin{array}{l}\text { Saturated Vapor } \\
\text { Concentration: }\end{array}$ & Not available \\
\hline Freezing Point: & Not available & Softening Point: & Not available \\
\hline Heat Value: & Not available & Solubility in Water: & $4.16 \mathrm{ppm}$ at $25^{\circ} \mathrm{C}$ \\
\hline Melting Point: & $179-182^{\circ} \mathrm{C}$ & $\begin{array}{l}\text { Specific Gravity or } \\
\text { Density (Water=1): }\end{array}$ & 2.2 \\
\hline Molecular/Chemical Formula: & $\mathrm{C} 15 \mathrm{H} 12 \mathrm{Br} 4 \mathrm{O} 2$ & Vapor Density: & Not available \\
\hline $\begin{array}{l}\text { Molecular Weight: } \\
\text { Octanol/Water Partition }\end{array}$ & 543.7 & $\begin{array}{l}\text { Vapor Pressure: } \\
\text { Volatile Organic }\end{array}$ & Not available \\
\hline Coefficient: & 34,644 & Compounds: & Not available \\
\hline Odor: & Slight & & \\
\hline Odor Threshold: & Not available & Viscosity: & Not available \\
\hline Water/Oil Distribution Coefficien & & & Not available \\
\hline Particle Size: & Not available & Weight Per Gallon: & Not available \\
\hline Additional Informatio & Minimum Igr & $>10 \mathrm{~J}$ & \\
\hline
\end{tabular}




\section{Product Name: $\quad$ Great Lakes BA-59P and BA-59PC}

\section{SECTION XI - TOXICOLOGICAL INFORMATION}

\begin{tabular}{|l|l|l|l|}
\hline VALUE (LD50 OR LC50) & ANIMAL & ROUTES & COMPONENTS \\
\hline$>0.5 \mathrm{mg} / \mathrm{L} / 8 \mathrm{H}$ & Rat, Mouse, Guinea Pig & Acute Inhalation & Tetrabromobisphenol A \\
\hline$>10,000 \mathrm{mg} / \mathrm{kg}$ & Mouse & Acute Oral & Tetrabromobisphenol A \\
\hline$>2,000 \mathrm{mg} / \mathrm{kg}$ & Rabbit & Acute Dermal & Tetrabromobisphenol A \\
\hline$>50,000 \mathrm{mg} / \mathrm{kg}$ & Rat & Acute Oral & Tetrabromobisphenol A \\
\hline
\end{tabular}

\section{Toxicological Information:}

This material was not found to be acutely toxic in skin, inhalation or ingestion exposure studies. This material has been determined not to be a primary eye irritant in rabbits, or a primary skin irritant in rabbits or a mutagenic in the Ames Test. This material did not cause sensitization in a guinea pig maximization study. In a fourteen day rat inhalation study, no adverse effects were seen for exposures up to $18 \mathrm{mg} / \mathrm{L}$ for exposures of four hours/day for five days/week. In a twenty-one day dermal study in rabbits, no adverse effects were seen at levels up to $2,500 \mathrm{mg} / \mathrm{kg} /$ day for five days/week. Mild skin redness was observed in this study.

Twenty-eight day feeding studies in rats at doses to $1000 \mathrm{ppm}$ in the diet showed no compound related toxicities with little or no increase in bromine levels of fat or liver tissues.

In a pilot teratology study, female rats were administered by gavage at dose levels of $30,100,300$, $1,000,3,000$ and $10,000 \mathrm{ppm} / \mathrm{kg} /$ day. Three of five animals died in the $10,000 \mathrm{mg} / \mathrm{kg} /$ day group, while the remaining two animals revealed signs of toxicity. There were no differences in the mean number of viable or nonviable fetuses, absorptions, implantations, or corpora lutea when compared to the controls for animals receiving $3,000 \mathrm{mg} / \mathrm{kg}$.day or less. Other acute and chronic health hazards, as well as target organs, are unknown. As with all dusts, inhalation of air concentration levels above the PNOR may cause irritation and adverse lung effects. 
Great Lakes Chemical Corporation

MSDS Number: 00001

Product Name: Great Lakes DE-83R and DE-83
MATERIAL SAFETY

DATA SHEET

Effective Date: 12/10/1999

Page: 1 of 7

\begin{tabular}{|c|c|c|c|}
\hline SECTION I - CHE] & CAL PRODUC & ND C & ANY IDENTIFICATION \\
\hline Product Name: & Great Lakes & $-83 R$ a & DE-83 \\
\hline Manufacturer: & Great Lakes $\mathrm{Ch}$ & al Corpo & \\
\hline Address: & P.O. Box 2200 & City: & West Lafayette \\
\hline State: & Indiana & Zip: & $47996-2200$ \\
\hline Emergency Telephone & mber: & $949-516$ & \\
\hline Information Telephont & imber: & $497-610 c$ & $1-765-497-6123$ \\
\hline Chemtrec Phone: & $1-800-424-9300$ & & \\
\hline Effective Date: & $12 / 10 / 1999$ & Super & $07 / 27 / 1999$ \\
\hline MSDS Prepared By: & Regulatory Affa & epartme & ireat Lakes Chemical Corporation \\
\hline Synonyms: & $\begin{array}{l}\text { Decabromodiph } \\
\text { Oxybispentabro }\end{array}$ & $\begin{array}{l}\text { ether; B } \\
\text { enzene; } 1\end{array}$ & $\begin{array}{l}\text { entabromophenyl) ether; } 1,1 \text { '- } \\
\text { abromodiphenyl oxide }\end{array}$ \\
\hline Product Use: & Flame Retardan & & \\
\hline Chemical Name: & Benzene, 1, '-ox & {$[2,3,4,5$,} & atabromo- \\
\hline Chemical Family: & Brominated dipl & oxide & \\
\hline
\end{tabular}

\section{SECTION IX - PHYSICAL \& CHEMICAL PROPERTIES}

\begin{tabular}{|c|c|c|c|}
\hline Appearance: & White to cream powder & Percent Volatile: & Not available \\
\hline Boiling Point: & Not available & pH Value: & Not available \\
\hline Bulk Density: & $1.07(\mathrm{~L}) ; 1.42(\mathrm{P})$ & pH Concentration: & Not available \\
\hline Color: & White to cream & Physical State: & Solid \\
\hline Decomposition Temperature: & Not available & Reactivity in Water: & Not water reactive \\
\hline Evaporation Rate: & Not available & $\begin{array}{l}\text { Saturated Vapor } \\
\text { Concentration: }\end{array}$ & Not available \\
\hline Freezing Point: & Not available & Softening Point: & Not available \\
\hline Heat Value: & Not available & Solubility in Water: & $0.1 \mathrm{ppb}$ at $25^{\circ} \mathrm{C}$ \\
\hline Melting Point: & $300-310^{\circ} \mathrm{C}$ & $\begin{array}{l}\text { Specific Gravity or } \\
\text { Density (Water=1): }\end{array}$ & 3.3 \\
\hline Molecular/Chemical Formula: & $\mathrm{C} 12 \mathrm{Br} 10 \mathrm{O}$ & Vapor Density: & Not available \\
\hline $\begin{array}{l}\text { Molecular Weight: } \\
\text { Octanol/Water Partition }\end{array}$ & 959.2 & $\begin{array}{l}\text { Vapor Pressure: } \\
\text { Volatile Organic }\end{array}$ & 4.63E-6 Pa at $21^{\circ} \mathrm{C}$ \\
\hline $\begin{array}{l}\text { Coefficient: } \\
\text { Odor: }\end{array}$ & $\begin{array}{l}\text { Log Kow }=6.265 \\
\text { No odor }\end{array}$ & Compounds: & Not available \\
\hline Odor Threshold: & Not available & Viscosity: & Not available \\
\hline Water/Oil Distribution Coeffici & & & Not available \\
\hline Particle Size: & $4 \mathrm{u}$ (max. ave.) & Weight Per Gallon: & Not available \\
\hline
\end{tabular}

\section{SECTION XI - TOXICOLOGICAL INFORMATION}

\begin{tabular}{|l|l|l|l|}
\hline VALUE (LD50 OR LC50) & ANIMAL & ROUTES & COMPONENTS \\
\hline$>50 \mathrm{mg} / \mathrm{L}$ & Rat & Acute Inhalation & Decabromodiphenyl oxide \\
\hline$>2,000 \mathrm{mg} / \mathrm{kg}$ & Rabbit & Acute Dermal & Decabromodiphenyl oxide \\
\hline$>5,000 \mathrm{mg} / \mathrm{kg}$ & Rat & Acute Oral & Decabromodiphenyl oxide \\
\hline
\end{tabular}

Toxicological Information:

Negative results were obtained in an Ames Test and in a bacterial reverse mutation assay for this material. In a 30-day study in rats, decabromodiphenyl oxide was found to cause hepatotoxicity and thyroid effects at $0.1 \%$ and $1.0 \%$ in the diet. However, in three separate 28 day feeding studies in rats at $100 \mathrm{mg} / \mathrm{kg}$ and $1000 \mathrm{mg} / \mathrm{kg}$ in the diet, no adverse liver or thyroid effects were observed. In a 2-year feeding study at $0.01,0.1$, and $1 \mathrm{mg} / \mathrm{kg}$ levels, no hepatotoxicity or thyroid effects were reported. In a 2-year feeding study with rats at levels of 50,000 and 25,000 ppm (approx. 2,000 and 1,000 mg/day), benign neoplastic nodules of the liver were observed in a dose-related manner. Chronic overexposure may result in liver effects. As with all dusts, inhalation of air concentration levels above the PNOR may cause irritation and adverse lung effects. 

14cesto
DELSA 44USX 2.03

EOLUTER

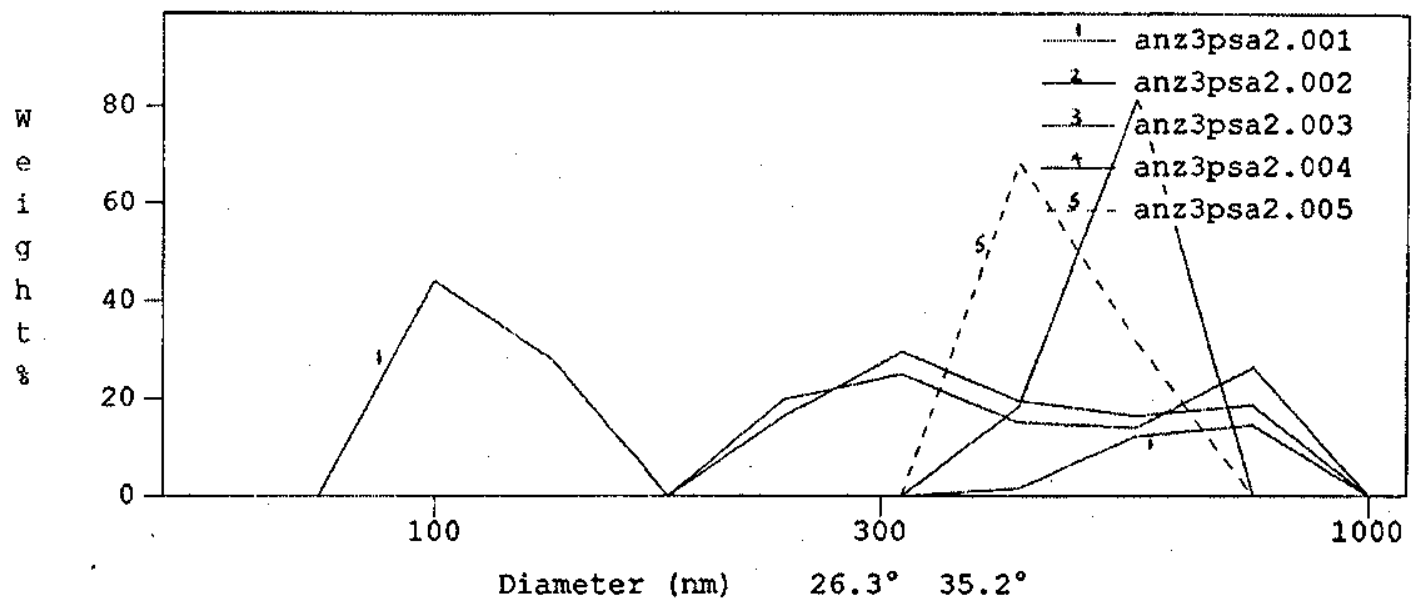

\section{AZUB particle sizing}

\begin{tabular}{|l|l|l|l|}
\hline \multicolumn{4}{|l|}{ Sample: anz3psa2.001 (sAZUB) } \\
\hline $35.2^{\circ}$ & Mean weight & S.D. & Amount \\
\hline 1 & $113 \mathrm{~nm}$ & $18 \mathrm{~nm}$ & $72 \%$ \\
\hline 2 & $651 \mathrm{~nm}$ & $120 \mathrm{~nm}$ & $28 \%$ \\
\hline Sample: anz3psa2.002 \\
\hline 1 & $537 \mathrm{~nm}$ & $60 \mathrm{~nm}$ & $100 \%$ \\
\hline Sample: anz3psa2.003 \\
\hline 1 & $465 \mathrm{~nm}$ & $220 \mathrm{~nm}$ & $100 \%$ \\
\hline Sample: anz3psa2.004 \\
\hline 1 & $444 \mathrm{~nm}$ & $190 \mathrm{~nm}$ & $100 \%$ \\
\hline Sample: anz3psa2.005 \\
\hline 1 & $466 \mathrm{~nm}$ & $72 \mathrm{~nm}$ & $100 \%$ \\
\hline
\end{tabular}

anz3psa2.001

\begin{tabular}{|l|l|l|l|l|l|l|l|l|l|l|l|l|l|l|l|l|}
\hline No. & 1 & 2 & 3 & 4 & 5 & 6 & 7 & 8 & 9 & 10 & 11 & 12 & 13 & 14 & 15 & 16 \\
\hline $\begin{array}{l}\text { Diameter } \\
(\mathrm{nm})\end{array}$ & 10 & 13 & 18 & 24 & 32 & 42 & 56 & 75 & 100 & 133 & 178 & 237 & 316 & 422 & 562 & 750 \\
\hline $\begin{array}{l}\text { Weight } \\
(\%)\end{array}$ & 0 & 0 & 0 & 0 & 0 & 0 & 0 & 0 & 44 & 28 & 0 & 0 & 0 & 1.5 & 12 & 14 \\
\hline
\end{tabular}




\section{CDULTER}

\section{AZUB particle sizing}

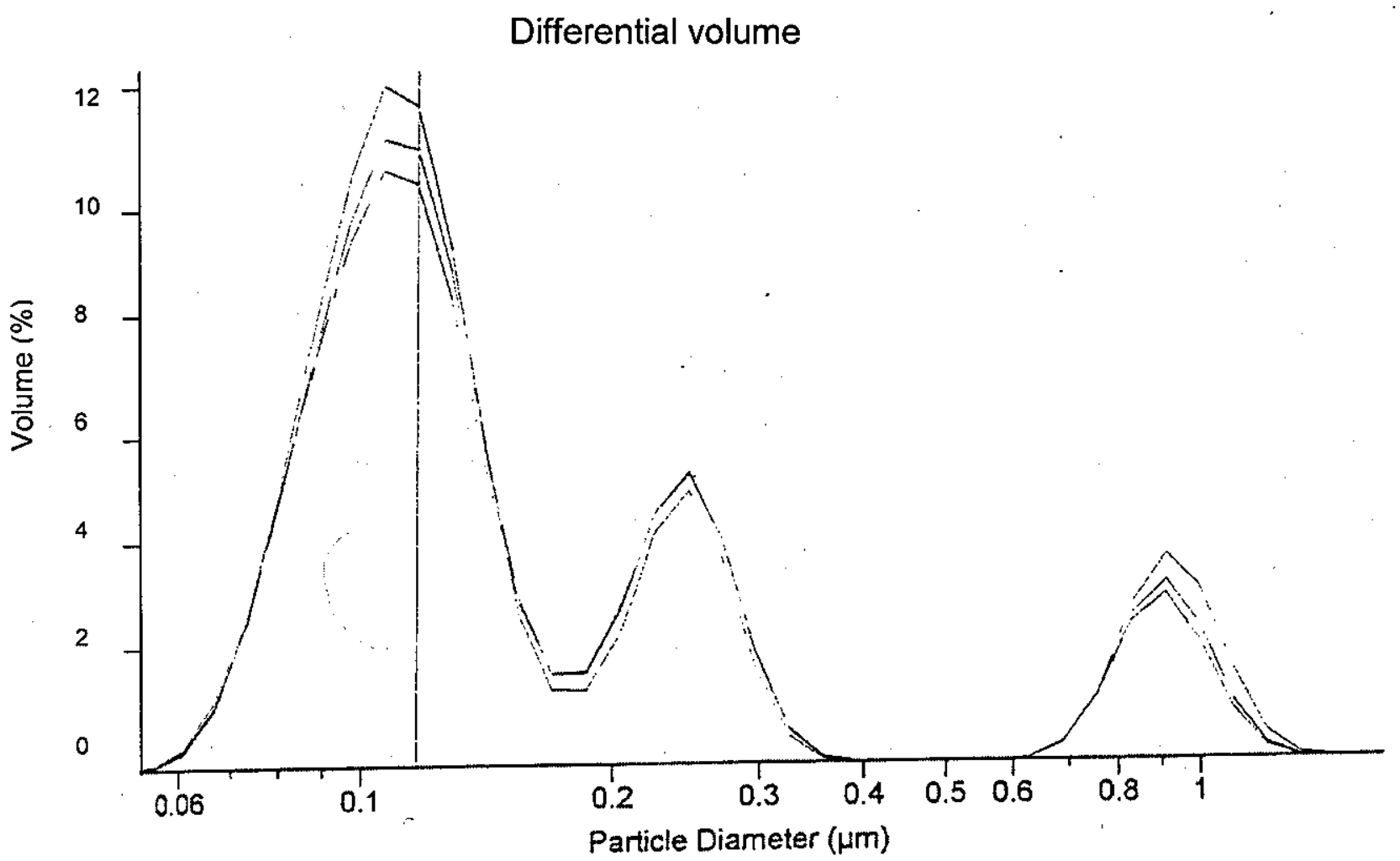

Calculations from $0.040 \mu \mathrm{m}$ to $2000 \mu \mathrm{m}$

Volume

Mean:

Median:

Mean/median Ratio:

Mode:

$\%$

Size $\mu \mathrm{m}$
10

0.682
$100 \%$

$0.216 \mu \mathrm{m}$

$0.121 \mu \mathrm{m}$

1.787

$0.107 \mu \mathrm{m}$
50

0.121
75 90

0.215

0.0993

0.0853 


\section{HCFIEA LA-90O}

PARTICLE SIZE DISTRIBUTION ANALYZER

Distribution Graph
Sample Name:A05 5MIN SONIC $10 / 95$ ID\# : $951011-160$
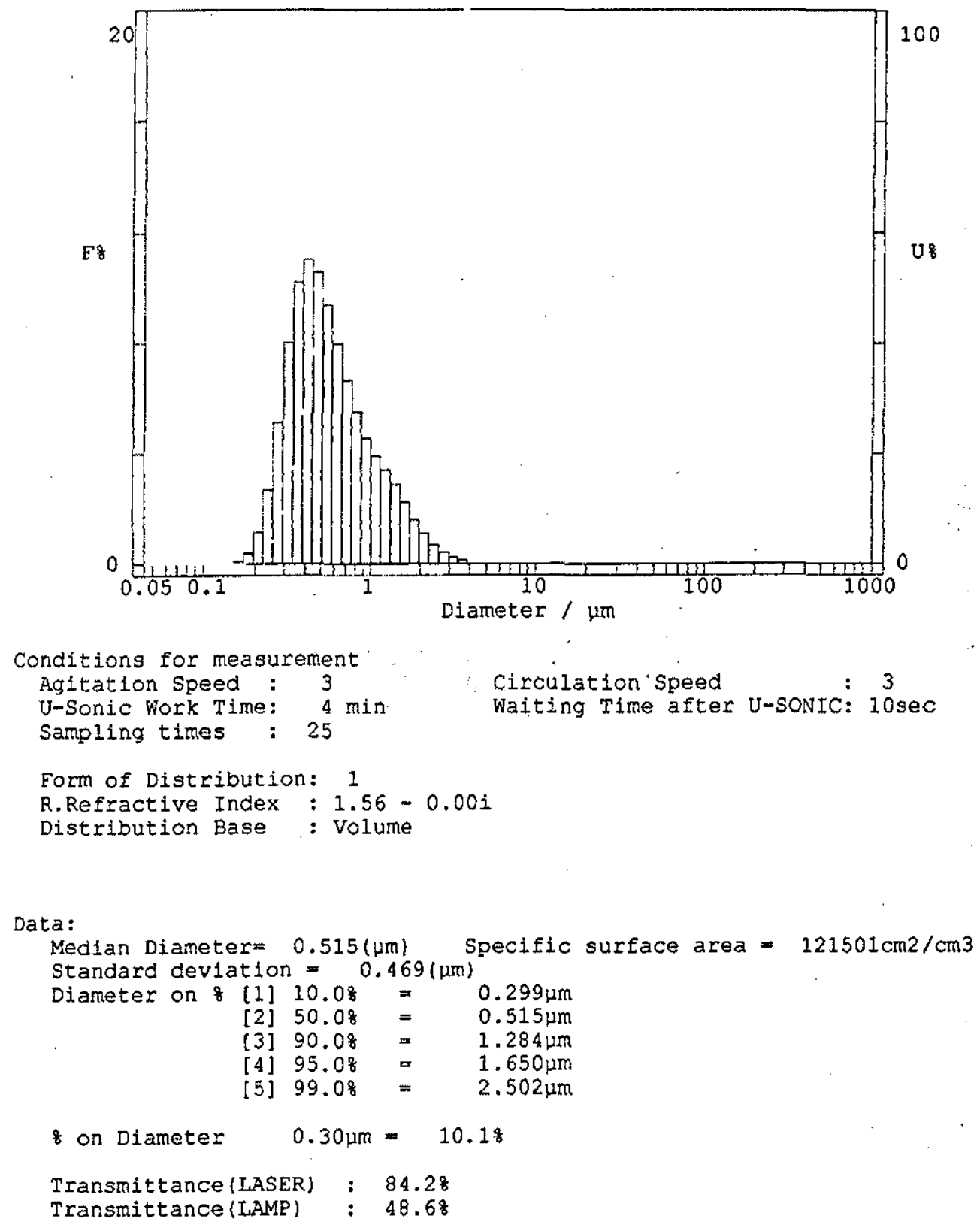


\section{HORIBA LA-9OO}

PARTICLE SIZE DISTRIBUTION ANALYZER

Sample name: Red Star
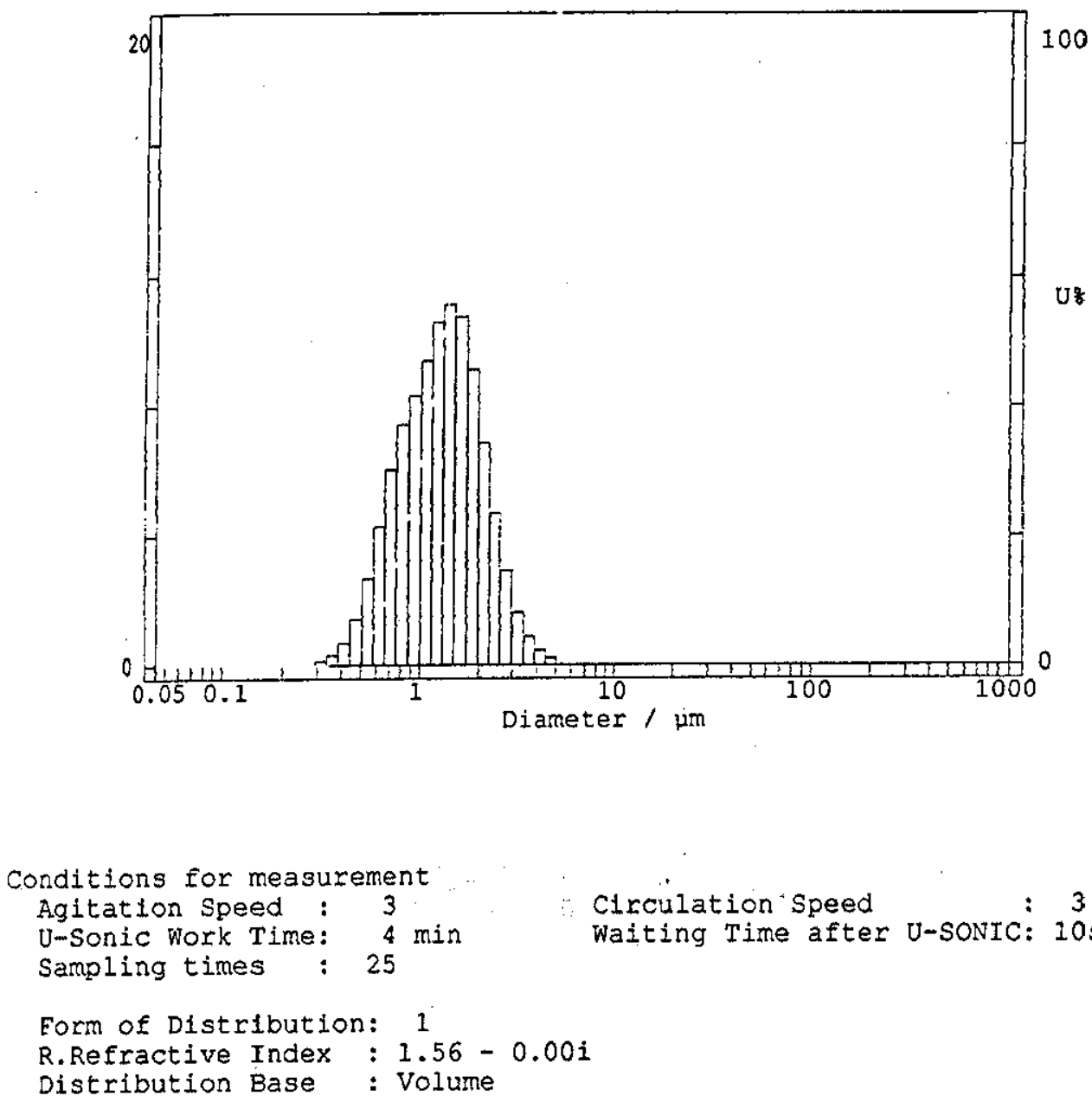

Data:

Median Diameter $=0.515(\mu \mathrm{m}) \quad$ Specific surface area $=52849 \mathrm{~cm} 2 / \mathrm{cm} 3$

Standard deviation $=0.469(\mathrm{\mu m})$

Diameter on 8 [1] $10.08=0.675 \mu \mathrm{m}$

[2] $50.08=1.305 \mu \mathrm{m}$

[3] $90.08=2.323 \mu \mathrm{m}$

[4] $95.08=2.737 \mu \mathrm{m}$

[5] $99.08=3.713 \mu \mathrm{m}$

8 on Diameter $\quad 0.30 \mu \mathrm{m}=$

Transmittance (LASER) : $84.2 \%$

Transmittance (LAMP) : 48.68 


\section{Anzon 8}

Richard Seddon

I.P.T.M.E.

Loughborough University

Loughborough

Leicestershire

LE11 3TU
Anzon Ltd

Cookson House, Willington Quay

Wallsend, Tyne and Wear NE28 6UQ

Telophone: (0191) 2622211

Fax: (0191) 2634481 Telex: 537357

$15^{\text {th }}$ May, 1998

Dear Richard,

Please find enclosed a half kilogramme sample of a flushed Red Star material. As we have discussed previously, this material has similar wax content to the flushed Azub $(20 \%)$ and has been produced using the same procedure.

The Red Star used has a particle size of $1.18 \mu \mathrm{m}$ measured on the Fisher.

If you need any further information please do not hesitate to call. Hope to speak to you soon

Cheers,

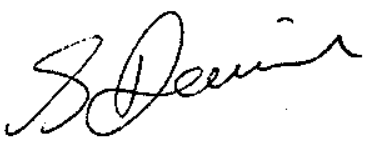

Steve Devine

R\&D Supervisor 


\section{APPENDIX B: IMPACT TEST RESULTS}

\section{Rosand Instrumented Falling Weight Impact Test Results}

The impact results in this section are numbered in the same manner as seen in the Results section of this thesis. The first compounds are the ABS controls (C1 to C6). The remaining compounds ( 1 to 32 ) have the relevant ABS control shown for that compound in brackets. An example is shown below for compound 11, which was originally formulated alongside ABS control 3 (C3).

\begin{tabular}{|c|c|c|c|c|c|}
\hline Compound & $\begin{array}{c}\text { Peak Force } \\
(\mathbf{N})\end{array}$ & $\begin{array}{c}\text { Peak Deflection } \\
(\mathbf{m m})\end{array}$ & $\begin{array}{c}\text { Peak Energy } \\
(\mathrm{J})\end{array}$ & $\begin{array}{c}\text { Failure Deflection } \\
(\mathbf{m m})\end{array}$ & $\begin{array}{c}\text { Failure Energy } \\
(\mathrm{J})\end{array}$ \\
\hline $\mathbf{A B S}+\mathbf{4 . 9 w t} \%$ RS (using 5.33wt\% MB2) & & & \\
\hline $\mathbf{1 1}(\mathbf{C 3})$ & 836 & 1.476 & 0.607 & 1.911 & 0.842 \\
& 848 & 1.506 & 0.645 & 1.935 & 0.883 \\
& 835 & 1.472 & 0.637 & 1.902 & 0.871 \\
& 790 & 1.253 & 0.46 & 1.763 & 0.729 \\
& 820 & 1.447 & 0.612 & 1.889 & 0.845 \\
& 818 & 1.487 & 0.638 & 1.92 & 0.867 \\
& 831 & 1.474 & 0.638 & 1.902 & 0.87 \\
& 803 & 1.439 & 0.608 & 1.879 & 0.835 \\
\hline
\end{tabular}




\begin{tabular}{|c|c|c|c|c|c|}
\hline Compound & $\begin{array}{c}\text { Peak Force } \\
(N)\end{array}$ & $\begin{array}{c}\text { Peak Deflection } \\
(\mathrm{mm})\end{array}$ & $\begin{array}{c}\text { Peak Energy } \\
(J)\end{array}$ & $\begin{array}{c}\text { Failure Deflection } \\
(\mathrm{mm})\end{array}$ & $\begin{array}{c}\text { Failure Energy } \\
(J)\end{array}$ \\
\hline \multicolumn{6}{|c|}{ Unfilled ABS (Control 1) } \\
\hline \multirow[t]{9}{*}{$\mathrm{Cl}$} & 937 & 1.704 & 0.818 & 2.241 & 1.112 \\
\hline & 930 & 1.669 & 0.822 & 2.195 & 1.113 \\
\hline & 916 & 1.605 & 0.763 & 2.142 & 1.056 \\
\hline & 940 & 1.641 & 0.807 & 2.200 & 1.121 \\
\hline & 938 & 1.730 & 0.870 & 2.247 & 1.158 \\
\hline & 939 & 1.639 & 0.800 & 2.174 & 1.100 \\
\hline & 872 & 1.590 & 0.722 & 2.152 & 1.013 \\
\hline & 918 & 1.628 & 0.763 & 2.169 & 1.064 \\
\hline & $924(23)$ & $1.651(0.05)$ & $0.796(0.05)$ & $2.190(0.04)$ & $1.092(0.05)$ \\
\hline
\end{tabular}

\section{Unfilled ABS (Control 2)}

\begin{tabular}{|l|l|l|l|l|l|}
\hline C2 & 969 & 1.633 & 0.810 & 2.047 & 1.078 \\
& 975 & 1.618 & 0.802 & 2.037 & 1.075 \\
& 992 & 1.686 & 0.849 & 2.088 & 1.120 \\
& 962 & 1.633 & 0.803 & 2.052 & 1.071 \\
& 999 & 1.636 & 0.834 & 2.063 & 1.114 \\
& 986 & 1.655 & 0.822 & 2.078 & 1.096 \\
& 886 & 1.569 & 0.733 & 2.006 & 0.988 \\
& 894 & 1.583 & 0.746 & 2.007 & 0.999 \\
\hline & $958(44)$ & $1.627(0.04)$ & $0.800(0.04)$ & $2.047(0.03)$ & $1.068(0.05)$ \\
\hline
\end{tabular}

\section{Unfilled ABS (Control 3)}

\begin{tabular}{|c|c|c|c|c|c|}
\hline C3 & 998 & 1.720 & 0.852 & 2.157 & 1.137 \\
& 1010 & 1.719 & 0.876 & 2.147 & 1.159 \\
915 & 1.637 & 0.773 & 2.047 & 1.024 \\
970 & 1.706 & 0.839 & 2.129 & 1.112 \\
& 1010 & 1.733 & 0.862 & 2.170 & 1.148 \\
& 1010 & 1.733 & 0.870 & 2.170 & 1.155 \\
& 987 & 1.703 & 0.837 & 2.133 & 1.115 \\
& 932 & 1.697 & 0.793 & 2.098 & 1.049 \\
\hline & $979(37)$ & $1.706(0.03)$ & $0.838(0.04)$ & $2.131(0.04)$ & $1.112(0.05)$ \\
\hline
\end{tabular}

Unfilled ABS (Control 4)

\begin{tabular}{|c|c|c|c|c|c|}
\hline. C4 & 976 & 1.722 & 0.820 & 2.147 & 1.100 \\
& 997 & 1.673 & 0.850 & 2.093 & 1.140 \\
& 1000 & 1.691 & 0.870 & 2.116 & 1.150 \\
984 & 1.696 & 0.840 & 2.123 & 1.120 \\
953 & 1.618 & 0.770 & 2.052 & 1.040 \\
& 1010 & 1.765 & 0.890 & 2.209 & 1.180 \\
& 986 & 1.688 & 0.830 & 2.097 & 1.100 \\
& 973 & 1.765 & 0.850 & 2.177 & 1.120 \\
\hline & $985(19)$ & $1.703(0.05)$ & $0.840(0.04)$ & $2.127(0.05)$ & $1.119(0.05)$ \\
\hline
\end{tabular}




\begin{tabular}{|c|c|c|c|c|c|}
\hline Compound & $\begin{array}{c}\text { Peak Force } \\
(N)\end{array}$ & $\begin{array}{c}\text { Peak Deflection } \\
(\mathrm{mm})\end{array}$ & $\begin{array}{c}\text { Peak Energy } \\
\text { (J) }\end{array}$ & $\begin{array}{c}\text { Failure Deflection } \\
(\mathrm{mm})\end{array}$ & $\begin{array}{c}\text { Failure Energy } \\
(J)\end{array}$ \\
\hline \multicolumn{6}{|c|}{ Unfilled ABS (Control 5) } \\
\hline $\mathbf{C 5}$ & $\begin{array}{c}945 \\
942 \\
1070 \\
944 \\
930 \\
939 \\
1030 \\
953 \\
\end{array}$ & $\begin{array}{l}1.709 \\
1.738 \\
1.781 \\
1.674 \\
1.696 \\
1.710 \\
1.763 \\
1.729 \\
\end{array}$ & $\begin{array}{l}0.780 \\
0.780 \\
0.890 \\
0.790 \\
0.770 \\
0.780 \\
0.850 \\
0.810 \\
\end{array}$ & $\begin{array}{l}2.132 \\
2.164 \\
2.211 \\
2.086 \\
2.112 \\
2.126 \\
2.192 \\
2.151 \\
\end{array}$ & $\begin{array}{l}1.050 \\
1.050 \\
1.190 \\
1.050 \\
1.030 \\
1.040 \\
1.140 \\
1.080 \\
\end{array}$ \\
\hline & $969(51)$ & $1.725(0.04)$ & $0.806(0.04)$ & $2.147(0.04)$ & $1.079(0.06)$ \\
\hline
\end{tabular}

Unfilled ABS (Control 6)

\begin{tabular}{|c|c|c|c|c|c|}
\hline C6 & 1010 & 1.647 & 0.850 & 2.116 & 1.140 \\
& 1000 & 1.688 & 0.850 & 2.175 & 1.160 \\
& 974 & 1.616 & 0.810 & 2.016 & 1.080 \\
& 990 & 1.681 & 0.840 & 2.129 & 1.130 \\
& 955 & 1.634 & 0.810 & 2.075 & 1.080 \\
& 1030 & 1.671 & 0.870 & 2.209 & 1.190 \\
& 978 & 1.623 & 0.820 & 2.039 & 1.090 \\
& 953 & 1.643 & 0.810 & 2.075 & 1.080 \\
\hline & $986(27)$ & $1.650(0.03)$ & $0.833(0.02)$ & $2.104(0.07)$ & $1.119(0.04)$ \\
\hline
\end{tabular}

ABS + 4.1wt\% Red Star (RS) $\mathrm{Sb}_{2} \mathrm{O}_{3}$

\begin{tabular}{|c|c|c|c|c|c|}
\hline 1 (C3) & 810 & 1.262 & 0.474 & 1.811 & 0.778 \\
& 811 & 1.272 & 0.487 & 1.835 & 0.811 \\
& 789 & 1.258 & 0.462 & 1.753 & 0.718 \\
& 790 & 1.263 & 0.46 & 1.781 & 0.73 \\
& 802 & 1.263 & 0.47 & 1.739 & 0.723 \\
& 811 & 1.31 & 0.501 & 1.826 & 0.783 \\
& 790 & 1.244 & 0.456 & 1.736 & 0.707 \\
& 808 & 1.272 & 0.485 & 1.839 & 0.805 \\
\hline & $801(10)$ & $1.268(0.02)$ & $0.474(0.02)$ & $1.790(0.04)$ & $0.757(0.04)$ \\
\hline
\end{tabular}

ABS + 5.49wt\% Microfine $\mathbf{A 0 5}$ (A05) $\mathbf{S b}_{2} \mathbf{O}_{3}$
\begin{tabular}{|c|c|c|c|c|c|}
\hline $2(\mathbf{C 1})$ & 824 & 1.443 & 0.572 & 1.927 & 0.819 \\
& 879 & 1.416 & 0.61 & 1.926 & 0.882 \\
& 840 & 1.381 & 0.549 & 1.898 & 0.82 \\
& 838 & 1.357 & 0.534 & 1.872 & 0.802 \\
& 832 & 1.325 & 0.51 & 1.836 & 0.766 \\
& 854 & 1.371 & 0.573 & 1.906 & 0.851 \\
& 886 & 1.459 & 0.64 & 2.017 & 0.923 \\
& 839 & 1.395 & 0.557 & 1.885 & 0.815 \\
\hline & $849(22)$ & $1.393(0.05)$ & $0.568(0.04)$ & $1.908(0.05)$ & $0.835(0.05)$ \\
\hline
\end{tabular}




\begin{tabular}{|c|c|c|c|c|c|}
\hline Compound & $\begin{array}{c}\text { Peak Force } \\
(N)\end{array}$ & $\begin{array}{c}\text { Peak Deflection } \\
(\mathrm{mm})\end{array}$ & $\begin{array}{c}\text { Peak Energy } \\
(J)\end{array}$ & $\begin{array}{c}\text { Failure Deflection } \\
(\mathrm{mm})\end{array}$ & $\begin{array}{c}\text { Failure Energy } \\
(J)\end{array}$ \\
\hline \multicolumn{6}{|c|}{ ABS $+3.85 w t \%$ pan dried $R S\left(A Z U B^{R S}\right) S^{R} \mathrm{O}_{3}$} \\
\hline $3(\mathrm{C3})$ & $\begin{array}{l}794 \\
791 \\
779 \\
793 \\
824 \\
834 \\
798 \\
791 \\
\end{array}$ & $\begin{array}{c}1.272 \\
1.268 \\
1.269 \\
1.268 \\
1.506 \\
1.49 \\
1.455 \\
1.301 \\
\end{array}$ & $\begin{array}{c}0.465 \\
0.461 \\
0.459 \\
0.456 \\
0.658 \\
0.641 \\
0.62 \\
0.465 \\
\end{array}$ & $\begin{array}{c}1.894 \\
1.87 \\
1.87 \\
1.835 \\
1.943 \\
1.926 \\
1.901 \\
1.876 \\
\end{array}$ & $\begin{array}{c}0.819 \\
0.79 \\
0.781 \\
0.758 \\
0.888 \\
0.876 \\
0.848 \\
0.776 \\
\end{array}$ \\
\hline & $801(19)$ & $1.354(0.11)$ & $0.528(0.09)$ & $1.889(0.03)$ & $0.817(0.05)$ \\
\hline
\end{tabular}

ABS + 4.93wt \% pan dried AZUB (pAZUB) $\mathrm{Sb}_{2} \mathrm{O}_{3}$

\begin{tabular}{|l|l|l|l|l|l|}
\hline $\mathbf{4}(\mathbf{C 1})$ & 913 & 1.626 & 0.767 & 2.161 & 1.043 \\
& 851 & 1.495 & 0.642 & 2.057 & 0.916 \\
& 912 & 1.618 & 0.766 & 2.146 & 1.042 \\
& 913 & 1.625 & 0.776 & 2.156 & 1.054 \\
& 912 & 1.59 & 0.746 & 2.129 & 1.015 \\
& 895 & 1.603 & 0.746 & 2.133 & 1.015 \\
& 906 & 1.614 & 0.742 & 2.133 & 1.008 \\
& 910 & 1.643 & 0.781 & 2.174 & 1.057 \\
\hline & $902(21)$ & $1.602(0.05)$ & $0.746(0.04)$ & $2.136(0.04)$ & $1.019(0.05)$ \\
\hline
\end{tabular}

ABS + 3.45wt\% spray dried AZUB (sAZUB) $\mathbf{S b}_{2} \mathbf{O}_{3}$
\begin{tabular}{|c|c|c|c|c|c|}
\hline $\mathbf{5 ( C 5 )}$ & 918 & 1.665 & 0.76 & 2.087 & 1.02 \\
& 933 & 1.661 & 0.77 & 2.077 & 1.02 \\
& 958 & 1.708 & 0.8 & 2.122 & 1.07 \\
& 950 & 1.662 & 0.8 & 2.081 & 1.06 \\
& 934 & 1.642 & 0.76 & 2.058 & 1.02 \\
& 960 & 1.71 & 0.8 & 2.128 & 1.07 \\
& 1040 & 1.872 & 0.86 & 2.301 & 1.15 \\
& 985 & 1.731 & 0.82 & 2.137 & 1.09 \\
\hline & $960(41)$ & $1.706(0.08)$ & $0.796(0.04)$ & $2.123(0.08)$ & $1.061(0.05)$ \\
\hline
\end{tabular}

ABS + 1.1 wt\% castor wax
\begin{tabular}{|c|c|c|c|c|c|}
\hline $6(\mathbf{C 4})$ & 968 & 1.755 & 0.82 & 2.172 & 1.09 \\
& 1020 & 1.801 & 0.91 & 2.263 & 1.21 \\
& 945 & 1.673 & 0.79 & 2.094 & 1.05 \\
& 981 & 1.723 & 0.84 & 2.158 & 1.12 \\
& 961 & 1.719 & 0.81 & 2.15 & 1.09 \\
& 940 & 1.696 & 0.8 & 2.115 & 1.07 \\
& 959 & 1.696 & 0.82 & 2.117 & 1.09 \\
& 979 & 1.692 & 0.82 & 2.113 & 1.1 \\
\hline & $969(25)$ & $1.719(0.04)$ & $0.826(0.04)$ & $2.148(0.05)$ & $1.103(0.05)$ \\
\hline
\end{tabular}




\begin{tabular}{|c|c|c|c|c|c|}
\hline Compound & $\begin{array}{c}\text { Peak Force } \\
\text { (N) }\end{array}$ & $\begin{array}{c}\text { Peak Deflection } \\
(\mathrm{mm})\end{array}$ & $\begin{array}{c}\text { Peak Energy } \\
(J)\end{array}$ & $\begin{array}{c}\text { Failure Deflection } \\
(\mathrm{mm})\end{array}$ & $\begin{array}{c}\text { Failure Energy } \\
(J)\end{array}$ \\
\hline \multicolumn{6}{|c|}{ ABS $+1.33 w t \%$ MB1 $(0.67 w t \%$ additional PB $)$} \\
\hline $7(\mathrm{C} 3)$ & \begin{tabular}{|c|}
1010 \\
943 \\
1030 \\
943 \\
1010 \\
1060 \\
1020 \\
943 \\
\end{tabular} & $\begin{array}{l}1.792 \\
1.692 \\
1.773 \\
1.657 \\
1.729 \\
1.783 \\
1.744 \\
1.683 \\
\end{array}$ & $\begin{array}{c}0.876 \\
0.819 \\
0.91 \\
0.808 \\
0.883 \\
0.954 \\
0.891 \\
0.812 \\
\end{array}$ & $\begin{array}{c}2.234 \\
2.12 \\
2.234 \\
2.102 \\
2.17 \\
2.238 \\
2.193 \\
2.111 \\
\end{array}$ & $\begin{array}{c}1.165 \\
1.084 \\
1.21 \\
1.079 \\
1.171 \\
1.264 \\
1.181 \\
1.078 \\
\end{array}$ \\
\hline & $995(46)$ & $1.732(0.05)$ & $0.869(0.05)$ & $2.175(0.06)$ & $1.154(0.07)$ \\
\hline
\end{tabular}

\begin{tabular}{|c|c|c|c|c|c|}
\hline \multirow[t]{8}{*}{$8(\mathrm{C} 3)$} & 1030 & 1.807 & 0.93 & 2.291 & 1.243 \\
\hline & 993 & 1.765 & 0.885 & 2.288 & 1.202 \\
\hline & 999 & 1.474 & 0.878 & 2.22 & 1.17 \\
\hline & 1040 & 1.87 & 0.966 & 2.357 & 1.289 \\
\hline & 963 & 1.725 & 0.84 & 2.206 & 1.124 \\
\hline & 1040 & 1.81 & 0.934 & 2.319 & 1.259 \\
\hline & 1020 & 1.805 & 0.922 & 2.29 & 1.231 \\
\hline & 1000 & 1.852 & 0.925 & 2.366 & 1.248 \\
\hline & $1011(27)$ & $1.764(0.13)$ & $0.910(0.04)$ & $2.292(0.06)$ & $1.221(0.05)$ \\
\hline
\end{tabular}

ABS + 12wt \% MB1 (6wt\% additional PB)
\begin{tabular}{|c|c|c|c|c|c|}
\hline $9(\mathbf{C 3})$ & 997 & 1.843 & 0.929 & 2.507 & 1.347 \\
& 984 & 1.812 & 0.89 & 2.536 & 1.36 \\
970 & 1.802 & 0.874 & 2.502 & 1.311 \\
985 & 1.834 & 0.897 & 2.467 & 1.317 \\
997 & 1.825 & 0.92 & 2.509 & 1.358 \\
& 1020 & 2.038 & 1.138 & 2.554 & 1.461 \\
& 1000 & 1.852 & 0.935 & 2.553 & 1.393 \\
& 993 & 1.853 & 0.926 & 2.504 & 1.355 \\
\hline & $993(15)$ & $1.857(0.08)$ & $0.939(0.08)$ & $2.517(0.03)$ & $1.363(0.05)$ \\
\hline
\end{tabular}

\begin{tabular}{|c|c|c|c|c|c|}
\hline \multirow[t]{8}{*}{$10(\mathrm{C} 3)$} & 810 & 1.262 & 0.474 & 1.811 & 0.778 \\
\hline & 811 & 1.272 & 0.487 & 1.835 & 0.811 \\
\hline & 789 & 1.258 & 0.462 & 1.753 & 0.718 \\
\hline & 790 & 1.263 & 0.46 & 1.781 & 0.73 \\
\hline & 802 & 1.263 & 0.47 & 1.739 & 0.723 \\
\hline & 811 & 1.31 & 0.501 & 1.826 & 0.783 \\
\hline & 790 & 1.244 & 0.456 & 1.736 & 0.707 \\
\hline & 808 & 1.272 & 0.485 & 1.839 & 0.805 \\
\hline & $801(10)$ & $1.268(0.02)$ & $0.474(0.02)$ & $1.790(0.04)$ & $0.757(0.04)$ \\
\hline
\end{tabular}




\begin{tabular}{|c|c|c|c|c|c|}
\hline Compound & $\begin{array}{c}\text { Peak Force } \\
\text { (N) }\end{array}$ & $\begin{array}{c}\text { Peak Deflection } \\
(\mathrm{mm})\end{array}$ & $\begin{array}{c}\text { Peak Energy } \\
(J)\end{array}$ & $\begin{array}{c}\text { Failure Deflection } \\
(\mathrm{mm})\end{array}$ & $\begin{array}{c}\text { Failure Energy } \\
\text { (J) }\end{array}$ \\
\hline \multicolumn{6}{|c|}{ ABS + 4.9wt $\%$ RS (using 5.33wt $\%$ MB2) } \\
\hline \multirow[t]{9}{*}{$11(\mathrm{C3})$} & 836 & 1.476 & 0.607 & 1.911 & 0.842 \\
\hline & 848 & 1.506 & 0.645 & 1.935 & 0.883 \\
\hline & 835 & 1.472 & 0.637 & 1.902 & 0.871 \\
\hline & 790 & 1.253 & 0.46 & 1.763 & 0.729 \\
\hline & 820 & 1.447 & 0.612 & 1.889 & 0.845 \\
\hline & 818 & 1.487 & 0.638 & 1.92 & 0.867 \\
\hline & 831 & 1.474 & 0.638 & 1.902 & 0.87 \\
\hline & 803 & 1.439 & 0.608 & 1.879 & 0.835 \\
\hline & $823(19)$ & $1.444(0.08)$ & $0.606(0.06)$ & $1.888(0.05)$ & $0.843(0.05)$ \\
\hline
\end{tabular}

ABS + 4.0wt\% RS (using 8wt\% MB3)
\begin{tabular}{|c|c|c|c|c|c|}
\hline 12 (C3) & 825 & 1.46 & 0.635 & 1.902 & 0.869 \\
& 891 & 1.545 & 0.7 & 1.971 & 0.95 \\
& 832 & 1.489 & 0.649 & 1.915 & 0.881 \\
& 822 & 1.478 & 0.637 & 1.925 & 0.87 \\
& 800 & 1.272 & 0.465 & 1.894 & 0.818 \\
& 804 & 1.273 & 0.475 & 1.879 & 0.822 \\
& 804 & 1.476 & 0.632 & 1.93 & 0.861 \\
& 822 & 1.48 & 0.635 & 1.929 & 0.868 \\
\hline & $825(29)$ & $1.434(0.10)$ & $0.604(0.09)$ & $1.918(0.03)$ & $0.867(0.04)$ \\
\hline
\end{tabular}

ABS + 3.81 wt \% RS (using 16wt \% MB4)

\begin{tabular}{|c|c|c|c|c|c|}
\hline $13(\mathrm{C3})$ & 955 & 1.735 & 0.823 & 2.192 & 1.1 \\
& 901 & 1.681 & 0.773 & 2.139 & 1.034 \\
& 970 & 1.772 & 0.855 & 2.262 & 1.142 \\
& 962 & 1.751 & 0.831 & 2.243 & 1.115 \\
& 912 & 1.703 & 0.784 & 2.166 & 1.047 \\
& 873 & 1.653 & 0.747 & 2.106 & 1 \\
& 978 & 1.735 & 0.844 & 2.206 & 1.127 \\
& 944 & 1.729 & 0.826 & 2.22 & 1.109 \\
\hline & $937(37)$ & $1.720(0.04)$ & $0.810(0.04)$ & $2.192(0.05)$ & $1.084(0.05)$ \\
\hline
\end{tabular}

ABS + 4.11wt\% AZUB Sb $_{2} \mathbf{O}_{3}$
\begin{tabular}{|c|c|c|c|c|c|}
\hline $14(\mathbf{C} 3)$ & 973 & 1.683 & 0.807 & 2.093 & 1.074 \\
& 934 & 1.635 & 0.779 & 2.039 & 1.035 \\
& 925 & 1.655 & 0.783 & 2.067 & 1.04 \\
& 907 & 1.621 & 0.754 & 2.034 & 1.004 \\
& 891 & 1.615 & 0.741 & 2.025 & 0.987 \\
& 946 & 1.667 & 0.8 & 2.066 & 1.056 \\
& 952 & 1.674 & 0.811 & 2.08 & 1.073 \\
& 949 & 1.653 & 0.798 & 2.061 & 1.06 \\
\hline & $935(26)$ & $1.650(0.03)$ & $0.784(0.03)$ & $2.058(0.02)$ & $1.041(0.03)$ \\
\hline
\end{tabular}




\begin{tabular}{|c|c|c|c|c|c|}
\hline Compound & $\begin{array}{c}\text { Peak Force } \\
\text { Peak Deflection } \\
(\mathbf{N})\end{array}$ & $\begin{array}{c}\text { Peak Energy } \\
(\mathbf{m m})\end{array}$ & $\begin{array}{c}\text { Failure Deflection } \\
(\mathbf{J})\end{array}$ & $\begin{array}{c}\text { Failure Energy } \\
(\mathbf{m m})\end{array}$ \\
\hline $\mathbf{A B S}+\mathbf{4 . 0 2 w t} \%$ AZUB Sb $\mathbf{O}_{3}$ (using 16wt\% MB5) & & \\
\hline $\mathbf{1 5}(\mathbf{C 4})$ & 959 & 1.81 & 0.84 & 2.345 & 1.13 \\
& 898 & 1.797 & 0.82 & 2.346 & 1.09 \\
& 933 & 1.82 & 0.85 & 2.332 & 1.13 \\
& 929 & 1.81 & 0.83 & 2.35 & 1.12 \\
& 942 & 1.81 & 0.84 & 2.331 & 1.13 \\
& 944 & 1.819 & 0.86 & 2.336 & 1.14 \\
& 920 & 1.802 & 0.83 & 2.342 & 1.11 \\
& 940 & 1.814 & 0.84 & 2.34 & 1.12 \\
\hline
\end{tabular}

ABS + 19.8wt \% BTBPE

\begin{tabular}{|c|c|c|c|c|c|}
\hline 16 (C2) & 809 & 1.294 & 0.483 & 1.915 & 0.84 \\
& 818 & 1.317 & 0.482 & 1.856 & 0.763 \\
& 826 & 1.297 & 0.483 & 1.951 & 0.897 \\
& 889 & 1.202 & 0.681 & 1.605 & 0.922 \\
& 867 & 1.161 & 0.637 & 1.569 & 0.873 \\
& 841 & 1.285 & 0.489 & 1.936 & 0.897 \\
& 841 & 1.217 & 0.478 & 1.854 & 0.85 \\
& 907 & 1.194 & 0.68 & 1.594 & 0.926 \\
\hline & $850(35)$ & $1.246(0.06)$ & $0.552(0.10)$ & $1.785(0.17)$ & $0.871(0.05)$ \\
\hline
\end{tabular}

ABS + 21.0 wt\% TBBA
\begin{tabular}{|c|c|c|c|c|c|}
\hline $17(\mathbf{C 2})$ & 810 & 1.195 & 0.458 & 1.58 & 0.677 \\
& 809 & 1.2 & 0.46 & 1.583 & 0.678 \\
& 798 & 1.186 & 0.459 & 1.56 & 0.67 \\
& 816 & 1.181 & 0.466 & 1.564 & 0.686 \\
& 833 & 1.189 & 0.47 & 1.565 & 0.692 \\
& 837 & 1.232 & 0.502 & 1.629 & 0.728 \\
& 831 & 1.217 & 0.492 & 1.604 & 0.714 \\
& 856 & 0.839 & 0.394 & 1.23 & 0.629 \\
& 839 & 1.209 & 0.493 & 1.596 & 0.719 \\
\hline & $825(18)$ & $1.161(0.12)$ & $0.466(0.03)$ & $1.546(0.12)$ & $0.688(0.03)$ \\
\hline
\end{tabular}

ABS + 20.1 wt\% DBDPO
\begin{tabular}{|c|c|c|c|c|c|}
\hline $18(\mathbf{C 6})$ & 607 & 0.811 & 0.2 & 1.187 & 0.36 \\
& 597 & 0.82 & 0.2 & 1.235 & 0.37 \\
& 564 & 0.807 & 0.19 & 1.237 & 0.35 \\
556 & 0.793 & 0.18 & 1.155 & 0.33 \\
& 581 & 0.789 & 0.19 & 1.132 & 0.34 \\
& 603 & 0.811 & 0.2 & 1.192 & 0.36 \\
& 573 & 0.801 & 0.19 & 1.192 & 0.35 \\
& 576 & 0.792 & 0.19 & 1.127 & 0.33 \\
\hline & $582(19)$ & $0.803(0.01)$ & $0.193(0.01)$ & $1.182(0.04)$ & $0.349(0.02)$ \\
\hline
\end{tabular}




\begin{tabular}{|c|c|c|c|c|}
\hline Compound & Peak Force Peak Deflection & Peak Energy & Failure Deflection & Failure Energy \\
$(N)$ & $(\mathrm{mm})$ & $(J)$ & $(\mathrm{mm})$ & $(J)$ \\
\hline
\end{tabular}

ABS + 18.2wt\% sDBDPO (Total spray dried material= 21.4wt\%)
\begin{tabular}{|c|c|c|c|c|c|}
\hline $19(\mathbf{C 5})$ & 585 & 0.889 & 0.21 & 1.286 & 0.36 \\
& 595 & 0.898 & 0.21 & 1.293 & 0.37 \\
& 575 & 0.927 & 0.21 & 1.363 & 0.37 \\
& 574 & 0.922 & 0.21 & 1.346 & 0.37 \\
& 600 & 0.904 & 0.22 & 1.327 & 0.38 \\
& 585 & 0.953 & 0.21 & 1.334 & 0.36 \\
& 591 & 0.941 & 0.22 & 1.409 & 0.39 \\
& 595 & 0.939 & 0.22 & 1.379 & 0.39 \\
\hline & $588(10)$ & $0.922(0.02)$ & $0.214(0.01)$ & $1.342(0.04)$ & $0.374(0.01)$ \\
\hline
\end{tabular}

ABS + 4.1 wt \% RS + 21.5wt\% BTBPE
\begin{tabular}{|c|c|c|c|c|c|}
\hline $20(\mathbf{C 2})$ & 762 & 1.231 & 0.421 & 1.582 & 0.618 \\
& 751 & 0.798 & 0.33 & 1.162 & 0.528 \\
& 717 & 1.209 & 0.404 & 1.565 & 0.59 \\
& 757 & 1.256 & 0.427 & 1.618 & 0.627 \\
& 757 & 1.236 & 0.426 & 1.596 & 0.624 \\
& 757 & 1.241 & 0.424 & 1.606 & 0.623 \\
& 758 & 1.236 & 0.424 & 1.6 & 0.625 \\
& 757 & 1.251 & 0.436 & 1.613 & 0.635 \\
\hline & $752(14)$ & $1.182(0.16)$ & $0.412(0.03)$ & $1.543(0.16)$ & $0.609(0.04)$ \\
\hline
\end{tabular}

ABS + 3.98wt\% RS + 19.7wt \% TBBA
\begin{tabular}{|c|c|c|c|c|c|}
\hline $21(\mathbf{C 2})$ & 678 & 1.067 & 0.366 & 1.439 & 0.545 \\
& 631 & 0.875 & 0.244 & 1.37 & 0.448 \\
& 736 & 1.113 & 0.408 & 1.471 & 0.598 \\
& 714 & 1.113 & 0.405 & 1.474 & 0.59 \\
& 692 & 1.085 & 0.375 & 1.444 & 0.554 \\
& 724 & 1.127 & 0.402 & 1.482 & 0.595 \\
& 666 & 1.063 & 0.367 & 1.433 & 0.542 \\
& 662 & 1.045 & 0.363 & 1.428 & 0.541 \\
\hline & $688(35)$ & $1.061(0.08)$ & $0.366(0.05)$ & $1.443(0.04)$ & $0.552(0.05)$ \\
\hline
\end{tabular}

ABS + 4.06wt \% RS + 23.8wt \% DBDPO
\begin{tabular}{|c|c|c|c|c|c|}
\hline 22 (C6) & 502 & 0.754 & 0.16 & 1.023 & 0.27 \\
& 355 & 0.663 & 0.12 & 0.962 & 0.2 \\
& 330 & 0.658 & 0.11 & 0.967 & 0.19 \\
& 374 & 0.677 & 0.12 & 0.972 & 0.21 \\
& 413 & 0.695 & 0.13 & 0.982 & 0.23 \\
& 546 & 0.76 & 0.17 & 1.041 & 0.29 \\
& 380 & 0.674 & 0.13 & 0.958 & 0.21 \\
& 417 & 0.695 & 0.13 & 0.981 & 0.23 \\
\hline & $415(80)$ & $0.697(0.04)$ & $0.134(0.02)$ & $0.986(0.03)$ & $0.229(0.04)$ \\
\hline
\end{tabular}




\begin{tabular}{|c|c|c|c|c|c|}
\hline Compound & Peak Force Peak Deflection & Peak Energy & Failure Deflection & Failure Energy \\
& $(N)$ & $(\mathrm{mm})$ & $(J)$ & $(\mathrm{mm})$ & $(J)$ \\
\hline
\end{tabular}

ABS + 4.4wt\% RS (16wt\% MB4) + 19.9wt\% BTBPE
\begin{tabular}{|c|c|c|c|c|c|}
\hline $23(\mathbf{C 4})$ & 778 & 1.752 & 0.68 & 2.162 & 0.89 \\
& 775 & 1.772 & 0.66 & 2.186 & 0.97 \\
& 761 & 1.691 & 0.64 & 2.125 & 0.85 \\
& 866 & 1.841 & 0.75 & 2.246 & 0.98 \\
& 767 & 1.772 & 0.67 & 2.159 & 0.91 \\
& 876 & 1.791 & 0.75 & 2.205 & 0.99 \\
& 822 & 1.751 & 0.67 & 2.176 & 0.9 \\
& 855 & 1.791 & 0.72 & 2.21 & 0.95 \\
\hline & $826(48)$ & $1.770(0.05)$ & $0.702(0.05)$ & $2.187(0.04)$ & $0.927(0.06)$ \\
\hline
\end{tabular}

ABS + 4.5wt\% RS (16wt\% MB4) + 18.6wt \% TBBA
\begin{tabular}{|c|c|c|c|c|c|}
\hline $\mathbf{2 4}$ (C4) & 735 & 1.283 & 0.42 & 1.673 & 0.61 \\
& 795 & 1.409 & 0.48 & 1.861 & 0.72 \\
& 724 & 1.339 & 0.42 & 1.733 & 0.61 \\
& 739 & 1.326 & 0.43 & 1.721 & 0.63 \\
& 791 & 1.393 & 0.47 & 1.801 & 0.68 \\
& 791 & 1.384 & 0.49 & 1.795 & 0.7 \\
& 759 & 1.324 & 0.45 & 1.722 & 0.65 \\
& 770 & 1.32 & 0.44 & 1.718 & 0.65 \\
\hline & $763(28)$ & $1.347(0.04)$ & $0.450(0.03)$ & $1.753(0.06)$ & $0.656(0.04)$ \\
\hline
\end{tabular}

ABS + 3.82wt \% pAZUB + $22.1 w t \%$ BTBPE

\begin{tabular}{|c|c|c|c|c|c|}
\hline $25(\mathbf{C 5})$ & 835 & 1.43 & 0.46 & 1.874 & 0.71 \\
& 853 & 1.419 & 0.46 & 1.864 & 0.72 \\
& 805 & 1.39 & 0.46 & 1.785 & 0.67 \\
& 858 & 1.488 & 0.48 & 2.076 & 0.84 \\
& 836 & 1.397 & 0.47 & 1.799 & 0.7 \\
& 879 & 1.384 & 0.47 & 1.804 & 0.71 \\
& 865 & 1.376 & 0.48 & 1.773 & 0.72 \\
& 869 & 1.491 & 0.48 & 1.9 & 0.72 \\
\hline & $850(26)$ & $1.422(0.05)$ & $0.471(0.01)$ & $1.859(0.11)$ & $0.724(0.05)$ \\
\hline
\end{tabular}

ABS + 4.34wt\% pAZUB + 14.6wt\% TBBA
\begin{tabular}{|c|c|c|c|c|c|}
\hline $\mathbf{2 6 ( C 5 )}$ & 886 & 1.307 & 0.49 & 1.711 & 0.74 \\
& 901 & 1.351 & 0.53 & 1.748 & 0.77 \\
& 885 & 1.334 & 0.49 & 1.735 & 0.73 \\
& 908 & 1.357 & 0.5 & 1.764 & 0.75 \\
& 824 & 1.281 & 0.45 & 1.68 & 0.67 \\
& 938 & 1.352 & 0.51 & 1.754 & 0.77 \\
& 850 & 1.331 & 0.46 & 1.73 & 0.69 \\
& 908 & 1.343 & 0.51 & 1.75 & 0.75 \\
\hline & $888(39)$ & $1.332(0.03)$ & $0.493(0.03)$ & $1.734(0.03)$ & $0.734(0.04)$ \\
\hline
\end{tabular}




\begin{tabular}{|c|c|c|c|c|c|}
\hline Compound & $\begin{array}{c}\text { Peak Force } \\
\text { (N) }\end{array}$ & $\begin{array}{c}\text { Peak Deflection } \\
(\mathrm{mm})\end{array}$ & $\begin{array}{c}\text { Peak Energy } \\
\text { (J) }\end{array}$ & $\begin{array}{c}\text { Failure Deflection } \\
(\mathrm{mm})\end{array}$ & $\begin{array}{c}\text { Failure Energy } \\
(J)\end{array}$ \\
\hline \multicolumn{6}{|c|}{ ABS $+3.5 w t \%$ sAZUB $+22.0 w t \%$ BTBPE } \\
\hline 27 (C5) & $\begin{array}{l}816 \\
838 \\
815 \\
80.1 \\
777 \\
818 \\
764 \\
856 \\
\end{array}$ & $\begin{array}{c}1.289 \\
1.359 \\
1.42 \\
1.306 \\
1.292 \\
1.308 \\
1.253 \\
1.318 \\
\end{array}$ & $\begin{array}{l}0.46 \\
0.47 \\
0.46 \\
0.45 \\
0.44 \\
0.46 \\
0.44 \\
0.48 \\
\end{array}$ & $\begin{array}{c}1.678 \\
1.86 \\
1.914 \\
1.71 \\
1.689 \\
1.707 \\
1.64 \\
1.726 \\
\end{array}$ & $\begin{array}{l}0.68 \\
0.76 \\
0.73 \\
0.67 \\
0.65 \\
0.68 \\
0.64 \\
0.72 \\
\end{array}$ \\
\hline & $811(30)$ & $1.318(0.05)$ & $0.458(0.01)$ & $1.741(0.10)$ & $0.691(0.04)$ \\
\hline
\end{tabular}

ABS + 3.6wt \% sAZUB + 20wt \% TBBA

\begin{tabular}{|c|c|c|c|c|c|}
\hline 28 (C5) & 744 & 1.229 & 0.4 & 1.619 & 0.6 \\
& 713 & 1.18 & 0.39 & 1.582 & 0.58 \\
& 709 & 1.211 & 0.39 & 1.601 & 0.58 \\
& 745 & 1.226 & 0.4 & 1.623 & 0.6 \\
& 737 & 1.203 & 0.4 & 1.593 & 0.6 \\
& 764 & 1.23 & 0.42 & 1.617 & 0.62 \\
& 715 & 1.29 & 0.4 & 1.689 & 0.59 \\
& 767 & 1.261 & 0.42 & 1.66 & 0.63 \\
\hline & $737(23)$ & $1.229(0.03)$ & $0.403(0.01)$ & $1.623(0.04)$ & $0.600(0.02)$ \\
\hline
\end{tabular}

ABS + 4.0wt\% sAZUB + 21.4wt\% DBDPO
\begin{tabular}{|c|c|c|c|c|c|}
\hline 29 (C6) & 530 & 0.746 & 0.16 & 1.017 & 0.28 \\
& 508 & 0.746 & 0.16 & 1.017 & 0.27 \\
& 385 & 0.679 & 0.13 & 0.972 & 0.22 \\
& 523 & 0.743 & 0.16 & 1.013 & 0.28 \\
& 524 & 0.747 & 0.16 & 1.018 & 0.28 \\
& 419 & 0.714 & 0.14 & 0.999 & 0.23 \\
& 526 & 0.77 & 0.16 & 1.027 & 0.27 \\
& 457 & 0.729 & 0.14 & 1.004 & 0.25 \\
\hline & $484(56)$ & $0.734(0.03)$ & $0.151(0.01)$ & $1.008(0.02)$ & $0.260(0.02)$ \\
\hline
\end{tabular}

\section{ABS + 5.15wt \% sAZUB + 20.7wt \% sDBDPO}

\begin{tabular}{|c|c|c|c|c|c|}
\hline $30(\mathbf{C 6})$ & 520 & 0.756 & 0.17 & 1.022 & 0.28 \\
& 611 & 0.81 & 0.2 & 1.206 & 0.37 \\
& 616 & 0.82 & 0.21 & 1.23 & 0.38 \\
& 539 & 0.765 & 0.17 & 1.054 & 0.29 \\
& 602 & 0.789 & 0.19 & 1.123 & 0.35 \\
& 545 & 0.765 & 0.17 & 1.04 & 0.3 \\
& 574 & 0.774 & 0.18 & 1.096 & 0.33 \\
& 560 & 0.766 & 0.18 & 1.054 & 0.31 \\
\hline & $571(36)$ & $0.781(0.02)$ & $0.184(0.02)$ & $1.103(0.08)$ & $0.326(0.04)$ \\
\hline
\end{tabular}




\begin{tabular}{|c|c|c|c|c|c|}
\hline Compound & Peak Force & Peak Deflection & Peak Energy & Failure Deflection & Failure Energy \\
& $(\mathrm{N})$ & $(\mathrm{mm})$ & $(J)$ & $(\mathrm{mm})$ & $(\mathrm{J})$ \\
\hline
\end{tabular}

ABS + 3.5wt \% AZUB (16wt \% MB5) + 20.5wt \% BTBPE

\begin{tabular}{|l|l|l|l|l|l|}
\hline 31 (C4) & 961 & 1.907 & 0.85 & 2.323 & 1.12 \\
& 883 & 1.826 & 0.75 & 2.256 & 1.03 \\
& 900 & 1.852 & 0.78 & 2.255 & 1.03 \\
& 863 & 1.829 & 0.75 & 2.23 & 0.98 \\
& 855 & 1.736 & 0.75 & 2.166 & 0.99 \\
& 957 & 1.925 & 0.84 & 2.369 & 1.12 \\
& 832 & 1.75 & 0.71 & 2.166 & 0.94 \\
& 891 & 1.806 & 0.77 & 2.213 & 1.01 \\
\hline & $894(50)$ & $1.829(0.07)$ & $0.779(0.05)$ & $2.246(0.08)$ & $1.027(0.07)$ \\
\hline
\end{tabular}

ABS + 3.7wt \% AZUB (16wt \% MB5) + 20.5wt\% TBBA
\begin{tabular}{|c|c|c|c|c|c|}
\hline 32 (C4) & 760 & 1.349 & 0.41 & 1.744 & 0.62 \\
& 731 & 1.283 & 0.42 & 1.676 & 0.62 \\
& 739 & 1.329 & 0.41 & 1.723 & 0.61 \\
& 678 & 1.269 & 0.38 & 1.663 & 0.57 \\
& 724 & 1.283 & 0.42 & 1.677 & 0.61 \\
& 749 & 1.341 & 0.43 & 1.72 & 0.63 \\
& 779 & 1.348 & 0.45 & 1.756 & 0.66 \\
& 749 & 1.391 & 0.43 & 1.791 & 0.63 \\
\hline & $739(30)$ & $1.324(0.04)$ & $0.419(0.02)$ & $1.719(0.05)$ & $0.619(0.03)$ \\
\hline
\end{tabular}




\section{APPENDix C: FleXural Test Results}

\section{3-point Bend Flexural Test Results}

The flexural results in this section are numbered in the same manner as for the impact results in Appendix B. The first compounds are the ABS controls ( $\mathrm{C} 1$ to $\mathrm{C} 6)$. The remaining compounds ( 1 to 32 ) have the relevant ABS control shown for that compound in brackets.

The formula used for three point bend flexural modulus and flexural strength conform to ASTM D790/BS2782 Part3 Method A where:

Flexural Modulus

$$
E b=\frac{L^{3} m}{4 b d^{3}}
$$

Flexural Strength

$$
\sigma_{b}=\frac{3 F L}{2 b d^{2}}
$$

Where: $\quad \mathrm{L}=$ support span

$\mathrm{F}=$ maximum load

$\mathrm{M}=$ slope of linear portion of curve

$\mathrm{b}=$ sample width

$\mathrm{d}=$ sample thickness 


\begin{tabular}{|c|c|c|c|c|c|}
\hline Compound & $\begin{array}{c}\text { Peak } \\
\text { Load } \\
(N)\end{array}$ & $\begin{array}{c}\text { Deflection @ } \\
\text { Peak Load } \\
(\mathrm{mm})\end{array}$ & $\begin{array}{c}\text { Work } \\
\text { Done } \\
(J) \\
\end{array}$ & $\begin{array}{c}\text { Flexural } \\
\text { Modulus } \\
(M P a) \\
\end{array}$ & $\begin{array}{c}\text { Flexural } \\
\text { Strength } \\
(\mathrm{MPa}) \\
\end{array}$ \\
\hline \multicolumn{6}{|c|}{ Unfilled ABS (Control 1) } \\
\hline \multirow[t]{9}{*}{$\mathrm{Cl}$} & 115.6 & 6.808 & 1132 & 2253 & 65.92 \\
\hline & 116 & 7.391 & 1135 & 2263 & 66.06 \\
\hline & 114.8 & 6.976 & 1128 & 2246 & 65.44 \\
\hline & 116 & 6.766 & 1140 & 2274 & 66.02 \\
\hline & 117.1 & 6.184 & 1147 & 2287 & 66.71 \\
\hline & 116.3 & 6.517 & 1141 & 2271 & 66.31 \\
\hline & 116.3 & 6.309 & 1130 & 2226 & 66.27 \\
\hline & 114.8 & 5.351 & 1129 & 2265 & 65.45 \\
\hline & $115.9(0.8)$ & $6.538(0.6)$ & $1135(7)$ & $2261(19)$ & $66.02(0.4)$ \\
\hline
\end{tabular}

Unfilled ABS (Control 2)

\begin{tabular}{|l|l|l|l|l|l|}
\hline C2 & 116.7 & 6.241 & 1126 & 2188 & 66.53 \\
& 115.6 & 5.975 & 1101 & 2137 & 65.88 \\
& 113.7 & 5.474 & 1085 & 2073 & 64.79 \\
& 112.9 & 5.609 & 1076 & 2076 & 65.20 \\
& 112.9 & 5.576 & 1096 & 2186 & 65.20 \\
& 112.9 & 6.544 & 1086 & 2132 & 65.20 \\
& 112.2 & 6.359 & 1080 & 2178 & 64.76 \\
& 111.8 & 5.859 & 1092 & 2185 & 64.34 \\
\hline & $113.6(1.7)$ & $5.955(0.4)$ & $1093(16)$ & $2144(48)$ & $65.24(0.7)$ \\
\hline
\end{tabular}

Un filled ABS (Control 3)

\begin{tabular}{|l|l|l|l|l|l|}
\hline C3 & 115.2 & 5.84 & 1128 & 2248 & 64.93 \\
& 116.7 & 6.725 & 1141 & 2263 & 65.64 \\
& 114.8 & 6.26 & 1127 & 2269 & 64.70 \\
115.2 & 5.979 & 1129 & 2254 & 64.91 \\
& 115.6 & 5.892 & 1133 & 2262 & 64.96 \\
114.8 & 6.077 & 1129 & 2251 & 64.77 \\
& 115.6 & 6.876 & 1128 & 2253 & 65.05 \\
& 114.8 & 5.994 & 1128 & 2264 & 64.58 \\
\hline & $115.3(0.6)$ & $6.205(0.4)$ & $1130(5)$ & $2258(7)$ & $64.94(0.3)$ \\
\hline
\end{tabular}

Unfilled ABS (Control 4)

\begin{tabular}{|l|c|c|c|c|c|}
\hline C4 & 117.1 & 6.758 & 1126 & 2145 & 66.18 \\
& 119 & 6.407 & 1158 & 2260 & 67.26 \\
& 120.9 & 6.423 & 1168 & 2251 & 68.33 \\
119.4 & 6.292 & 1160 & 2246 & 67.47 \\
120.2 & 6.042 & 1165 & 2252 & 67.90 \\
120.9 & 7.142 & 1170 & 2225 & 68.33 \\
& 119.8 & 7.01 & 1163 & 2238 & 67.69 \\
& 117.5 & 6.258 & 1140 & 2163 & 66.39 \\
\hline & $119.4(1.4)$ & $6.542(0.4)$ & $1156(15)$ & $2223(44)$ & $67.44(0.8)$ \\
\hline
\end{tabular}




\begin{tabular}{|c|c|c|c|c|c|}
\hline Compound & $\begin{array}{c}\text { Peak } \\
\text { Load } \\
(N)\end{array}$ & $\begin{array}{c}\text { Deflection@ } \\
\text { Peak Load } \\
(\mathrm{mm})\end{array}$ & $\begin{array}{c}\text { Work } \\
\text { Done } \\
(J)\end{array}$ & $\begin{array}{c}\text { Flexural } \\
\text { Modulus } \\
(M P a)\end{array}$ & $\begin{array}{c}\text { Flexural } \\
\text { Strength } \\
(M P a)\end{array}$ \\
\hline \multicolumn{6}{|c|}{ Unfilled ABS (Control 5) } \\
\hline \multirow[t]{9}{*}{ C5 } & 117.9 & 5.777 & 1152 & 2277 & 66.06 \\
\hline & 116 & 6.393 & 1141 & 2306 & 65.25 \\
\hline & 116 & 6.26 & 1144 & 2320 & 65.25 \\
\hline & 114.1 & 6.093 & 1116 & 2264 & 64.18 \\
\hline & 116.3 & 10.99 & 1140 & 2251 & 65.46 \\
\hline & 115.6 & 6.059 & 1138 & 2286 & 65.03 \\
\hline & 116 & 5.874 & 1140 & 2276 & 65.25 \\
\hline & 117.5 & 6.258 & 1140 & 2263 & 66.39 \\
\hline & $116.2(1.2)$ & $6.713(1.7)$ & $1139(10)$ & $2280(23)$ & $65.36(0.7)$ \\
\hline
\end{tabular}

\section{Unfilled ABS (Control 6)}

\begin{tabular}{|l|c|c|c|c|c|}
\hline C6 & 113.7 & 6.01 & 1090 & 2033 & 63.34 \\
& 114.1 & 6.341 & 1093 & 2045 & 63.55 \\
& 113.3 & 5.608 & 1100 & 2142 & 63.13 \\
113.3 & 5.159 & 1115 & 2162 & 63.13 \\
112.9 & 5.876 & 1112 & 2202 & 62.92 \\
114.1 & 5.874 & 1117 & 2175 & 63.55 \\
& 114.4 & 5.376 & 1114 & 2194 & 63.77 \\
& 113.3 & 5.09 & 1113 & 2205 & 63.13 \\
\hline & $113.6(0.5)$ & $5.667(0.4)$ & $1107(11)$ & $2145(69)$ & $63.32(0.3)$ \\
\hline
\end{tabular}

$\mathrm{ABS}+4.1 \mathrm{wt} \%$ Red $\mathrm{Star}(\mathrm{RS}) \mathrm{Sb}_{2} \mathrm{O}_{3}$

\begin{tabular}{|c|c|c|c|c|c|}
\hline 1 (C3) & 105.3 & 5.477 & 1051 & 2275 & 59.59 \\
& 106 & 6.107 & 1058 & 2277 & 60.16 \\
& 106.4 & 5.743 & 1061 & 2285 & 60.14 \\
& 106.4 & 5.743 & 1057 & 2282 & 60.30 \\
& 106 & 5.46 & 1056 & 2300 & 60.04 \\
& 105.7 & 10.15 & 1055 & 2280 & 59.91 \\
& 104.5 & 5.46 & 1041 & 2263 & 59.06 \\
& 104.9 & 6.125 & 1050 & 2274 & 59.38 \\
\hline & $105.7(0.7)$ & $6.283(1.6)$ & $1054(6)$ & $2280(11)$ & $59.82(0.4)$ \\
\hline
\end{tabular}

ABS + 5.49wt \% Microfine A05 (A05) $\mathrm{Sb}_{2} \mathrm{O}_{3}$

\begin{tabular}{|c|c|c|c|c|c|}
\hline $\mathbf{2}(\mathbf{C} 1)$ & 111.4 & 6.059 & 1100 & 2249 & 63.61 \\
& 112.5 & 6.435 & 1114 & 2254 & 63.52 \\
& 112.5 & 6.185 & 1121 & 2265 & 63.23 \\
& 113.3 & 6.893 & 1124 & 2264 & 63.63 \\
& 114.1 & 6.351 & 1127 & 2236 & 63.95 \\
& 114.8 & 5.517 & 1131 & 2251 & 64.42 \\
& 112.2 & 5.392 & 1113 & 2248 & 62.87 \\
& 112.5 & 6.351 & 1113 & 2273 & 63.32 \\
\hline & $112.9(1.1)$ & $6.148(0.5)$ & $1118(10)$ & $2255(12)$ & $63.57(0.5)$ \\
\hline
\end{tabular}




\begin{tabular}{|c|c|c|c|c|c|}
\hline Compound & $\begin{array}{c}\text { Peak } \\
\text { Load } \\
(N)\end{array}$ & $\begin{array}{c}\text { Deflection@ } \\
\text { PeakLoad } \\
(\mathrm{mm})\end{array}$ & $\begin{array}{c}\text { Work } \\
\text { Done } \\
(J) \\
\end{array}$ & $\begin{array}{c}\text { Flexural } \\
\text { Modulus } \\
(M P a) \\
\end{array}$ & $\begin{array}{c}\text { Flexural } \\
\text { Strength } \\
(\mathrm{MPa}) \\
\end{array}$ \\
\hline \multicolumn{6}{|c|}{$\mathrm{ABS}+3.85 w \mathrm{t} \%$ pan dried $\mathrm{RS}\left(\mathrm{AZUB}^{\mathrm{RS}}\right) \mathrm{Sb}_{2} \mathrm{O}_{3}$} \\
\hline \multirow[t]{9}{*}{$3(\mathbf{C 3})$} & 101.1 & 5.492 & 1011 & 2235 & 57.27 \\
\hline & 102.2 & 6.543 & 1019 & 2240 & 57.87 \\
\hline & 100.3 & 4.994 & 1007 & 2239 & 56.88 \\
\hline & 101.5 & 6.026 & 1014 & 2246 & 57.46 \\
\hline & 99.18 & 5.043 & 998.6 & 2229 & 56.25 \\
\hline & 100.3 & 5.794 & 1007 & 2253 & 56.80 \\
\hline & 99.95 & 5.609 & 1009 & 2238 & 56.52 \\
\hline & 101.1 & 5.492 & 997.2 & 2244 & 57.27 \\
\hline & $100.7(1.0)$ & $5.624(0.5)$ & $1008(7)$ & $2241(7)$ & $57.04(0.5)$ \\
\hline
\end{tabular}

$\mathrm{ABS}+4.93 w \mathrm{w} \%$ pan dried AZUB (pAZUB) $\mathrm{Sb}_{2} \mathrm{O}_{3}$

\begin{tabular}{|c|c|c|c|c|c|}
\hline $4(\mathrm{Cl})$ & 112.5 & 5.893 & 1112 & 2236 & 64.12 \\
& 113.3 & 6.268 & 1121 & 2295 & 64.55 \\
& 111.8 & 5.975 & 1111 & 2295 & 63.68 \\
& 112.2 & 6.06 & 1112 & 2216 & 62.75 \\
& 112.2 & 10.52 & 1110 & 2211 & 62.86 \\
& 110.6 & 5.81 & 1106 & 2234 & 61.89 \\
& 111.8 & 6.308 & 1111 & 2206 & 62.34 \\
& 111.8 & 10.89 & 1111 & 2232 & 62.56 \\
\hline & $112.0(0.8)$ & $7.216(2.2)$ & $1112(4)$ & $2241(35)$ & $63.09(0.9)$ \\
\hline
\end{tabular}

ABS + 3.45wt \% spray dried AZUB (sAZUB) $\mathrm{Sb}_{2} \mathrm{O}_{3}$

\begin{tabular}{|c|c|c|c|c|c|}
\hline 5 (C5) & 113.7 & 5.926 & 1125 & 2279 & 64.35 \\
& 113.7 & 11.03 & 1121 & 2327 & 64.35 \\
& 114.1 & 6.258 & 1130 & 2358 & 64.57 \\
& 111.8 & 5.707 & 1105 & 2260 & 63.27 \\
& 112.9 & 5.991 & 1117 & 2342 & 63.92 \\
& 113.7 & 5.626 & 1127 & 2357 & 64.35 \\
& 111.8 & 5.76 & 1103 & 2271 & 63.27 \\
& 111.4 & 5.974 & 1091 & 2287 & 63.05 \\
\hline & $112.9(1.1)$ & $6.534(1.8)$ & $1115(14)$ & $2310(40)$ & $63.89(0.6)$ \\
\hline
\end{tabular}

ABS $+1.1 w t \%$ castor wax

\begin{tabular}{|c|c|c|c|c|c|}
\hline $6(\mathrm{C} 4)$ & 112.9 & 10.56 & 1101 & 2082 & 63.12 \\
& 116 & 6.675 & 1131 & 2159 & 64.82 \\
& 115.6 & 6.859 & 1131 & 2200 & 64.61 \\
& 115.6 & 5.857 & 1127 & 2145 & 64.61 \\
& 114.8 & 6.344 & 1122 & 2169 & 64.18 \\
& 114.8 & 6.325 & 1125 & 2192 & 64.18 \\
& 114.1 & 6.592 & 1115 & 2156 & 63.76 \\
& 115.2 & 6.342 & 1125 & 2164 & 64.39 \\
\hline & $114.9(1.0)$ & $6.944(1.5)$ & $1122(10)$ & $2158(36)$ & $64.21(0.6)$ \\
\hline
\end{tabular}




\begin{tabular}{|c|c|c|c|c|c|}
\hline Compound & $\begin{array}{c}\text { Peak } \\
\text { Load } \\
(N)\end{array}$ & $\begin{array}{c}\text { Deflection@ } \\
\text { PeakLoad } \\
(\mathrm{mm})\end{array}$ & $\begin{array}{c}\text { Work } \\
\text { Done } \\
(J)\end{array}$ & $\begin{array}{c}\text { Flexural } \\
\text { Modulus } \\
\text { (MPa) }\end{array}$ & $\begin{array}{c}\text { Flexural } \\
\text { Strength } \\
(\mathrm{MPa})\end{array}$ \\
\hline \multicolumn{6}{|c|}{ ABS $+1.33 w t \%$ MB1 $(0.67 w t \%$ additional PB $)$} \\
\hline \multirow[t]{9}{*}{$7(\mathrm{C} 3)$} & 114.4 & 6.177 & 1117 & 2247 & 64.95 \\
\hline & 114.4 & 6.209 & 1122 & 2258 & 64.71 \\
\hline & 114.4 & 5.959 & 1126 & 2265 & 64.64 \\
\hline & 114.1 & 5.908 & 1121 & 2260 & 64.42 \\
\hline & 114.1 & 6.494 & 1118 & 2264 & 64.58 \\
\hline & 113.3 & 5.959 & 1113 & 2257 & 63.91 \\
\hline & 112.9 & 6.224 & 1109 & 2264 & 63.86 \\
\hline & 112.5 & 6.211 & 1100 & 2248 & 63.52 \\
\hline & $113.8(0.8)$ & $6.143(0.2)$ & $1116(8)$ & $2258(7)$ & $64.32(0.5)$ \\
\hline
\end{tabular}

ABS + 4wt \% MB1 (2wt \% additional PB)

\begin{tabular}{|c|c|c|c|c|c|}
\hline $8(\mathbf{C 3})$ & 109.9 & 6.727 & 1072 & 2180 & 62.30 \\
& 111.4 & 6.158 & 1092 & 2203 & 63.01 \\
& 110.6 & 6.508 & 1086 & 2207 & 62.72 \\
& 111.8 & 6.258 & 1096 & 2207 & 63.12 \\
& 111.4 & 6.574 & 1087 & 2198 & 62.93 \\
& 110.2 & 6.059 & 1086 & 2185 & 62.24 \\
& 110.2 & 6.041 & 1085 & 2190 & 62.31 \\
& 109.9 & 6.042 & 1081 & 2195 & 62.10 \\
\hline & $110.7(0.8)$ & $6.296(0.3)$ & $1086(7)$ & $2196(10)$ & $62.59(0.4)$ \\
\hline
\end{tabular}

ABS + 12wt \% MB1 (6wt \% additional PB)

\begin{tabular}{|c|c|c|c|c|c|}
\hline $9(\mathbf{C 3})$ & 103.4 & 6.274 & 1008 & 2050 & 58.85 \\
& 103.8 & 7.209 & 1013 & 2049 & 58.82 \\
& 103.8 & 7.142 & 1015 & 2060 & 58.77 \\
& 103 & 5.892 & 1010 & 2048 & 58.28 \\
& 103.4 & 6.226 & 1012 & 2036 & 58.46 \\
& 103 & 5.791 & 1005 & 2056 & 58.46 \\
& 102.2 & 6.18 & 1003 & 2045 & 57.78 \\
& 102.6 & 6.174 & 1005 & 2043 & 58.13 \\
\hline & $103.2(0.6)$ & $6.361(0.5)$ & $1009(4)$ & $2048(7)$ & $58.44(0.4)$ \\
\hline
\end{tabular}

ABS + 4.1 wt \% RS S $\mathbf{b}_{2} \mathbf{O}_{3}$ (direct addition)
\begin{tabular}{|c|c|c|c|c|c|}
\hline $10(\mathbf{C 3})$ & 105.3 & 5.477 & 1051 & 2275 & 59.59 \\
& 106 & 6.107 & 1058 & 2277 & 60.16 \\
106.4 & 5.743 & 1061 & 2285 & 60.14 \\
& 106.4 & 5.743 & 1057 & 2282 & 60.30 \\
& 106 & 5.46 & 1056 & 2300 & 60.04 \\
& 105.7 & 10.15 & 1055 & 2280 & 59.91 \\
& 104.5 & 5.46 & 1041 & 2263 & 59.06 \\
& 104.9 & 6.125 & 1050 & 2274 & 59.38 \\
\hline & $105.7(0.7)$ & $6.283(1.6)$ & $1054(6)$ & $2280(11)$ & $59.82(0.4)$ \\
\hline
\end{tabular}




\begin{tabular}{|c|c|c|c|c|c|}
\hline Compound & $\begin{array}{c}\text { Peak } \\
\text { Load } \\
(\mathbf{N})\end{array}$ & $\begin{array}{c}\text { Deflection @ } \\
\text { Peak Load } \\
(\mathbf{m m})\end{array}$ & $\begin{array}{c}\text { Work } \\
\text { Done } \\
(\boldsymbol{J})\end{array}$ & $\begin{array}{c}\text { Flexural } \\
\text { Modulus } \\
(\text { MPa })\end{array}$ & $\begin{array}{c}\text { Flexural } \\
\text { Strength } \\
(\mathbf{M P a})\end{array}$ \\
\hline ABS+4.9wt\% RS (using 5.33wt\% MB2) & & & \\
\hline $\mathbf{1 1 ( C 3 )}$ & 107.6 & 6.828 & 1062 & 2228 & 60.72 \\
& 107.6 & 5.826 & 1072 & 2277 & 60.83 \\
& 107.6 & 5.743 & 1065 & 2272 & 60.72 \\
& 106.4 & 5.693 & 1063 & 2275 & 60.08 \\
& 105.7 & 5.861 & 1056 & 2265 & 59.69 \\
& 105.7 & 5.477 & 1052 & 2253 & 59.62 \\
& 105.7 & 5.827 & 1051 & 2270 & 59.81 \\
& 105.7 & 6.493 & 1049 & 2263 & 59.75 \\
\hline
\end{tabular}

ABS + 4.0wt \% RS (using 8wt \% MB3)

\begin{tabular}{|c|c|c|c|c|c|}
\hline 12 (C3) & 106.8 & 5.909 & 1049 & 2219 & 60.88 \\
& 106 & 5.892 & 1053 & 2221 & 60.20 \\
& 106 & 5.959 & 1048 & 2217 & 60.13 \\
& 106.8 & 6.427 & 1057 & 2223 & 60.42 \\
& 105.3 & 5.792 & 1048 & 2224 & 59.69 \\
& 105.3 & 5.544 & 1046 & 2220 & 59.82 \\
& 104.9 & 5.876 & 1042 & 2208 & 59.55 \\
& 104.1 & 5.842 & 1039 & 2219 & 59.07 \\
\hline & $105.7(0.9)$ & $5.905(0.2)$ & $1048(6)$ & $2219(5)$ & $59.97(0.6)$ \\
\hline
\end{tabular}

ABS + 3.81wt \% RS (using 16wt\% MB4)
\begin{tabular}{|c|c|c|c|c|c|}
\hline 13 (C3) & 99.95 & 6.059 & 983.6 & 2065 & 57.08 \\
& 100.3 & 6.093 & 989.3 & 2064 & 57.09 \\
& 99.18 & 5.977 & 978.3 & 2060 & 56.44 \\
& 99.56 & 5.627 & 984.3 & 2081 & 56.79 \\
& 100.3 & 6.095 & 984.8 & 2067 & 57.14 \\
& 98.42 & 5.594 & 976.1 & 2047 & 55.96 \\
& 99.56 & 5.395 & 985.4 & 2070 & 56.65 \\
& 99.95 & 6.275 & 979.2 & 2070 & 56.88 \\
\hline & $99.7(0.6)$ & $5.889(0.3)$ & $983(4)$ & $2066(10)$ & $56.75(0.4)$ \\
\hline
\end{tabular}

$\mathrm{ABS}+4.11 \mathrm{wt} \% \mathrm{pAZUB} \mathrm{Sb}_{2} \mathrm{O}_{3}$

\begin{tabular}{|c|c|c|c|c|c|}
\hline 14 (C3) & 103 & 5.226 & 1031 & 2207 & 57.98 \\
& 104.1 & 6.01 & 1040 & 2244 & 58.61 \\
& 102.6 & 5.989 & 1028 & 2259 & 58.00 \\
& 101.9 & 5.51 & 1025 & 2245 & 57.46 \\
& 102.6 & 6.01 & 1030 & 2231 & 57.80 \\
& 102.6 & 4.873 & 1028 & 2260 & 58.06 \\
& 102.2 & 5.46 & 1021 & 2244 & 57.74 \\
& 101.5 & 5.825 & 1018 & 2256 & 57.28 \\
\hline & $102.6(0.8)$ & $5.613(0.4)$ & $1028(7)$ & $2243(18)$ & $57.87(0.4)$ \\
\hline
\end{tabular}




\begin{tabular}{|c|c|c|c|c|c|}
\hline Compound & $\begin{array}{c}\text { Peak } \\
\text { Load } \\
(N)\end{array}$ & $\begin{array}{c}\text { Deflection@ } \\
\text { PeakLoad } \\
(\mathrm{mm})\end{array}$ & $\begin{array}{c}\text { Work } \\
\text { Done } \\
(J)\end{array}$ & $\begin{array}{c}\text { Flexural } \\
\text { Modulus } \\
\text { (MPa) }\end{array}$ & $\begin{array}{c}\text { Flexural } \\
\text { Strength } \\
\text { (MPa) }\end{array}$ \\
\hline \multicolumn{6}{|c|}{$\mathrm{ABS}+4.02 \mathrm{wt} \% \mathrm{AZUB} \mathrm{Sb}_{2} \mathrm{O}_{3}$ (using $16 \mathrm{wt} \% \mathrm{MB} 5$ ) } \\
\hline \multirow[t]{9}{*}{$15(\mathrm{C} 4)$} & 97.66 & 6.41 & 953.2 & 1897 & 54.87 \\
\hline & 101.1 & 6.225 & 986.9 & 1973 & 56.80 \\
\hline & 101.5 & 6.441 & 994.9 & 1976 & 57.02 \\
\hline & 100.7 & 6.025 & 993.2 & 1990 & 56.59 \\
\hline & 100.7 & 5.478 & 994 & 1996 & 56.59 \\
\hline & 101.1 & 5.291 & 995.5 & 1994 & 56.80 \\
\hline & 101.1 & 6.193 & 984.6 & 2001 & 56.80 \\
\hline & 99.18 & 5.558 & 980.1 & 1972 & 55.73 \\
\hline & $100.4(1.3)$ & $5.953(0.4)$ & $985(14)$ & $1975(33)$ & $56.40(0.7)$ \\
\hline
\end{tabular}

ABS + 19.8wt\% BTBPE
\begin{tabular}{|c|c|c|c|c|c|}
\hline $\mathbf{1 6 ( C 2 )}$ & 108 & 5.059 & 1050 & 2056 & 60.72 \\
& 107.2 & 5.524 & 1062 & 2162 & 60.29 \\
& 108 & 6.208 & 1060 & 2161 & 60.72 \\
& 106 & 6.193 & 1051 & 2148 & 59.64 \\
& 108 & 5.126 & 1053 & 2137 & 60.72 \\
& 107.2 & 6.161 & 1030 & 2067 & 60.29 \\
& 104.9 & 6.409 & 1042 & 2162 & 59.00 \\
& 105.3 & 5.593 & 1044 & 2151 & 59.22 \\
\hline & $106.8(1.3)$ & $5.784(0.5)$ & $1049(10)$ & $2131(44)$ & $60.08(0.7)$ \\
\hline
\end{tabular}

ABS + $21.0 w t \%$ TBBA

\begin{tabular}{|c|c|c|c|c|c|}
\hline 17 (C2) & 122.1 & 6.159 & 1208 & 2534 & 68.09 \\
& 122.1 & 5.509 & 1212 & 2577 & 68.09 \\
& 121.3 & 6.176 & 1201 & 2561 & 67.67 \\
& 120.5 & 5.676 & 1201 & 2567 & 67.24 \\
& 119.8 & 6.024 & 1201 & 2553 & 66.81 \\
& 119.4 & 5.092 & 1196 & 2513 & 66.60 \\
& 119 & 5.392 & 1194 & 2549 & 66.39 \\
& 120.5 & 5.794 & 1198 & 2520 & 67.24 \\
\hline & $120.6(1.2)$ & $5.728(0.4)$ & $1201(6)$ & $2547(23)$ & $67.27(0.6)$ \\
\hline
\end{tabular}

ABS + 20.1wt\% DBDPO
\begin{tabular}{|c|c|c|c|c|c|}
\hline $18(\mathbf{C 6})$ & 106 & 5.54 & 864.5 & 2216 & 61.15 \\
& 111 & 6.31 & 884.6 & 2284 & 64.01 \\
& 110.6 & 5.36 & 894 & 2319 & 63.79 \\
& 110.6 & 6.194 & 949 & 2298 & 63.79 \\
110.6 & 7.428 & 895.6 & 2315 & 63.79 \\
& 111.4 & 5.593 & 831.1 & 2347 & 64.23 \\
& 111.4 & 5.544 & 937.3 & 2370 & 64.23 \\
& 110.2 & 6.408 & 816.7 & 2341 & 63.57 \\
\hline & $110.2(1.8)$ & $6.047(0.7)$ & $884(46)$ & $2311(47)$ & $63.57(1.0)$ \\
\hline
\end{tabular}




\begin{tabular}{|c|c|c|c|c|c|}
\hline Compound & $\begin{array}{c}\text { Peak } \\
\text { Load } \\
(N)\end{array}$ & $\begin{array}{c}\text { Deflection } \\
\text { Peak Load }\end{array}$ & $\begin{array}{c}\text { Work } \\
\text { Done } \\
(\mathrm{mm})\end{array}$ & $\begin{array}{c}\text { Flexural } \\
\text { Modulus } \\
(\mathrm{M})\end{array}$ & $\begin{array}{c}\text { Flexural } \\
\text { Strength } \\
(\mathrm{MPa})\end{array}$ \\
\hline
\end{tabular}

ABS + 18.2wt \% sDBDPO (Total spray dried material $=21.4 w t \%$ )

\begin{tabular}{|l|c|c|c|c|c|}
\hline 19 (C5) & 103.4 & 5.024 & 1037 & 2348 & 58.16 \\
& 99.56 & 5.71 & 1007 & 2281 & 56.02 \\
& 99.18 & 5.006 & 983.2 & 2332 & 55.80 \\
& 99.95 & 5.148 & 1013 & 2357 & 56.23 \\
& 99.95 & 4.923 & 853.8 & 2354 & 56.23 \\
& 99.95 & 4.842 & 1017 & 2307 & 56.23 \\
& 100.1 & 4.992 & 1001 & 2314 & 56.36 \\
& 100 & 5.023 & 987.6 & 2299 & 56.33 \\
\hline & $100.3(1.3)$ & $5.084(0.3)$ & $987(57)$ & $2324(28)$ & $56.42(0.7)$ \\
\hline
\end{tabular}

ABS + 4.1wt \% RS + 21.5wt\% BTBPE

\begin{tabular}{|c|c|c|c|c|c|}
\hline 20 (C2) & 104.9 & 5.194 & 1040 & 2136 & 58.19 \\
& 102.6 & 4.747 & 1022 & 2121 & 56.92 \\
& 103 & 5.107 & 1025 & 2151 & 57.14 \\
& 101.1 & 5.024 & 1007 & 2129 & 56.08 \\
102.6 & 5.807 & 1017 & 2172 & 59.92 \\
& 101.5 & 4.925 & 1014 & 2176 & 59.29 \\
& 99.95 & 5.092 & 1004 & 2142 & 55.44 \\
& 99.95 & 10.59 & 1005 & 2174 & 55.44 \\
\hline & $102.0(1.7)$ & $5.811(2.0)$ & $1017(12)$ & $2150(22)$ & $57.30(1.7)$ \\
\hline
\end{tabular}

ABS + 3.98wt \% RS + 19.7wt \% TBBA
\begin{tabular}{|c|c|c|c|c|c|}
\hline $21(\mathbf{C 2})$ & 119.4 & 6.342 & 1196 & 2602 & 66.99 \\
& 117.9 & 5.092 & 1189 & 2611 & 66.14 \\
& 117.9 & 4.874 & 1178 & 2615 & 66.14 \\
& 117.1 & 5.593 & 1179 & 2591 & 65.71 \\
& 117.5 & 4.809 & 1192 & 2670 & 65.92 \\
& 116.7 & 4.893 & 1112 & 2662 & 65.50 \\
& 114.4 & 5.26 & 1156 & 2582 & 64.21 \\
\hline & $117.3(1.5)$ & $5.266(0.5)$ & $1172(29)$ & $2619(34)$ & $65.80(0.8)$ \\
\hline
\end{tabular}

ABS + 4.06wt\% RS + 23.8wt\% DBDPO
\begin{tabular}{|c|c|c|c|c|c|}
\hline 22 (C6) & 101.5 & 4.476 & 400.8 & 2206 & 55.62 \\
& 103 & 5.007 & 386.4 & 2211 & 56.46 \\
104.9 & 5.875 & 465.2 & 2190 & 57.50 \\
& 101.9 & 4.794 & 342.9 & 2199 & 55.83 \\
105.3 & 5.459 & 443 & 2222 & 57.71 \\
& 104.1 & 5.159 & 402 & 2226 & 57.08 \\
& 105.3 & 5.612 & 431.3 & 2248 & 57.71 \\
& 103.8 & 5.359 & 405.9 & 2226 & 56.87 \\
\hline & $103.7(1.5)$ & $5.218(0.5)$ & $410(37)$ & $2216(18)$ & $56.85(0.8)$ \\
\hline
\end{tabular}




\begin{tabular}{|c|c|c|c|c|c|}
\hline Compound & $\begin{array}{c}\text { Peak } \\
\text { Load } \\
(\mathrm{N})\end{array}$ & $\begin{array}{c}\text { Deflection@ } \\
\text { Peak Load } \\
(\mathbf{m m})\end{array}$ & $\begin{array}{c}\text { Work } \\
\text { Done } \\
(\boldsymbol{J})\end{array}$ & $\begin{array}{c}\text { Flexural } \\
\text { Modulus } \\
(\text { MPa })\end{array}$ & $\begin{array}{c}\text { Flexural } \\
\text { Strength } \\
(\mathbf{M P a})\end{array}$ \\
\hline ABS+4.4wt\% RS(16wt\% MB4)+19.9wt\% BTBPE & & \\
\hline $\mathbf{2 3 ( \mathbf { C 4 } )}$ & 95.37 & 5.893 & 943.2 & 1900 & 52.88 \\
& 95.75 & 6.175 & 948.7 & 1935 & 53.09 \\
& 94.99 & 6.174 & 938.7 & 1864 & 52.67 \\
& 98.04 & 6.39 & 967.9 & 1953 & 54.36 \\
& 93.08 & 10.73 & 920.5 & 1868 & 51.61 \\
& 95.75 & 11.03 & 944.4 & 1949 & 53.09 \\
& 96.89 & 5.541 & 955.5 & 1940 & 53.73 \\
& 97.27 & 6.627 & 962.4 & 1946 & 53.94 \\
\hline
\end{tabular}

ABS + 4.5wt\% RS (16wt\% MB4) + 18.6wt \% TBBA
\begin{tabular}{|c|c|c|c|c|c|}
\hline $24(\mathbf{C 4})$ & 106.8 & 9.744 & 1068 & 2322 & 58.72 \\
& 115.6 & 10.91 & 1145 & 2408 & 63.55 \\
117.1 & 10.68 & 1169 & 2425 & 64.38 \\
& 114.4 & 10.66 & 1127 & 2338 & 62.92 \\
& 113.3 & 9.978 & 1130 & 2345 & 62.29 \\
& 114.8 & 11.34 & 1144 & 2392 & 63.13 \\
& 113.7 & 10.99 & 1129 & 2347 & 62.50 \\
& 113.7 & 9.827 & 1127 & 2344 & 62.50 \\
\hline & $113.7(3.0)$ & $10.516(0.6)$ & $1130(29)$ & $2365(38)$ & $62.50(1.7)$ \\
\hline
\end{tabular}

ABS + 3.82wt\% pAZUB + 22.1wt \% BTBPE
\begin{tabular}{|c|c|c|c|c|c|}
\hline 25 (C5) & 108.3 & 5.992 & 1078 & 2250 & 60.95 \\
& 108.3 & 5.024 & 1079 & 2295 & 60.95 \\
& 109.5 & 5.727 & 1090 & 2342 & 61.60 \\
109.1 & 5.375 & 1089 & 2307 & 61.38 \\
& 108.3 & 5.442 & 1086 & 2350 & 60.95 \\
& 108.3 & 5.576 & 1078 & 2264 & 60.95 \\
& 109.1 & 5.392 & 1090 & 2301 & 61.38 \\
& 109 & 5.404 & 1083 & 2297 & 61.36 \\
\hline & $108.7(0.5)$ & $5.492(0.3)$ & $1084(5)$ & $2301(34)$ & $61.19(0.3)$ \\
\hline
\end{tabular}

ABS + 4.34wt \% pAZUB + 14.6wt \% TBBA
\begin{tabular}{|c|c|c|c|c|c|}
\hline $26($ C5) & 104.1 & 5.46 & 1046 & 2366 & 59.32 \\
& 104.5 & 10.64 & 1055 & 2379 & 59.53 \\
& 102.6 & 5.908 & 1035 & 2359 & 58.45 \\
& 103.8 & 5.126 & 1053 & 2382 & 59.10 \\
& 101.5 & 5.442 & 1028 & 2348 & 57.80 \\
& 102.2 & 4.824 & 1035 & 2359 & 58.23 \\
& 104.3 & 5.402 & 1050 & 2372 & 59.43 \\
& 102.4 & 5.428 & 1036 & 2360 & 58.34 \\
\hline & $103.2(1.1)$ & $6.029(1.9)$ & $1042(10)$ & $2366(11)$ & $58.78(0.6)$ \\
\hline
\end{tabular}




\begin{tabular}{|c|c|c|c|c|c|}
\hline Compound & $\begin{array}{c}\text { Peak } \\
\text { Load } \\
(N)\end{array}$ & $\begin{array}{c}\text { Deflection@ } \\
\text { Peak Load } \\
(\mathrm{mm}) \\
\end{array}$ & $\begin{array}{c}\text { Work } \\
\text { Done } \\
(J)\end{array}$ & $\begin{array}{c}\text { Flexural } \\
\text { Modulus } \\
(M P a)\end{array}$ & $\begin{array}{c}\text { Flexural } \\
\text { Strength } \\
\text { (MPa) }\end{array}$ \\
\hline \multicolumn{6}{|c|}{ ABS $+3.5 w t \%$ sAZUB $+22.0 w t \%$ BTBPE } \\
\hline \multirow[t]{9}{*}{$27(\mathrm{C} 5)$} & 108 & 5.976 & 1075 & 2287 & 60.38 \\
\hline & 107.6 & 5.56 & 1078 & 2334 & 60.17 \\
\hline & 106.4 & 5.109 & 1073 & 2381 & 59.53 \\
\hline & 106.4 & 6.111 & 1071 & 2338 & 59.53 \\
\hline & 106.4 & 10.63 & 1069 & 2288 & 59.53 \\
\hline & 108 & 10.84 & 1076 & 2354 & 60.38 \\
\hline & 106 & 5.96 & 1065 & 2303 & 59.32 \\
\hline & 104.9 & 5.276 & 1057 & 2321 & 58.68 \\
\hline & $106.7(1.1)$ & $6.933(2.4)$ & $1071(7)$ & $2326(33)$ & $59.69(0.6)$ \\
\hline
\end{tabular}

ABS + 3.6wt $\%$ sAZUB + 20wt $\%$ TBBA

\begin{tabular}{|c|c|c|c|c|c|}
\hline $\mathbf{2 8}(\mathbf{C 5})$ & 124.7 & 5.443 & 1253 & 2774 & 70.61 \\
& 123.2 & 5.427 & 888.5 & 2781 & 69.75 \\
& 125.1 & 5.41 & 1262 & 2817 & 70.83 \\
& 125.5 & 5.259 & 1263 & 2785 & 71.04 \\
& 125.1 & 5.343 & 1265 & 2848 & 70.83 \\
& 123.6 & 5.475 & 1248 & 2815 & 69.96 \\
& 124.1 & 5.382 & 1254 & 2801 & 70.25 \\
& 125.1 & 5.258 & 1260 & 2795 & 70.83 \\
\hline & $124.6(0.8)$ & $5.375(0.1)$ & $1212(131)$ & $2802(24)$ & $70.51(0.5)$ \\
\hline
\end{tabular}

ABS + 4.0wt \% sAZUB + 21.4wt \% DBDPO

\begin{tabular}{|c|c|c|c|c|c|}
\hline 29 (C6) & 104.5 & 4.743 & 596.8 & 2269 & 59.04 \\
& 107.6 & 5.724 & 551.1 & 2356 & 60.77 \\
& 107.6 & 6.447 & 593.7 & 2291 & 60.77 \\
& 107.6 & 6.46 & 569.8 & 2308 & 60.77 \\
& 105.7 & 6.024 & 489.8 & 2326 & 59.69 \\
& 108 & 6.225 & 520.1 & 2323 & 60.98 \\
& 107.2 & 5.972 & 573 & 2337 & 60.55 \\
& 106.4 & 6.209 & 502 & 2349 & 60.12 \\
\hline & $106.8(1.2)$ & $5.976(0.6)$ & $550(41)$ & $2320(29)$ & $60.34(0.7)$ \\
\hline
\end{tabular}

ABS + 5.15wt\% sAZUB + 20.7wt\% sDBDPO
\begin{tabular}{|c|c|c|c|c|c|}
\hline $30(\mathbf{C 6})$ & 101.5 & 5.173 & 563.2 & 2251 & 56.63 \\
& 102.6 & 5.142 & 553.4 & 2280 & 57.27 \\
& 101.5 & 5.358 & 618.7 & 2289 & 56.63 \\
& 103.4 & 4.857 & 642.1 & 2279 & 57.69 \\
& 105.3 & 5.374 & 600.4 & 2302 & 58.76 \\
& 103.8 & 5.392 & 595.9 & 2344 & 57.91 \\
& 102.2 & 5.11 & 699.5 & 2302 & 57.06 \\
& 103 & 5.427 & 659.6 & 2336 & 57.48 \\
\hline & $102.9(1.3)$ & $5.229(0.2)$ & $617(49)$ & $2298(31)$ & $57.43(0.7)$ \\
\hline
\end{tabular}




\begin{tabular}{|c|c|c|c|c|c|}
\hline Compound & $\begin{array}{c}\text { Peak } \\
\text { Load } \\
(N)\end{array}$ & $\begin{array}{c}\text { Deflection @ } \\
\text { Peak Load } \\
(\mathrm{mm})\end{array}$ & $\begin{array}{c}\text { Work } \\
\text { Done } \\
(J)\end{array}$ & $\begin{array}{c}\text { Flexural } \\
\text { Modulus } \\
(\mathrm{MPa})\end{array}$ & $\begin{array}{c}\text { Flexural } \\
\text { Strength } \\
(\mathrm{MPa})\end{array}$ \\
\hline
\end{tabular}

ABS + 3.5wt\% AZUB (16wt\% MB5) + 20.5wt\% BTBPE
\begin{tabular}{|c|c|c|c|c|c|}
\hline 31 (C4) & 92.7 & 4.957 & 920.3 & 1862 & 51.16 \\
& 93.84 & 5.841 & 921.8 & 1848 & 51.79 \\
& 93.46 & 5.626 & 925.5 & 1878 & 51.58 \\
91.93 & 5.475 & 921.2 & 1925 & 50.74 \\
92.7 & 6.593 & 924.7 & 1888 & 51.16 \\
& 94.22 & 5.775 & 940 & 1911 & 52.00 \\
& 94.22 & 4.958 & 939.5 & 1901 & 52.00 \\
& 91.93 & 6.211 & 912.5 & 1862 & 50.74 \\
\hline & $93.1(0.9)$ & $5.680(0.6)$ & $926(10)$ & $1884(27)$ & $51.40(0.5)$ \\
\hline
\end{tabular}

ABS + 3.7wt \% AZUB (16wt \% MB5) + 20.5wt \% TBBA

\begin{tabular}{|c|c|c|c|c|c|}
\hline 32 (C4) & 114.1 & 5.657 & 1137 & 2351 & 62.57 \\
& 111.4 & 5.46 & 1121 & 2345 & 61.10 \\
& 111.4 & 10.36 & 1110 & 2330 & 61.10 \\
& 110.6 & 5.757 & 1112 & 2334 & 60.69 \\
& 109.9 & 6.193 & 1100 & 2281 & 60.27 \\
& 111 & 11.35 & 1111 & 2332 & 60.89 \\
& 111.4 & 9.792 & 1111 & 2365 & 61.10 \\
& 110.2 & 10.33 & 1106 & 2329 & 60.48 \\
\hline & $111.3(1.3)$ & $8.112(2.6)$ & $1114(11)$ & $2333(25)$ & $61.03(0.7)$ \\
\hline
\end{tabular}




\section{APPENDIX D: LOI FlaMe TEST RESUlts}

\section{Limiting Oxygen Index (Results and Calculations)}

The oxygen index testing was carried out using Dixon's 'up and down' statistical approach to determine the LOI values. A step size of 0.2 units was used and was calculated to be valid between the limits:

0.66 standard deviation $<\mathrm{d}<1.5$ standard deviation.

Table: Values of $\mathrm{k}$ for calculating oxygen index concentration from determinations made by Dixon's 'up and down' method.

\begin{tabular}{|c|c|c|c|c|c|c|}
\hline & 1 & 2 & 3 & 4 & 5 & 6 \\
\hline & $\begin{array}{l}\text { Responses for the last } \\
\text { five measurements }\end{array}$ & \multicolumn{4}{|c|}{$\begin{array}{l}\text { Values of } \mathrm{k} \text { for which the first } \mathrm{N}_{\mathrm{L}} \\
\text { determinations are: }\end{array}$} & \\
\hline & (a) & 0 & $\mathrm{OO}$ & 000 & 0000 & \\
\hline 1 & $\mathrm{X0000}$ & -0.55 & -0.55 & -0.55 & -0.55 & OXXXX \\
\hline 2 & $x 000 x$ & -1.25 & -1.25 & -1.25 & -1.25 & OXXXO \\
\hline 3 & xooxo & 0.37 & 0.38 & 0.38 & 0.38 & OXXOX \\
\hline 4 & $x 00 x x$ & -0.17 & -0.14 & -0.14 & -0.14 & OXXOO \\
\hline 5 & XOXOO & 0.02 & 0.04 & 0.04 & 0.04 & oxoxx \\
\hline 6 & xOXOX & -0.50 & -0.46 & -0.45 & -0.45 & OXOXO \\
\hline 7 & XOXXO & 1.17 & 1.24 & 1.25 & 1.25 & oxoOX \\
\hline 8 & $x O X X X$ & 0.61 & 0.73 & 0.76 & 0.76 & $0 \times 000$ \\
\hline 9 & $x \times 000$ & -0.30 & -0.27 & -0.26 & -0.26 & $00 \times x \times$ \\
\hline 10 & XXOOX & -0.83 & -0.76 & -0.75 & -0.75 & $00 \times \times 0$ \\
\hline 11 & $x \times O \times O$ & 0.83 & 0.94 & 0.95 & 0.95 & OOXOX \\
\hline 12 & $X X O X X$ & 0.30 & 0.46 & 0.50 & 0.50 & $00 \times 00$ \\
\hline 13 & XXXOO & 0.50 & 0.65 & 0.68 & 0.68 & OOOXX \\
\hline 14 & $X X X O X$ & -0.04 & 0.19 & 0.24 & 0.25 & $000 \times 0$ \\
\hline 15 & $X X X X O$ & 1.60 & 1.92 & 2.00 & 2.01 & O000x \\
\hline \multirow[t]{4}{*}{16} & \multirow[t]{4}{*}{$x \times x \times x$} & 0.89 & 1.33 & 1.47 & 1.50 & 00000 \\
\hline & & \multicolumn{4}{|c|}{$\begin{array}{l}\text { Values of } \mathrm{k} \text { for which the first } \mathrm{N}_{\mathrm{L}} \\
\text { determinations are: }\end{array}$} & \multirow[t]{3}{*}{$\begin{array}{l}\text { Responses for the last } \\
\text { five measurements }\end{array}$} \\
\hline & & $x$ & $x x$ & $x X X$ & $X X X X$ & \\
\hline & & \multicolumn{4}{|c|}{$\begin{array}{l}\text { are as given in the table above opposite the } \\
\text { appropriate response in column } 6 \text {, but with } \\
\text { the sign of k reversed, i.e. OI }=C_{f}-k d\end{array}$} & \\
\hline
\end{tabular}


Compound:

Unfilled ABS

Part 1: Determination of initial oxygen concentration ( $X$ and $O$ response at $\leq 1 \% \mathrm{O}_{2}$ interval)

\begin{tabular}{|l|c|c|l|l|l|l|}
\hline Oxygen concentration & 18.0 & 19.0 & & & & \\
\hline Burning time (s) & 50 & $>180$ & & & & \\
\hline Burn length (mm) & 4 & 25 & & & & \\
\hline Pass (O) or Fail (X) & $\mathrm{O}$ & $\mathrm{X}$ & & & & \\
\hline
\end{tabular}

Part 2: Determination of oxygen index value

\begin{tabular}{|c|c|c|c|c|c|c|c|}
\hline \multicolumn{8}{|c|}{$\mathrm{N}_{\mathrm{T}}$ series } \\
\hline \multicolumn{7}{|c|}{$\mathrm{N}_{\mathrm{L}}$ Calculation } & \multirow{2}{*}{ Column } \\
\hline Oxygen concentration & 18.0 & 18.2 & 18.4 & 18.6 & & & \\
\hline Burning time (s) & 35 & 40 & 55 & $>180$ & & & \\
\hline Burn length $(\mathrm{mm})$ & 2 & 2 & 3 & 26 & & & \\
\hline Pass $(\mathrm{O})$ or Fail $(\mathrm{X})$ & $\mathrm{O}$ & $\mathrm{O}$ & $\mathrm{O}$ & $\mathrm{X}$ & & & 4 \\
\hline \multicolumn{6}{|l|}{$C_{F}$ Calculation } & $\mathrm{C}_{\mathrm{F}}$ & Row \\
\hline Oxygen concentration & & 18.6 & 18.8 & 18.6 & 18.4 & 18.6 & \\
\hline Burning time (s) & & 165 & $>180$ & $>180$ & 165 & 179 & \\
\hline Burn length $(\mathrm{mm})$ & & 13 & 35 & 17 & 11 & 13 & \\
\hline Pass $(\mathrm{O})$ or Fail $(\mathrm{X})$ & & $\mathrm{O}$ & $X$ & $\mathrm{X}$ & $\mathrm{O}$ & $\mathrm{O}$ & 4 \\
\hline k value & & & & & & & -0.14 \\
\hline $\mathrm{OI}=\mathrm{C}_{\mathrm{F}}+\mathbf{k d}$ & $=18.6$ & $0.14 x$ & $=18$. & & & & 18.6 \\
\hline
\end{tabular}

Compound:

[1] ABS + 4.1 wt\% RS

Part 1: Determination of initial oxygen concentration (X and $O$ response at $\leq 1 \% \mathrm{O}_{2}$ interval)

\begin{tabular}{|l|c|c|l|l|l|l|}
\hline Oxygen concentration & 19.0 & 18.0 & & & & \\
\hline Burning time (s) & $>180$ & 40 & & & & \\
\hline Burn length (mm) & 25 & 5 & & & & \\
\hline Pass (O) or Fail (X) & $\mathrm{X}$ & $\mathrm{O}$ & & & & \\
\hline
\end{tabular}

Part 2: Determination of oxygen index value

\begin{tabular}{|c|c|c|c|c|c|c|c|}
\hline \multicolumn{8}{|c|}{$\mathbf{N}_{\mathrm{T}}$ series } \\
\hline \multicolumn{7}{|c|}{$\mathrm{N}_{\mathrm{L}}$ Calculation } & Column \\
\hline Oxygen concentration & 18.0 & 18.2 & 18.4 & 18.6 & 18.8 & & \\
\hline Burning time (s) & 40 & 70 & 100 & 130 & $>180$ & & \\
\hline Burn length (mm) & 5 & 6 & 9 & 10 & 25 & & \\
\hline Pass (O) or Fail (X) & $\mathrm{O}$ & $\mathrm{O}$ & $\mathrm{O}$ & $\mathrm{O}$ & $\mathrm{X}$ & & 5 \\
\hline \multicolumn{6}{|l|}{$C_{F}$ Calculation } & $\mathrm{C}_{\mathrm{F}}$ & Row \\
\hline Oxygen concentration & & 18.8 & 18.6 & 18.8 & 18.6 & 18.8 & \\
\hline Burning time (s) & & $>180$ & 120 & $>180$ & 125 & $>180$ & \\
\hline Burn length $(\mathrm{mm})$ & & 24 & 11 & 26 & 12 & 26 & \\
\hline $\operatorname{Pass}(\mathrm{O})$ or Fail $(\mathrm{X})$ & & $x$ & $\mathrm{O}$ & $x$ & $\mathrm{O}$ & $\mathrm{X}$ & 6 \\
\hline k value & & & & & & & -0.45 \\
\hline$O I=C_{F}+k d$ & $=18.8$ & $0.45 x$ & $=18$ & & & & 18.7 \\
\hline
\end{tabular}


Compound:

[2] ABS + 5.49wt \% A05

Part 1: Determination of initial oxygen concentration ( $X$ and $O$ response at $\leq 1 \% \mathrm{O}_{2}$ interval)

\begin{tabular}{|l|c|c|l|l|l|l|}
\hline Oxygen concentration & 18.0 & 19.0 & & & & \\
\hline Burning time (s) & 40 & $>180$ & & & & \\
\hline Burn length (mm) & 4 & 20 & & & & \\
\hline Pass (O) or Fail (X) & $\mathrm{O}$ & $\mathrm{X}$ & & & & \\
\hline
\end{tabular}

Part 2: Determination of oxygen index value

\begin{tabular}{|c|c|c|c|c|c|c|c|}
\hline \multicolumn{8}{|c|}{$N_{T}$ series } \\
\hline \multicolumn{7}{|c|}{$\mathrm{N}_{\mathrm{L}}$ Calculation } & Column \\
\hline Oxygen concentration & 19.0 & 19.2 & & & & & \\
\hline Burning time (s) & 160 & $>180$ & & & & & \\
\hline Burn length $(\mathrm{mm})$ & 17 & 25 & & & & & \\
\hline Pass $(\mathrm{O})$ or Fail $(\mathrm{X})$ & $\mathrm{O}$ & $X$ & & & & & 2 \\
\hline \multicolumn{6}{|l|}{$C_{F}$ Calculation } & $\mathrm{C}_{F}$ & Row \\
\hline Oxygen concentration & & 19.2 & 19.0 & 18.8 & 19.0 & 19.2 & \\
\hline Burning time (s) & & $>180$ & $>180$ & 150 & 165 & 175 & \\
\hline Burn length $(\mathrm{mm})$ & & 30 & 25 & 15 & 20 & 22 & \\
\hline Pass $(\mathrm{O})$ or Fail $(\mathrm{X})$ & & $\mathrm{X}$ & $X$ & $\mathrm{O}$ & $\mathrm{O}$ & $\mathrm{O}$ & 9 \\
\hline k value & & & & & & & -0.3 \\
\hline$O I=C_{F}+k d$ & $=19.2$ & $(-0.3)$ & $0.2)=$ & & & & 19.1 \\
\hline
\end{tabular}

Compound:

[4] ABS + 4.93wt $\%$ pAZUB

Part 1: Determination of initial oxygen concentration ( $X$ and $O$ response at $\leq 1 \% \mathrm{O}_{2}$ interval)

\begin{tabular}{|l|c|c|l|l|l|l|}
\hline Oxygen concentration & 18.0 & 19.0 & & & & \\
\hline Burning time (s) & 50 & $>180$ & & & & \\
\hline Burn length (mm) & 5 & & & & & \\
\hline Pass (O) or Fail (X) & $\mathrm{O}$ & $\mathrm{X}$ & & & & \\
\hline
\end{tabular}

Part 2: Determination of oxygen index value

\begin{tabular}{|c|c|c|c|c|c|c|c|}
\hline \multicolumn{8}{|c|}{$\mathrm{N}_{\mathrm{T}}$ series } \\
\hline \multicolumn{7}{|c|}{$\mathbf{N}_{\mathbf{L}}$ Calculation } & \multirow[t]{2}{*}{ Column } \\
\hline Oxygen concentration & 18.0 & 18.2 & 18.4 & 18.6 & 18.8 & 19.0 & \\
\hline Burning time (s) & 50 & 70 & 85 & 120 & 150 & $>180$ & \\
\hline Burn length $(\mathrm{mm})$ & 5 & 6 & 9 & 11 & 15 & 17 & \\
\hline Pass $(\mathrm{O})$ or Fail $(\mathrm{X})$ & $\mathrm{O}$ & $\mathrm{O}$ & $\mathrm{O}$ & $\mathrm{O}$ & $\mathrm{O}$ & $\mathrm{X}$ & 5 \\
\hline \multicolumn{6}{|l|}{$C_{F}$ Calculation } & $C_{F}$ & Row \\
\hline Oxygen concentration & & 19.0 & 18.8 & 19.0 & 18.8 & 19.0 & \\
\hline Burning time (s) & & $\geq 180$ & 160 & $>180$ & 155 & 170 & \\
\hline Burn length (mm) & & 18 & 15 . & 19 & 15 & 17 & \\
\hline Pass $(\mathrm{O})$ or Fail $(\mathrm{X})$ & & $\mathrm{X}$ & $\mathrm{O}$ & $\mathrm{X}$ & $\mathrm{O}$ & $\mathrm{O}$ & $\mathbf{5}$ \\
\hline $\mathrm{k}$ value & & & & & & & 0.04 \\
\hline $\mathrm{OI}=\mathrm{C}_{\mathrm{F}}+\mathbf{k d}$ & $=19.0$ & $.04 \times$ & $=19.0$ & & & & 19.0 \\
\hline
\end{tabular}


Compound:

[5] ABS + 3.45wt\% sAZUB

Part 1: Determination of initial oxygen concentration ( $X$ and $O$ response at $\leq 1 \% \mathrm{O}_{2}$ interval)

\begin{tabular}{|l|c|c|l|l|l|l|}
\hline Oxygen concentration & 19.0 & 18.0 & & & & \\
\hline Burning time (s) & $>180$ & 50 & & & & \\
\hline Burn length (mm) & 28 & 7 & & & & \\
\hline Pass (O) or Fail (X) & $\mathrm{X}$ & $\mathrm{O}$ & & & & \\
\hline
\end{tabular}

Part 2: Determination of oxygen index value

\begin{tabular}{|c|c|c|c|c|c|c|c|}
\hline \multicolumn{8}{|c|}{$\mathbf{N}_{\mathrm{T}}$ series } \\
\hline \multicolumn{7}{|c|}{$\mathbf{N}_{\mathrm{L}}$ Calculation } & \multirow[t]{2}{*}{ Column } \\
\hline Oxygen concentration & 18.0 & 18.2 & 18.4 & 18.6 & & & \\
\hline Burning time (s) & 50 & 75 & 130 & $>180$ & & & \\
\hline Burn length $(\mathrm{mm})$ & 7 & 8 & 10 & 23 & & & \\
\hline Pass $(\mathrm{O})$ or Fail $(\mathrm{X})$ & $\mathrm{O}$ & $\mathrm{O}$ & $\underline{\mathrm{O}}$ & $\mathrm{X}$ & & & 4 \\
\hline \multicolumn{6}{|l|}{$\mathrm{C}_{\mathrm{F}}$ Calculation } & $\mathbf{C}_{\mathrm{F}}$ & Row \\
\hline Oxygen concentration & & 18.6 & 18.4 & 18.6 & 18.8 & 18.6 & \\
\hline Burning time (s) & & $>180$ & 120 & 170 & $>180$ & $>180$ & \\
\hline Burn length (mm) & & 23 & 11 & 25 & 30 & 27 & \\
\hline Pass (O) or Fail (X) & & $\mathrm{X}$ & $\mathrm{O}$ & $\mathrm{O}$ & $\mathrm{X}$ & $\mathrm{X}$ & 4 \\
\hline k value & & & & & & & -0.14 \\
\hline$O I=C_{F}+k d$ & $=18.6$ & $0.14 \times$ & $=18$. & & & & 18.6 \\
\hline
\end{tabular}

Compound:

[16] ABS + 19.8wt\% BTBPE

Part 1: Determination of initial oxygen concentration ( $X$ and $O$ response at $\leq 1 \% O_{2}$ interval)

\begin{tabular}{|l|c|c|c|c|c|c|}
\hline Oxygen concentration & 20.0 & 21.0 & 22.0 & 23.0 & & \\
\hline Burning time (s) & 50 & 45 & 100 & $>180$ & & \\
\hline Burn length (mm) & 12 & 10 & 18 & 50 & & \\
\hline Pass (O) or Fail (X) & $\mathrm{O}$ & $\mathrm{O}$ & $\mathrm{O}$ & $\mathrm{X}$ & & \\
\hline
\end{tabular}

Part 2: Determination of oxygen index value

\begin{tabular}{|c|c|c|c|c|c|c|c|}
\hline \multicolumn{8}{|c|}{$N_{T}$ series } \\
\hline \multicolumn{7}{|c|}{$\mathrm{N}_{\mathrm{L}}$ Calculation } & \multirow[t]{2}{*}{ Column } \\
\hline Oxygen concentration & 22.0 & 22.2 & 22.4 & 22.6 & & & \\
\hline Burning time (s) & 95 & 105 & 155 & $>180$ & & & \\
\hline Burn length (mm) & 16 & 16 & 26 & 45 & & & \\
\hline Pass $(\mathrm{O})$ or Fail $(\mathrm{X})$ & $\mathrm{O}$ & $\mathrm{O}$ & $\mathrm{O}$ & $\mathrm{X}$ & & & 4 \\
\hline \multicolumn{6}{|l|}{$\mathrm{C}_{\mathrm{F}}$ Calculation } & $\mathrm{C}_{\mathrm{F}}$ & Row \\
\hline Oxygen concentration & & 22.6 & 22.4 & 22.6 & 22.4 & 22.6 & \\
\hline Burning time (s) & & $>180$ & 150 & $>180$ & 145 & $>180$ & \\
\hline Burn length (mm) & & 44 & 25 & 50 & 23 & 45 & \\
\hline Pass $(\mathrm{O})$ or Fail $(\mathrm{X})$ & & $X$ & $\mathrm{O}$ & $\mathrm{X}$ & $\mathrm{O}$ & $\mathrm{X}$ & 6 \\
\hline$k$ value & & & & & & & -0.45 \\
\hline $\mathrm{OI}=\mathrm{C}_{\mathrm{F}}+\mathrm{kd}$ & $=22.6$ & $0.45 \mathrm{x}$ & $=22$. & & & & 22.5 \\
\hline
\end{tabular}


Compound:

[17] ABS + 21.0wt \% TBBA

Part 1: Determination of initial oxygen concentration ( $X$ and $O$ response at $\leq 1 \% \mathrm{O}_{2}$ interval)

Oxygen concentration

Burning time (s)

Burn length (mm)

Pass (O) or Fail (X)

\begin{tabular}{|c|c|c|l|l|l|}
\hline 21.0 & 22.0 & 23.0 & & & \\
\hline 70 & 160 & $>180$ & & & \\
\hline 20 & 27 & 50 & & & \\
\hline $\mathrm{O}$ & $\mathrm{O}$ & $\mathrm{X}$ & & & \\
\hline
\end{tabular}

Part 2: Determination of oxygen index value

\begin{tabular}{|c|c|c|c|c|c|c|c|}
\hline \multicolumn{8}{|c|}{$\mathrm{N}_{\mathrm{T}}$ series } \\
\hline \multicolumn{7}{|c|}{$N_{L}$ Calculation } & Column \\
\hline Oxygen concentration & 22.0 & 22.2 & & & & & \\
\hline Burning time (s) & 165 & $>180$ & & & & & \\
\hline Burn length (mm) & 30 & 45 & & & & & \\
\hline Pass (O) or Fail (X) & $\mathrm{O}$ & $X$ & & & & & 2 \\
\hline \multicolumn{6}{|l|}{$\mathrm{C}_{\mathrm{F}}$ Calculation } & $\mathrm{C}_{\mathrm{F}}$ & Row \\
\hline Oxygen concentration & & 22.2 & 22.0 & 22.2 & 22.0 & 22.2 & \\
\hline Burning time (s) & & $>180$ & 155 & $>180$ & 170 & $>180$ & \\
\hline Burn length $(\mathrm{mm})$ & & 50 & 25 & 42 & 35 & 50 & \\
\hline Pass (O) or Fail (X) & & $X$ & $\mathrm{O}$ & $\mathrm{X}$ & $\mathrm{O}$ & $\mathrm{X}$ & 6 \\
\hline k value & & & & & & & -0.5 \\
\hline $\mathrm{O} I=\mathrm{C}_{\mathrm{F}}+\mathbf{k d}$ & $=22.2$ & $.50 \times 0$. & 2.1 & & & & 22.1 \\
\hline
\end{tabular}

Compound:

[18] ABS + 20.1wt\% DBDPO

Part 1: Determination of initial oxygen concentration ( $X$ and $O$ response at $\leq 1 \% \mathrm{O}_{2}$ interval)

Oxygen concentration

Burning time (s)

Burn length (mm)

Pass $(\mathrm{O})$ or Fail $(\mathrm{X})$

\begin{tabular}{|c|c|l|l|l|l|}
\hline 24.0 & 23.0 & & & & \\
\hline$>180$ & 70 & & & & \\
\hline 50 & 10 & & & & \\
\hline $\mathrm{X}$ & $\mathrm{O}$ & & & & \\
\hline
\end{tabular}

Part 2: Determination of oxygen index value

\begin{tabular}{|c|c|c|c|c|c|c|c|}
\hline \multicolumn{8}{|c|}{$\mathbf{N}_{\mathrm{T}}$ series } \\
\hline \multicolumn{7}{|c|}{$\mathrm{N}_{\mathrm{L}}$ Calculation } & Column \\
\hline Oxygen concentration & 23.0 & 23.2 & 23.4 & & & & \\
\hline Burning time (s) & 76 & 160 & $\geq 180$ & & & & \\
\hline Burn length (mm) & 9 & 32 & 45 & & & & \\
\hline Pass $(\mathrm{O})$ or Fail $(\mathrm{X})$ & $\mathrm{O}$ & $\mathrm{O}$ & $\underline{X}$ & & & & 3 \\
\hline \multicolumn{6}{|l|}{$\mathrm{C}_{\mathrm{F}}$ Calculation } & $\mathbf{C}_{\mathrm{F}}$ & Row \\
\hline Oxygen concentration & & 23.4 & 23.2 & 23.4 & 23.2 & 23.4 & \\
\hline Burning time (s) & & $>180$ & 130 & $>180$ & 140 & $>180$ & \\
\hline Burn length (mm) & & 50 & 26 & 50 & 27 & 50 & \\
\hline Pass $(\mathrm{O})$ or Fail $(\mathrm{X})$ & & $\mathrm{X}$ & $\mathrm{O}$ & $\mathrm{X}$ & 0 & $\mathrm{X}$ & 6 \\
\hline $\mathrm{k}$ value & & & & & & & -0.46 \\
\hline $\mathrm{OI}=\mathrm{C}_{\mathrm{F}}+\mathrm{kd}$ & $=23.4$ & $0.46 x$ & $=23$. & & & & 23.3 \\
\hline
\end{tabular}


Compound:

[19] ABS + 21.4wt\% sDBDPO

Part 1: Determination of initial oxygen concentration ( $\mathrm{X}$ and $\mathrm{O}$ response at $\leq 1 \% \mathrm{O}_{2}$ interval)

\begin{tabular}{|l|c|c|c|c|c|c|}
\hline Oxygen concentration & 22.0 & 23.0 & 24.0 & & & \\
\hline Burning time (s) & 35 & 120 & $>180$ & & & \\
\hline Burn length (mm) & 2 & 11 & 50 & & & \\
\hline Pass (O) or Fail (X) & $\mathrm{O}$ & $\mathrm{O}$ & $\mathrm{X}$ & & & \\
\hline
\end{tabular}

Part 2: Determination of oxygen index value

\begin{tabular}{|c|c|c|c|c|c|c|c|}
\hline \multicolumn{8}{|c|}{$N_{T}$ series } \\
\hline \multicolumn{7}{|c|}{$\mathbf{N}_{\mathrm{l}}$ Calculation } & \multirow[t]{2}{*}{ Column } \\
\hline Oxygen concentration & 23.0 & 23.2 & 23.4 & 23.6 & 23.8 & 24.0 & \\
\hline Burning time (s) & 75 & 75 & 65 & 90 & 100 & $>180$ & \\
\hline Burn length $(\mathrm{mm})$ & 4 & 8 & 10 & 12 & 20 & 40 & \\
\hline Pass $(\mathrm{O})$ or Fail $(\mathrm{X})$ & $\mathrm{O}$ & $\mathrm{O}$ & $\mathrm{O}$ & $\mathrm{O}$ & $\mathrm{O}$ & $\mathrm{X}$ & 5 \\
\hline \multicolumn{6}{|l|}{$\mathrm{C}_{\mathrm{F}}$ Calculation } & $C_{F}$ & Row \\
\hline Oxygen concentration & & 24.0 & 24.2 & 24.0 & 23.8 & 24.0 & \\
\hline Burning time (s) & & 70 & $>180$ & $\geq 180$ & 90 & $>180$ & \\
\hline Burn length $(\mathrm{mm})$ & & 20 & 50 & 44 & 19 & 35 & \\
\hline Pass $(\mathrm{O})$ or Fail $(\mathrm{X})$ & & $\mathrm{O}$ & $\mathrm{X}$ & $\mathrm{X}$ & $\mathrm{O}$ & $\mathrm{X}$ & 3 \\
\hline kvalue & & & & & & & 0.38 \\
\hline $\mathbf{O I}=\mathbf{C}_{\mathrm{F}}+\mathbf{k d}$ & $=24.0$ & $0.38 x$ & $=\mathbf{2 4 . 0 8}$ & & & & 24.1 \\
\hline
\end{tabular}

Compound:

[20] ABS + 4.1wt\% RS + 21.5wt\% BTBPE

Part 1: Determination of initial oxygen concentration ( $X$ and $O$ response at $\leq 1 \% \mathrm{O}_{2}$ interval)

\begin{tabular}{|l|c|c|c|c|l|l|}
\hline Oxygen concentration & 26.0 & 27.0 & 28.0 & 29.0 & & \\
\hline Burning time (s) & 35 & 45 & 40 & $>180$ & & \\
\hline Burn length (mm) & 5 & 12 & 7 & 50 & & \\
\hline Pass (O) or Fail (X) & $\mathrm{O}$ & $\mathrm{O}$ & $\mathrm{O}$ & $\mathrm{X}$ & & \\
\hline
\end{tabular}

Part 2: Determination of oxygen index value

\begin{tabular}{|c|c|c|c|c|c|c|c|}
\hline \multicolumn{8}{|c|}{$\mathrm{N}_{\mathrm{T}}$ series } \\
\hline \multicolumn{7}{|c|}{$N_{L}$ Calculation } & Column \\
\hline Oxygen concentration & 28.0 & 28.2 & 28.4 & 28.6 & & & \\
\hline Burning time (s) & 80 & 30 & 35 & $>180$ & 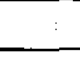 & & \\
\hline Burn length (mm) & 22 & 10 & 11 & 50 & & & \\
\hline Pass $(\mathrm{O})$ or Fail $(\mathrm{X})$ & $\mathrm{O}$ & $\mathrm{O}$ & $\mathrm{O}$ & $X$ & & & 4 \\
\hline \multicolumn{6}{|l|}{$\mathrm{C}_{\mathrm{F}}$ Calculation } & $C_{F}$ & Row \\
\hline Oxygen concentration & & 28.6 & 28.4 & 28.6 & 28.4 & 28.6 & \\
\hline Burning time (s) & & $>180$ & 100 & $>180$ & 120 & $>180$ & \\
\hline Burn length (mm) & & 49 & 26 & 50 & 25 & 50 & \\
\hline $\operatorname{Pass}(\mathrm{O})$ or Fail $(\mathrm{X})$ & & $\mathrm{X}$ & $\mathrm{O}$ & $\mathrm{X}$ & $\mathrm{O}$ & $\mathrm{X}$ & 6 \\
\hline $\mathrm{k}$ value & & & & & & & -0.45 \\
\hline $\mathbf{O I}=\mathbf{C}_{\mathrm{F}}+\mathbf{k d}$ & $=28.6$ & $0.45 x$ & $=28$. & & & & 28.5 \\
\hline
\end{tabular}


Compound:

[21] ABS + 3.98wt\% RS + 19.7wt \% TBBA

Part 1: Determination of initial oxygen concentration ( $X$ and $O$ response at $\leq 1 \% \mathrm{O}_{2}$ interval)

Oxygen concentration

Burning time (s)

Burn length (mm)

Pass (O) or Fail (X)

\begin{tabular}{|c|c|c|l|l|l|}
\hline 27.0 & 28.0 & 29.0 & & & \\
\hline 40 & 45 & $>180$ & & & \\
\hline 4 & 6 & 50 & & & \\
\hline $\mathrm{O}$ & $\mathrm{O}$ & $\mathrm{X}$ & & & \\
\hline
\end{tabular}

\section{Part 2: Determination of oxygen index value}

\begin{tabular}{|c|c|c|c|c|c|c|c|}
\hline \multicolumn{8}{|c|}{$\mathrm{N}_{\mathrm{T}}$ series } \\
\hline \multicolumn{7}{|c|}{$\mathrm{N}_{\mathrm{L}}$ Calculation } & \multirow[t]{2}{*}{ Column } \\
\hline Oxygen concentration & 28.0 & 28.2 & 28.4 & & & & \\
\hline Burning time (s) & 50 & 40 & $>180$ & & & & \\
\hline Burn length $(\mathrm{mm})$ & 7 & 5 & 50 & & & & \\
\hline Pass $(\mathrm{O})$ or Fail $(\mathrm{X})$ & $\mathrm{O}$ & $\mathrm{O}$ & $x$ & & & & 3 \\
\hline \multicolumn{6}{|l|}{$C_{F}$ Calculation } & $\mathbf{C}_{\mathbf{F}}$ & Row \\
\hline Oxygen concentration & & 28.4 & 28.2 & 28.0 & 28.2 & 28.4 & \\
\hline Burning time (s) & & $>180$ & $>180$ & 120 & 120 & $>180$ & \\
\hline Burn length (mm) & & 50 & 50 & 35 & 29 & 50 & \\
\hline Pass $(\mathrm{O})$ or Fail $(\mathrm{X})$ & & $X$ & $\mathrm{X}$ & $\mathrm{O}$ & $\mathrm{O}$ & $\mathrm{X}$ & 10 \\
\hline k value & & & & & & & -0.76 \\
\hline $\mathrm{OI}=\mathrm{C}_{\mathrm{F}}+\mathbf{k d}$ & $=28.4$ & $-0.76 x$ & $=28.2$ & & & & 28.2 \\
\hline
\end{tabular}

Compound:

[22] ABS + 4.1wt \% RS + 23.8wt \% DBDPO

Part 1: Determination of initial oxygen concentration ( $X$ and $O$ response at $\leq 1 \% \mathrm{O}_{2}$ interval) Oxygen concentration

Burning time (s)

Burn length (mm)

Pass (O) or Fail (X)

\begin{tabular}{|c|c|c|l|l|l|}
\hline 28.0 & 29.0 & 30.0 & & & \\
\hline 30 & 35 & 150 & & & \\
\hline 6 & 6 & 50 & & & \\
\hline $\mathrm{O}$ & $\mathrm{O}$ & $\mathrm{X}$ & & & \\
\hline
\end{tabular}

\section{Part 2: Determination of oxygen index value}

\begin{tabular}{|c|c|c|c|c|c|c|c|}
\hline \multicolumn{8}{|c|}{$\mathrm{N}_{\mathrm{T}}$ series } \\
\hline \multicolumn{7}{|c|}{$\mathrm{N}_{\mathrm{L}}$ Calculation } & \multirow[t]{2}{*}{ Column } \\
\hline Oxygen concentration & 29.0 & 29.2 & 29.4 & 29.6 & & & \\
\hline Burning time (s) & 90 & 60 & 60 & $>180$ & & & \\
\hline Burn length $(\mathrm{mm})$ & 18 & 10 & 15 & 50 & & & \\
\hline Pass $(\mathrm{O})$ or Fail $(\mathrm{X})$ & $\mathrm{O}$ & $\mathrm{O}$ & $\mathrm{O}$ & $\mathrm{X}$ & & & 4 \\
\hline \multicolumn{6}{|l|}{$\mathrm{C}_{\mathrm{F}}$ Calculation } & $\mathrm{C}_{\mathrm{F}}$ & Row \\
\hline Oxygen concentration & & 29.6 & 29.4 & 29.6 & 29.8 & 29.6 & \\
\hline Burning time (s) & & $>180$ & 100 & 160 & $>180$ & $>180$ & \\
\hline Burn length (mm) & & 50 & 15 & 40 & 50 & 50 & \\
\hline Pass (O) or Fail (X) & & $\mathrm{X}$ & $\mathrm{O}$ & $\mathrm{O}$ & $\mathrm{X}$ & $X$ & 4 \\
\hline $\mathrm{k}$ value & & & & & & & -0.14 \\
\hline $\mathrm{OI}=\mathrm{C}_{\mathrm{F}}+\mathbf{k d}$ & $=29.6$ & $0.14 \times$ & $=29$. & & & & 29.6 \\
\hline
\end{tabular}


Compound:

[23] ABS + 4.4wt\% RS (MB4) + 19.9wt\% BTBPE

Part 1: Determination of initial oxygen concentration ( $X$ and $O$ response at $\leq 1 \% \mathrm{O}_{2}$ interval)

Oxygen concentration

Burning time (s)

Burn length (mm)

Pass $(\mathrm{O})$ or Fail $(\mathrm{X})$

\begin{tabular}{|c|c|c|c|c|l|}
\hline 27.0 & 28.0 & 29.0 & 31.0 & 32.0 & \\
\hline 30 & 30 & 35 & 150 & 120 & \\
\hline 6 & 5 & 7 & 25 & 50 & \\
\hline $\mathrm{O}$ & $\mathrm{O}$ & $\mathrm{O}$ & $\mathrm{O}$ & $\mathrm{X}$ & \\
\hline
\end{tabular}

Part 2: Determination of oxygen index value

\begin{tabular}{|c|c|c|c|c|c|c|c|}
\hline \multicolumn{8}{|c|}{$N_{T}$ series } \\
\hline \multicolumn{7}{|c|}{$N_{L}$ Calculation } & Column \\
\hline Oxygen concentration & 31.0 & 31.2 & & & & & \\
\hline Burning time (s) & 50 & 120 & & & & & \\
\hline Burn length (mm) & 9 & 50 & & & & & \\
\hline Pass (O) or Fail (X) & $\mathrm{O}$ & $\underline{X}$ & & & & & 2 \\
\hline \multicolumn{6}{|l|}{$\mathrm{C}_{\mathrm{F}}$ Calculation } & $\mathrm{C}_{\mathrm{F}}$ & Row \\
\hline Oxygen concentration & & 31.2 & 31.0 & 30.8 & 30.6 & 30.4 & \\
\hline Burning time (s) & & 130 & 145 & 160 & 150 & 115 & \\
\hline Burn length (mm) & & 50 & 50 & 50 & 50 & 50 & \\
\hline Pass (O) or Fail (X) & & $\mathrm{X}$ & $\mathrm{X}$ & $\mathrm{X}$ & $\mathrm{X}$ & $X$ & 16 \\
\hline$k$ value & & & & & & & 0.89 \\
\hline $\mathrm{OI}=\mathrm{C}_{\mathrm{F}}+\mathbf{k d}$ & $=30.4$ & $.89 \times$ & $=30.58$ & & & & 30.6 \\
\hline
\end{tabular}

Compound:

[24] ABS + 4.5wt\% RS (MB4) + 18.6wt \% TBBA

Part 1: Determination of initial oxygen concentration ( $X$ and $O$ response at $\leq 1 \% \mathrm{O}_{2}$ interval)

\begin{tabular}{|l|c|c|l|l|l|l|}
\hline Oxygen concentration & 30.0 & 31.0 & & & & \\
\hline Burning time (s) & 45 & 120 & & & & \\
\hline Burn length (mm) & 6 & 50 & & & & \\
\hline Pass (O) or Fail (X) & $\mathrm{O}$ & $\mathrm{X}$ & & & & \\
\hline
\end{tabular}

Part 2: Determination of oxygen index value

\begin{tabular}{|c|c|c|c|c|c|c|c|}
\hline \multicolumn{8}{|c|}{$N_{T}$ series } \\
\hline \multicolumn{7}{|c|}{$\mathrm{N}_{\mathrm{L}}$ Calculation } & \multirow[t]{2}{*}{ Column } \\
\hline Oxygen concentration & 30.0 & 30.2 & 30.4 & & & & \\
\hline Burning time (s) & 50 & 55 & 120 & & & & \\
\hline Burn length (mm) & 6 & 8 & 50 & & & & \\
\hline Pass (O) or Fail (X) & $\mathrm{O}$ & $\underline{O}$ & $\mathrm{X}$ & & & & 3 \\
\hline \multicolumn{6}{|l|}{$\mathrm{C}_{\mathrm{F}}$ Calculation } & $\mathrm{C}_{\mathrm{F}}$ & Row \\
\hline Oxygen concentration & & 30.4 & 30.2 & 30.0 & 30.2 & 30.4 & \\
\hline Burning time (s) & & 120 & 150 & 120 & 80 & 110 & \\
\hline Burn length (mm) & & 50 & 50 & 25 & 12 & 50 & \\
\hline Pass $(\mathrm{O})$ or Fail $(\mathrm{X})$ & & $\mathrm{X}$ & $\mathrm{X}$ & $\mathrm{O}$ & $\mathrm{O}$ & $\mathrm{X}$ & 10 \\
\hline$k$ value & & & & & & & -0.76 \\
\hline $\mathrm{OI}=\mathrm{C}_{\mathrm{F}}+\mathbf{k d}$ & $=30.4$ & $0.76 x$ & $=30$. & & & & 30.2 \\
\hline
\end{tabular}


Compound:

[25] ABS + 3.82wt \% pAZUB + 22.1wt\% BTBPE

Part 1: Determination of initial oxygen concentration ( $X$ and $O$ response at $\leq 1 \% \mathrm{O}_{2}$ interval)

Oxygen concentration

Burning time (s)

Burn length (mm)

Pass (O) or Fail (X)

\begin{tabular}{|c|c|c|l|l|l|}
\hline 27.0 & 28.0 & 29.0 & & & \\
\hline 50 & 120 & 120 & & & \\
\hline 8 & 16 & 50 & & & \\
\hline $\mathrm{O}$ & $\mathrm{O}$ & $\mathrm{X}$ & & & \\
\hline
\end{tabular}

Part 2: Determination of oxygen index value

\begin{tabular}{|c|c|c|c|c|c|c|c|}
\hline \multicolumn{8}{|c|}{$N_{T}$ series } \\
\hline \multicolumn{7}{|c|}{$\mathbf{N}_{\mathrm{L}}$ Calculation } & Column \\
\hline Oxygen concentration & 28.0 & 28.2 & & & & & \\
\hline Burning time (s) & 130 & 175 & & & & & \\
\hline Burn length (mm) & 20 & 50 & & & & & \\
\hline Pass (O) or Fail $(\mathrm{X})$ & $\mathrm{O}$ & $\mathrm{x}$ & & & & & 2 \\
\hline \multicolumn{6}{|l|}{$\mathrm{C}_{\mathrm{F}}$ Calculation } & $\mathbf{C}_{\mathrm{F}}$ & Row \\
\hline Oxygen concentration & & 28.2 & 28.0 & 27.8 & 28.0 & 28.2 & \\
\hline Burning time (s) & & 160 & $>180$ & 100 & 120 & 150 & \\
\hline Burn length $(\mathrm{mm})$ & & 50 & 40 & 20 & 15 & 50 & \\
\hline Pass $(\mathrm{O})$ or Fail $(\mathrm{X})$ & & $\mathrm{X}$ & $\mathrm{X}$ & $\mathrm{O}$ & $\mathrm{O}$ & $\mathrm{X}$ & 10 \\
\hline$k$ value & & & & & & & -0.83 \\
\hline$O I=C_{F}+k d$ & $=28.2$ & $-0.83 x$ & $=28$ & & & & 28.0 \\
\hline
\end{tabular}

Compound:

[26] ABS + 4.34wt \% pAZUB + 14.6wt \% TBBA

Part 1: Determination of initial oxygen concentration ( $X$ and $O$ response at $\leq 1 \% \mathrm{O}_{2}$ interval)

\begin{tabular}{|l|c|c|c|c|l|l|}
\hline Oxygen concentration & 26.0 & 25.0 & 24.0 & & & \\
\hline Burning time (s) & $>180$ & $>180$ & 55 & & & \\
\hline Burn length (mm) & 45 & 37 & 8 & & & \\
\hline Pass (O) or Fail (X) & $\mathrm{X}$ & $\mathrm{X}$ & $\mathrm{O}$ & & & \\
\hline
\end{tabular}

Part 2: Determination of oxygen index value

\begin{tabular}{|c|c|c|c|c|c|c|c|}
\hline \multicolumn{8}{|c|}{$N_{T}$ series } \\
\hline \multicolumn{7}{|c|}{$\mathrm{N}_{\mathrm{L}}$ Calculation } & Column \\
\hline Oxygen concentration & 24.0 & 24.2 & 24.4 & 24.6 & 24.8 & 25.0 & \\
\hline Burning time (s) & 60 & 60 & 80 & 55 & 55 & 170 & \\
\hline Burn length $(\mathrm{mm})$ & 8 & 9 & 15 & 11 & 11 & 50 & \\
\hline Pass $(\mathrm{O})$ or Fail $(\mathrm{X})$ & $\mathrm{O}$ & $\mathrm{O}$ & $\mathrm{O}$ & $\mathrm{O}$ & $\mathrm{O}$ & $\underline{X}$ & 5 \\
\hline \multicolumn{6}{|l|}{$C_{F}$ Calculation } & $\mathbf{C}_{F}$ & Row \\
\hline Oxygen concentration & & 25.0 & 24.8 & 25.0 & 24.8 & 25.0 & \\
\hline Burning time $(\mathrm{s})$ & & $>180$ & 80 & $>180$ & 75 & $>180$ & \\
\hline Burn length (mm) & & 50 & 15 & 50 & 14 & 50 & \\
\hline Pass $(\mathrm{O})$ or Fail $(\mathrm{X})$ & & $\mathrm{X}$ & $\mathrm{O}$ & $\mathrm{X}$ & $\mathrm{O}$ & $\mathrm{X}$ & 6 \\
\hline$k$ value & & & & & & & -0.45 \\
\hline$O I=C_{F}+k d$ & $=25.0+$ & $0.45 x$ & $=24$. & & & & 24.9 \\
\hline
\end{tabular}


Compound:

[27] ABS + 3.5wt \% sAZUB + 22.0wt \% BTBPE

Part 1: Determination of initial oxygen concentration ( $X$ and $O$ response at $\leq 1 \% \mathrm{O}_{2}$ interval)

\begin{tabular}{|l|c|c|c|c|c|c|}
\hline Oxygen concentration & 26.0 & 27.0 & 28.0 & & & \\
\hline Burning time (s) & 55 & 60 & $>180$ & & & \\
\hline Burn length (mm) & 9 & 9 & 50 & & & \\
\hline Pass (O) or Fail (X) & $\mathrm{O}$ & $\mathrm{O}$ & $\mathrm{X}$ & & & \\
\hline
\end{tabular}

Part 2: Determination of oxygen index value

\begin{tabular}{|c|c|c|c|c|c|c|c|}
\hline \multicolumn{8}{|c|}{$N_{T}$ series } \\
\hline \multicolumn{7}{|c|}{$\mathbf{N}_{\mathbf{L}}$ Calculation } & \multirow[t]{2}{*}{ Column } \\
\hline Oxygen concentration & 27.0 & 27.2 & 27.4 & 27.6 & & & \\
\hline Burning time (s) & 55 & 90 & 178 & $>180$ & & & \\
\hline Burn length (mm) & 10 & 13 & 28 & 40 & & & \\
\hline Pass (O) or Fail (X) & $\mathrm{O}$ & $\mathrm{O}$ & $\mathrm{O}$ & $\mathrm{X}$ & & & 4 \\
\hline \multicolumn{6}{|l|}{$C_{F}$ Calculation } & $\mathrm{C}_{\mathrm{F}}$ & Row \\
\hline Oxygen concentration & & 27.6 & 27.4 & 27.6 & 27.4 & 27.6 & \\
\hline Burning time (s) & & $>180$ & 160 & $>180$ & 165 & $>180$ & \\
\hline Burn length (mm) & & 50 & 30 & 50 & 35 & 48 & \\
\hline Pass $(\mathrm{O})$ or Fail $(\mathrm{X})$ & & $\mathrm{X}$ & $\mathrm{O}$ & $\mathrm{X}$ & $\mathrm{O}$ & $\mathrm{X}$ & 6 \\
\hline $\mathrm{k}$ value & & & & & & & -0.45 \\
\hline $\mathrm{OI}=\mathrm{C}_{\mathrm{F}}+\mathrm{kd}$ & $=27.6$ & $0.45 x$ & $=27$ & & & & 27.5 \\
\hline
\end{tabular}

Compound:

[28] ABS + 3.6wt \% sAZUB + 20wt \% TBBA

Part 1: Determination of initial oxygen concentration ( $X$ and $O$ response at $\leq 1 \% \mathrm{O}_{2}$ interval)

\begin{tabular}{|l|c|c|l|l|l|l|}
\hline Oxygen concentration & 27.0 & 26.0 & & & & \\
\hline Burning time (s) & $>180$ & 55 & & & & \\
\hline Burn length (mm) & 42 & 7 & & & & \\
\hline Pass (O) or Fail (X) & $\mathrm{X}$ & $\mathrm{O}$ & & & & \\
\hline
\end{tabular}

Part 2: Determination of oxygen index value

\begin{tabular}{|c|c|c|c|c|c|c|c|}
\hline \multicolumn{8}{|c|}{$\mathrm{N}_{\mathrm{T}}$ series } \\
\hline \multicolumn{7}{|c|}{$\mathbf{N}_{\mathrm{L}}$ Calculation } & \multirow[t]{2}{*}{ Column } \\
\hline Oxygen concentration & 26.0 & 26.2 & 26.4 & 26.6 & 26.8 & 27.0 & \\
\hline Burning time (s) & 50 & 45 & 95 & 90 & 50 & $>180$ & \\
\hline Burn length (mm) & 6 & 9 & 13 & 13 & 8 & 40 & \\
\hline Pass $(\mathrm{O})$ or Fail $(\mathrm{X})$ & $\mathrm{O}$ & O & 0 & $\mathrm{O}$ & 0 & $\mathrm{X}$ & 5 \\
\hline \multicolumn{6}{|l|}{$\mathrm{C}_{\mathrm{F}}$ Calculation } & $\mathbf{C}_{\mathbf{F}}$ & Row \\
\hline Oxygen concentration & & 27.0 & 26.8 & 27.0 & 26.8 & 27.0 & \\
\hline Burning time (s) & & $>180$ & 70 & $>180$ & 55. & $>180$ & \\
\hline Burn length $(\mathrm{mm})$ & & 42 & 10 & 50 & 8 & 44 & \\
\hline Pass $(\mathrm{O})$ or Fail $(\mathrm{X})$ & & $\mathrm{X}$ & $\mathrm{O}$ & $\mathrm{X}$ & $\mathrm{O}$ & $\mathrm{X}$ & 6 \\
\hline$k$ value & & & & & & & -0.45 \\
\hline$O I=C_{F}+k d$ & $=\mathbf{2 7} .0$ & $0.45 x$ & $=26$. & & & & 26.9 \\
\hline
\end{tabular}


Compound:

[29] ABS + 4.0wt\% sAZUB + 21.4wt\% DBDPO

Part 1: Determination of initial oxygen concentration ( $X$ and $O$ response at $\leq 1 \% \mathrm{O}_{2}$ interval)

\begin{tabular}{|l|c|c|l|l|l|l|}
\hline Oxygen concentration & 28.0 & 29.0 & & & & \\
\hline Burning time (s) & 60 & 120 & & & & \\
\hline Burn length (mm) & 16 & 50 & & & & \\
\hline Pass (O) or Fail (X) & $\mathrm{O}$ & $\mathrm{X}$ & & & & \\
\hline
\end{tabular}

Part 2: Determination of oxygen index value

\begin{tabular}{|c|c|c|c|c|c|c|c|}
\hline \multicolumn{8}{|c|}{$\mathrm{N}_{\mathrm{T}}$ series } \\
\hline \multicolumn{7}{|c|}{$\mathbf{N}_{\mathrm{L}}$ Calculation } & \multirow[t]{2}{*}{ Column } \\
\hline Oxygen concentration & 28.0 & 28.2 & 28.4 & 28.6 & 28.8 & & \\
\hline Burning time (s) & 70 & 85 & 90 & 70 & 135 & & \\
\hline Burn length (mm) & 15 & 20 & 16 & 13 & 50 & & \\
\hline Pass $(\mathrm{O})$ or Fail $(\mathrm{X})$ & $\mathrm{O}$ & $\mathrm{O}$ & $\mathrm{O}$ & $\mathrm{O}$ & $X$ & & 5 \\
\hline \multicolumn{6}{|l|}{$\mathrm{C}_{F}$ Calculation } & $\mathbf{C}_{\mathrm{F}}$ & Row \\
\hline Oxygen concentration & & 28.8 & 28.6 & 28.8 & 28.6 & 28.4 & \\
\hline Burning time (s) & & 140 & 100 & 130 & $>180$ & 85 & \\
\hline Burn length $(\mathrm{mm})$ & & 50 & 20 & 50 & 35 & 18 & \\
\hline Pass $(\mathrm{O})$ or Fail $(\mathrm{X})$ & & $\mathrm{X}$ & $\mathrm{O}$ & $X$ & $\mathrm{X}$ & $\mathrm{O}$ & 7 \\
\hline $\mathrm{k}$ value & & & & & & & 1.25 \\
\hline $\mathrm{OI}=\mathrm{C}_{\mathrm{F}}+\mathbf{k d}$ & $=28.4$ & $1.25 \mathrm{x}$ & $=28.6$ & & & & 28.7 \\
\hline
\end{tabular}

Compound:

[30] ABS + 5.15wt \% sAZUB + 20.7wt\% sDBDPO

Part 1: Determination of initial oxygen concentration ( $X$ and $O$ response at $\leq 1 \% \mathrm{O}_{2}$ interval)

\begin{tabular}{|l|c|c|c|c|c|c|}
\hline Oxygen concentration & 28.0 & 29.0 & 30.0 & 31.0 & & \\
\hline Burning time (s) & 40 & 50 & 90 & 120 & & \\
\hline Burn length (mm) & 8 & 12 & 20 & 50 & & \\
\hline Pass (O) or Fail (X) & $\mathrm{O}$ & $\mathrm{O}$ & $\mathrm{O}$ & $\mathrm{X}$ & & \\
\hline
\end{tabular}

Part 2: Determination of oxygen index value

\begin{tabular}{|c|c|c|c|c|c|c|c|}
\hline \multicolumn{8}{|c|}{$\mathrm{N}_{\mathrm{T}}$ series } \\
\hline \multicolumn{7}{|c|}{$\mathbf{N}_{\mathbf{L}}$ Calculation } & \multirow[t]{2}{*}{ Column } \\
\hline Oxygen concentration & 30.0 & 30.2 & & & & & \\
\hline Burning time (s) & 100 & 120 & & & & & \\
\hline Burn length (mm) & 21 & 50 & & & & & \\
\hline Pass $(O)$ or Fail $(X)$ & $\mathrm{O}$ & $X$ & & & & & 2 \\
\hline \multicolumn{6}{|l|}{$\mathrm{C}_{\mathrm{F}}$ Calculation } & $\mathrm{C}_{\mathrm{F}}$ & Row \\
\hline Oxygen concentration & & 30.2 & 30.0 & 29.8 & 29.6 & 29.4 & \\
\hline Burning time (s) & & 110 & 100 & 125 & 140 & 110 & \\
\hline Burn length (mm) & & 50 & 50 & 50 & 50 & 40 & \\
\hline Pass $(\mathrm{O})$ or Fail $(\mathrm{X})$ & & $\mathrm{X}$ & $\mathrm{X}$ & $X$ & $\mathrm{X}$ & $\mathrm{O}$ & 15 \\
\hline $\mathrm{k}$ value & & & & & & & 1.6 \\
\hline$O I=C_{F}+k d$ & $=29.4$ & $.6 \times 0$ & 29.72 & & & & 29.7 \\
\hline
\end{tabular}


Compound:

[31] ABS + 3.5wt \% sAZUB (MB5) + 20.5wt \% BTBPE

Part 1: Determination of initial oxygen concentration ( $X$ and $O$ response at $\leq 1 \% \mathrm{O}_{2}$ interval)

\begin{tabular}{|l|c|c|c|c|c|c|}
\hline Oxygen concentration & 30.0 & 29.0 & 28.0 & 27.0 & 26.0 & \\
\hline Burning time (s) & 120 & 140 & 170 & $>180$ & 30 & \\
\hline Burn length (mm) & 50 & 50 & 50 & 45 & 5 & \\
\hline Pass (O) or Fail (X) & $\mathrm{X}$ & $\mathrm{X}$ & $\mathrm{X}$ & $\mathrm{X}$ & $\mathrm{O}$ & \\
\hline
\end{tabular}

Part 2: Determination of oxygen index value

\begin{tabular}{|c|c|c|c|c|c|c|c|}
\hline \multicolumn{8}{|c|}{$\mathrm{N}_{\mathrm{T}}$ series } \\
\hline \multicolumn{7}{|c|}{$\mathrm{N}_{\mathrm{L}}$ Calculation } & \multirow[t]{2}{*}{ Column } \\
\hline Oxygen concentration & 26.0 & 26.2 & 26.4 & 26.6 & 26.8 & 27.0 & \\
\hline Burning time (s) & 30 & 50 & 75 & 110 & 95 & $>180$ & \\
\hline Burn length $(\mathrm{mm})$ & 5 & 7 & 12 & 15 & 12 & 42 & \\
\hline Pass $(\mathrm{O})$ or Fail $(\mathrm{X})$ & $\mathrm{O}$ & $\mathrm{O}$ & $\mathrm{O}$ & $\mathrm{O}$ & $\mathrm{O}$ & $X$ & 5 \\
\hline \multicolumn{6}{|l|}{$\mathrm{C}_{\mathrm{F}}$ Calculation } & $\mathbf{C}_{\mathrm{F}}$ & Row \\
\hline Oxygen concentration & & 27.0 & 26.8 & 27.0 & 26.8 & 27.0 & \\
\hline Burning time (s) & & $>180$ & 100 & $>180$ & 95 & 165 & \\
\hline Burn length (mm) & & 50 & 13 & 44 & 11 & 35 & \\
\hline Pass $(\mathrm{O})$ or Fail $(\mathrm{X})$ & & $\mathrm{X}$ & $\mathrm{O}$ & $\mathrm{X}$ & $\mathrm{O}$ & $\mathrm{O}$ & 5 \\
\hline k value & & & & & & & 0.04 \\
\hline $\mathrm{OI}=\mathrm{C}_{\mathrm{F}}+\mathrm{kd}$ & $=\mathbf{2 7 . 0}$ & $0.04 \times 6$ & $=27.0$ & & & & 27.0 \\
\hline
\end{tabular}

Compound:

[32] ABS + 3.7wt \% sAZUB (MB5) + 20.5wt \% TBBA

Part 1: Determination of initial oxygen concentration ( $X$ and $O$ response at $\leq 1 \% \mathrm{O}_{2}$ interval)

\begin{tabular}{|l|c|c|l|l|l|l|}
\hline Oxygen concentration & 27.0 & 28.0 & & & & \\
\hline Burning time (s) & 40 & $>180$ & & & & \\
\hline Burn length (mm) & 5 & 50 & & & & \\
\hline Pass (O) or Fail (X) & $\mathrm{O}$ & $\mathrm{X}$ & & & & \\
\hline
\end{tabular}

Part 2: Determination of oxygen index value

\begin{tabular}{|l|c|c|c|c|c|c|c|}
\hline \multicolumn{7}{|c|}{$\mathrm{N}_{\mathrm{L}}$ Calculation } \\
\hline
\end{tabular}


1 